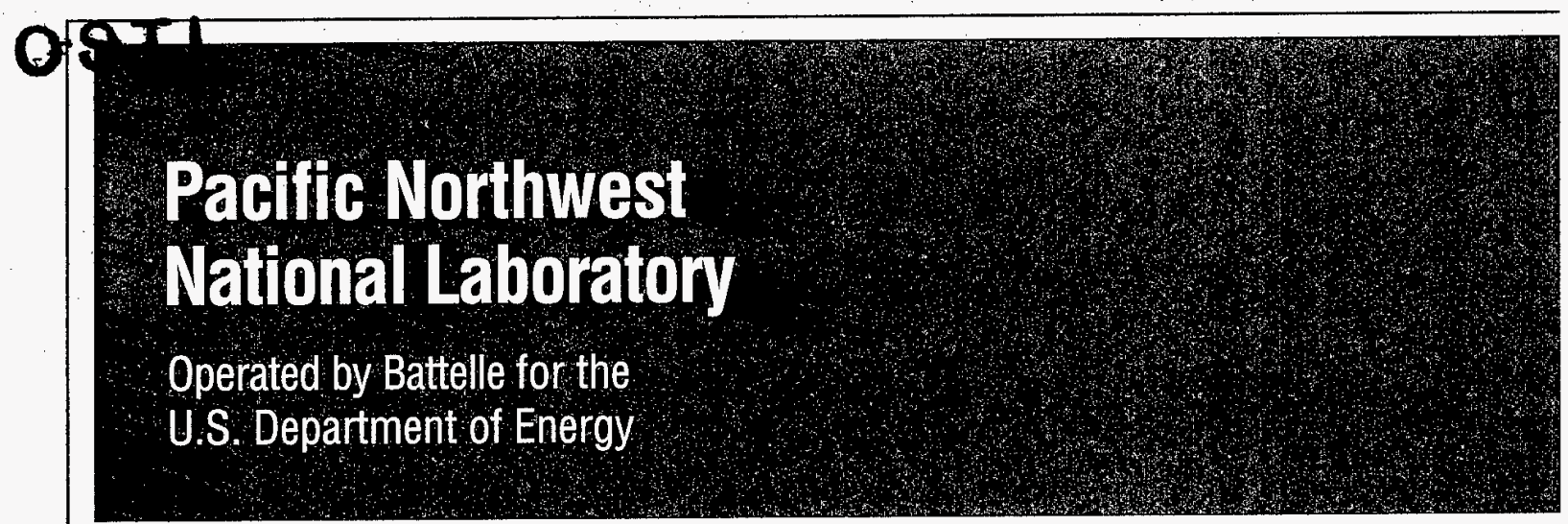

\title{
Flammable Gas Issues in
}

Double-Contained Receiver Tanks
L. M. Peurrung
L. R. Pederson
L. A. Mahoney
S. A. Bryan
C. W. Stewart
C. L. Shepard
P. A. Gauglitz

June 1998

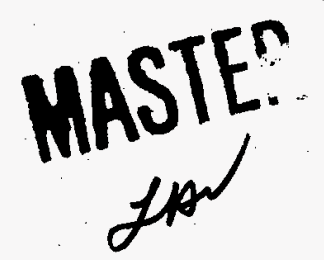

DISTRIBUTION OF THIS DOCUMENT IS UNLMITE

Prepared for the U.S. Department of Energy under Contract DE-AC06-76RLO 1830 


\title{
DISCLAIMER
}

This report was prepared as an account of work sponsored by an agency of the United States Government. Neither the United States Government nor any agency thereof, nor Battelle Memorial Institute, nor any of their employees, makes any warranty, express or implied, or assumes any legal liability or responsibility for the accuracy, completeness, or usefulness of any information, apparatus, product, or process disclosed, or represents that its use would not infringe privately owned rights. Reference herein to any specific commercial product, process, or service by trade name, trademark, manufacturer, or otherwise does not necessarily constitute or imply its endorsement, recommendation, or favoring by the United States Government or any agency thereof, or Battelle Memorial Institute. The views and opinions of authors expressed herein do not necessarily state or reflect those of the United States Government or any agency thereof.

\author{
PACIFIC NORTHWEST NATIONAL LABORATORY \\ operated by \\ BATTELLE \\ for the \\ UNITED STATES DEPARTMENTT OF ENERGY \\ under Contract DE-AC06-76RLO 1830
}

This document was printed on recycled paper. 
LM Peurrung

LA Mahoney

CW Stewart

PA Gauglitz

LR Pederson

SA Bryan

CL Shepard

June 1998

Prepared for

the U.S. Department of Energy

under Contract DE-AC06-76RLO 1830

Pacific Northwest National Laboratory

Richland, Washington 99352 


\section{Summary}

Four double-contained receiver tanks (DCRTs) at Hanford will be used to store salt-well pumped liquids from tanks on the Flammable Gas Watch List. This document was created to serve as a technical basis or reference document for flammable gas issues in DCRTs. The document identifies, describes, evaluates, and attempts to quantify potential gas carryover and release mechanisms. It estimates several key parameters needed for these calculations, such as initial aqueous concentrations and ventilation rate, and evaluates the uncertainty in those estimates. It justifies the use of the Schumpe model for estimating vapor-liquid equilibrium constants. It identifies several potential waste compatibility issues (such as mixing and $\mathrm{pH}$ or temperature changes) that could lead to gas release and provides a basis for calculating their effects. It evaluates the potential for gas retention in precipitated solids within a DCRT and whether retention could lead to a buoyant displacement instability (rollover) event. It discusses rates of radiolytic, thermal, and corrosive hydrogen generation within the DCRT. It also describes in detail the accepted method of calculating the lower flammability limit (LFL) for mixtures of flammable gases.

The report incorporates these analyses into two models for calculating headspace flammability, one based on instantaneous equilibrium between dissolved gases and the headspace and one incorporating limited release rates based on mass-transfer considerations. Finally, it demonstrates the use of both models to estimate headspace flammable gas concentrations and minimum ventilation rates required to maintain concentrations below $25 \%$ of the LFL. The report describes the methodology, the results at the only known (but probably highly underestimated) ventilation rate of $3 \mathrm{cfh}$, and the parametric sensitivity of the results. However, no actual predictions of DCRT headspace flammability are implied. This document is intended to provide background information for future DCRT modeling and recommendations for improving the technical basis of modeling. Although modeling results are presented here, the waste properties and potential pumping scenarios are so variable as to require case-by-case modeling for a safety basis. This document, therefore, does not and cannot provide a safety basis but rather guidance (based on current knowledge) as to conditions that a safety basis should meet.

We have identified no major flaws in the approach previously published in a calc-note by Hedengren et al. (1997). Although we developed a somewhat different mathematical model for predicting flammable gas concentrations within the DCRT, we found little difference between our predictions and those from Hedengren et al when the same initial dissolved gas concentrations were assumed. We also found that for most purposes the assumption of equilibrium does not produce large overestimates of DCRT headspace flammability until ventilation rates are much higher than the $3 \mathrm{cfh}$ assumed in the other analyses.

The analyses in this document indicate that

- Carryover of free gas to the DCRT in the form of "hitchhiker" bubbles is possible but only as armored bubbles less than 10 microns in diameter. Even if all of these bubbles were released once they reach the DCRT, they would contribute an insignificant volume of flammable gas to the headspace (Section 3). 
- Carryover of adsorbed gas on entrained particles is also possible, but it would be an insignificant contribution to the flammability of the DCRT headspace (Section 4).

- The dominant mechanism of gas carryover is, therefore, dissolved gas transferred with the pumped liquid (Section 2).

- The only ventilation that can be credited with confidence in a safety analysis is the 3- or 5-cfh airflow bubbling through the differential pressure (DP) tubes (depending on whether two or three tubes are used). However, additional inleakage of air is likely around riser covers and the manual tape level instrument. To improve confidence in the safe operation of the DCRTs, the actual ventilation rate could be measured by sampling the DCRT or its ventilation exhaust for components of the waste gases that are not found in air or using tracer gases (Section 7).

- The composition of the low-solubility gas mixture retained in the high-solids layers of tanks whose gas composition has not been measured can be modeled as $65 \%$ hydrogen and 5\% methane, with the remainder nonflammable gases. This composition is based on retained gas sampler (RGS) results for the free gas retained in submerged high-solids waste layers. This composition is appropriate for estimating the dissolved low-solubility gas concentration in liquid that is to be pumped from the waste matrix, where it is in equilibrium with the retained free gas. These values differ from those used by Hedengren et al. (1997), which were 97\% hydrogen and 3\% methane (Section 2)

- Liquid that is pumped from supernatant layers contains less hydrogen than liquid in the waste matrix does, according to RGS measurements. The low-solubility gas mixture in supernatant liquid layers in tanks whose gas composition has not been measured can be modeled as $19 \%$ hydrogen and $7 \%$ methane, the median composition measured by the RGS in supernatant layers (Section 2).

- Certain ammonia measurements may underestimate the true ammonia concentration in the waste if the sample is depleted in ammonia compared with the average in the pumpable waste. Grab samples from the middle or bottom of the tank are more likely to represent the ammonia concentration in the liquid pumped from the waste matrix and are strongly preferred as modeling inputs when liquid is to be pumped from the matrix (Section 2).

- Ammonia concentrations measured in conventional core samples may be a factor of 1.5 lower than the original concentration in the sample due to ammonia loss from the drainable liquid during core sample extrusion. Grab samples undergo little loss (Section 2).

- The limited available data suggest that the Schumpe model provides the current best estimates for Henry's Law constants (Section 2.2).

- The model described by $\mathrm{Hu}$ (1997) overpredicts the rates of hydrogen generation for calculating DCRT headspace flammability (Section 5). 
- Precipitation and accumulation of solids to form a nonconvective layer is possible but only for waste transferred from the hotter tanks, and its formation would require many months. If enough gas were retained in the layer to make it buoyant, a buoyant displacement instability could occur and release a large fraction of the retained gas into the tank's headspace. However, such an event is not expected to raise the headspace concentration beyond the LFL. The time required to form a nonconvective layer and accumulate gas is a year or more, so it is a concern only in very abnormal DCRT operations in which a nearly full tank is allowed to stand indefinitely (Section 6).

- The LFL for upward flame propagation is appropriate for determining flammability in a DCRT. The upward propagation LFL for a gas mixture can be determined using LeChatelier's linear mixing law. Nitrous oxide can be considered an inert species unless fuel concentrations approach the (higher) LFL for downward flame propagation, and water vapor cannot be counted on to prevent combustion (Section 8).

- Compared with the nonequilibrium mass-transfer-limited model, the equilibrium model overestimates the hydrogen contribution to flammability by more than a factor of 2 during fill and by $10 \%$ or less after filling is complete. But because dissolved hydrogen is not a major contributor to DCRT flammability for most tank wastes, the equilibrium model in most cases gives a fairly close estimate (within $20 \%$ of the nonequilibrium value) of the total DCRT headspace flammability when the ventilation rate is in the 3 to $30 \mathrm{cfh}$ range. At 5-cfm (300-cfh) ventilation, the equilibrium model predicts 20 to $50 \%$ higher flammabilities than the nonequilibrium model does. These results show the extent of the conservatism in the equilibrium assumptions used in other modeling (Hedengren et al. 1997) (Section 9).

- Based on the presented methodology, high-temperature, low-salt, and/or high-ammonia wastes have the highest flammability potential. At a ventilation rate of only $3 \mathrm{cfh}$, the equilibrium model predicts that 10 tank wastes (S-102, S-109, SX-102, SX-103, SX-105, SX-106, U-103, U-105, U-106, and U-108) ${ }^{(2)}$ could produce flammabilities that are close to or exceed $25 \%$ of the LFL in the DCRT for the base-case fill scenario (80\% fill at $4 \mathrm{gpm}$ ). These values should not be taken as actual flammability predictions because a minimum ventilation rate was used to predict them, but they do indicate which wastes (or types of wastes) have the highest potential for flammability. The wastes with the highest potential flammability are those modeled as having high dissolved ammonia concentrations (S-102, SX-102, SX-103, SX-105, SX-106, U-103, U-105, and U-108), high temperatures (SX-102, SX-103, and SX-105), high dissolved hydrogen concentrations resulting from low salt in the liquid (S-109), or high hydrogen generation rates caused by high temperature or high TOC (SX-103, SX-105, U-103, U-105, and U-106). Hydrogen dominates the flammability for two tanks: S-109 (due to low salt concentrations) and U-106 (due to high post-fill hydrogen generation rates). The nonequilibrium model also predicts flammabilities that exceed 25\% of the LFL for nine of these wastes; the exception is S-109 (Section 9).

(a) Hanford tanks are designated with the prefix 241- followed by the tank farm letters and actual tank number. In this report the 241- prefix is dropped, as it is in common usage. 
- Of the eight tanks for whose wastes the ammonia flammability contribution exceeded $25 \%$ of the LFL in the minimum-ventilation equilibrium scenario, only the predictions for SX-103 and U-103 wastes were based on measured dissolved ammonia concentrations. The relative flammability of the other six should be considered preliminary and highly uncertain pending ammonia concentration measurements (Section 9).

- Five of the tanks whose wastes were predicted (at minimum ventilation) to produce high flammability in the DCRT headspace, SX-103, SX-105, U-103, U-105, and U-106, were predicted by both models to have hydrogen generation rates high enough to make hydrogen a flammability concern in the post-fill, steady-state period. There is evidence (based on hydrogen generation rates calculated from tank headspace measurements) that the hydrogen generation model overestimates the generation rate in three of these tanks, SX-103, SX-105, and U-106. The hydrogen contribution to the DCRT headspace flammability therefore is exaggerated for these three tanks. Further work may be needed to develop an improved hydrogen generation model, a more complete set of hydrogen generation estimates from headspace hydrogen measurements, or both (Section 9).

- The nonequilibrium and equilibrium models predict headspace flammabilities that are typically within $20 \%$ of each other at low ventilation rates. However, this small difference in predicted flammability translates into a large difference in the ventilation rate required to produce $25 \%$ LFL in the headspace because increasing the ventilation tends to have a relatively small influence on reducing the headspace flammability. Therefore, the equilibrium model substantially overpredicts the ventilation rates required to maintain DCRT headspace flammability below $25 \%$ of the LFL (Section 9).

- The minimum required ventilation rates calculated by the nonequilibrium model are highest for wastes from Tanks SX-103 and SX-105, at 2.2 to $2.5 \mathrm{cfm}$ (130 to $150 \mathrm{cfh}$ ), respectively. While Hedengren et al. (1997) suggested possible operational changes, such as reducing the feed rate, that might allow such tanks to be pumped without exceeding $25 \%$ of the LFL even with minimal ventilation, this document does not address such changes (Section 9).

- The nonequilibrium model shows that a ventilation rate of less than $3 \mathrm{cfm}$ (180 $\mathrm{cfh})$ maintains the headspace below $25 \%$ of the LFL (based on the present ammonia concentration data). By contrast, the extremely low 3-cfh flow assumed in other analyses predicts that at least nine wastes can exceed $25 \%$ of the LFL (based on a conservative but probably overpredictive hydrogen generation model and on current assumptions for dissolved hydrogen and ammonia concentrations). Because even a small ventilation flow can mitigate headspace flammability (especially under post-fill conditions), it is vital to measure the actual flow under typical operating conditions (Section 9).

- In some scenarios, the amount of gas released by mixing wastes from two tanks is larger than the amount either waste alone would release. However, temperature increases in the tank that would tend to release gas are considered unlikely, and releases due to caustic or water addition are small (Section 9). 
- Decreasing the feed rate to the DCRT does not always cause a decrease in flammability during filling. It can cause an increase, depending on the hydrogen generation rate and on the ratio of dissolved hydrogen to ammonia in the feed. Thus, assuming the operational maximum feed rate of $4 \mathrm{gpm}$ does not necessarily produce a conservative estimate of DCRT headspace flammability. Case-by-case modeling is needed to establish the actual safety envelope for DCRT use. The tank wastes are too variable to allow the generic statement that headspace flammability is always highest at high feed rates (Section 9).

\section{Summary of key findings}

- Dissolved gas (both ammonia and, to a lesser degree, hydrogen) is the dominant mechanism of flammable gas carryover from a source tank to a DCRT. This gas, along with hydrogen generated within the waste, volatilizes into the DCRT headspace. However, headspace flammable gas concentrations are likely to remain below their equilibrium values due to mass transfer limitations, even when DCRT ventilation rates are only in the cfh range.

- For some SSTs, particularly those containing high-temperature, low-salt, and/or highammonia wastes, salt-well pumping at the maximum rate of $4 \mathrm{gpm}$ could result in a DCRT headspace exceeding $25 \%$ of the LFL if the minimum ventilation rate of $3 \mathrm{cfh}$ were present. However, actual passive ventilation rates are probably significantly higher, and the calculations are based on unmeasured or uncertain gas concentrations in the waste. A formal uncertainty analysis is deferred, however, pending measurements of DCRT ventilation rates.

\section{Summary References}

Hedengren DC, JD Bingham, SA Barker, JM Conner, and SD Estey. 1997. Calculation of Flammable Gas Mixtures in Double-Contained Receiver Tanks. HNF-SD-WM-CN-118 Rev. 0, Lockheed Martin Hanford Company, Richland, Washington.

Hu TA. 1997. Calculations of Hydrogen Release Rate at Steady State for Double-Shell Tanks. HNF-SD-WM-CN-117 Rev. 0, Lockheed Martin Hanford Corporation, Richland, Washington. 


\section{Acknowledgments}

Project Hanford Management Contractor staff members have been consulted throughout the development of this document. The PNNL team would particularly like to acknowledge the contributions of Blaine Barton, Dave Hedengren, Mike Koch, Roland Brown, Dirk Wiggins, Randy Powers, and John Conner. Bob White and Mary Brewster of Los Alamos National Laboratory participated in an early screening of ideas and technical issues. The authors would also like to thank the DOE and contractor project managers who have provided input to help ensure that all of the relevant technical issues are addressed. 


\section{Acronym List}

acf

acfh

acfm

BIO

CC

cfh

cfm

DCRT

DOE

DP

DSSF

DST

FGWL

FY

gpm

GRE

HEPA

HTCE

LFL

LHMC

NCPLX

NHC

NMHCs

PHMC

PNNL

RGS

SCM

SCOPE

SST

STP

TOC

WHC actual cubic feet

actual cubic feet per hour

actual cubic feet per minute

Basis for Interim Operations

complexant concentrate

cubic feet per hour

cubic feet per minute

double-contained receiver tank

U.S. Department of Energy

differential pressure

double-shell slurry feed

double-shell tank

Flammable Gas Watch List

fiscal year

gallons per minute

gas release event

high efficiency particulate air (filter)

Hanford Tank Cluster designation (value)

lower flammability limit

Lockheed Martin Hanford Company

noncomplexed

Numatec Hanford Corporation

non-methane hydrocarbons

Project Hanford Management Contract

Pacific Northwest National Laboratory

retained gas sampler

standard cubic meters

Safety Control Optimization by Performance Evaluation

single-shell tank

standard temperature and pressure

total organic carbon

Westinghouse Hanford Company 


\section{Contents}

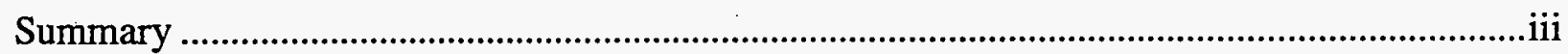

Acknowledgments ......................................................................................................................

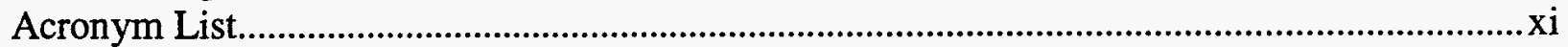

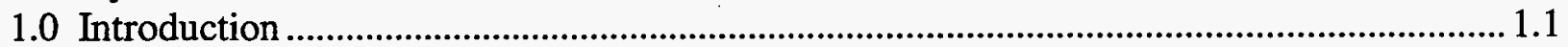

1.1 Purpose and Scope ……………….............................................................................. 1.2

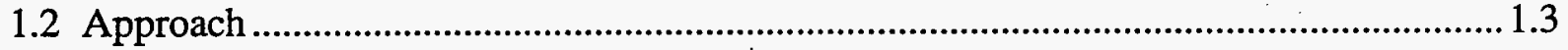

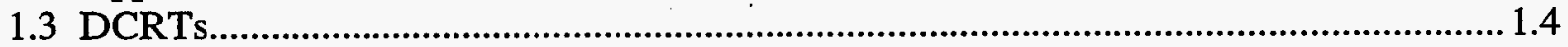

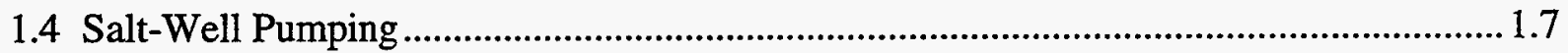

1.5 Transfer Lines ............................................................................................................. 1.8

1.6 Document Organization .............................................................................................. 1.8

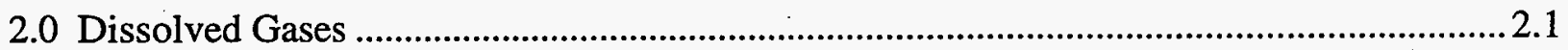

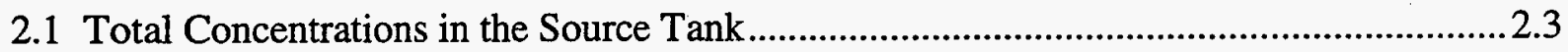

2.1.1 Low-Solubility Components ........................................................................................ 2.3

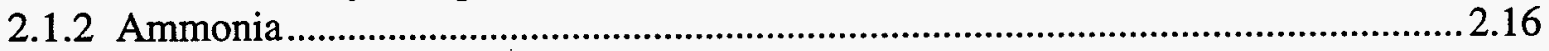

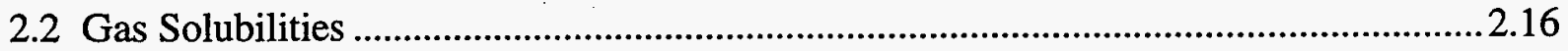

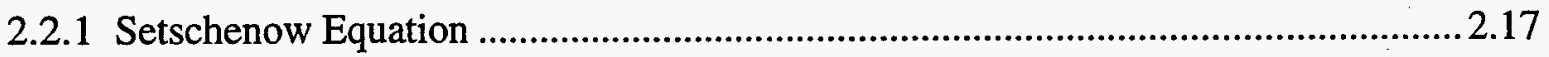

2.2.2 Schumpe Model.................................................................................................. 2.17

2.2.3 Pitzer Ion Interaction Model....................................................................................2.18

2.2.4 Simplified Pitzer Ion Interaction Model....................................................................2.19

2.2.5 Comparison with Experimental Gas Solubility Results for Simulated Wastes ........2.19

2.2.6 Application of the Schumpe Solubility Model........................................................2.2.22

2.3 Dissolved Concentrations of Flammable Gases in the Source Tank ...............................2.2.23

2.4 Losses of Flammable Gases Before Entering the DCRT ...................................................2.24

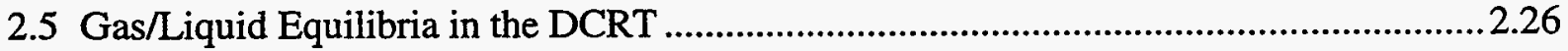

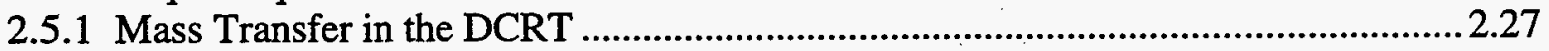

2.5.2 Variation in Solubility in the DCRT .....................................................................2.33

3.0 Transport of Gas Bubbles into DCRTs .................................................................................. 3.1

3.1 Retention Mechanisms and Categories of Bubbles........................................................... 3.1

3.2 Trapping of Typical Bubbles .............................................................................................. 3.2

3.3 Conditions for the Existence of Very Small Bubbles ...........................................................3.3

3.4 Transport of Hitchhiker Bubbles Through the Waste .............................................................. 3.7

3.5 The Fraction of Gas Contained in Small Bubbles................................................................10

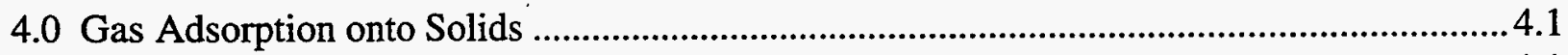

4.1 Background ....................................................................................................................

4.2 Retention and Release of Adsorbed Gas ....................................................................... 4.2

4.3 Conclusions ......................................................................................................................... 4.4

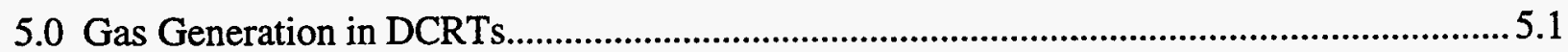

5.1 Hydrogen Generation Rate Estimates Proposed by Hopkins and Graves........................... 5.1

5.1.1 Thermolytic Rates ........................................................................................................5.2

5.1.2 Radiolytic Rates ...................................................................................................... 5.3 
5.2 Modified Estimate of Hydrogen Generation ................................................................... 5.3

5.2.1 Thermolytic Rates .................................................................................................. 5.4

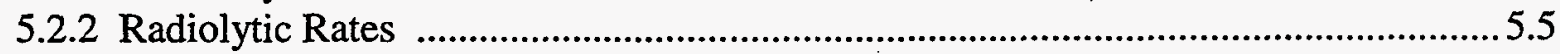

5.3 Rate of Generation by Corrosion ................................................................................. 5.6

5.4 Comparison of Calculated Hydrogen Release Rates at Steady-State and Field-Measured Values for Hanford Wastes ........................................................... 5.7

5.5 Summary ...................................................................................................................... 5.11

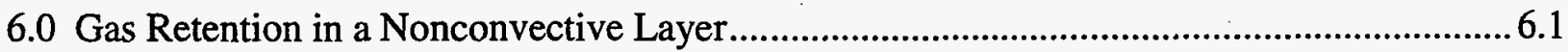

6.1 Formation of a Nonconvective Layer in a DCRT ……...................................................... 6.1

6.2 Potential for Gas Release from a DCRT Nonconvective Layer ........................................ 6.2

6.2.1 Potential for Buoyant Displacement Event .................................................................. 6.2

6.2.2 Potential for Gas Release by Buoyant Displacement..................................................6.6

6.2.3 Gas Release Volume .......................................................................................... 6.7

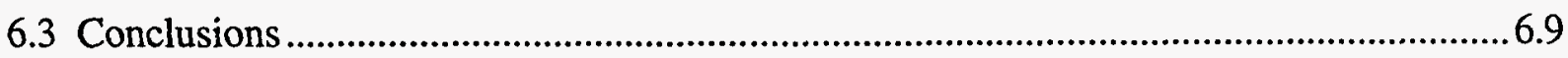

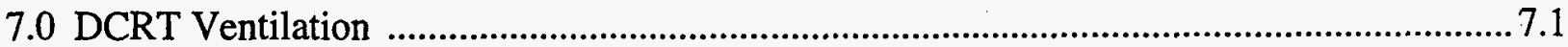

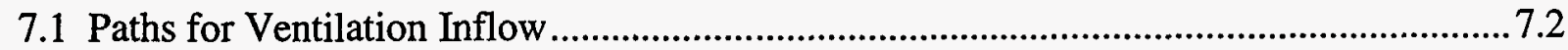

7.2 Potential Ventilation Flow Rates .................................................................................... 7.3

7.3 Confirming Ventilation Flow Rates ................................................................................. 7.4

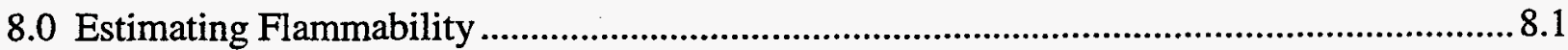

8.1 Flammability of Hydrogen-Methane-Ammonia Mixtures ................................................... 8.1

8.2 Flammability of Ammonia-Rich Mixtures....................................................................... 8.2

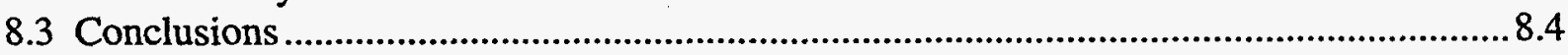

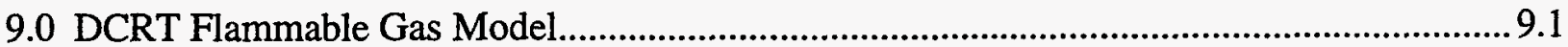

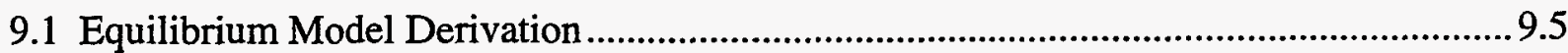

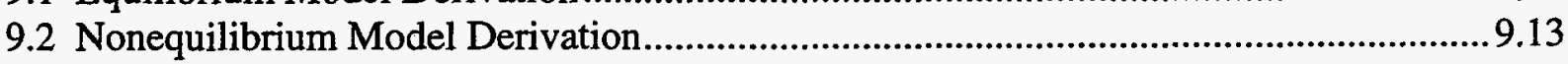

9.3 Testing the Equilibrium Model Against the Prior Model ....................................................18

9.4 Flammability Calculations Based on Section 2 Inputs .......................................................2.

9.5 Comparison of Equilibrium and Nonequilibrium Models .................................................2.

9.6 Effects of Uncertainty in the Parameters ..........................................................................26

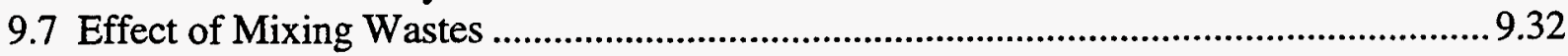

9.8 Overall Uncertainties and Conservatisms .........................................................................35

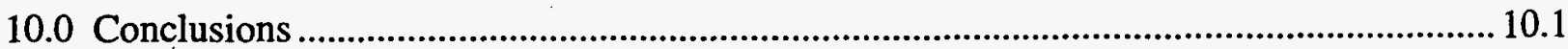

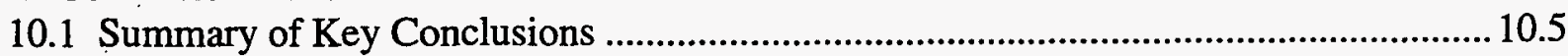

10.2 Recommendations for Future Work ........................................................................... 10.5

11.0 References

Appendix: Sampled Ammonia Results for Single-Shell Tanks ................................................... A.1 


\section{Figures}

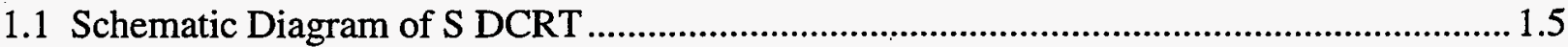

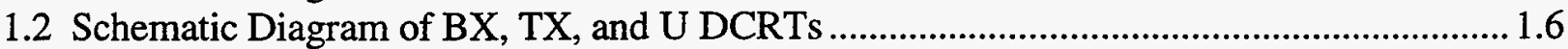

3.1 Free Bubble Collapse Time Versus Diameter ........................................................................ 3.6

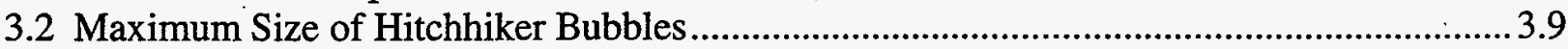

3.3 Cumulative Volume Fraction Versus Bubble Diameter ...................................................12

4.1 Comparison of Henry's Law Constants for the Decantate and Complete Slurry

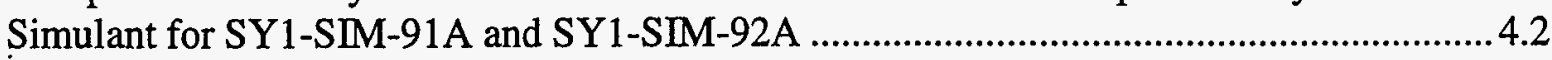

4.2 Quantity of Material Adsorbed Versus Average Solid Particle Size ...................................... 4.3

5.1 Comparison of Hydrogen/Nitrous Oxide Product Ratios to Model and Field Data Hydrogen Ratios for for DSTs..................................................................... 5.8

5.2 Comparison of Hydrogen/Nitrous Oxide Product Ratios to Model/

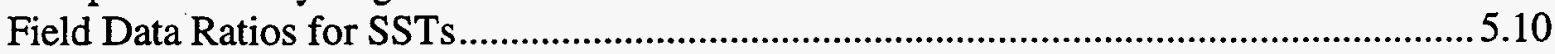

6.1 Void Ratio Versus Nonconvective Layer Depths ................................................................ 6.5

6.2 Envelope of Potential Buoyant Displacement Gas Release in DCRTs..................................6.7

7.1 Schematic of DCRT Ventilation System ............................................................................ 7.1

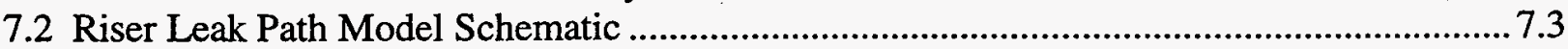

7.3 Potential Ventilation Flow Through Transfer Pump Flange .................................................... 7.4

8.1 Equilibrium Water Vapor Fraction and Ammonia Flammability .......................................... 8.3

9.1 DCRT Flammability-Based Bounds on Feed Concentration and Hydrogen Generation Rate, for Average Waste and the Base Case Fill Scenario................................ 9.28

9.2 Variation of DCRT Headspace Flammability for Average Waste and the Base Case Fill Scenario.

9.3 Effect on DCRT Headspace Flammability of Mixing SX-104 and U-105 Wastes .............9.33

9.4 Effect on DCRT Headspace Flammability of Adding Hot and Cold Water Flushes to BY-101 Waste.

9.5 Effect on DCRT Headspace Flammability of Adding Caustic and Cold Water Flushes to Modified T-104 Waste.

\section{Tables}

1.1 DCRT Tank and Vault Capacity .....

2.1 SST Ammonia Concentrations Shown by HTCE Cluster...................................................... 2.14

2.2 Comparison of Ammonia Concentrations with Hedengren et al. (1997) ...............................2.15

2.3 Gas Interaction Parameters for Hypothetical Average Salt ................................................2.2.

2.4 Calculated Mass-Transfer Coefficients ................................................................................ 2.32

3.1 Classification of Bubbles and Their Ability to Transport ......................................................... 3.2

3.2 Parameter Values for Bubble Collapse Calculation ...............................................................

3.3 Parameter Values Used in Bubble Transport Calculations .......................................................... 3.9

5.1 Comparison of Model and Field Data Hydrogen Generation Rates for DSTs.......................5.8

5.2 Comparison of Model and Field Data Hydrogen Generation Rates for SSTs ..................... 5.10

6.1 Gas Release from a DCRT Nonconvective Layer ................................................................. 6.9

8.1 Lower Flammability Limits in Air ........................................................................................ 8.1

9.1 Partial Comparison of Predictions made by the Hedengren et al. (1997) and Present Models Using the Same Inputs. 
9.2 Comparison of Hedengren et al. (1997) Model Results with Previous Inputs and Equilibrium Model with Revised Inputs

9.3 Comparison of Predictions Made by the Equilibrium and Nonequilibrium Models for 3-acth Ventilation

9.4 Comparison of Predictions Made by the Equilibrium and Nonequilibrium Models for 30-acfh Ventilation

9.5 Comparison of Predictions Made by the Equilibrium and Nonequilibrium Models for 300-acfh Ventilation

9.6 Comparison of Mitigating Ventilation Rates Calculated by Equilibrium and Nonequilibrium Models .

9.7 DCRT Model Inputs for the Base Case for Two Wastes

9.8 Limiting Hydrogen/Ammonia Relationships to Maintain 25\% of the LFL 9.30 


\subsection{Introduction}

The Hanford Site has 149 single-shell tanks (SSTs) containing radioactive wastes that are complex mixes of radioactive and chemical products. Of these, 67 are known or suspected to have leaked liquid from the tanks into the surrounding soil, while 82 are considered sound (Hanlon 1996). To minimize the amount of material that could potentially leak into the surrounding soil, all of the SSTs will be interim stabilized by removing the drainable liquid. ${ }^{\text {(a) }}$ Of the SSTs, 117 have been declared stabilized, and only 32 require further processing (Hanlon 1996). ${ }^{\text {(b) }}$ Only 44 tanks have actually had drainable liquid removed; the remainder were declared stabilized administratively; that is, they were judged to contain less than 50,000 gallons of drainable interstitial liquid and less than 5,000 gallons of supernatant liquid.

The Tri-Party Agreement (Ecology 1996) has set a series of milestones for completing interim stabilization by September 2000. While process equipment exists for removing drainable liquid, and its operation is well known from previous pumping campaigns, a number of safety issues associated with the release and potential ignition of flammable gases within the tanks is slowing progress on completing the removal of drainable liquid. These concerns stem from the observation that some of the wastes in the SSTs generate and retain potentially hazardous quantities of flammable gases. Of the 32 SSTs remaining to be declared interim stabilized, 31 need to have drainable liquid removed by salt-well pumping. (Tank C-106 does not need saltwell pumping because its waste will be transferred to Tank AY-102.) ${ }^{(\mathrm{c})}$ Of these 31 SSTs, 17 are on the Flammable Gas Watch List (FGWL) (Hopkins 1995; Hanlon 1996). Flammable gas issues associated with all aspects of operation must be evaluated and resolved before salt-well pumping of the FGWL tanks can continue.

Salt-well pumping, or interim stabilization, began in the mid-1970s and is a wellestablished method for removing drainable interstitial liquid from SSTs (Grimes 1978). While salt-well pumping has been conducted for many years, attention has only recently been focused on the associated flammable gas safety issues. A significant effort has been made to predict the release of flammable gases into the headspace of the tank being salt-well pumped. The first quantitative studies of gas release during salt-well pumping were associated with the safety assessment for salt-well pumping FGWL tanks conducted by Los Alamos National Laboratory (WHC 1996). The safety assessment included an estimate of how much insoluble gas (that is, gas initially trapped in bubbles) would be released as a result of draining liquid from an SST. Peurrung et al. (1997) examined this problem in more detail and discussed the fate of both lowsolubility gases (such as hydrogen) and high-solubility gases (such as ammonia).

Both studies suggested that salt-well pumping would slowly release virtually all of the hydrogen gas above the interstitial liquid level into the headspace. Hydrogen, due to its low

(a) While essentially all of the drainable liquid must be removed, specific criteria are used to determine when liquid removal is sufficiently thorough to allow the SSTs to be designated as interim stabilized.

(b) Two additional tanks have been declared stabilized since 1996.

(c) Hanford tanks are designated with the prefix 241 - followed by the tank farm identification and actual tank number. In this report the 241- prefix is dropped, as it is in common usage. 
solubility, exists primarily in tank waste as trapped bubbles. Removing interstitial liquid creates pathways through the porous waste to the bubbles, allowing the hydrogen in them to migrate into the tank headspace. In contrast, the bulk of the ammonia inventory is dissolved in the waste liquids. Since salt-well pumping extracts the liquid, the ammonia contained therein is transferred to the receiver tank. However, ammonia in any residual liquid in the source tank gradually partitions into the headspace through the air pathways created during pumping. While the amount of pumpable liquid varies from tank to tank depending on the waste's consistency and configuration, Peurrung et al. (1997) predicted that roughly $80 \%$ of the liquid (and hence the ammonia) would be pumped into the receiver tank.

It is clear from this discussion that the presence of flammable gases in the waste affects not only the source tank (i.e., the tank being pumped) but also the receiving vessels and the transfer lines. In addition to the dissolved gas carried over with the waste liquid, gases continue to be generated radiolytically. Recognizing the need for an evaluation of flammable gas issues in double-contained receiver tanks (DCRTs), a calculation note (Hedengren et al. 1997) was issued describing a method for calculating the concentration of flammable gases in a DCRT headspace. This "calc-note" estimated the resulting flammability of the vapor, in percent of the lower flammability limit (LFL), a safety guideline at Hanford, resulting from transferring the contents of each of 27 SSTs into its corresponding DCRT under various filling and steady-state scenarios. The calc-note found only four source tanks (SX-101, SX-103, SX-105, and U-106) whose pumping would result in a DCRT vapor space in excess of $25 \%$ of the LFL if pumping occurred at a rate of $4 \mathrm{gpm}$ until the DCRT was $80 \%$ full while a ventilation rate of $3 \mathrm{cfh}$ was maintained. However, operational controls on the flow rate or degree of fill could keep the vapor space below $25 \%$ of the LFL even for these four tanks. (Moreover, as we will discuss in Section 7, ventilation rates are likely to be considerably higher than $3 \mathrm{cfh}$, which would also reduce headspace flammability.)

The calc-note addressed flammable gases in DCRTs. It estimated flammability based on several approximations and simplifying assumptions along with some best-estimate and conservative values of needed input parameters such as aqueous ammonia concentrations and Henry's Law constants. However, it did not attempt to justify or evaluate these assumptions in detail. Furthermore, it did not address a few potential gas transfer mechanisms that have been brought forward from time to time by staff involved in Hanford flammable gas issues (such as "hitchhiker" bubbles or gas adsorbed to solids) and did not analyze their potential impacts on flammability or provide a citable reference to such an analysis.

\subsection{Purpose and Scope}

The purpose of this document is to serve as a technical reference that identifies, describes, evaluates, and attempts to quantify potential gas carryover and release mechanisms in DCRTs. The document estimates several key parameters needed for these calculations, such as vapor-liquid equilibrium constants, initial aqueous concentrations, and ventilation rate and evaluates the uncertainty in those estimates. It identifies several potential waste compatibility issues (such as mixing and $\mathrm{pH}$ or temperature changes) that could lead to gas release and provides a basis for calculating their effect. It evaluates the potential for gas retention in precipitated solids within a DCRT and whether retention could lead to a buoyant displacement release. It discusses radiolytic, thermolytic, and corrosion gas generation within the DCRT and 
evaluates the treatment used in the calc-note. It also describes the accepted method of calculating LFL for mixtures of flammable gases in view of recent experimental data.

The report incorporates these analyses into two models for calculating headspace flammability, one based on instantaneous equilibrium between dissolved gases and the headspace and one incorporating limited release rates based on mass-transfer considerations. Finally, it demonstrates the use of both models to estimate headspace flammable gas concentrations and minimum ventilation rates required to maintain concentrations below $25 \%$ of the LFL. The report describes the methodology, the results at the only known (but probably highly underestimated) ventilation rate of $3 \mathrm{cfh}$, and the parametric sensitivity of the results. However, no actual predictions of DCRT headspace flammability are implied. This document is intended to provide technical background information for future DCRT modeling and recommendations for improving the technical basis of modeling. Although modeling results are presented here, the waste properties and potential pumping scenarios are so variable as to require case-by-case modeling for a safety basis. This document, therefore, does not and cannot provide a safety basis but rather contains guidance (based on current knowledge) as to conditions that a safety basis should meet.

The report focuses on wastes extracted from SSTs by salt-well pumping and dilution or mixing. Other waste streams (e.g., from the Plutonium Finishing Plant or the 222-S Analytical Laboratory) may also pass through DCRTs and be mixed with salt-well pumped wastes. A full analysis of the potential waste streams and mixing scenarios has not yet been performed, and we have not analyzed all possible scenarios. In general, however, the methodology in this report can be applied to mixing various types of waste.

This document is not meant to replace the calc-note, nor is its primary purpose to critique it. Rather, the document provides a technical basis for many of its assumptions and conclusions while suggesting some possible refinements. This document is not meant to be a safety. assessment or to serve in place of one. Finally, we do not consider the effect of a layer of separated organic phase (the only known example of which exists in Tank C-103).

\subsection{Approach}

This work does not represent new research in the areas of gas generation, retention, and release in waste tanks. The authors recognize the significant effort made to date in studying and quantifying these issues in single- and double-shell tanks (DSTs). Instead, this work synthesizes the existing expert opinion on flammable gas issues within the Hanford technical community and applies it to the problem of salt-well pumping of SST waste into DCRTs. A team of these experts met and developed a list of the relevant technical issues, then prepared individual sections of this report on the subject area of their expertise. Each section includes

- a description of the flammable gas issue

- a brief explanation of the physics or chemistry involved

- a discussion of the various opinions in the flammable gas community on this issue

- the expert's technical opinion and its justification (quantitative or qualitative), including a discussion of uncertainties and assumptions. 
In many cases, team members developed simple calculations or spreadsheets to evaluate their particular technical issue. These are included in their discussions. However, no new laboratory tests were conducted or measurements made in order to reduce uncertainties.

The primary contributors to this report are members of the Tank Waste Safety Program at Pacific Northwest National Laboratory (PNNL). ${ }^{(a)}$ However, those contributors have relied upon the staff of the Project Hanford Management Contract (PHMC) Team for their detailed knowledge of tank farm operations and equipment. These PHMC staff members have been consulted throughout the development of this document. DOE and contractor project managers also provided input (via a mid-year project review) to help ensure that all of the relevant technical issues were being addressed.

\subsection{DCRTs}

The DCRTs, sometimes referred to as catch stations, lift stations, or receiver vaults, are used throughout the Hanford 200 Areas for temporary storage of liquid radioactive wastes. These tanks are used to accumulate liquid waste generated by operations so that it can be transferred in batches to larger tanks. Each DCRT consists of a tank contained within a concrete vault, with the bulk of the structure underground except for a small building that houses controls and instrumentation. This document focuses on the four DCRTs designated for receiving waste liquids from salt-well pumping operations in SST farms: 244-BX, which serves B, BX, and BY tank farms; 244-S, which serves S and SX tank farms; 244-TX, which serves T, TX, and TY tank farms; and 244-U, which serves U tank farm. We will also briefly discuss DCRT 244-A, the lift station on the cross-site transfer line.

There are two DCRT configurations: in one the cylindrical tank is oriented vertically (A, $S$ ) and in the other, horizontally (BX, TX, and U). Schematic diagrams of both types are shown in Figures 1.1 and 1.2. The $S$ tank is $4.6 \mathrm{~m}$ in diameter and $4.7 \mathrm{~m}$ tall with a hemispherical dome $0.85 \mathrm{~m}$ high, while the A tank is similar in design but slightly smaller. The other three DCRTs are $3.7 \mathrm{~m}$ in diameter and $10.7 \mathrm{~m}$ long. Table 1.1 gives the capacity of the tank and vault for each DCRT (Noorani 1997). Operating capacity is $80 \%$ of the total capacity. Liquid enters the DCRTs from transfer lines that end at the top of the DCRT.

The ventilation systems for the DCRTs are described in Section 7. Notably, while the actual ventilation flow is almost certainly much higher, the only flow that has been credited in a safety analysis is the 3-cfh air flow bubbling through two small-diameter differential pressure (DP) or "dip" tubes that measure fluid level and specific gravity. (Ventilation rates in DCRTs are currently being measured, and the results will be incorporated into future versions of this document.) This "administrative" ventilation is significantly less than even the 2-15 scfm passive ventilation rates that have been measured in SSTs (Huckaby et al. 1997). Because of this limited ventilation, flammable gas concentrations in DCRTs are often calculated to be significantly higher than they are in SSTs, where under normal circumstances those gases are at concentrations well below the level of concern.

(a) Pacific Northwest National Laboratory is operated by Battelle for the U.S. Department of Energy under Contract DE-AC06-76RLO 1830. 


\section{TYPICAL DOUBLE-CONTAINED RECEIVER TANK (244-S; 244-A similar but smaller)}

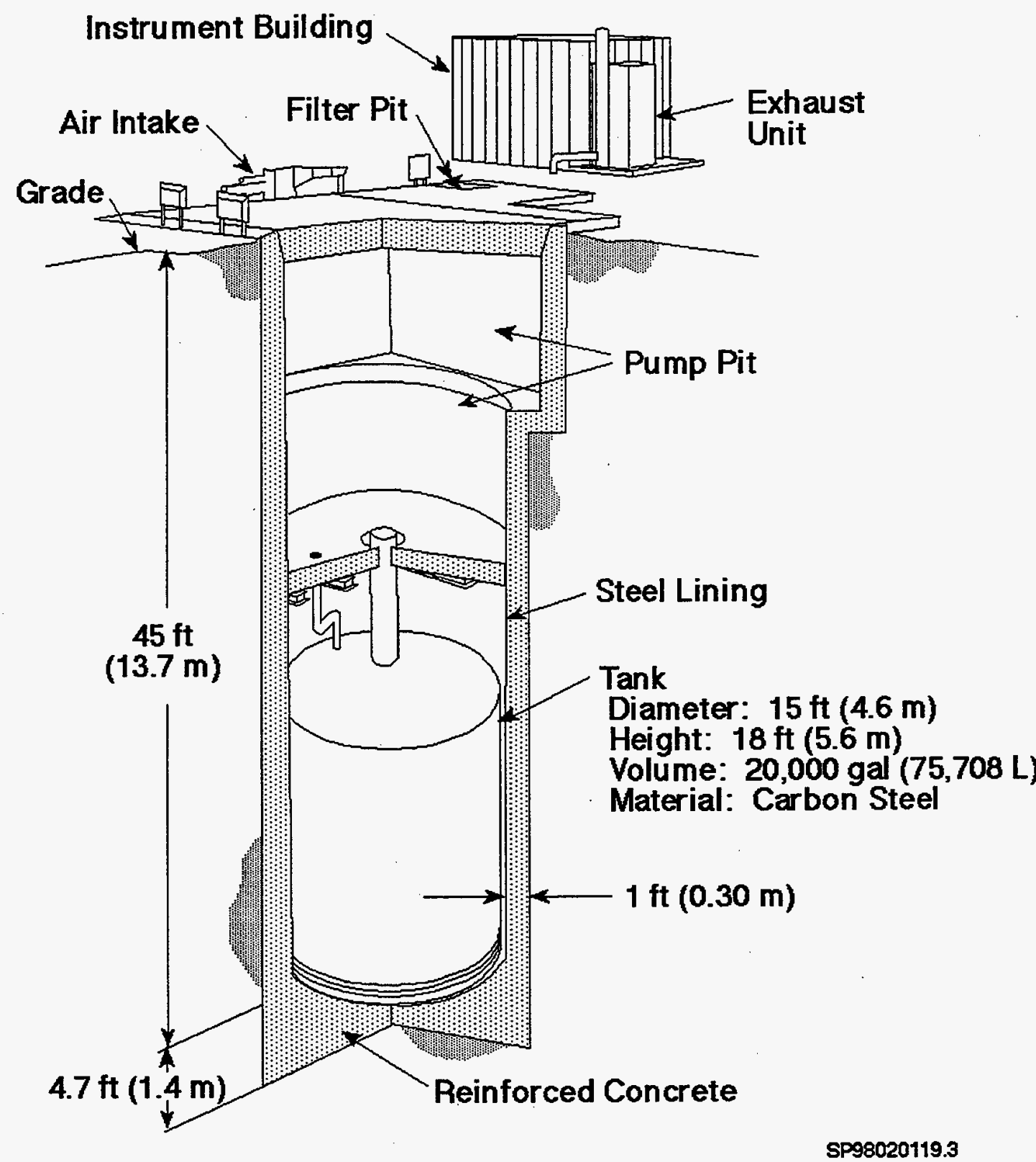

Figure 1.1. Schematic Diagram of S DCRT (A DCRT is similar in design but smaller)

Because multiple source tanks served by a single DCRT could be salt-well pumped simultaneously, there is a potential for mixing wastes with different compositions, temperatures, 


\section{TYPICAL DOUBLE-CONTAINED RECEIVER TANK}

(244-BX, 244-TX, and 244-U)

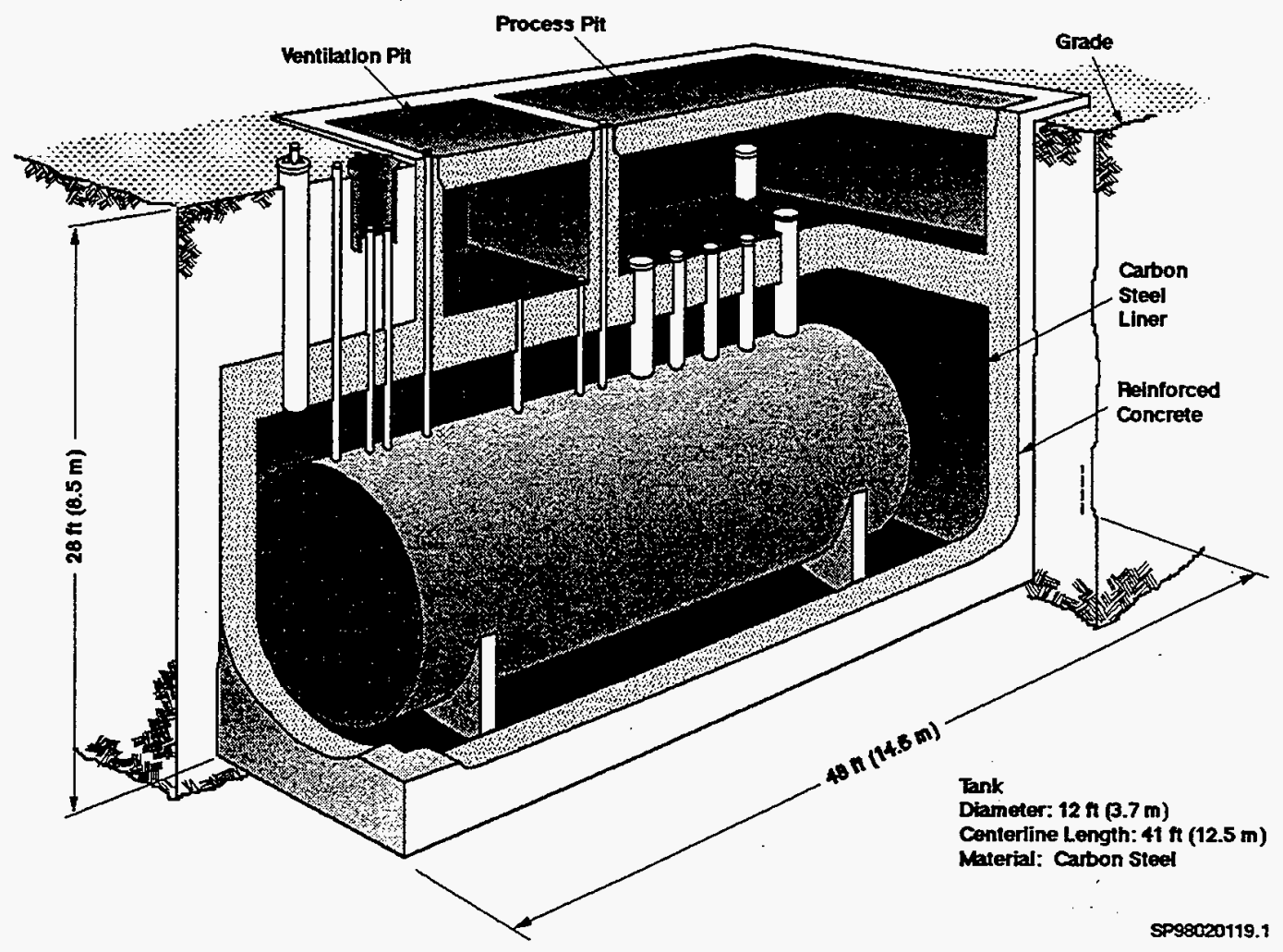

Figure 1.2. Schematic Diagram of $B X, T X$, and U DCRTs

or $\mathrm{pH}^{(\mathrm{a})}$ Water or caustic may also be added to the DCRT, affecting these same properties. These issues are addressed in Section 2 on gas solubility. Another implication of multiple pumping operations is that the total flow rate into a DCRT could exceed the maximum pumping rate for any individual salt-well pumping operation, which is $4 \mathrm{gpm}$.

Table 1.1. DCRT Tank and Vault Capacity

\begin{tabular}{|c|c|c|c|}
\hline DCRT Name & Tank Capacity (gal) & Operating Capacity (gal) & Vault Capacity (gal) \\
\hline A & 16,280 & 14,251 & 37,000 \\
\hline BX & 31,000 & 24,800 & 85,000 \\
\hline S & 20,280 & 16,213 & 49,210 \\
\hline TX & 31,000 & 24,800 & 85,000 \\
\hline U & 31,000 & 24,800 & 85,000 \\
\hline
\end{tabular}

(a) DC Hedengren, personal communication, September 18, 1997. 


\section{DCRT 244-A}

DCRT 244-A is the lift station at the low point of the cross-site transfer line, just west of the AN Tank Farm. It will not receive salt-well pumped liquids directly (wastes from A and AX tank farms will be pumped directly to Tank AN-101) $)^{(\text {a) }}$ but receives flush water after cross-site transfers and would collect waste in the event of a leak in the cross-site transfer line. Thus, any waste from FGWL tanks in the 200 West Area received by 244-A will be mixed with wastes from other tanks and diluted by flush water, unless there is a leak in the cross-site transfer line.

Because of the convoluted pathway of wastes sent to DCRT 244-A, we do not attempt a full analysis of its headspace concentrations. However, headspace flammable gas concentrations are likely to be much lower in 244-A than in DCRTs that receive salt-well pumped wastes directly from FGWL tanks. First, flammable gas concentrations in non-FGWL tank waste are likely to be lower than those in FGWL tanks, so mixing the two types before transfer should reduce flammability hazards somewhat. Second, dilution in flush water would reduce those hazards substantially, roughly in proportion to the waste's dilution factor. If leaked waste were received, it would not necessarily be diluted; however, its volume is likely to be smaller than the $80 \%$ of total capacity assumed for the other DCRTs. ${ }^{(b)}$ We therefore conclude that the analyses of the other four DCRTs are probably bounding for 244-A, though this would need to be confirmed for specific cases.

\subsection{Salt-Well Pumping}

Salt-well pumping removes a portion of the drainable liquid from the interstices between solid particles in the waste. A salt well with a screen and a jet pump are inserted into the waste through a tank riser. The screened portion is $10 \mathrm{in}$. in diameter and extends from several feet above the waste surface to within a few inches of the bottom of the tank, giving it a typical height of $14 \mathrm{~m}$. The screen is a helix of stainless steel wire of triangular cross-section welded to vertical support rods. ${ }^{(c)}$ The screen openings are $1.3 \mathrm{~mm}$ tall (the wire spacing) by $5 \mathrm{~cm}$ wide (the vertical support spacing) or $0.05 \times 2$ in. (WHC 1996). Liquid drains through the screen and into the salt well. Three DP tubes are used to monitor liquid level and specific gravity by slowly bubbling air through them and measuring differential pressure.

During pumping operations, liquid is withdrawn from the well at a rate of up to $4 \mathrm{gpm}$ (Hedengren et al. 1997), the design limit of the pump. The liquid in the salt well is not allowed to fall below a certain level (about $1 \mathrm{ft}$ ) to keep it above the pump intake and the bottoms of the two lower DP tubes. The system is designed to operate automatically so the liquid in the well is maintained at a constant level, resulting in a gradually decreasing pumping rate as the waste drains and the hydrostatic forces on the liquid decrease. (For tanks without a supernatant layer, the pumping rate often drops well below $4 \mathrm{gpm}$ very quickly.) In later stages, however, the well can generally be pumped down more rapidly than it can be refilled by draining. Pumping under these circumstances is sometimes intermittent, with short pumping campaigns to empty the well followed by periods of a day or more in which the well is recharging (Caley et al. 1996).
(a) RS Nicholson, personal communication, March 2, 1998.
(b) The entire volume of the cross-site transfer line is roughly 12,000 gallons, i.e., approximately $75 \%$ of the volume of 244-A.
(c) DD Wiggins, personal communication, January 6, 1998. 
However, liquid recirculates continuously through the jet pump even when it is not withdrawing fluid from the salt well, preventing direct connection of the headspaces of the source and receiver tanks. Pumping operations are terminated when certain acceptance criteria are achieved, including an overall pumping rate below $0.05 \mathrm{gpm}$ (WHC 1996).

\subsection{Transfer Lines}

The transfer system between each source tank and the DCRT that serves it includes the pump pit, single- and double-encased underground (or potentially above ground) transfer piping, valve and jumper pits, rigid and flexible jumpers, pit drain systems, and cleanout boxes (WHC 1996). Transfer piping is either 2- or 3-in. nominal diameter carbon steel. The total length of transfer line between a source tank and a DCRT is typically around $300 \mathrm{~m}$ (1000 ft) (WHC 1996), giving a transfer line volume on the order of a cubic meter (35.3 cubic feet).

Van Keuren and Ocoma (1998) issued a "calc note" on flammable gas issues in transfer lines. Their analyses show that during salt-well pumping, the transfer lines may not be filled with liquid. Flammable gases accumulate in the transfer line gas volume due to volatilization from the waste and generation within the lines from corrosion, thermolysis, and radiolysis. Using conservative values of both the dissolved ammonia concentration $(1000 \mu \mathrm{g} / \mathrm{ml})$ and hydrogen generation rates from $\mathrm{AN}-107$, they show that the transfer line headspace reaches the LFL in 2 to 57 days, depending on the pipe diameter and the fraction of its cross-section filled with liquid. We believe that mass transfer limitations may decrease the rate of flammable gas volatilization in transfer lines. A letter report on this subject will be released shortly.

\subsection{Document Organization}

Sections 2,3 , and 4 of this report describe three mechanisms by which flammable gases could potentially be carried from a source tank into a DCRT: dissolved gas, entrained bubbles, and gas adsorbed on entrained solids. By discussing vapor-liquid equilibria in both the source tank and the DCRT, Section 2 also describes how dissolved flammable gas would volatilize from the waste into the DCRT headspace and what the effects of temperature, $\mathrm{pH}$, and salt concentration are on solubility. Section 5 discusses gas generation within the DCRT itself, rounding out the list of potential sources of flammable gas.

Section 6 considers whether a solids layer might form, retain gas, and cause a buoyant displacement instability in a DCRT, as has occurred in some of the FGWL tanks. Section 7 discusses whether the DCRT headspace ventilation rate might be higher than the $3 \mathrm{cfh}$ provided by the DP tubes. Section 8 calculates headspace flammability for gas mixtures. Section 9 presents models for calculating DCRT headspace flammability given the initial dissolved concentrations of the gases, fill rate, ventilation rate, DCRT volume, and other parameters. The method and results are compared with the end-of-fill and post-fill steady-state concentration calculations of Hedengren et al. (1997). We then revise those estimates based on our estimates of the appropriate input parameters and discuss parametric sensitivity. This section also contains some examples of how mixing or diluting waste may affect volatilization of flammable gas. Section 10 summarizes our conclusions, and cited references appear in Section 11. Appendix A lists the ammonia concentration data available for SSTs through March 1998. 


\subsection{Dissolved Gases}

Tank wastes are known to trap bubbles (free gas) containing mixtures of flammable and nonflammable species. The concentration of each species in the retained gas is in thermodynamic equilibrium with the species' concentration dissolved in the surrounding liquid. Some of the gases, such as hydrogen, are relatively insoluble in tank waste, so the majority (but not all) of the hydrogen inventory in a tank is present in the relatively small free gas volume. However, other gases (such as ammonia) are quite soluble and reside primarily in the liquid phase.

Salt-well pumping, by transferring the pumpable liquid in the source tank to the DCRT, transfers the dissolved gas as well. As we show in this report, dissolved gas and gas generated within the DCRT are the primary sources of flammable gas affecting DCRT operations. (The flammability contribution of organic vapors from distinct solvent layers is outside the scope of this document and applies only to Tank C-103.) The total amount of dissolved flammable gas in the liquid transferred to the DCRT depends on the concentrations of flammable gases dissolved in the liquid in the source tank. The dissolved concentration of any species in the source tank depends on its partial pressure in the free gas and on its solubility in the waste liquid. The solubility is a controlling property for two reasons. The higher a gas's solubility, the more of it will be dissolved in the source tank liquid for a given partial pressure. However, the higher a gas's solubility, the less of it will be released into the DCRT headspace.

The first technical issue related to dissolved gases that we discuss is the total (gas-phase and liquid-phase) concentrations in the source tank waste. The major conclusions are

- The layer of waste from which liquid is pumped is a primary concern in characterizing the waste fed to the DCRT. If much of the feed is taken from a supernatant layer, the dissolved gas concentrations can be considerably different than if the liquid is pumped from liquid in a bottom layer or in large pockets in the waste matrix. It is thus important to consider the possible locations in the waste from which liquid may originate. The modeling described in this report (and documented in Section 9) assumes that liquid is pumped from within the waste matrix in tanks, for lack of more specific information.

- The composition of the low-solubility gas mixture retained in the high-solids layers of tanks whose gas composition has not been measured can be modeled as $65 \%$ hydrogen and $5 \%$ methane with the remainder nonflammable gases. The composition uncertainty for hydrogen in high-solids layers in unmeasured tanks is $+50 \%$ to $-70 \%$ of the hydrogen. The composition uncertainty for methane in high-solids layers in unmeasured tanks is $\pm 100 \%$ of the methane. This composition is based on the median of RGS results for the free gas retained in submerged high-solids waste layers (Shekarriz et al. 1997; Mahoney et al. 1997). The nonflammable gases, which include nitrogen, nitrous oxide (discussed in Section 8), and other nitrogen oxides, are treated as nitrogen for DCRT modeling purposes. This composition is appropriate for estimating the dissolved low-solubility gas concentration in liquid that is to be pumped from the waste matrix, where it is in equilibrium with the retained free gas. 
- Liquid that is pumped from supernatant layers contains less hydrogen than liquid in the waste matrix does, according to RGS measurements (Shekarriz et al. 1997). The low-solubility gas mixture in supernatant liquid layers in tanks whose gas composition has not been measured can be modeled as $19 \%$ hydrogen and $7 \%$ methane, the median composition measured by the RGS in supernatant layers. The composition uncertainty in the free gas in the supernatant in unmeasured tanks is $\pm 70 \%$ of the hydrogen and $\pm 100 \%$ of the methane.

- Certain ammonia measurements may underestimate the true ammonia concentration in the waste if the sample is depleted in ammonia compared with the average in the pumpable waste. Grab samples from the middle or bottom of the tank are more likely to represent the ammonia concentration in the liquid pumped from the waste matrix and are strongly preferred as modeling inputs when liquid is to be pumped from the matrix. The ammonia concentrations in near-surface samples may be a factor of 0.5 to 4 times the concentration in pumpable liquid from the waste matrix. (Top samples usually contain less ammonia than samples from the middle or bottom of the waste, probably because of ammonia evaporation, but there are exceptions; hence the uncertainty ranges down to a factor of less than unity.) Note, however, that nearsurface samples are appropriate for use in modeling liquid pumped from a supernatant liquid layer, a pumping scenario for which it would be inappropriate to use ammonia measured by taking deep grab samples. The choice of a representative ammonia sample or of a multiplying factor must be made on a case-by-case basis, considering the probable layer of origin of the pumped liquid.

- Ammonia concentrations measured in conventional core samples may be a factor of $1.5 \pm 0.5$ lower than the original concentration in the sample because of ammonia loss from the drainable liquid during core sample extrusion. Grab samples undergo little loss. They also are considered to have an uncertainty of $\pm 30 \%$.

- Because the in-tank and in-lab losses are independent of each other, the ammonia concentration measured in near-surface core samples should be multiplied both by a factor of 1.5 (for the extrusion losses) and by a sample representativeness factor (which must be selected on the basis of the pumping scenario).

Second, we describe the basis for estimating gas solubilities in the waste liquid and justify the use of the Schumpe model with tested parameters (Norton and Pederson 1995; Hermann et al. 1995). Third, we discuss the calculation of in-situ dissolved gas concentrations from the total concentrations and the solubilities. Fourth, we consider the question of whether dissolved gases are lost from the liquid in the salt well into the source tank headspace, which would reduce the flammable gas concentration in the feed to the DCRT. These losses are calculated to be less than $10 \%$ of the dissolved gas, so ignoring the loss introduces only a small conservatism into DCRT flammability estimates. Fifth, we calculate mass-transfer coefficients in the DCRT for use in a non-equilibrium model (which is derived in Section 9.6 and whose results are discussed in Section 9.7). And, finally, we consider dissolved gas release mechanisms in the DCRT, including the effects of waste mixing, $\mathrm{pH}$ change, and temperature change. The first two of these mechanisms could potentially increase the gas release in the DCRT, but temperature changes (other than those caused by waste mixing) are not expected to be 
significant. The assumptions used in the model derived by Hedengren et al. (1997) and the model in the present report are discussed and compared throughout this section.

\subsection{Total Concentrations in the Source Tank}

Hydrogen, methane, and ammonia are the species that contribute the most to headspace flammability in the DCRT. Some tanks are known to contain non-methane hydrocarbons (NMHC) as well, but these are typically present in low concentrations and can be treated as methane. This section contains a discussion of the source concentrations first of low-solubility gases (hydrogen and methane) and then of high-solubility gases (ammonia).

Nonflammable gases are also present in tank wastes and include nitrogen, nitrous oxide, and other nitrogen oxides. The negligible flammability of nitrous oxide (discussed in Section 8) contributes to flammability only by decreasing the downward propagation flammability limit to approach the upward propagation flammability limit. Because the upward limit, the lower and more limiting value, is used in modeling, the possible effect of nitrous oxide is essentially already accounted for, and nitrous oxide need not be tracked as a separate species.

\subsubsection{Low-Solubility Components}

Hydrogen, methane, nitrous oxide, nitrogen, and NMHC have very low solubilities in the waste, so their total concentrations (expressed in gmol/L of waste) are approximately equal to the concentration in the gas phase (in gmol/L of waste). (The inaccuracy of this assumption is small compared with typical errors in determining gas composition and pressure.) Because the amount of low-solubility gas in the liquid is small compared with what is in the retained gas, determining the gas pressure and composition in the waste quantitatively determines the total concentrations of these species. (The total concentration of a species equals the sum of the concentration in the retained gas and the concentration dissolved in the liquid, both expressed in $\mathrm{gmol} / \mathrm{L}$ of waste.) Once the total concentration of each low-solubility constituent is known, its dissolved concentration in the waste liquid (the DCRT feed) can be calculated by using its solubility (see Section 2.2) to partition the total concentration between the gas and liquid phases. The total pressure is also needed to calculate the dissolved concentrations of low-solubility gases. (The composition is multiplied by the total pressure to give the partial pressures of hydrogen, methane, and nonflammable gas; the dissolved concentrations of these gases are then calculated using the species' solubilities.) The topic of total pressure is covered in the discussion of calculation of dissolved gas concentrations.

The only source of direct data on the composition of low-solubility retained gases is RGS sampling (Shekarriz et al. 1997; Mahoney et al. 1997). The RGS method, which had been used on four DSTs and five SSTs as of the end of FY 1997, samples and measures the volume and composition of the free gas at several points in a tank. RGS analysis is carried out by extruding hermetically sealed core samples into an evacuated sealed container. The gases released by the extruded sample are pumped into collection canisters, whose pressure, temperature, and composition are measured, allowing calculation of the amount and composition of the gas in the sample. Although the low-solubility gases have been well characterized in RGS-sampled tanks, 
only a few tanks have been subjected to RGS. Thus, for the purposes of this discussion, gas compositions from those tanks must be extrapolated or related in some way to the compositions in unsampled tanks.

RGS composition data for five SSTs (Shekarriz et al. 1997; Mahoney et al. 1997) have ranged from less than $20 \mathrm{~mol}_{\%} \mathrm{H}_{2}$ (in several tanks) to nearly $80 \mathrm{~mol}^{\circ} \mathrm{H}_{2}$ (in A-101). A similar range has been seen in DSTs. Many of the measured compositions range between 50 and $80 \mathrm{~mol} \% \mathrm{H}_{2}$, as is shown in Figure 4.5.1 of Mahoney et al. (1997). Thus the hydrogen mole fraction in Hedengren et al. (1997), which is $97 \mathrm{~mol} \%$, is at least $17 \%$ higher than the highest measured hydrogen mole fraction.

Figure 4.5.1 in Mahoney et al. (1997) shows the compositions of insoluble retained gas that were measured by RGS analysis in four SSTs and four DSTs. Of the 41 samples shown, 32 are from the high-solids layers where essentially all of the gas in the waste is retained. The remaining nine are from liquid layers that may be supernatant (in the DSTs) or submerged (as in A-101).

The 32 samples from high-solids layers comprise 15 samples from SSTs and 17 from DSTs. Of the 15 samples from high-solids SST waste, five contained insoluble gas that was less than $40 \mathrm{~mol} \%$ hydrogen; five contained between 40 and $65 \mathrm{~mol} \%$ hydrogen; and five held between 65 and 80 mol\% hydrogen. Of the 17 samples from high-solids DST waste, five contained insoluble gas that was less than $40 \mathrm{~mol} \%$ hydrogen, nine held from 40 to $65 \mathrm{~mol} \%$ hydrogen, and three held 65 to 70 mol\% hydrogen. Because one SST (U-103) accounts for four of the five compositions that contain less than $40 \%$ hydrogen, we consider $65 \mathrm{~mol} \%$ to be a reasonable median value for the hydrogen content of gas retained in high-solids layers. The DST data follow a similar distribution (with a slightly lower median), which seems to confirm a general tendency in retained gas composition (whether in DSTs or SSTs).

The composition of the free gas in liquid waste layers is considerably different; in these cases, the median composition measured by RGS is $19 \mathrm{~mol} \%$ hydrogen, with a range of compositions from 12 to $27 \mathrm{~mol} \%$ hydrogen. The composition is much the same whether measured in the supernatant liquid layers of AW-101, AN-105, AN-104, and AN-103 or in the lower liquid layer in A-101.

Much modeling work, including that of Hedengren et al. (1997) and Hodgson et al. (1996), has conservatively used a hydrogen mole fraction of $97 \%$. This value was derived from observations of gas release events (GREs): the peak hydrogen in the headspace gave an estimate of the total hydrogen volume released (assuming perfect mixing throughout the dome), the observed level drop was used to estimate the total gas volume released, and the hydrogen mole fraction was calculated by dividing the former by the latter. This approach is subject to considerable uncertainty in that it depends on perfect mixing in the headspace and perfect response of the waste level to a gas release. The uncertainty can be seen in the fact that Hodgson et al. (1996) used hydrogen mole fractions of $90 \mathrm{~mol} \%$ or more for an AN-105 release and $74 \mathrm{~mol} \%$ for an AW-101 release, while the maximum hydrogen measured in RGS samples of $\mathrm{AN}-105$ and AW-101 retained gas was 70 and $50 \mathrm{~mol} \%$, respectively. 
Methane and non-methane hydrocarbons (NMHCs) make up the remaining flammable low-solubility gases. The methane mole fraction assumed by Hedengren et al. (1997), $3 \mathrm{~mol} \%$, is higher than the average RGS measurement but lower than the maximum. RGS data indicate that methane makes up less than $1 \mathrm{~mol} \%$ of the gas in more than three-fourths of the samples taken from the nine sampled tanks. (The higher-methane samples are all from DSTs AW-101 and $\mathrm{AN}$-104.) When NMHCs $\left(\mathrm{C}_{2} \mathrm{H}_{\mathrm{x}}, \mathrm{C}_{3} \mathrm{H}_{\mathrm{x}}\right.$, and others) are included, the combined total hydrocarbon (THC) exceeds $3 \mathrm{~mol} \%$ of the low-solubility gas in seven of the 40 RGS samples, including four from AW-101 (with a maximum THC of $6.6 \mathrm{~mol} \%$ of the low-solubility gas), one from AN-104 (3.1 mol\% THC), and two of the three samples from SST BY-109 (with a maximum of $3.4 \mathrm{~mol} \% \mathrm{THC}$ ).

NMHCs frequently have lower LFLs than methane, which has an LFL of 5 vol\% (equivalent to mol\% for an ideal or nearly ideal gas). The LFLs of $\mathrm{C}_{2} \mathrm{H}_{\mathrm{x}}$ compounds are, on the average, about 3 vol\% (CRC 1975). The LFLs of ethane, ethylene, ethyl alcohol, and acetaldehyde are $3,2.75,3.3$, and 4 vol\%. The LFLs of $\mathrm{C}_{3} \mathrm{H}_{\mathrm{x}}$ compounds are, on the average, about 2 vol\% (CRC 1975). The LFLs of propane, propylene, isopropyl alcohol, and acetone are $2.1,2.0,2.0$, and $2.6 \mathrm{vol} \%$, respectively. Higher hydrocarbons tend to have lower flammability limits; for example, the LFL of butane is $1.8 \mathrm{vol} \%$, and that of heptane is $1.1 \mathrm{vol} \%$. An average LFL for the higher hydrocarbons might be $1.2 \mathrm{vol} \%$. Thus, 3 vol\% of NMHCs can be equal in flammability to a greater amount of methane. This extra flammability should be accounted for in modeling NMHCs as methane.

The SSTs whose retained gas compositions have been measured provide a clue to the methane equivalence of the NMHCs in tank waste. The retained gas in Tank U-103 had an average composition of $0.42 \mathrm{~mol} \%$ methane, $0.49 \mathrm{~mol} \% \mathrm{C}_{2} \mathrm{H}_{x}, 0.01 \mathrm{~mol} \% \mathrm{C}_{3} \mathrm{H}_{\mathrm{x}}$, and $0.04 \mathrm{~mol} \%$ other hydrocarbons (Mahoney et al. 1997). When we use LFLs of $3 \mathrm{~mol} \%$ for $\mathrm{C}_{2} \mathrm{H}_{\mathrm{x}}, 2 \mathrm{~mol} \%$ for $\mathrm{C}_{3} \mathrm{H}_{\mathrm{x}}$, and $1.2 \mathrm{~mol} \%$ for other hydrocarbons to convert them to their flammability equivalent in methane, the U-103 gas is found to contain $1.2 \mathrm{~mol} \%$ of methane-equivalent. Using the same method, the retained gases in Tanks S-106, BY-109, and A-101 are found to contain 0.9, 5.8, and $1.3 \mathrm{~mol} \%$, respectively, of methane-equivalent (average composition). The tank whose retained gas inventory has the highest fraction of equivalent methane is AW-101 (a DST); its average composition included $6.6 \mathrm{~mol} \%$ of methane-equivalent.

We think the direct gas composition measurements that have been made using RGS are preferable to those calculated by indirect means. (Many of the SST RGS data were not yet available at the time of the Hedengren et al. study, making their use of $97 \mathrm{~mol} \%$ hydrogen a necessary conservative assumption.) The location of pumpable liquid (that is, whether it comes from the waste matrix or from a layer of liquid that is not mingled with solids and large amounts of free gas) must be considered in deciding which RGS samples represent the gas in equilibrium with the pumpable liquid. This determination must be made on a case-by-case basis.

For tanks that have been RGS sampled, of which only U-103 and S-106 are modeled in the present study, the average hydrogen and methane-equivalents in the retained gas inventory are modeled. Neither of these tanks has a well-defined liquid layer, so the gas composition represents the free gas in the waste matrix. The modeled U-103 retained gas is $22 \mathrm{~mol} \%$ hydrogen, $1.2 \mathrm{~mol} \%$ methane, and $76.8 \mathrm{~mol} \%$ nonflammable gas (Mahoney et al. 1997, Table 4.1.6). The modeled composition of S- 106 retained gas is $63 \mathrm{~mol} \%$ hydrogen, $0.9 \mathrm{~mol} \%$ 
methane, and $36.1 \mathrm{~mol} \%$ nonflammable gas (Mahoney et al. 1997, Table 4.2.6). The composition uncertainty in tanks that have undergone RGS sampling is $\pm 20 \%$ of the applicable mole fraction.

The modeled composition in tanks without composition measurements is based on the observed average flammable-gas composition in the nine tanks that have undergone RGS sampling. For liquid taken from the waste matrix in these tanks, the present model assumes that the gas in the source tank is $65 \mathrm{~mol} \%$ hydrogen and $5 \mathrm{~mol} \%$ methane-equivalent, with the remainder nonflammable gases (modeled as nitrogen). We expect this composition to be a best estimate of retained gas composition in the waste matrix. An upper-range estimate for the composition of gas in the waste matrix, based on RGS data, would be $80 \mathrm{~mol} \%$ hydrogen and $9 \mathrm{~mol} \%$ methane-equivalent. The ultimate upper-limit is, of course, $100 \mathrm{~mol} \%$ hydrogen in the low-solubility gas. The composition uncertainty for hydrogen in unmeasured tanks is $+50 \%$ of the hydrogen (for the pure-hydrogen case) and $-70 \%$ of the hydrogen (for low-hydrogen tanks that resemble U-103). The composition uncertainty for methane in unmeasured tanks is $\pm 100 \%$. of the methane, which accounts for the highest-THC samples that have been measured and for the pure-hydrogen zero-methane case.

The best estimate for the composition of retained gas in liquid layers in unmeasured tanks is $19 \mathrm{~mol} \%$ hydrogen and $7 \mathrm{~mol} \%$ methane-equivalent, with the remainder nonflammable gases. Our engineering judgment is that the composition uncertainty in the free gas in the supernatant in unmeasured tanks is $\pm 70 \%$ of the hydrogen and $\pm 100 \%$ of the methane. There is more uncertainty in the composition of the gas in liquid layers than in high-solids layers because the liquid-layer samples contained very little gas (less than $1 \mathrm{vol} \%$ ). When the measured gas was corrected for air entrained into the RGS samplers during sample acquisition, the uncertainty of the correction (which removed the $\mathrm{O}_{2}, \mathrm{Ar}$, and a quantity of $\mathrm{N}_{2}$ proportional to the $\mathrm{O}_{2}$ ) was high compared with the amount of gas present. Therefore, the uncertainty of the corrected composition is higher than is indicated by the observed variation between tanks, which is approximately $\pm 50 \%$ of the hydrogen.

\subsubsection{Ammonia}

Ammonia is a highly soluble species; at high $\mathrm{pH}$, the total concentration of ammonia (expressed in $\mathrm{gmol} / \mathrm{L}$ waste) is approximately equal to its dissolved concentration (also expressed in gmol/L waste). (The error introduced by making this approximation is less than the uncertainty in dissolved ammonia measurements.) The dissolved ammonia concentration in waste liquid (and so in the DCRT feed) is usually determined by direct measurement.

Many of the existing dissolved ammonia data may underestimate the actual concentrations in the liquid transferred to the DCRT. The liquid in conventional cores and grab samples may lose ammonia to the air during sample processing in the laboratory if the sample is exposed for more than a few minutes. ${ }^{(a)}$ On the other hand, RGS methods measure evaporated ammonia but can underestimate the "residual" amount of ammonia that does not evaporate from the

(a) Herting DL. October 7, 1994. "Rate of Ammonia Loss from Laboratory Samples." Letter report to GD Johnson, Westinghouse Hanford Company, Richland, Washington. 
sample (Shekarriz et al. 1997; Mahoney et al. 1997) ${ }^{(a)}$. In addition to the measurement difficulties, even a carefully protected sample may not be representative of the waste that is to be transferred to the DCRT. The part of the tank waste that is sampled, if it is near the waste surface, can be depleted in ammonia by mass transfer to the headspace.

The several types of ammonia measurement difficulties (as they pertain to DCRT modeling) are discussed in the following subsections. The available ammonia measurements can be found in the appendix.

\subsubsection{Ammonia in Grab Samples}

In general, only the drainable liquid from a grab sample is subjected to ammonia analysis. Grab samples are exposed to the air while being centrifuged (if solids are present), while undergoing subdivision into subsamples, and while being analyzed. When there are no solids present and the subsample is analyzed for ammonia before any other tests are made, the exposure time is generally less than 10 minutes. Centrifugation (to settle solids) can add another 10 minutes and, in some cases, more time (probably 10 minutes or less) can be spent on other analyses that precede ammonia tests.

Handling and analysis procedures have varied over the period represented by the ammonia measurements in the appendix to this report. In 1997, the procedure was revised so that the subsample used for ammonia analysis was "preserved" with dilute acid (to convert volatile ammonia to nonvolatile ammonium ion) and was taken from the sample before any other analysis procedures. The most recent grab samples (AX-101, SX-103, and SX-104) were subsampled, with some subsamples treated with acid and others left untreated so that the effect of acid preservation could be tested. No significant effect was found. ${ }^{(b)}$ The most recent samples can therefore be considered to have undergone negligible volatilization.

Earlier grab samples (which provide most of the data in the appendix) probably spent 10 to 30 minutes exposed to the air, because the ammonia subsamples were not necessarily the first ones taken, and were not acid-preserved. Under those circumstances, some volatilization loss

(a) The difficulty with determining ammonia from RGS samples is that ammonia is highly soluble and tends to remain in the liquid, and the RGS extraction process captures only the gas phase. Little ammonia is in the extracted gas; most of it remains dissolved in the sample liquid. To determine the residual dissolved ammonia, it is necessary to measure it directly or to find a physical relationship by which the residual ammonia can be calculated from the extracted ammonia. Both alternatives have unsolved technical problems. Direct measurement of the residual means scraping or draining the solids and liquid out of the RGS vessel after gases have been extracted and sending part of the sample for ion-specific electrode analysis. A significant amount of the ammonia is lost to hot-cell air in this process, so the residual ammonia is underestimated (in the same way discussed in Section 2.1.2.3). The indirect measurement of residual ammonia has been hindered by the difficulty of finding a relationship between extracted and residual ammonia. The equilibrium relation that exists in the tank because the gas and liquid spend a long time in intimate contact does not exist in the RGS process. Mass-transfer limitations within the sample and at its surface prevent equilibrium being approached, so the actual relationship between the extracted ammonia vapor and the dissolved residual ammonia is not well determined.

(b) Barton WB. May 20, 1997. Personal communication to LA Mahoney (PNNL), Richland, Washington. 
could have occurred. To examine the extent of ammonia loss from samples, experiments were performed in which ammonia was added to salt solutions of varying strengths. ${ }^{(a)}$ About $10 \mathrm{~mL}$ of each ammonia-spiked solution was stirred by a stir-bar in a $15-\mathrm{mL}$ vial that was open to the air, and the change in ammonia concentration was tracked over 24 hours. About $20 \%$ of the initial ammonia was lost from the most concentrated solution (about 12 molal salt) in the first 10 minutes; by 1 hour, about 35\% had been lost. This point, taken alone, suggests that measured ammonia concentrations might be 20 to $30 \%$ lower than actual concentrations.

However, another process that affects grab samples is post-sampling precipitation: cores are often taken at in-situ temperatures that are higher than hot-cell temperatures, so dissolved salts precipitate out of solution upon cooling. The result is that a sample that might originally have been entirely liquid becomes part liquid and part solids. The ammonia in the in-situ liquid is concentrated into the smaller quantity of drainable room-temperature liquid. This causes the measured ammonia concentrations per liter of liquid to be higher than the in-situ values. An extreme example can be seen in the bottom-most grab sample taken in A-101 (see appendix); the sample was entirely liquid at tank conditions, but at room temperature was mostly solids with little or no liquid draining from the waste. More commonly, as detailed in the appendix, solids are present as 1 to $50 \mathrm{vol} \%$ of the room-temperature sample. This point, taken alone, suggests that the ammonia concentrations measured in high-temperature tanks might overestimate actual concentrations by as much as a factor of 2 .

These two processes, volatilization and concentration, probably often offset each other in the grab samples whose ammonia subsamples were not taken early in subsampling, particularly when high solids both concentrate the ammonia and require the sample to be exposed to air for a longer time during centrifugation. Therefore, the present model treats all pre-1997 grab samples as requiring no scaling to account for measurement effects. By contrast, the 1997 grab samples (AX-101, SX-103, and SX-104) are corrected for solids precipitation. The lab-temperature liquid volume is considered to be equal to the separated liquid volume plus one-third of the settled solids volume (accounting for pore liquid). This lab-temperature liquid volume is used to scale the ammonia concentration in 1997 grab samples to the original in-situ grab-sample volume (which was all liquid). The uncertainty of grab sample ammonia concentrations is expected to be within the $\pm 30 \%$ range for the reasons given (i.e., the potential for $20-30 \%$ loss from evaporation and 10-30\% gain when solids precipitate).

\subsubsection{Ammonia in Conventional Core Samples}

Core samples are typically extruded into flat pans from which the free liquid drains in a shallow layer into an open jar. The liquid is exposed to the well-ventilated hot-cell atmosphere for one or two hours before ammonia analysis and is handled in much the same way as grab sample liquid. ${ }^{(b)}$

(a) Herting DL. October 7, 1994. "Rate of Ammonia Loss from Laboratory Samples." Letter report to

GD Johnson, Westinghouse Hanford Company, Richland, Washington.

(b) Ibid. 
The study performed by Herting addressed the possible losses from core samples. As discussed in Section 2.1.2.1, Herting's study of ammonia loss from stirred solution samples showed that as much as $20 \%$ of the original ("true") ammonia could be lost in 10 minutes, up to $35 \%$ lost in 1 hour, and up to $80 \%$ at 8 hours. Considering the differences between the test solutions and real waste samples and the differences in their handling, Herting concluded that core samples could lose "up to, but probably less than, one-half of the total ammonia present at the time of extrusion.", (a) Thus a factor of 2 would be used to provide an upper-bound estimate of the original ammonia concentration.

An average (non-upper-bound) value for ammonia loss from core samples might be about $30 \%$, implying that measured concentrations should be multiplied by about 1.5 to obtain the original concentrations. In the present model, ammonia measurements from conventional core samples are multiplied by 1.5 to give a best-estimate ammonia concentration that accounts for losses from core samples during the lengthy extrusion procedure. Note that, as for grab samples from high-temperature tanks, solids precipitation may increase the measured ammonia concentration over the in-situ value. Thus, the factor of 1.5 may give a high estimate of ammonia in hot tanks.

The uncertainty in the ammonia for core-sampled tank wastes, after applying the multiplying factor, is about $+30-50 \%$. The upper-end uncertainty is based on the difference between the upper-limit and best-estimate multiplying factors ( 2 and 1.5, respectively), and the lower-end uncertainty comes from the possibility that ammonia evaporation had little effect and from solids precipitation (the latter is applicable only to hot tanks).

\subsubsection{Ammonia in RGS Core Samples}

RGS cores are hermetically sealed when acquired and are extruded into an evacuated vessel. The low-solubility gas and vapor released from the sample are pumped into collection canisters. When the gas extraction has been completed, a substantial amount of ammonia remains behind in solution in the sample. The RGS methods therefore calculate extracted (pumped) and residual (remaining dissolved) ammonia separately. Because the evaporated ammonia is collected, volatilization losses are not an issue in RGS measurements; instead, the chief question is the accuracy of the estimate of residual ammonia.

Different extraction procedures and calculation methods have been used at different points in the RGS program. Detailed descriptions can be found in Shekarriz et al. (1997) for Tank A-101 and in Mahoney et al. (1997) for Tanks U-103, S-106, and BY-109. A crucial feature that all the RGS methods have in common is the assumption that the ammonia dissolved in the waste sample is in equilibrium with the ammonia vapor over the sample. Because this equilibrium depends on ammonia diffusion within the sample, which is a slow process, the assumption of equilibrium was almost certainly incorrect in many cases and would have led to an underestimation of the residual ammonia. The degree of underestimation probably varied depending on the exact procedure and the amount of time allowed for equilibration.

The extent of the RGS underestimation of ammonia concentrations is not fully known. The appendix to this report shows all the available ammonia data, including those for Tanks A-101 and S-106, for which both grab sample and RGS ammonia measurements are available. For these two tanks, comparisons of grab sample and RGS measurement methods are possible. 
In Tank A-101, which has relatively high ammonia concentrations, the maximum grabsample ammonia concentration (taken halfway down the salt well) was $531 \mu \mathrm{g} \mathrm{NH} / \mathrm{mL}$ liquid. The maximum RGS ammonia concentration, $1400 \mu \mathrm{g} \mathrm{NH}_{3} / \mathrm{mL}$ liquid, was at about the same elevation. Most RGS concentrations were about $250 \mu \mathrm{g} \mathrm{NH} / \mathrm{mL}$ liquid, higher than the second grab sample, which was taken near the top of the waste and contained $134 \mu \mathrm{g} \mathrm{NH} / \mathrm{mL}$ liquid. Despite the many reasons for regarding the RGS ammonia measurements as underestimates, they consistently show higher ammonia concentrations than the grab samples at the same locations in A-101.

For Tank S-106, a low-ammonia tank, a grab sample from the bottom of the salt well gave an ammonia concentration of $241 \mu \mathrm{g} \mathrm{NH} / \mathrm{mL}$ liquid. Most of the RGS measurements averaged about $60 \mu \mathrm{g} \mathrm{NH} / \mathrm{mL}$ liquid, with a single exceptionally high measurement of $290 \mu \mathrm{g}$ $\mathrm{NH}_{3} / \mathrm{mL}$ about halfway down the tank. The RGS measurement at the bottom of the tank was $90 \mu \mathrm{g} \mathrm{NH} / \mathrm{mL}$, substantially less than the grab sample measurement at the same elevation. Here, most of the RGS ammonia measurements were lower than the grab-sample ammonia by a factor of 2 or more; but again there was a single high ammonia concentration measured by RGS that exceeded the grab-sample measurement.

Tank U-103 had a maximum ammonia value (measured by RGS) of $3100 \mu \mathrm{g} \mathrm{NH} / \mathrm{mL}$. This ammonia concentration is the highest of any measured, whether by grab sample, core, or RGS methods, and therefore does not clearly support the hypothesis that ammonia concentrations are always under-measured by RGS.

Because of experimental evidence of slow ammonia equilibration (Mahoney et al. 1997), we remain concerned that RGS measurements may underestimate the ammonia concentrations in tank waste. However, the limited non-RGS ammonia data that are available from SSTs do not confirm that RGS underestimation affects every sample. Thus, using the maximum RGS measurement from a tank may avoid underestimation of the arnmonia concentration in the tank. In the present model, we use RGS ammonia data without any correction factor but regard them as having high uncertainty. Provisionally, after review of the comparative data above, we assign an uncertainty of $+100 \%$ and $-50 \%$ to RGS ammonia measurements.

\subsubsection{Non-Representativeness of Samples}

One possible process-related source of ammonia concentration underestimation is dilution of the waste liquid by water introduced as a result of salt-well operations. When a salt well is installed in a tank, water lancing is used to insert the well shaft. (Lancing may also be used to clear the screen of an existing salt well.) The salt-well screen is then put in place, and a minimum of 45 days is allowed for the water to equilibrate with the liquid in the waste, which field experience has shown to be an adequate period of time. Grab samples are taken before (not during) pumping operations; thus, if the salt well is a new one, the sampled liquid may still be diluted by some of the water used in lancing. Under these circumstances, the sample would not be representative of the tank contents. If the salt well was originally installed years before the grab samples were taken (as is typically the case because many SSTs were pumped in the 1970s or 1980s), dilution is not an issue. Certainly the amount of time passed between water lancing and sampling should be considered on a case-by-case basis when estimating ammonia concentrations for modeling. 
Another possible source of ammonia underestimation is near-surface depletion. Many of the dissolved ammonia concentration data come from samples taken near the liquid surface. The liquid at the surface is exposed to air in the headspace, allowing depletion through evaporation. However, the liquid is refreshed by convection from the waste below. The grab-sampled liquid may therefore be somewhat depleted in ammonia compared with the average concentration in the waste liquid pumped into the DCRT. The extent of the depletion depends on the relative rates of evaporation and transport within the waste. Another potential explanation for these differences is the variable rate of ammonia generation with depth in the waste.

The effects (if any) of surface depletion can be determined by reviewing ammonia profiles (the concentrations at a range of depths). The appendix contains data for five tanks (A-101, S-106, SX-103, T-107, and U-103) in which ammonia concentrations were measured at the top, middle, and bottom. Three of these tanks (A-101, S-106, and SX-103) have their highest ammonia concentration in the middle of the waste. The other two (U-103 and T-107) have the maximum at or near the bottom of the waste. These tanks either have their lowest measured ammonia concentration at the top (SX-103, U-103) or have equally low ammonia concentrations at the top and the bottom. The appendix also lists data for three tanks that have either top and middle (AX-101) or middle and bottom ammonia measurements (BY-109, U-102) only. In BY-109 and U-102, the middle concentrations are higher than those at the bottom. In AX-101, the top concentration is higher than the one at the middle.

We draw two conclusions from this review of the data. First, there is little reason to expect near-surface ammonia concentrations to be as high as, or higher than, those farther down in the waste. For seven of the eight tanks with ammonia profile data, surface concentrations are substantially lower than the maximum ammonia measurements. Second, low ammonia concentrations apparently can also occur at the bottom of the tank, an eventuality not predicted by the surface depletion mechanism (and perhaps attributable to variation of the ammonia generation rate with depth).

Theoretical modeling has been performed to estimate the extent of surface depletion. Terrones et al. (1997) modeled ammonia transport on several of the tanks for which RGS data were available. They calculated ammonia concentration profiles that were calibrated with the RGS ammonia measurements. The work included two sampled SSTs that contained surface liquid, U-103 and S-106. For S-106, the model calculated that the surface liquid layer (approximately 1-m deep) was depleted of ammonia by about a factor of 15 compared with the waste at the bottom of the tank. For U-103, the calculations showed that liquid in the pores at the top of the tank were depleted by about a factor of 9 with respect to the bottom waste liquid.

The factor by which the ammonia in surface liquid is depleted compared with the maximum (deepest) ammonia concentration is therefore roughly 10, based on RGS-linked modeling studies. However, this factor is large compared with those seen in the data, where in most cases the maximum measured concentration is 2 to 7 times the minimum. Thus the very limited data seem to indicate that near-surface ammonia concentrations should be multiplied by a factor of roughly 5 (rather than the model-based factor of 10 ) to estimate the maximum concentration. 
However, for DCRT modeling we do not need the surface depletion factor relative to the maximum ammonia concentration but the factor relative to the concentration in the average drainable liquid. The surface depletion factor relative to the ammonia in the average drainable liquid is a smaller number because the average drainable liquid has a lower ammonia concentration than the liquid at the bottom of the tank, for two reasons. First, the average ammonia concentration in the total tank liquid is significantly less (because of depletion in a broad zone near the top) than the maximum concentration at the tank bottom. Second, the lowammonia upper liquid is the most drainable part of the tank liquid because it has the largest head driving it out of the matrix into the salt well. This is especially true for supernatant layers, where present; supernatant not only has a high driving force for flow into the well but has little flow resistance. Therefore, the high-ammonia bottom liquid is precisely that which is least drainable, having less driving head and being held in the pores by capillary force. While much of the liquid from within the waste solids does drain into the salt well, a substantial fraction (20\% or more, depending on waste consistency and configuration [Peurrung et al. 1997]) remains as residual moisture in the waste.

Considering all these factors, the present model multiplies all near-surface ammonia measurements (the samples taken within the top third or fourth of the waste) by a "generic" factor of 2 for the purpose of preliminary modeling of DCRT feeds in lieu of specific pumping scenario information. This factor should not be considered an upper-bound conservatism but as a possibly conservative correction factor. The value of 2 should be reviewed for safety-basis appropriateness and on a case-by-case basis, taking the above-mentioned issues into consideration. It is a very rough approximation and carries with it high uncertainty (as the preceding discussion indicates). The uncertainty in the ammonia in near-top samples, after applying the multiplying factor of 2 , is considered to be $+100 \%-75 \%$, based on the differences observed between minimum and maximum concentrations measured at different heights. That is, if the near-surface datum is a minimum concentration, as it is in some tanks, the ammonia profile could make the average drainable ammonia concentration four times as high as the measurement (considering the highest ratios between minimum and maximum measurements). On the other hand, the near-surface datum could be one of the higher concentrations (as in AX-101), in which case the surface ammonia concentration would be an overestimate even before doubling.

This near-surface multiplying factor is used only when nothing but surface data are available for a tank. Because surface depletion is independent of extrusion losses, ammonia concentrations derived from a near-surface core extrusion are multiplied by a factor of 3 by the present model, with a factor of 2 for surface depletion and a factor of 1.5 for extrusion loss.

Another issue of sample representativeness is that of sample resolution. Even when ammonia has been measured at more than one or two depths in a tank, there is little assurance that the whole profile has been mapped and true maximum concentrations captured. As a conservatism, therefore, the present model uses the maximum ammonia concentration that is measured in any tank where measurements at more than one depth are available. The use of the maximum ammonia measurement is not a generic recommendation, however. Depending on how much liquid was to be pumped from the tank and what parts of the tank the liquid was expected to be drawn from, it might be appropriate to average all the ammonia measurements in a tank, or to use only those from the topmost or bottommost samples. 
Finally, there is some question about whether grab samples taken from the salt well at any depth are representative of ammonia concentrations in the interstitial liquid in the waste matrix. Once the fluid drains into the salt well, it is no longer in contact with retained gas and begins to lose its dissolved gases to the air (and to acquire dissolved air). Grab samples are taken while the salt-well liquid is unpumped and therefore has a long residence time, potentially allowing significant evaporation. Therefore, grab samples may undergo depletion in ammonia compared with the interstitial liquid (which is measured by RGS). Because significant variation in ammonia concentration is seen between grab samples taken at different depths, it must be that convection in the unpumped salt well is not rapid enough to mix the liquid to a uniform concentration. Therefore, the convection also may not be rapid enough to allow significant ammonia loss to the air. The extent of depletion of unpumped salt-well liquid is not known at this time; it would depend on the rate of ammonia evaporation relative to the rate of ammonia entering the salt well from the adjacent interstitial liquid. The uncertainty arising from this possible depletion is not known.

\subsubsection{Conclusions on Ammonia Concentration}

As discussed, the basis for inputs to DCRT ammonia modeling depends on the type of ammonia concentration measurements available. The appendix shows the dissolved ammonia concentrations the present model has used (or would use) for modeling a number of SSTs, including those modeled by Hedengren et al. (1997).

In many cases, ammonia data were not available for tanks that were to be modeled. In these cases, the present model employed the maximum modeling ammonia concentration for the group of tanks whose contents were similar to those of the tank with missing data. The grouping used was based on content clusters devised by Remund et al. (1995) to separate the SSTs into categories based on waste compositions calculated from the historical tank content estimates (HTCE). The assumption made in the present DCRT model is that there may be some similarity in ammonia production and transport among tanks in the same cluster because their contents are similar (based on HTCE). The existing data do not conclusively verify this assumption, although in some clusters there is consistency within a broad range such that most values in these clusters are fairly high or fairly low. Table 2.1 shows the distribution of ammonia concentrations in those HTCE clusters for which more than one non-surface ammonia measurement is available.

Measured concentrations are used in Table 2.1; corrections for losses are not applied. Judging by the table, there is high uncertainty in assigning ammonia concentrations to unmeasured tanks based on the HTCE cluster. Another sign of the uncertainty in defining waste properties by cluster is the variation of tank temperatures (listed in the appendix) within HTCE clusters. The cluster-based ammonia inputs are probably conservative, but conservatism is not ensured by the cluster method. The same can be said for any ammonia concentration that is assumed in the absence of measurements.

Actual ammonia measurements made from salt-well grab samples are preferable to these extrapolations and (when obtained) should be compared with "cluster" predictions (or other types of prediction) to try to improve future estimates of ammonia in unmeasured tanks. 
Table 2.1. SST Ammonia Concentrations Shown by HTCE Cluster

\begin{tabular}{|l|l|ll|}
\hline $\begin{array}{l}\text { HTCE } \\
\text { Cluster }\end{array}$ & Tank & \multicolumn{2}{|l|}{$\begin{array}{l}\text { Mid-Tank or Bottom } \\
\mathrm{NH}_{3} \text { Concentration Range } \\
(\mu \mathrm{g} \mathrm{NH} / \text { mL liquid) }\end{array}$} \\
\hline 7 & $\mathrm{C}-110$ & 86 & (core) \\
& T-107 & $42-225$ & (core) \\
\hline 11 & S-101 & 279 & (grab) \\
& SX-104 & 78 & (1997 grab) \\
\hline \multirow{3}{*}{13} & S-103 & 864 & (grab) \\
\hline 15 & U-103 & $1700-3100$ & (RGS) \\
\hline \multirow{3}{*}{20} & BY-103 & $\leq 68$ & (grab) \\
& BY-109 & $220-480$ & (RGS) \\
\hline & S-106 & $40-290$ & (RGS) \\
& S-108 & $\leq 126$ & (grab) \\
& S-109 & $\leq 128$ & (grab) \\
& SX-103 & $1090-1800$ & (1997 grab) \\
\hline 22 & A-101 & $190-1400$ & (RGS) \\
& AX-101 & $1120-1840$ & (1997 grab) \\
\hline
\end{tabular}

Table 2.2 shows the concentrations of ammonia used in the present model (Section 9). The table includes only the tanks that Hedengren et al. (1997) modeled and compares the present model input concentrations with those used by Hedengren et al. A number of differences arise from the availability of new RGS and grab-sample data, the method of accounting for extrusion and surface depletion, and the method used to estimate values for tanks with no available data. Hedengren et al. took their dissolved ammonia concentrations from push-core samples and grab samples that were almost all from the salt-well screen, although a few were taken from supernatant layers. These samples, without exception, were measured as containing less than $1000 \mu \mathrm{g} / \mathrm{mL}(58,800 \mu \mathrm{mol} / \mathrm{L})$ of ammonia. Hedengren et al. therefore used $1000 \mu \mathrm{g} / \mathrm{mL}$ as an upper limit for the dissolved ammonia concentration in tanks where no sample data were available. The exception to this rule was the SX farm, for which they used the 1997 measurement of $78.4 \mu \mathrm{g} / \mathrm{mL}(4,600 \mu \mathrm{mol} / \mathrm{L})$ that was made in SX-104. However, later data (for U-103, SX-103, and AX-101) show that ammonia concentrations can exceed $1000 \mu \mathrm{g} / \mathrm{mL}$ and that tanks in the SX farm are not bounded by the SX-104 ammonia concentration.

The differences in the two models' ammonia inputs for tanks with no measurements should be considered a warning of the high level of uncertainty in assigning ammonia concentrations. Table 2.2 also shows which measurement methods or assumptions were used to derive the ammonia concentrations used in the present model, along with the uncertainty associated with each present input. 
Table 2.2. Comparison of Present Ammonia Concentrations with Those in Hedengren et al. (1997)

\begin{tabular}{|c|c|c|c|}
\hline \multirow[t]{2}{*}{ Tank } & \multicolumn{2}{|c|}{$\begin{array}{l}\text { Ammonia concentrations } \\
\text { used in DCRT modeling } \\
\text { ( } \mu \mathrm{g} \mathrm{NH}_{3} / \mathrm{mL} \text { liquid) }\end{array}$} & \multirow{2}{*}{$\begin{array}{l}\text { Source and uncertainty } \\
\text { of present model input }\end{array}$} \\
\hline & $\begin{array}{l}\text { Hedengren } \\
\text { et al. }\end{array}$ & $\begin{array}{c}\text { Present } \\
\text { model }\end{array}$ & \\
\hline BY-103 & 1000 & 68 & $\begin{array}{l}\text { deep grab sample; no multiplying factor, but } \\
\text { is at detection limit; }+30 \% \text {, but }-50 \% \text { for } \\
\text { detection limit }\end{array}$ \\
\hline BY-105 & 1000 & 480 & $\begin{array}{l}\text { based on maximum of Cluster } 15 \text { (max. BY-109 } \\
\text { RGS); because BY- } 105 \text { is unmeasured, } \\
\text { uncertainty cannot be meaningfully estimated }\end{array}$ \\
\hline$\overline{B Y-106}$ & 1000 & 480 & $\begin{array}{l}\text { based on maximum of Cluster } 15 \text { (max. BY-109 } \\
\text { RGS); because BY-106 is unmeasured, } \\
\text { uncertainty cannot be meaningfully estimated }\end{array}$ \\
\hline S-101 & 279 & 279 & $\begin{array}{l}\text { deep grab sample; no multiplying factor; } \\
\pm 30 \%\end{array}$ \\
\hline S-102 & 1000 & 3100 & $\begin{array}{l}\text { based on maximum of Cluster } 13 \text { (max. U-103 } \\
\text { RGS); because S-102 is unmeasured, uncertainty } \\
\text { cannot be meaningfully estimated }\end{array}$ \\
\hline S-103 & 864 & 864 & $\begin{array}{l}\text { deep grab sample; no multiplying factor; } \\
\pm 30 \%\end{array}$ \\
\hline S-106 & 241 & 290 & max. of RGS measurements; $+100 \%-50 \%$ \\
\hline S-107 & 840 & 840 & $\begin{array}{l}\text { deep grab sample; no multiplying factor; } \\
\pm 30 \%\end{array}$ \\
\hline S-109 & 128 & 128 & $\begin{array}{l}\text { deep grab sample; no multiplying factor, but } \\
\text { is at detection limit; } \pm 30 \%\end{array}$ \\
\hline S-111 & 1000 & 200 & $\begin{array}{l}\text { near-top core sample; max. measured ammonia } \\
\text { multiplied by } 3 \text {; uncertainty is roughly }+150 \% \\
-75 \%\end{array}$ \\
\hline S-112 & 1000 & 290 & $\begin{array}{l}\text { based on maximum of low-temperature Cluster } \\
20 \text { (max. S-106 RGS); because } S-112 \text { is } \\
\text { unmeasured, uncertainty cannot be meaningfully } \\
\text { estimated }\end{array}$ \\
\hline SX-102 & $\overline{78.4}$ & 1490 & $\begin{array}{l}\text { based on maximum of high-temperature Cluster } \\
20 \text { (max. SX-103 deep grab); because SX-102 is } \\
\text { unmeasured, uncertainty cannot be meaningfully } \\
\text { estimated }\end{array}$ \\
\hline SX-103 & 78.4 & 1490 & $\begin{array}{l}\text { deep grab sample; no multiplying factor; } \\
\pm 30 \%\end{array}$ \\
\hline SX-104 & 78.4 & 64 & $\begin{array}{l}\text { deep grab sample; no multiplying factor; } \\
\pm 30 \%\end{array}$ \\
\hline SX-105 & 78.4 & 1490 & $\begin{array}{l}\text { based on maximum of high-temperature Cluster } \\
20 \text { (max. SX-103 deep grab); because SX-105 is } \\
\text { unmeasured, uncertainty cannot be meaningfully } \\
\text { estimated }\end{array}$ \\
\hline$\overline{\text { SX-106 }}$ & 78.4 & 3100 & $\begin{array}{l}\text { based on maximum of Cluster } 13 \text { (max. U-103 } \\
\text { RGS); because SX-106 is unmeasured, } \\
\text { uncertainty cannot be meaningfully estimated }\end{array}$ \\
\hline
\end{tabular}


Table 2.2 (contd)

\begin{tabular}{|c|c|c|c|}
\hline \multirow[t]{2}{*}{ Tank } & \multicolumn{2}{|c|}{$\begin{array}{l}\text { Ammonia concentrations } \\
\text { used in DCRT modeling } \\
\text { ( } \mu \mathrm{g} \mathrm{NH} / \text { mL liquid })\end{array}$} & \multirow{2}{*}{$\begin{array}{l}\text { Source and uncertainty } \\
\text { of present model input }\end{array}$} \\
\hline & $\begin{array}{l}\text { Hedengren } \\
\text { et al. }\end{array}$ & $\begin{array}{l}\text { Present } \\
\text { model }\end{array}$ & \\
\hline $\mathrm{T}-104$ & 1000 & 330 & $\begin{array}{l}\text { based on maximum of Cluster } 7 \text { (max. T-107 } \\
\text { deep core); because T-104 is unmeasured, } \\
\text { uncertainty cannot be meaningfully estimated }\end{array}$ \\
\hline $\mathrm{T}-110$ & 1000 & 400 & $\begin{array}{l}\text { based on maximum of Cluster } 19 \text { (T-105 deep } \\
\text { core; at detection limit, so no multiplying factor } \\
\text { applied); because } \mathrm{T}-110 \text { is unmeasured, } \\
\text { uncertainty cannot be meaningfully estimated }\end{array}$ \\
\hline U-102 & 1000 & 186 & $\begin{array}{l}\text { deep grab sample; no multiplying factor; } \\
\pm 30 \%\end{array}$ \\
\hline U-103 & 1000 & 3100 & max. of RGS measurements; $+100 \%-50 \%$ \\
\hline U-105 & 1000 & 3100 & $\begin{array}{l}\text { based on maximum of Cluster } 13 \text { (max. U-103 } \\
\text { RGS); because U-105 is unmeasured, uncertainty } \\
\text { cannot be meaningfully estimated }\end{array}$ \\
\hline U-106 & 1000 & 290 & $\begin{array}{l}\text { based on maximum of low-temperature Cluster } \\
20 \text { (max. S- } 106 \text { RGS); because U-106 is } \\
\text { unmeasured, uncertainty cannot be meaningfully } \\
\text { estimated }\end{array}$ \\
\hline U-107 & 1000 & 3100 & $\begin{array}{l}\text { based on maximum of Cluster } 13 \text { (max. } \\
\text { U-103 RGS); because U-107 is unmeasured, } \\
\text { uncertainty cannot be meaningfully } \\
\text { estimated }\end{array}$ \\
\hline U-108 & 1000 & 3100 & $\begin{array}{l}\text { based on maximum of Cluster } 13 \text { (max. U-103 } \\
\text { RGS); because U-108 is unmeasured, uncertainty } \\
\text { cannot be meaningfully estimated }\end{array}$ \\
\hline U-109 & 1000 & 3100 & $\begin{array}{l}\text { based on maximum of Cluster } 13 \text { (max. U-103 } \\
\text { RGS); because U-109 is unmeasured, uncertainty } \\
\text { cannot be meaningfully estimated }\end{array}$ \\
\hline U-111 & 1000 & 160 & $\begin{array}{l}\text { surface grab samples at detection limit; no } \\
\text { multiplying factor; }+100 \%-50 \% \text { for surface } \\
\text { depletion and detection limit uncertainties }\end{array}$ \\
\hline
\end{tabular}

\subsection{Gas Solubilities}

Gas solubilities are needed to relate gas-phase concentrations to liquid-phase concentrations. The DCRT feed concentrations of low-solubility gases are calculated from the gas solubilities, composition, and pressure. The equilibria between the liquid and gas in the DCRT also depend on solubilities; the ammonia equilibrium is more sensitive to solubility effects than the low-solubility gases. This section discusses the calculation of Henry's Law constants, which govern the gas solubility, and their dependence on temperature and salt concentration.

Gas solubilities in aqueous solutions are often sufficiently well described by Henry's Law, which states that the vapor pressure of a dilute solute is directly proportional to the concentration of the solute in solution. One form of Henry's Law follows: 


$$
\mathrm{K}_{\mathrm{H}}(\mathrm{i})=\gamma_{\mathrm{i}} \mathrm{m}_{\mathrm{i}} / \mathrm{f}_{\mathrm{i}} \approx \gamma_{\mathrm{i}} \mathrm{m}_{\mathrm{i}} / \mathrm{p}_{\mathrm{i}}
$$

where $\mathrm{K}_{\mathrm{H}}(\mathrm{i})$ is the Henry's Law constant for gas i (mol/kg solvent-atm), $\gamma_{\mathrm{i}}$ is the activity coefficient for gas $i$ in the aqueous solution, $m_{i}$ is the concentration of gas $i$ in water solvent (mol/kg water), and $f_{i}$ is the fugacity of that gas. Fugacity may be replaced by the partial pressure, $\mathrm{p}_{\mathrm{i}}(\mathrm{atm})$, for essentially ideal gas mixtures. For dilute gases dissolved in pure water, $\gamma_{i} \approx 1$. In aqueous solutions containing complex, concentrated electrolytes such as Hanford tankwastes, gas solubilities are lower than in pure water, and $\gamma_{\mathrm{i}}<1$. The challenge in describing gas solubilities in any concentrated electrolyte is to define values for $\gamma_{\mathrm{i}}$. Given that direct measurement of gas solubilities in mixed chemical and radioactive wastes is often not practical, it is necessary to rely on solubility models and measurements of simulants.

\subsubsection{Setschenow Equation}

Setschenow (1889) was the first to relate a decrease in gas solubility in aqueous solutions to the concentration of an electrolyte:

$$
\log \left(\mathrm{c}_{\mathrm{G}, \mathrm{O}} / \mathrm{c}_{\mathrm{G}}\right)=\mathrm{K} \mathrm{m}_{\mathrm{S}}\left(=\log \left(\gamma_{\mathrm{j}}\right)\right)
$$

where $\mathrm{c}_{\mathrm{G}, \mathrm{O}}$ is the solubility of a particular gas in pure water, $\mathrm{c}_{\mathrm{G}}$ is the solubility of that same gas in the presence of a dissolved salt, $\mathrm{m}_{\mathrm{S}}$ is the concentration of a dissolved salt $\left(\mathrm{kmol} / \mathrm{m}^{3}\right)$, and $\mathrm{K}$ is the Setschenow constant ( $\mathrm{kg}$ water/mole salt). The Setschenow constant is specific to a particular gas and a particular electrolyte and is temperature-dependent. While reasonably applicable to describing gas solubilities as a function of electrolyte concentration to approximately 0.1 molal, Eq: (2.2) tends to overestimate the salting-out effect (lowering of solubility) at high electrolyte concentrations. Eq. (2.2) is not directly applicable to mixed electrolyte systems such as those in Hanford tanks.

\subsubsection{Schumpe Model}

Modifications to the Setschenow equation have allowed its extension to mixed electrolyte solutions (Schumpe 1993; Hermann et al. 1995; Weisenberger and Schumpe 1996):

$$
\log \left(\mathrm{c}_{\mathrm{G}, \mathrm{O}} / \mathrm{c}_{\mathrm{G}}\right)=\Sigma\left(\mathrm{h}_{\mathrm{ion}}+\mathrm{h}_{\mathrm{g}}\right) \mathrm{m}_{\mathrm{i}}
$$

where $h_{\text {ion }}$ represents a set of ion-specific parameters, $h_{g}$ represents a set of gas-specific parameters, and $\mathrm{m}_{\mathrm{i}}$ is the concentration of the specific ion $\left(\mathrm{kmol} / \mathrm{m}^{3}\right)$. Temperature dependencies of ion-specific and gas-specific parameters were given in Weisenberger and Schumpe (1996). The relation of Eq. (2.3) was found to hold reasonably well for salt concentrations to $2 \mathrm{kmol} / \mathrm{m}^{3}$ and sometimes to more than $5 \mathrm{kmol} / \mathrm{m}^{3}$ (Weisenberger and Schumpe 1996). Unfortunately, Hanford wastes are often much more concentrated than the range of applicability of the Setschenow equation. Further, ion-specific interaction parameters are not known for all components of Hanford wastes, aluminate being a notable example. 


\subsubsection{Pitzer Ion Interaction Model}

The Pitzer ion interaction model is among the more successful methods devised to estimate gas solubilities in mixed electrolytes (Pitzer 1987, 1990). This model requires a relatively large set of binary and ternary interaction parameters that are derived from experimental data to calculate the activity coefficient $\gamma_{\mathrm{i}}$ for the gas being dissolved in a solution containing electrolytes. A simplified expression has been given by Clegg and Brimblecombe (1990) for slightly soluble gases (no self-interaction terms):

$$
\begin{aligned}
& \ln \gamma_{\mathrm{i}}=\Sigma \lambda_{\mathrm{ic}} \mathrm{m}_{\mathrm{c}}+2 \Sigma \lambda_{\mathrm{ia}} \mathrm{m}_{\mathrm{a}}+\Sigma \Sigma \mathrm{m}_{\mathrm{c}} \mathrm{m}_{\mathrm{a}} \zeta_{\text {ica }} \\
& +\Sigma \Sigma \mathrm{m}_{\mathrm{c}} \mathrm{m}_{\mathrm{c}^{\prime}} \eta_{\mathrm{icc}}+\Sigma \Sigma \mathrm{m}_{\mathrm{a}} \mathrm{m}_{\mathrm{a}^{\prime}} \eta_{\mathrm{ia}}{ }^{\prime}
\end{aligned}
$$

where subscripts i, c, and a represent neutrals (gas being absorbed), cations, and anions, respectively; and $\lambda_{\mathrm{ij}}, \zeta_{\mathrm{ijk}}$, and $\eta_{\mathrm{ixx}}$ are interaction parameters that must be determined from experimental data. Interaction parameters for all of the components of Hanford tank wastes, however, have not yet been established. Hanford waste mixtures are generally more concentrated and more complex than solutions from which existing ion interaction parameters were derived. Temperature dependencies are not well established for many of the ion interaction terms. Thus when using this approach to model gas solubilities in Hanford wastes, it is necessary to estimate interaction parameters for many important ions based on the behavior of similar waste components.

For highly soluble ammonia, Clegg and Brimblecombe (1989) have reviewed available literature and compiled ion interaction parameters in simple and multicomponent electrolyte solutions. The activity coefficient for ammonia in a solution of a salt $\mathrm{M}_{v_{+}} \mathrm{X}_{\mathrm{v}_{-}}$is given by (Clegg and Brimblecombe 1989)

$$
\begin{aligned}
& \ln \left(\gamma\left(\mathrm{NH}_{3}\right)\right)=2 \mathrm{~m}\left(\mathrm{NH}_{3}\right) \lambda_{\mathrm{N}, \mathrm{N}}+2 \mathrm{~m}\left(\mathrm{M}_{\mathrm{V}+} \mathrm{X}_{\mathrm{V}-}\right)\left(v^{+} \lambda_{\mathrm{N}, \mathrm{M}}+v^{-} \lambda_{\mathrm{N}, \mathrm{X}}\right)+ \\
& 6 \mathrm{~m}\left(\mathrm{M}_{V^{+}} \mathrm{X}_{\mathrm{V}_{-}}\right) \mathrm{m}\left(\mathrm{NH}_{3}\right)\left(v^{+} \mu_{\mathrm{N}, \mathrm{N}, \mathrm{M}}+v^{-} \mu_{\mathrm{N}, \mathrm{N}, \mathrm{X}}\right)
\end{aligned}
$$

where $\lambda_{\mathrm{N}, \mathrm{N}}$ is an ammonia self-interaction parameter; $\lambda_{\mathrm{N}, \mathrm{M}}$ and $\lambda_{\mathrm{N}, \mathrm{X}}$ are ammonia cation and ammonia anion interaction parameters, respectively; and $\mu_{\mathrm{N}, \mathrm{N}, \mathrm{M}}$ and $\mu_{\mathrm{N}, \mathrm{N}, \mathrm{X}}$ are second-order ammonia-cation and ammonia-anion interaction parameters, respectively. Higher-order interaction terms from the original reference have been dropped in Eq. (2.5). In its simplest form, Eq. (2.5) corresponds to that of Eq. (2.1), the Setschenow equation (Setschenow 1889). The term $\lambda_{\mathrm{N}, \mathrm{N}}$ was further defined by the expression (Clegg and Brimblecombe 1989):

$$
\lambda_{\mathrm{N}, \mathrm{N}}=0.033161-21.12816 / \mathrm{T}+4665.1461 / \mathrm{T}^{2}
$$

In the above equation, the temperature, $T$, is absolute. First- and second-order interaction coefficients for a number of salts were compiled. It was concluded that the interaction parameters are generally additive for multicomponent electrolytes. As in the case of slightly soluble gases, gas-ion interaction terms for all of the principal ions present in Hanford wastes are not known. The aluminate ion is a notable example. 


\subsubsection{Simplified Pitzer Ion Interaction Model}

Estimates of nitrous oxide, ammonia, hydrogen, and nitrogen solubilities in Hanford tank wastes have been made using the Edwards et al. (1978) modification to the Pitzer ion interaction model (Pasamehmetoglu et al. 1994). These estimates were made by defining an "average" saltsalt interaction parameter, assuming that the best fit for a large number of salts yields parameters that approximate the hypothetical average salt. This approach provides a means to circumvent the need for gas-ion and ion-ion interaction parameters for all of the salts in complex Hanford wastes. For a 1-1 electrolyte, this expression has been given (Pasamehmetoglu et al. 1994):

$$
\begin{array}{rl}
\ln \gamma_{\mathrm{i}}=2 \beta_{0, \text { is }} & \mathrm{m}_{\mathrm{s}}+\beta_{1, \text { is }}\left[1-\left(1+2 \bullet \mathrm{m}_{\mathrm{s}}\right) \exp \left(-2 \bullet \mathrm{m}_{\mathrm{s}}\right)\right] \\
+\beta_{1, \mathrm{ss}} & 14\left[-1+\left(1+2 \cdot \mathrm{m}_{\mathrm{s}}+2 \mathrm{~m}_{\mathrm{s}}\right) \exp \left(-2 \bullet \mathrm{m}_{\mathrm{s}}\right)\right]
\end{array}
$$

where $m_{s}$ is the molal concentration of salt (moles $/ \mathrm{kg}$ water), $\beta_{0, \text { is }}$ ( $\mathrm{kg}$ water $/ \mathrm{mole}$ salt) and $\beta_{1, \text { is }}$ are gas-salt interaction parameters, and $\beta_{1, s s}$ is the salt-salt interaction parameter. This latter term is independent of the identity of the gas species. Pasamehmetoglu et al. (1994) determined a value for $\beta_{1, s s}$ by averaging results for sixty $1-1$ electrolytes at $25^{\circ} \mathrm{C}$ and obtained a value of 0.17 . Their analysis of available literature data on gas solubility in electrolytes produced values of $\beta_{0, \text { is }}$ and $\beta_{1, \text { is }}$ for hydrogen, nitrogen, nitrous oxide, and ammonia, as shown in Table 2.3.

\subsubsection{Comparison with Experimental Gas Solubility Results for Simulated Wastes}

Because of the paucity of gas solubility data pertinent to the highly concentrated, multicomponent brines that make up Hanford wastes, it is difficult to assess which, if any, of the above models most accurately reflect actual waste behavior. Gas-ion and ion-ion interaction parameters are not available for all of the components of the wastes, including a principal component aluminate. Temperature dependencies are not well defined.

Regardless of which model is chosen, estimates of gas-salt interactions will be required. Fortunately, gas solubility results are available for simulated Hanford waste mixtures, providing some means of assessing the accuracy of solubility models. Norton and Pederson $(1994,1995)$ reported solubilities of ammonia, oxygen, hydrogen, methane, and nitrous oxide for SY-101 simulants that contained sodium hydroxide, sodium nitrite, sodium nitrate, sodium aluminate, and sodium carbonate ${ }^{(\mathrm{a})}$. Results were obtained for two simulant compositions: SY1-SIM-93B, a homogeneous simulant, and SY1-SIM-91A, a slurry (Bryan and Pederson 1994). Using a homogeneous simulant eliminated the complications associated with a changing electrolyte concentration as a function of temperature that would be encountered with a slurry simulant.

The solubility of ammonia in the homogeneous simulant SY1-SIM-93B was approximately half that in pure water when normalized to the quantity of water present in the

(a) Salt concentrations in the homogeneous simulant were $6.02 \mathrm{M} \mathrm{Na}^{+}, 1.62 \mathrm{M} \mathrm{OH}^{-}, 0.42 \mathrm{M} \mathrm{AlO}_{2}^{-}$, $1.63 \mathrm{M} \mathrm{NO}_{3}{ }^{-}, 1.95 \mathrm{M} \mathrm{NO}_{2}{ }^{-}$, and $0.20 \mathrm{M} \mathrm{CO}_{3}{ }^{2-}$. For comparison, the SST waste liquids in this report are generally $0.9-12.5 \mathrm{M} \mathrm{Na}^{+}, 0-3.0 \mathrm{M} \mathrm{OH}^{-}, 0-1.5 \mathrm{M} \mathrm{Al} \mathrm{O}_{2}^{-}, 0.3-4.8 \mathrm{M} \mathrm{NO}_{3}^{-}, 0-5.7 \mathrm{M} \mathrm{NO}_{2}^{-}$, and $0-$ $1.2 \mathrm{M} \mathrm{CO}_{3}{ }^{2-}$, with traces of other ions. 
Table 2.3. Gas Interaction Parameters for Hypothetical Average Salt, with $\beta_{1, \text { ss }}=0.17$ (from Pasamehmetoglu et al. 1994)

\begin{tabular}{|l|l|l|}
\hline Gas & $\beta_{0, \text { is }}$ & $\beta_{1, \text { is }}$ \\
\hline $\mathrm{H}_{2}$ & 0.0531 & 0.2644 \\
\hline $\mathrm{N}_{2}$ & 0.0531 & 0.2644 \\
\hline $\mathrm{N}_{2} \mathrm{O}$ & 0.0466 & 0.3692 \\
\hline $\mathrm{NH}_{3}$ & 0.0375 & 0.2997 \\
\hline
\end{tabular}

simulant (Norton and Pederson 1994, 1995). Ammonia solubility in the slurry simulant SY1SIM-91A was about a factor of 8 less than in pure water at $30^{\circ} \mathrm{C}$ and about a factor of 4 less at $70^{\circ} \mathrm{C}$. Experimental data for the homogeneous simulant were in good agreement with the Schumpe model, based on the Setschenow equation (Schumpe 1993; Hermann et al. 1995), with the Pitzer ion interaction model using parameters given by Clegg and Brimblecombe (1989), and with the modified Pitzer model (Pasamehmetoglu et al. 1994). At the lowest studied concentration of ammonia $\left(0.675 \mathrm{M} \mathrm{NH}_{3}\right)$, the Schumpe model overpredicted the ammonia partial pressure by $13 \%$ (at $28^{\circ} \mathrm{C}$ ) to $46 \%\left(\right.$ at $71^{\circ} \mathrm{C}$ ). Overpredictions were higher at higher ammonia concentrations, but the concentrations are not expected to be as high as the lowest used in the experiment.

Though oxygen is not modeled as a flammable gas, it serves as another example of predicted versus measured solubilities of low-solubility gases. Oxygen solubilities in the homogeneous simulant were lowered by approximately a factor of 10 relative to those in pure water at room temperature (Norton and Pederson 1995). Experimentally determined oxygen solubilities in the simulant were in relatively good agreement with both the Pitzer and Schumpe models. Clegg and Brimblecombe (1990) have given detailed Pitzer ion interaction parameters for oxygen, including a first-order temperature dependence of the interaction terms; this gave the best fit to experimental data. The Schumpe model (Hermann et al. 1995) agreed very well with the Pitzer model (used with ion interaction parameters from Clegg and Brimblecombe [1990]) at low temperatures but tended to slightly underestimate oxygen solubilities at higher temperatures. Gas-salt parameters were not available for use with the modified Pitzer model (Pasamehmetoglu et al. 1994), so a comparison between model and experiment was not possible.

For hydrogen, room temperature solubilities were smaller in the homogeneous simulant by a factor of approximately 5 to 7 compared with pure water (Norton and Pederson 1995). Measured hydrogen solubilities were reasonably well described by the Schumpe model within experimental error but were approximately a factor of 3 less than predictions of the modified Pitzer model (Pasamehmetoglu et al. 1994).

The applicability of the Setschenow equation as modified by Schumpe (1993) (Hermann et al. 1995) and the modified Pitzer model (Pasamehmetoglu et al. 1994) was addressed by Kubic. ${ }^{(a)}$ He concluded that the modified Pitzer model is far superior to the Setschenow approach, especially when extrapolating from measurements taken at low and moderate ionic strengths to high concentrations. Both models were reported to give accurate results if based on

(a) Kubic WL Jr. 1996. Evaluation of Weisenberger and Schumpe Correlation for Gas Solubility. Letter report, Los Alamos National Laboratory, Los Alamos, New Mexico. 
data obtained using high salt concentrations, however. ${ }^{\text {(a) }}$ The value of this comparison is difficult to judge, because it was not based on actual laboratory measurements but on simulated results: "Because of the lack of data for gas solubility in concentrated salt solutions, we generated a simulated set of solubility data for a mixture containing up to 25 molal dissolved salts." (a) The methods used to generate those simulated solubilities were not documented. Kubic did not consider the hydrogen solubility results of Norton and Pederson (1995) in this assessment, but in a more recent document (Kubic 1997) he rejected those results as being inconsistent with published literature. The literature in question was not identified, so it is not clear to what extent the literature electrolytes were comparable to waste simulant. The solubility literature typically deals with dilute and/or single-salt electrolytes.

Nitrogen was approximately a factor of 10 less soluble in the homogeneous simulant than in pure water (Norton and Pederson 1995). Experimentally determined nitrogen solubilities also were well described by the Schumpe model (Schumpe 1993; Hermann et al. 1995). As was the case for hydrogen, the modified Pitzer model (Pasamehmetoglu et al. 1994) led to an overestimate of the expected solubility by approximately a factor of 3 . Detailed Pitzer ion interaction parameters, including a temperature dependence, were not available for nitrogen dissolved in concentrated, multicomponent electrolyte solutions.

Methane solubilities were lowered in the simulated waste mixture by about a factor of 10 compared with those in pure water. Parameters were available only for the Schumpe model, which provided solubility estimates in reasonably good agreement with experimental results.

Nitrous oxide solubilities were a factor of 5 to 7 less in the simulated waste mixture than in pure water. Agreement with predictions of the Schumpe model was within experimental uncertainties. Experimental results were approximately a factor of 3 smaller than predictions of the modified Pitzer model (Pasamehmetoglu et al. 1994). Nitrous oxide is the most soluble of the five gases included in this study by one to two orders of magnitude.

In the 1996 letter report, Kubic compared predictions of the modified Pitzer model (Pasamehmetoglu et al. 1994) with early experimental results reported by Pederson in $1992^{(a)}$ and found good agreement. He reported that the Schumpe model underpredicted nitrous oxide solubilities by about a factor of 3 . However, Pederson's experimental data were obtained as a function of temperature using slurry simulant SY1-SIM-92A. Information on the concentration of dissolved electrolytes as a function of temperature was not reported. Solid precipitates do not affect the solubility of gases within the electrolyte itself. Given the complexity of the simulant in this case, it is difficult to compare model and experiment. Kubic had not considered the more recent data of Norton and Pederson (1995) for nitrous oxide in a well-defined simulant.

In summary, there are few experimental gas experimental solubility data in salt solutions similar to Hanford wastes on which to base a comparison of model and experiment. Experimental solubility results for ammonia (Norton and Pederson 1994, 1995) are reasonably well described by all three models considered: the Schumpe model, which is based on the Setschenow equation (Schumpe 1993; Hermann et al. 1995); the Pitzer ion interaction model (Clegg and

(a) Pederson LR. March 1992. "Nitrous oxide solubility in waste." Presentation to the Tank Waste Science Panel. Pacific Northwest Laboratory, Richland, Washington. 
Brimblecombe 1989); and the modified Pitzer model (Pasamehmetoglu et al. 1994). For sparingly soluble gases, the Schumpe model agreed with the experimental results of Norton and Pederson (1995) within experimental uncertainty. Where detailed Pitzer parameters were available, experimental results were well described by the Pitzer ion interaction model (Norton and Pederson 1995). The modified Pitzer model, using parameters given by Pasamehmetoglu et al. (1994), overestimated the solubilities of sparingly soluble gases by a factor of approximately 3 .

Of the three models considered, the Pitzer ion interaction model is expected to be the most accurate, assuming detailed gas-ion and ion-ion interaction parameters are known for all of the salts that are present. Unfortunately, this is not the case for Hanford wastes, requiring estimates to be made. The modified Pitzer model, by defining average salt properties, circumvents the need for detailed interaction parameters. Calculations using this model are straightforward and should have significant utility in predicting the gas solubility behavior of complex wastes. Unfortunately, using parameters given to date, the model tends to overpredict the solubility of sparingly soluble gases by about a factor of 3 (based on experimental solubility data obtained using simulants).

The Schumpe model, a linear model based on the Setschenow equation, was not designed for the high salt concentrations found in Hanford waste tanks. Agreement with experimental gas solubility data obtained using simulants was good within experimental uncertainties, however. The Schumpe model is easily used if electrolyte concentrations are known. Because of its agreement with simulant data and its ease of use, the Schumpe model is considered appropriate for DCRT modeling and is used in the model in this report (Section 9). This approach was also used in the modeling carried out by Hedengren et al. (1997).

\subsubsection{Application of the Schumpe Solubility Model}

To obtain the agreement with observations seen by Norton and Pederson (1995), we found it necessary to use precisely the Schumpe model parameters that they used (Hermann et al. 1995), not the later expanded set that has been used in RGS calculations (Shekarriz et al. 1997; Mahoney et al. 1997) and in DCRT modeling (Hedengren et al. 1997).

The Schumpe model parameters provided by Hermann et al. (1995) were intended for use at or near $25^{\circ} \mathrm{C}$. Furthermore, they included an $h_{\text {ion }}$ parameter for the effect of the $\mathrm{Al}^{3+}$ ion on solubility but not for $\mathrm{AlO}_{2}^{-}$, the form in which aluminum is found under highly basic tank conditions. Norton and Pederson (1995) approximated the effect of aluminate ion $\left(\mathrm{AlO}_{2}{ }^{-}\right)$on gas solubility by assigning it an $h_{\text {ion }}$ parameter of $0.1 \mathrm{~L} / \mathrm{mol}$, an assumption in the middle of the range of $h_{\text {ion }}$ values for other ions, and by decreasing the measured hydroxide concentration to reflect the incorporation of hydroxide into aluminate. The stoichiometry of this reaction, under basic conditions, is

$$
\mathrm{Al}^{3+}+4 \mathrm{OH}^{-}=\mathrm{AlO}_{2}^{-}+2 \mathrm{H}_{2} \mathrm{O}
$$


As already noted, recent modeling work (Shekarriz et al. 1997; Mahoney et al. 1997; Hedengren et al. 1997) ${ }^{(a)}$ has not used the same Schumpe model parameters as Norton and Pederson (1995). Instead, modeling has employed a later set (Weisenberger and Schumpe 1996) that was expanded to cover a wider temperature range, and has treated aluminum as $\mathrm{Al}^{3+}$ while leaving the hydroxide concentration unchanged. When these parameters are used with the Schumpe model, it overpredicts the ammonia partial pressure (for the lowest tested ammonia concentration) by $75 \%$ at $28^{\circ} \mathrm{C}$ (instead of $13 \%$ ), and by $127 \%$ at $71^{\circ} \mathrm{C}$ (instead of $46 \%$ ). Similar underpredictions of low-solubility gases occur, so dissolved hydrogen and methane concentrations are underpredicted by not using the same parameters used by Norton and Pederson (1995).

The substitute parameter set causes the DCRT flammability contribution of hydrogen and methane to be underestimated and the contribution of ammonia to be overestimated. Accordingly, the present model uses the same parameter set used by Norton and Pederson (1995), despite the existence of a later version.

\subsection{Dissolved Concentrations of Flammable Gases in the Source Tank}

As noted in Section 2.1.2, the dissolved concentration of ammonia is essentially equal to the total (dissolved plus free-gas) concentration. The total ammonia concentrations to be used for flammable gas modeling in the DCRT are given in that section (and tabulated in detail in the appendix). The dissolved concentrations of the sparingly soluble gases remain to be determined but can be calculated, assuming thermodynamic equilibrium, from their partial pressure in the free gas in the source tank using Henry's Law.

For this purpose, Hedengren et al. (1997) took the total gas pressure in each source tank to be the hydrostatic pressure experienced by the gas at an elevation of $22.5 \%$ of the high-solids layer depth (Hodgson et al. 1996). This assumption is conservative; RGS and void-fraction instrument data (Shekarriz et al. 1997; Mahoney et al. 1997; Stewart et al. 1996) show that the average gas level is at an elevation of about $50 \%$ of the solids layer depth.

Hedengren et al. (1997) conservatively assumed the hydrogen and methane partial pressures to add up to the hydrostatic pressure, neglecting the partial pressures of water and ammonia. For the low-solubility gases, the Schumpe model with updated parameters (Schumpe 1993; Weisenberger and Schumpe 1996) was used to predict gas solubility and hence the concentration of dissolved gas in the liquid. This approach is valid and slightly conservative, because at temperatures above $55^{\circ} \mathrm{C}$ the water vapor pressure can amount to $15 \%$ or more of the source pressure.

The present model (described at greater length in Section 9) uses the same total gas/ vapor pressure as Hedengren et al. but accounts for water and ammonia partial pressures as well as the partial pressures of hydrogen, methane, and nonflammable gas (modeled as nitrogen).

(a) The substitute parameter set has had little effect on RGS calculations because the Schumpe model is used only to estimate the in-situ gas volume fraction. The volume fraction depends almost entirely on the low-solubility gases, which are quantitatively present in gas phase no matter which parameter set is used. The major effect on RGS work is that the calculated ammonia partial pressure in the retained gas is lower than reported, an effect well within the uncertainty of the RGS ammonia measurement. 


\subsection{Losses of Flammable Gases Before Entering the DCRT}

As described in Section 1, salt-well pumping first drains the ammonia-depleted liquid in the supernatant layer, if one exists, and then drains the salt well. As the well empties, liquid drains into it from the bulk waste and is pumped out. However, the liquid resides in the well for a finite period of time before it is removed. Therefore, the ammonia concentration in the salt well will be further depleted by evaporation. The extent of depletion depends on how rapidly ammonia evaporates from the salt-well walls and the top surface of the liquid in the well compared to the pumping rate.

The extent of ammonia depletion in the salt-well liquid during pumping can be calculated by assuming a steady state. Liquid seeps into the salt well at the same rate as it is pumped out, which is typical of salt-well operations, so the volume of liquid in the salt well is constant (and is typically 15 to $30 \mathrm{~cm}$ in depth). Gas from the tank headspace enters and leaves the "salt-well headspace," the volume of gas in the empty part of the salt-well shaft. At steady state, ammonia leaves the salt-well liquid by evaporation and pumping at the same rate at which it enters by seepage, so the ammonia concentration in the salt-well liquid is constant. The mass balances on the liquid and gas in the salt-well shaft are

$$
\begin{aligned}
& c_{I N} Q_{I N}-c_{S W} Q_{S W}-h A_{S W}\left(c_{S w}-c_{H S} R T \rho_{L} \omega_{L} K_{H}\right)=0 \\
& h A_{S W}\left(c_{S W}-c_{H S} R T \rho_{L} \omega_{L} K_{H}\right)-c_{H S} Q_{H S}=0
\end{aligned}
$$

where

$$
\begin{aligned}
& \mathrm{c}_{\mathrm{SW}}=\text { concentration }(\mathrm{mol} / \mathrm{L} \text { liq) of ammonia in salt-well liquid } \\
& c_{\mathrm{HS}}=\text { concentration (mol/L gas) of ammonia in salt-well headspace } \\
& \mathrm{c}_{\mathbb{N}} \quad=\text { concentration }(\mathrm{mol} / \mathrm{L} \text { liq) of ammonia in tank waste } \\
& \mathrm{Q}_{\text {HS }}=\text { volumetric flow rate }\left(\mathrm{m}^{3} / \mathrm{s}\right) \text { of gas between the tank headspace and } \\
& \text { the gas space in the salt well } \\
& \mathrm{Q}_{\mathbb{N}}=\text { volumetric flow rate of liquid seeping into the salt well (between } \\
& 4 \text { and } 0.05 \mathrm{gpm} \text {, or } 3 \times 10^{-6} \text { to } 3 \times 10^{-4} \mathrm{~m}^{3} / \mathrm{s} \text { ) } \\
& \mathrm{Q}_{\mathrm{SW}}=\text { volumetric pumping rate, equal to } \mathrm{Q}_{\mathrm{IN}} \\
& \rho_{\mathrm{L}} \quad=\text { the density of the liquid (typically about } 1400 \mathrm{~kg} / \mathrm{m}^{3} \text { ) } \\
& \omega_{\mathrm{L}} \quad=\text { the water mass fraction in the liquid (typically about } 0.5 \text { ) } \\
& \mathrm{R} \quad \text { gas constant }\left(\mathrm{Pa} \mathrm{m}^{3} / \mathrm{mol} \mathrm{K}\right) \\
& \mathrm{T}=\text { the temperature in the salt well (on the average, } 40^{\circ} \mathrm{C}=313 \mathrm{~K} \text { ) } \\
& \mathrm{K}_{\mathrm{H}}=\text { the Henry's Law constant for ammonia in salt-well liquid (average value for } \\
& \text { temperatures in tanks is } \sim 10 \mathrm{~mol} / \mathrm{atm} \mathrm{kg} \text { water; results are not sensitive to } \mathrm{K}_{\mathrm{H}} \text { ) } \\
& \mathrm{A}_{\mathrm{SW}}=\text { cross-sectional area of the salt well (for a 1-ft diameter, } 0.073 \mathrm{~m}^{2} \text { ) } \\
& \mathrm{h}=\text { mass transfer coefficient of ammonia evaporation }\left(\left[\mathrm{mol} / \mathrm{s} \mathrm{m}^{2}\right] /\left[\mathrm{mol} / \mathrm{m}^{3}\right]\right) \text {. }
\end{aligned}
$$

Eq. (2.9a) and (2.9b) can be solved to give

$$
c_{S W}=\frac{c_{\mathbb{N}} Q_{\mathbb{N}}\left(Q_{H S}+h A_{S W} R T \rho_{L} \omega_{L} K_{H}\right)}{\left(Q_{I N}+h A_{S W}\right)\left(Q_{H S}+h A_{S W} R T \rho_{L} \omega_{L} K_{H}\right)-h^{2} A_{S W}^{2} R T \rho_{L} \omega_{L} K_{H}}
$$




$$
\mathrm{f}=\frac{1}{1+\frac{\mathrm{Q}_{\mathbb{N}}}{\mathrm{Q}_{\mathrm{HS}}} R T \rho_{\mathrm{L}} \omega_{\mathrm{L}} \mathrm{K}_{\mathrm{H}}+\mathrm{Q}_{\mathrm{IN}} / \mathrm{hA} A_{\mathrm{SW}}}
$$

where $f$ is the fraction by which ammonia is depleted in salt-well liquid, $\left(1-c_{S w} / c_{\mathbb{N}}\right)$.

The mass-transfer coefficient $\mathrm{h}$ can be found using the standard penetration-theory equation (Treybal 1980):

$$
\mathrm{h}=2 \sqrt{\frac{\mathrm{D}}{\pi \tau_{\mathrm{sw}}}}
$$

where

$\tau_{\mathrm{SW}}=$ the time (s) for which the circulating salt-well liquid is at the surface, exposed to evaporation

$\mathrm{D}=$ the diffusion coefficient of ammonia in the salt-well liquid (approximately $2 \times 10^{-10} \mathrm{~m}^{2} / \mathrm{s}$, from Bobroff et al. [1997])

The ammonia depletion of the salt-well liquid (the fraction $\mathrm{f}$ ) depends strongly on the exposure time of the salt-well liquid, $\tau_{\mathrm{sw}}$, which is difficult to specify, and the liquid drainage/ pumping rate, $\mathrm{Q}_{\mathbb{N}}$, which is a controllable process variable. (The ammonia depletion also depends slightly on the exchange rate of the gas in the salt-well head, $\mathrm{Q}_{\text {нв. }}$ ) The liquid exposure time is probably most strongly related to the flow induced by the pump (though thermal convection may increase the circulation and decrease the exposure time in some tanks). We take the exposure time as equal to the salt-well diameter divided by an approximate flow velocity, which is estimated as the pumping rate divided by half the salt-well area. (Half the area is taken to be upflow, half downflow.)

Assume a reasonable value of the mass-transfer parameter, $\mathrm{Q}_{\text {нs, }}$, a gas exchange rate of $0.0006 \mathrm{~m}^{3} / \mathrm{s}$ (which is consistent with a 30 -minute mixing time for the gas in the salt-well headspace). For this rate of gas exchange, the ammonia depletion of the salt-well liquid is primarily a function of the pumping rate. At $4 \mathrm{gpm}$ (an exposure time of 1.5 minutes), the ammonia depletion is about $0.14 \%$. At $0.05 \mathrm{gpm}$ (an exposure time of 2 hours), the depletion is about $1.4 \%$. Suppose that thermal convection decreases the exposure time for $0.05 \mathrm{gpm}$ pumping to 1.5 minutes; then the depletion is about $10 \%$. Only slightly greater depletion is found for the dissolved low-solubility gases than for ammonia because mass-transfer in this system is controlled by the liquid circulation term in the denominator of Eq. (2.11).

This is only an approximate analysis to assess the potential for significant depletion of dissolved gases in the salt well. Most of the assumptions are based on standard waste properties or pumping procedures. The two parameters that are not well quantified are the gas exchange rate, $\mathrm{QHS}_{\mathrm{HS}}$, and the salt-well liquid exposure time, $\tau_{\mathrm{HS}}$. The gas exchange rate can range over a factor of 10 from the value assumed without significantly changing the results. Thus this assumption is not crucial to the conclusions. While the results are sensitive to the salt-well liquid exposure time, depletion fractions as high as $8 \%$ are possible only if one assumes long liquid exposure times that correspond to liquid velocities of $0.01 \mathrm{ft} / \mathrm{hr}$ or less. Such low velocities are 
physically unreasonable because pumping alone leads to velocities of about $0.4 \mathrm{ft} / \mathrm{hr}$ even at a rate of $0.05 \mathrm{gpm}$. Thus, even though there are two hard-to-quantify parameters, it can still be established via this model that high in-well depletion is physically unlikely during pumping. Therefore, we conclude that depletion of liquid in the salt well is probably $10 \%$ or less and is not an important consideration in calculating the amount of flammable gas transferred to the DCRT.

\subsection{Gas/Liquid Equilibria in the DCRT}

The release of the dissolved gases into the DCRT headspace can be conservatively modeled as an instantaneous equilibrium between the gases in the headspace (predominantly air) and the gases dissolved in the entering liquid (though it is possible to avoid the conservatism of the equilibrium assumption by accounting for mass-transfer limitations on releases, as we shall show). Hedengren et al. (1997) treated the release of dissolved gases and vapors in the DCRT somewhat differently, using a different approach for each gas:

- Hydrogen, whether generated or delivered from the source tank, was assumed to be entirely and instantaneously released to the current headspace volume rather than to equilibrate. There is little conservatism in this assumption, because the solubility (i.e., the fraction of gas retained in the liquid) is so low.

- All of the methane dissolved in the incoming liquid was assumed to be released instantaneously to the minimum headspace volume (the volume at the end of fill). This assumption introduces very little overprediction at the time of maximum concentration (minimum headspace volume) but initially may overpredict the methane flammability contribution by a factor of 5 .

- The ammonia partial pressure was assumed to be that in equilibrium with the original source-tank ammonia concentration, ignoring the depletion of ammonia in the DCRT liquid that results from ammonia evaporation in the DCRT. The omissions of depletion introduce only a small conservatism at the time of maximum concentration, though the conservatism is substantial when the tank is nearly empty. The ammonia solubility, and hence its partial pressure, was calculated using the Schumpe model with the substitute parameter set and was assumed to be the same as in the source tank, with no changes made for dilution, temperature change, or $\mathrm{pH}$ change.

This report derives and presents two models. The first is an equilibrium model whose derivation and results are presented in Sections 9.1, 9.3, and 9.4. The equilibrium model treats hydrogen, methane, nitrogen, ammonia, and water on the same basis by assuming that all reach equilibrium with the DCRT headspace as they enter during filling. Equilibrium is further assumed to be maintained after the fill is complete.

The second model addresses concerns that mass-transfer limitations might significantly reduce the DCRT headspace flammability, particularly at high ventilation rates. Section 2.5.1 discusses mass-transfer rates in the DCRT and provides estimates of mass-transfer coefficients. These coefficients are used in Section 9.5 to calculate nonequilibrium DCRT headspace 
flammabilities for a subset of SSTs, providing an estimate of the degree of conservatism caused by the equilibrium assumption. Section 2.5.2 discusses how temperature and $\mathrm{pH}$ might affect the equilibria in the DCRT.

\subsubsection{Mass Transfer in the DCRT}

Dissolved gases and water vapor are transferred to the headspace of the DCRT from the falling feed flow and from the convecting mass of liquid already in the DCRT. These two release sources must be treated separately because their mass-transfer mechanisms and surface areas are substantially different.

The definitions of the gas- and liquid-side mass transfer coefficients that are used in this report are as follows, for each of the dissolved constituents:

$$
\begin{aligned}
& k_{\mathrm{Li}}=\frac{N_{i}}{A_{t}\left(c_{\mathrm{Fi}}-c_{\mathrm{Li}}\right)} \\
& \mathrm{k}_{\mathrm{Gi}}=\frac{N_{\mathrm{i}}}{A_{t}\left(\frac{c_{\mathrm{Li}}}{K_{\mathrm{Hi}} \mathrm{RT}}-c_{\mathrm{Gi}}\right)}
\end{aligned}
$$

where

$$
\begin{aligned}
& \mathrm{k}_{\mathrm{Li}}=\text { the liquid-side mass-transfer coefficient of constituent } \mathrm{i} \\
& \left(\mathrm{mol} / \mathrm{s} / \mathrm{m}^{2}\right) /\left(\Delta \mathrm{mol} / \mathrm{m}^{3}\right) \\
& \mathrm{k}_{\mathrm{Gi}}=\text { the gas-side mass-transfer coefficient of constituent } \mathrm{i} \\
& \left(\mathrm{mol} / \mathrm{s} / \mathrm{m}^{2}\right) /\left(\Delta \mathrm{mol} / \mathrm{m}^{3}\right) \\
& \mathrm{N}_{\mathrm{i}}=\text { the mass transfer rate of constituent } \mathrm{i} \text { from liquid to gas (mol/s) } \\
& A_{t}=\text { the mass-transfer area }\left(\mathrm{m}^{2}\right) \\
& c_{\mathrm{Fi}}=\text { the concentration of constituent } \mathrm{i} \text { in the bulk liquid }\left(\mathrm{mol} / \mathrm{m}^{3}\right) \\
& c_{\text {Lfi }}=\text { the concentration of constituent } i \text { at the liquid surface }\left(\mathrm{mol} / \mathrm{m}^{3}\right) \\
& c_{\mathrm{Gi}}=\text { the concentration of constituent } \mathrm{i} \text { in the bulk gas }\left(\mathrm{mol} / \mathrm{m}^{3}\right) \\
& \mathrm{K}_{\mathrm{Hi}}=\text { Henry's law constant of constituent } \mathrm{i} \text { at the liquid temperature and } \\
& \text { salt concentration }\left(\mathrm{mol} / \mathrm{m}^{3} / \mathrm{Pa}\right) \\
& \mathrm{R}=\text { gas constant }\left(\mathrm{Pa} \mathrm{\textrm {m } ^ { 3 }} / \mathrm{mol} \mathrm{K}\right) \\
& \mathrm{T}=\text { the temperature of the gas }(\mathrm{K})
\end{aligned}
$$

For water, the gas-side mass-transfer coefficient is defined by

$$
k_{G w}=\frac{N_{w}}{A_{t}\left(\frac{p_{w}}{R T}-c_{G w}\right)}
$$

where

$$
\begin{aligned}
\mathrm{k}_{\mathrm{Gw}}= & \text { the gas-side mass-transfer coefficient of water } \\
& \left(\mathrm{mol} / \mathrm{s} / \mathrm{m}^{2}\right) /\left(\Delta \mathrm{mol} / \mathrm{m}^{3}\right)
\end{aligned}
$$




$$
\begin{aligned}
& N_{w}=\text { the evaporation rate of water }(\mathrm{mol} / \mathrm{s}) \\
& p_{w}=\text { the water vapor pressure in equilibrium with the bulk liquid }(\mathrm{Pa}) \\
& \mathrm{c}_{\mathrm{Gw}}=\text { the concentration of water vapor in the bulk gas }\left(\mathrm{mol} / \mathrm{m}^{3}\right)
\end{aligned}
$$

No liquid-side mass-transfer coefficient is required for water because it is a major constituent and is not substantially depleted by evaporation.

The mass-transfer rate, $\mathrm{N}_{\mathrm{i}}$, is calculated for each dissolved constituent by combining Eq. (2.13) and (2.14) to eliminate the unknown interfacial concentration, $c_{L f i}$, to obtain an expression for the mass-transfer rate:

$$
\mathrm{N}_{\mathrm{i}}=\frac{\mathrm{k}_{\mathrm{Gi}}}{1+\mathrm{k}_{\mathrm{Gi}} / \mathrm{k}_{\mathrm{Li}} \mathrm{K}_{\mathrm{Hi}} \mathrm{RT}} \mathrm{A}_{\mathrm{t}}\left(\frac{\mathrm{c}_{\mathrm{Fi}}}{\mathrm{K}_{\mathrm{Hi}} \mathrm{RT}}-\mathrm{c}_{\mathrm{Gi}}\right)=\mathrm{k}_{\mathrm{i}} \mathrm{A}_{\mathrm{t}}\left(\frac{\mathrm{c}_{\mathrm{Fi}}}{\mathrm{K}_{\mathrm{Hi}} \mathrm{RT}}-\mathrm{c}_{\mathrm{Gi}}\right)
$$

Here $k_{i}$ is the overall mass-transfer coefficient, which is substantially larger for ammonia than for the low-solubility gases because it depends on the constituent solubility, $\mathrm{K}_{\mathrm{Hi}}$.

\subsubsection{Mass Transfer from the Falling Feed}

The feed enters the DCRT through a vertical pipe at the top of the tank and from there falls freely to the liquid surface. Because the feed rate is slow (between 0.05 and $4 \mathrm{gpm}$ ), and the inner diameter of the inlet is relatively large $(5 \mathrm{~cm}$, or $2 \mathrm{in}$.), the feed probably tends to flow in a film in the DCRT inlet pipe. Although the exact film thickness in the inlet pipe is not used directly to estimate mass transfer, it is approximately calculated below to support the argument that the feed flow can be modeled as falling droplets.

For a feed with a density of $1400 \mathrm{~kg} / \mathrm{m}^{3}$, the liquid rate (expressed per unit of pipe circumference) is 0.03 to $2 \mathrm{~kg} / \mathrm{m} \cdot \mathrm{s}$. By comparison, the minimum liquid rate required to wet a vertical surface is 0.03 to $0.3 \mathrm{~kg} / \mathrm{m} \cdot \mathrm{s}$ (Perry and Green 1984). Thus it is possible that the inside of the inlet pipe is not completely wetted at low flow rates and plausible that the flow is in the form of a film. The film thickness was calculated using a standard falling-film model (Perry and Green 1984, p. 5-59) with a liquid viscosity of 25 cP. (Waste liquid viscosities range from 3 to $60 \mathrm{cP}$ [Mahoney and Trent 1995].) The film thickness expected for these liquid rates ranges from about 1 to $4 \mathrm{~mm}$. Thus, the pipe is expected to be less than $10 \%$ full of liquid.

Because the feed enters as a trickle rather than a gush, it is reasonable to assume that it will break up into isolated droplets. These droplets are assumed to be of the maximum size that is stable in free-fall. According to Clift et al. (1978), the maximum experimentally-observed diameter is

$$
\mathrm{D}_{\mathrm{lim}}=3.2 \sqrt{\frac{\sigma}{\mathrm{g} \rho_{\mathrm{L}}}}
$$

where

$$
D_{\text {lim }}=\text { maximum stable drop diameter }
$$




$$
\begin{aligned}
\sigma= & \text { surface tension; } 0.08 \mathrm{~N} / \mathrm{m}, \text { based on simulant data of Norton and } \\
& \text { Pederson (1994) } \\
g \quad= & \text { acceleration of gravity }(9.8 \mathrm{~m} / \mathrm{s}) \\
\rho_{\mathrm{L}}= & \text { liquid density (about } \left.1400 \mathrm{~kg} / \mathrm{m}^{3}\right)
\end{aligned}
$$

The maximum stable drop diameter is therefore about $8 \mathrm{~mm}$, though the exact value depends on the properties of the waste being modeled.

The falling drops of feed are acted upon by drag and gravity, accelerating downward. The mass transfer coefficients depend on the drop velocity. Therefore, the velocity and the mass transfer coefficients were calculated at a number of points along the droplet trajectory to provide an integrated estimate of mass-transfer. By combining the acceleration due to gravity with the drag force on the surface, we obtain the net downward drop acceleration:

$$
a_{\text {net }}=g-\frac{C_{D} \rho_{f} v_{d}^{2}}{2} \frac{(\pi / 4) D_{l i m}^{2}}{\rho_{L}(\pi / 6) D_{l i m}^{3}}
$$

where $\mathrm{a}_{\text {net }}=$ net downward drop acceleration, including drag

$\mathrm{C}_{\mathrm{D}}=$ drag coefficient of a sphere

$\rho_{\mathrm{f}}=$ the gas density in the film around the sphere (the gas density at the average of the liquid temperature and the gas temperature)

$v_{d}=$ the velocity of the drop.

Standard Reynolds numbers and drag coefficients for spheres (Perry and Green 1984) were used in calculating the net drop acceleration:

$$
\begin{array}{ll}
\operatorname{Re}=\frac{v_{d} D_{\text {lim }} \rho_{f}}{\mu_{f}} & \text { for } \operatorname{Re}>508 \\
C_{D}=0.44 & \text { for } 1.9<\operatorname{Re}<508 \\
C_{D}=\frac{18.5}{\operatorname{Re}^{0.6}} & \text { for } \operatorname{Re}<1.9 \\
C_{D}=\frac{24}{\operatorname{Re}} &
\end{array}
$$

where

$$
\begin{aligned}
& \mathrm{Re}=\text { Reynolds number of the falling drop } \\
& \mu_{\mathrm{f}}=\text { film viscosity of the gas. }
\end{aligned}
$$

The drop velocity was obtained by numerical integration over the drop distance. For a distance of $4.6 \mathrm{~m}$ (15 ft), which corresponds to the S DCRT when nearly empty, the final drop velocity

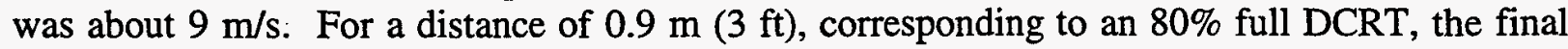
velocity was about $4 \mathrm{~m} / \mathrm{s}$. 
The liquid-side mass-transfer coefficients for the dissolved constituents were derived from penetration theory (Treybal 1980, p. 61), according to which

$$
\mathrm{k}_{\mathrm{L}}=2 \sqrt{\frac{\mathrm{D}_{\mathrm{L}}}{\pi \theta}}
$$

where

$$
\begin{aligned}
& D_{L}=\text { the diffusivity of the constituent in the liquid }\left(\mathrm{m}^{2} / \mathrm{s}\right) \\
& \theta=\text { the time for which an element of liquid is at the droplet surface and } \\
& \text { therefore exposed to mass-transfer. }
\end{aligned}
$$

For the purpose of calculating the mass-transfer exposure time of liquid in a falling drop, the liquid in the drop is assumed to circulate across the surface with a velocity equal to the drop's fall velocity. In other words, a no-slip boundary condition is assumed for the liquid and gas velocities. The exposure time is, then, equal to half the drop circumference (i.e., the length of the path on the surface) divided by the fall velocity. The liquid-side mass-transfer coefficient for the falling drop is then

$$
\mathrm{k}_{\mathrm{L}}^{\prime}=2 \sqrt{\frac{\mathrm{D}_{\mathrm{L}}}{\pi\left(\pi \mathrm{D}_{\text {lim }} / 2 \mathrm{v}_{\mathrm{d}}\right)}}
$$

The gas-side mass-transfer coefficients for water and dissolved constituents were based on the heat-transfer coefficient for forced convection over a sphere (Kreith 1973, p. 473). The Chilton-Colburn analogy was applied (Treybal 1980) to provide the corresponding correlation for the gas-side mass-transfer coefficient resulting from forced convection over a sphere:

$$
\mathrm{k}_{\mathrm{G}}^{\prime}=\frac{\mathrm{D}_{\mathrm{f}}}{D_{\lim }}\left(2+\left(0.4 \operatorname{Re}^{0.5}+0.06 \operatorname{Re}^{0.67}\right)\left(\frac{\mu_{\mathrm{f}}}{\rho_{\mathrm{f}} \mathrm{D}_{\mathrm{f}}}\right)^{0.4}\right)
$$

where $D_{f}=$ the diffusivity of the constituent in the gas film $\left(\mathrm{m}^{2} / \mathrm{s}\right)$.

The correlation in Eq. (2.23) holds for Reynolds numbers between 3.4 and 76,000. The drop Reynolds numbers are typically between 100 and 4,000 .

Eq. (2.22) and (2.23) were used, together with standard properties of the constituents, water, and air, to calculate the local mass-transfer coefficients (which were found to vary by more than a factor of 2 during the fall). Both the gas- and liquid-side mass-transfer coefficients for the droplet were integrated over the droplet fall trajectory. The effects of the depletion of dissolved constituents, and of the decrease in droplet temperature caused by water evaporation, were included in the droplet mass-transfer coefficients. The calculated evaporative temperature decrease was small, less than $5^{\circ} \mathrm{C}$ for waste that entered at $73^{\circ} \mathrm{C}$. 


\subsubsection{Mass Transfer from the Convecting Liquid}

The liquid in the bottom of the tank is not expected to be stagnant, even after the feed flow is finished. Natural convection is expected to arise because of evaporative cooling at the liquid surface, eventually assisted by self-heating of the radioactive liquid. Although recirculation pumps are sometimes used for mixing the added caustic solution during $\mathrm{pH}$ adjustment and are typically used before pumping waste out of the DCRT, they are not used when waste is fed to the DCRT or while it is stored in the DCRT. Thus, thermally driven flow is the only source of liquid motion.

Similarly, natural convection is expected to dominate the gas flow in the DCRT headspace. Antoniak and Recknagle (1997) used the thermal-hydraulic code TEMPEST to model thermally-driven flow in the dome space of an SST. When a small temperature difference of $0.9^{\circ} \mathrm{C}$ was assumed to exist between the top and bottom (liquid) of the SST dome space, the convective velocities were on the order of tenths of a foot per second. Velocities of similar magnitude can be expected in the DCRT headspace. The gas velocity induced in the headspace by ventilation is small by comparison, even for a higher than expected ventilation rate such as $5 \mathrm{acfm}(300 \mathrm{acfh})$. The cross-sectional headspace area of an $80 \%$-full DCRT is on the order of $70 \mathrm{ft}^{2}$, so the average ventilation-induced gas velocity is less than $5 \mathrm{ft} / \mathrm{hr}\left(1.4 \times 10^{-3} \mathrm{ft} / \mathrm{sec}\right)$, much less than the expected velocity from natural convection.

The natural convective velocities in the liquid are not well known but can be estimated. Preliminary TEMPEST modeling of a 6-ft-deep liquid layer in a DST has found that convective velocities in the liquid are on the order of $0.01 \mathrm{ft} / \mathrm{s} .{ }^{(a)}$ (The temperature difference across the layer was found by heat-transfer and fluid-flow calculations, not imposed as a boundary condition, and was less than $0.1^{\circ} \mathrm{C}$.) The depth of the liquid is the scaling distance for natural convection. Liquid depths in the DCRT range from 0 to $12 \mathrm{ft}$, so the DST estimate (with $6 \mathrm{ft}$ of liquid) probably gives a reasonable estimate of the convective velocity in DCRT liquid.

The liquid-side mass-transfer coefficients for the convecting liquid were estimated using penetration theory. The width of the convection cell is assumed equal to the DCRT radius; this width, divided by the convection velocity, gives the mass-transfer exposure time for the liquid.

$$
\mathrm{k}_{\mathrm{L}}=2 \sqrt{\frac{\mathrm{D}_{\mathrm{L}}}{\pi\left(\mathrm{d}_{\mathrm{DCRT}} / 2 \mathrm{v}_{\mathrm{c}}\right)}}
$$

where

$$
\begin{aligned}
& \mathrm{d}_{\mathrm{DCRT}}=\mathrm{DCRT} \text { diameter } \\
& \mathrm{v}_{\mathrm{c}}=\text { convective velocity in the bulk liquid. }
\end{aligned}
$$

The gas-side mass-transfer coefficients over the liquid were based on the heat-transfer coefficient for free convection over a heated square plate (Kreith 1973, p. 398). As suggested in the reference, the correlations were modified for use with a circular surface by substituting the length $\left(0.9 \cdot d_{D C R T}\right)$ for the length of the side of the square. The Chilton-Colburn analogy provided the corresponding correlations for the gas-side mass-transfer coefficient:

(a) Antoniak ZI. 1998. Personal communication with LA Mahoney (PNNL). 


$$
\begin{array}{ll}
\mathrm{k}_{\mathrm{G}}=\frac{0.14 D_{\mathrm{f}}}{0.9 \mathrm{~d}_{\mathrm{DCRT}}}\left(\mathrm{Gr} \frac{\mu_{\mathrm{f}}}{\rho_{\mathrm{f}} \mathrm{D}_{\mathrm{f}}}\right)^{1 / 3} & \text { for } 2 \times 10^{7}<\mathrm{Gr}<3 \times 10^{10} \\
\mathrm{k}_{\mathrm{G}}=\frac{0.54 \mathrm{D}_{\mathrm{f}}}{0.9 \mathrm{~d}_{\mathrm{DCRT}}}\left(\operatorname{Gr} \frac{\mu_{\mathrm{f}}}{\rho_{\mathrm{f}} \mathrm{D}_{\mathrm{f}}}\right)^{1 / 4} & \text { for } 10^{5}<\mathrm{Gr}<2 \times 10^{7} \\
\mathrm{Gr}=\frac{\rho_{\mathrm{f}}^{2} \mathrm{~g} \Delta \mathrm{T}\left(0.9 \mathrm{~d}_{\mathrm{DCRT}}\right)^{3}}{\mu_{\mathrm{f}}^{2} \mathrm{~T}} & \text { for a gas }
\end{array}
$$

where

$\mathrm{Gr}=$ the Grashof number over the heated surface; in general $\mathrm{Gr}$ is about $7 \times 10^{9}$, in the turbulent regime.

$\Delta \mathrm{T}=$ the temperature difference between the liquid and the gas; a value of $1^{\circ} \mathrm{C}$ was assumed.

Other driving forces for liquid motion are possible but contribute negligibly to mass transfer. Even at $4 \mathrm{gpm}$, the effect of inlet flow is likely to be purely local. The assumed thermal convective velocity of $0.01 \mathrm{ft} / \mathrm{s}$ is equivalent to $4 \mathrm{gpm}$ distributed evenly over a $1.1 \mathrm{ft}^{2}$ area. The actual cross-sectional area of a DCRT is substantially larger than this, on the rough order of $100 \mathrm{ft}^{2}$, making inlet flow a trivial influence. Gas generation, which could induce flow via bubble formation, has a maximum rate of about $1 \mathrm{ft}^{3} /$ day. If gas is released as rapidly as it is generated, which will be true when steady state is achieved in the DCRT, this generation rate of $1.2 \times 10^{-5} \mathrm{ft}^{3} / \mathrm{s}$ converts, over a $100 \mathrm{ft}^{2}$ area, to a velocity of about $10^{-7} \mathrm{ft} / \mathrm{s}$. Again, this is a trivial influence compared with thermal convection.

\subsubsection{Overall Mass Transfer}

The gas- and liquid-side mass-transfer coefficients calculated for a typical waste (that of Tank SX-102) are shown in Table 2.4. Liquid-side mass transfer is consistently the rate-limiting process, as is typically the case in mass-transfer between gases and liquids. The effect of non-

\begin{tabular}{|c|c|c|c|c|c|c|}
\hline \multirow[b]{3}{*}{ Species } & \multicolumn{4}{|c|}{ Droplet } & \multirow{2}{*}{\multicolumn{2}{|c|}{ Convecting liquid }} \\
\hline & \multicolumn{2}{|c|}{ 15-ft fall } & \multicolumn{2}{|c|}{ 3-ft fall } & & \\
\hline & $\begin{array}{c}\text { Gas-side } \\
\left(\mathrm{mol} / \mathrm{s} / \mathrm{m}^{2}\right) / \\
\left(\Delta \mathrm{mol} / \mathrm{m}^{3}\right)\end{array}$ & $\begin{array}{l}\text { Liquid-side } \\
\left(\mathrm{mol} / \mathrm{s} / \mathrm{m}^{2}\right) / \\
\left(\Delta \mathrm{mol} / \mathrm{m}^{3}\right)\end{array}$ & $\begin{array}{c}\text { Gas-side } \\
\left(\mathrm{mol} / \mathrm{s} / \mathrm{m}^{2}\right) / \\
\left(\Delta \mathrm{mol} / \mathrm{m}^{3}\right)\end{array}$ & $\begin{array}{l}\text { Liquid-side } \\
\left(\mathrm{mol} / \mathrm{s} / \mathrm{m}^{2}\right) / \\
\left(\Delta \mathrm{mol} / \mathrm{m}^{3}\right)\end{array}$ & $\begin{array}{c}\text { Gas-side } \\
\left(\mathrm{mol} / \mathrm{s} / \mathrm{m}^{2}\right) / \\
\left(\Delta \mathrm{mol} / \mathrm{m}^{3}\right)\end{array}$ & $\begin{array}{l}\text { Liquid-side } \\
\left(\mathrm{mol} / \mathrm{s} / \mathrm{m}^{2}\right) / \\
\left(\Delta \mathrm{mol} / \mathrm{m}^{3}\right)\end{array}$ \\
\hline $\mathrm{NH}_{3}$ & 0.098 & $1.2 \times 10^{-3}$ & 0.067 & $8.2 \times 10^{-4}$ & $1.5 \times 10^{-3}$ & $2.0 \times 10^{-6}$ \\
\hline $\mathrm{H}_{2}$ & 0.20 & $2.0 \times 10^{-3}$ & 0.14 & $13 \times 10^{-4}$ & $3.2 \times 10^{-3}$ & $3.3 \times 10^{-6}$ \\
\hline $\mathrm{CH}_{4}$ & 0.090 & $1.3 \times 10^{-3}$ & 0.061 & $8.8 \times 10^{-4}$ & $1.4 \times 10^{-3}$ & $2.2 \times 10^{-6}$ \\
\hline $\mathrm{N}_{2}$ & 0.12 & $1.1 \times 10^{-3}$ & 0.081 & $7.7 \times 10^{-4}$ & $1.9 \times 10^{-3}$ & $1.9 \times 10^{-6}$ \\
\hline Water & 0.10 & & 0.070 & & $1.6 \times 10^{-3}$ & \\
\hline
\end{tabular}
equilibrium mass transfer on the DCRT headspace flammability is described in Section 9.5.

Table 2.4. Calculated Mass-Transfer Coefficients 


\subsubsection{Variation in Solubility in the DCRT}

The equilibria in the DCRT depend on the gas solubilities. The uncertainty in the Schumpe solubility model has already been discussed (Section 2.2). The release of the lowsolubility gases in the DCRT is almost completely unaffected by the exact values of their solubilities, because essentially all of the dissolved low-solubility gas that enters the DCRT is released to the headspace at equilibrium. Thus it makes little difference to the hydrogen and methane flammability whether temperature and salt concentration changes occur in the DCRT and cause changes in gas solubility. Such changes may affect hydrogen generation rates, however, as shown in Section 5.

Possible variations in the solubility of ammonia might pose a more significant flammability concern. The solubility of ammonia is about four times greater at $25^{\circ} \mathrm{C}$ than it is at $70^{\circ} \mathrm{C}$ (Norton and Pederson 1995). Therefore, if the waste self-heats once it enters the DCRT, more ammonia would be released than was estimated by the assumption of unchanging temperature (Hedengren et al. 1997). However, consideration of the ratio of the heat-transfer surface to the heat-generating volume leads to the conclusion that it is unlikely for waste to reach a higher temperature in the DCRT than in the source tank. The SSTs for which flammable gas concentrations were calculated by Hedengren et al. (1997) contain between 200 and $700 \mathrm{~cm}(80$ and $280 \mathrm{in}$.) of waste and are $22.9 \mathrm{~m} \mathrm{(75} \mathrm{ft)} \mathrm{in} \mathrm{diameter.} \mathrm{The} \mathrm{ratio} \mathrm{of} \mathrm{the} \mathrm{total} \mathrm{heat} \mathrm{transfer} \mathrm{area}$ of the waste (top, bottom, and tank sides) to the waste volume is between 0.46 and $1.16 \mathrm{~m}^{-1}$ in these source tanks. In the horizontal DCRTs in the BX, TX, and U farms, the area-to-volume ratio is 20 when the tank is $10 \%$ full, decreasing to $1.24 \mathrm{~m}^{-1}$ when the tank is $80 \%$ full. For the same fill range, the vertical DCRTs (S farm) range from 33 to $4.9 \mathrm{~m}^{-1}$.

In addition, the heat capacity is greater for the liquid in the DCRT than for the liquid/solid waste in the tank, so more heat is needed to raise its temperature (Mahoney and Trent 1995). The waste's self-insulation is also lower in the DCRT because convective heattransfer within the waste is more efficient. All these factors tend to predict lower temperatures in the DCRT than in the source tank, as long as the same kinds of cooling mechanisms operate at the tank walls and waste surface. Therefore, the present model (like the earlier one) treats the waste temperature in the DCRT as being equal to that in the source tank.

The likelihood that the waste temperature is different in the DCRT than in the source tank introduces an as yet unquantified uncertainty into the modeling results. The hydrogen and methane flammabilities are not significantly affected by the DCRT temperature, but the ammonia vapor pressure decreases by roughly $20 \%$ for each $5{ }^{\circ} \mathrm{C}$ of temperature decrease. Thus, there is potential for significant changes in ammonia flammability as a result of temperature changes. An analysis of heat transfer effects will be included in the next revision of this document.

The mixing of wastes from different tanks within DCRTs is a possibility not modeled by Hedengren et al. (1997). If high-temperature waste (or a hot water flush) was added to the DCRT when it was partially full of low-temperature, high-ammonia waste, the overall temperature increase could cause a significant amount of ammonia to evaporate. A less likely result of mixing is heat generated by mixing and dilution, or even by chemical reaction. As a result of temperature change alone, the contribution of ammonia to the DCRT LFL could 
potentially increase by a factor of 4 . Another possible cause of ammonia evaporation that was not modeled by Hedengren et al. (1997) is the addition of higher-salt waste to the tank after it has been partly filled with low-salt, high-ammonia waste. The decrease in gas solubility that would accompany the salt addition would drive ammonia out of solution. Because the ammonia solubility in high-salt wastes, as calculated by the Schumpe model, is about $5 \%$ of that in water, the potential for evaporation related to salt-concentration increase is high.

Because ammonia, like other gases, is more soluble in less salty solutions, dilution of high-ammonia waste would lower the ammonia partial pressure and reduce its flammability contribution. Adding water to waste, therefore, does not create a flammability problem as long as the temperature and $\mathrm{pH}$ of the diluent are appropriate.

However, adding highly basic diluent (strong $\mathrm{NaOH}$ solutions) to waste with a $\mathrm{pH}$ less than about 10 could shift the $\mathrm{NH}_{4}{ }^{+} / \mathrm{NH}_{3}$ equilibrium toward volatile $\mathrm{NH}_{3}$ and cause the evaporation of what was previously nonvolatile ionized $\mathrm{NH}_{4}{ }^{+}$. The extent of the equilibrium shift would depend on the $\mathrm{pH}$ change, which in turn would depend in part on the acid/base buffer capacity of the waste. The dissociation constant $\left(\mathrm{K}_{\mathrm{b}}\right)$ of ammonia in low-salt solutions is $1.85 \times 10^{-5}$ in the temperature range of interest (CRC 1975). It follows that at a $\mathrm{pH}$ of 10 , the $\mathrm{NH}_{4}{ }^{+} / \mathrm{NH}_{3}$ ratio is about 0.16; the addition of strong base to waste with $\mathrm{pH} 10$ would therefore increase the $\mathrm{NH}_{3}$ partial pressure by no more than $16 \%$. As $\mathrm{pH}$ decreases, the evaporation that could result from added base would increase as the inverse of the hydroxide concentration, which can be seen from the dissociation relationship:

$$
\left[\mathrm{NH}_{4}{ }^{+}\right] /\left[\mathrm{NH}_{3}\right]=\mathrm{K}_{\mathrm{b}} /\left[\mathrm{OH}^{-}\right]
$$

The dissociation behavior of ammonia in high-salt solutions such as tank waste is similar.

The present DCRT model described in Section 9 therefore includes the capacity to calculate the temperature and salt concentration effects of mixing wastes using the Schumpe model. The present model does not calculate the effects of self-heating or cooling of the waste but treats the mixing of wastes in terms of a heat balance between the two streams. The present DCRT model also tracks the effect of $\mathrm{pH}$, using the acid/base dissociation relationship in Eq. (2.27). Calculations of flammable gas concentrations in DCRTs and their parametric sensitivity are deferred until Section 9 so that other potential mechanisms of gas carryover and generation can be discussed first. 


\subsection{Transport of Gas Bubbles into DCRTs}

Release (evaporation) of dissolved gas is the dominant mechanism of gas carryover into DCRTs. However, the possibility of carryover of entrained bubbles has been raised. Once within the DCRT, any entrained gas might be released into the tank headspace. Hedengren et al. (1997) neglected this gas carryover mechanism, citing a memo containing preliminary estimates

developed by PA Gauglitz (PNNL). ${ }^{(2)}$ This section presents these calculations, develops them further, and discusses the issue in more detail. Its objectives are first to estimate the entrained gas fraction in the liquid transported to the DCRT by salt-well pumping and second to estimate what fraction of the entrained gas bubbles are released to the headspace of the DCRT. The conclusion is that entrained gas bubbles are not an issue.

In this section, the mechanisms of bubble retention are summarized. The subsequent sections consider the fate of bubbles grouped in a series of categories that include all retained bubbles. For some categories of retained bubbles, the fate of the bubbles is easily determined. For the most difficult case of "hitchhiker" (armored) bubbles, a more lengthy discussion is needed to determine bubble fate.

"Hitchhiker" bubbles are hypothetical small bubbles that are carried with the liquid flow and are attached to or surrounded by solid particles. That is, they "hitchhike" on suspended particles. It is often proposed that these bubbles comprise a significant fraction of the retained gas in the tank being pumped and are transported through the waste into the salt well to the DCRT with the liquid. There, they somehow detach from their host particle and rise to the surface, where they contribute to the flammable gas concentration in the DCRT headspace. This section attempts to establish the technical basis for hitchhiker bubbles, quantify the amount of gas they are capable of transporting, and establish the hazard they might create in the DCRT.

\subsection{Retention Mechanisms and Categories of Bubbles}

A substantial amount of work has focused on the mechanisms of bubble retention. Recent laboratory studies on simulated and actual waste samples have provided a framework to classify bubble retention mechanisms (Gauglitz et al. 1994a, 1994b, 1995, 1996; Rassat et al. 1997). Other recent experimental results can also be classified by this framework (Walker et al. 1994; Bredt et al. 1995; Bredt and Tingey 1996; Rassat and Gauglitz 1995). The principal mechanisms of bubble retention can be grouped into three categories: bubbles retained by the strength of the waste material, bubbles retained by capillary forces, and bubbles retained by direct attachment to particles (armored bubbles). In typical waste configurations, waste strength and capillary forces dominate bubble retention. While armored bubbles certainly exist and have been studied (Rossen and Kam 1996; Rossen and Das 1995), they are thought to play a minor role in the overall retention and release of gas (Johnson et al. 1997; Gauglitz et al. 1996).

(a) Duke Engineering Services Hanford internal memo, 2N140-RDS-97001. July 7, 1997. R Smith to CE Leach. 
Bubbles retained by capillary forces finger between the waste particles. The movement of bubbles through the small pore throats between waste particles is strongly resisted by surface tension forces. Bubbles retained by yield strength have displaced the waste particles, but the buoyant force on the bubble is too small to overcome the material strength, and the bubble cannot rise.

To quantify the transport of retained bubbles, it is useful to classify the bubbles by size and consider the fate of each category. Table 3.1 describes three categories of bubbles. Based on what we know of bubble retention, typical bubbles are 0.1 to $10 \mathrm{~mm}$ in diameter. These bubbles are effectively trapped, as discussed in Section 3.2. Very small free bubbles, less than about 100 microns in diameter, quickly disappear by dissolving into the liquid, as discussed in Section 3.3. The main concern is the somewhat neutrally buoyant armored (hitchhiker) bubbles, very small bubbles attached to very small particles. Sections 3.4 and 3.5 explain why so little gas is associated with these bubbles that the consequences of their transport are insignificant.

\subsection{Trapping of Typical Bubbles}

During salt-well pumping, the hydraulic gradient is weak and retained bubbles are unlikely to be dislodged by the liquid flow. Literature results on the trapping of an analogous nonwetting phase, oil droplets, can be used to quantify the force necessary to dislodge "typical" bubbles $(0.1 \mathrm{~mm}$ to $10 \mathrm{~mm}$ ). Dullien (1992) summarizes the transport of immiscible fluids in detail, including a discussion of the velocity needed to mobilize trapped droplets. The results are presented as a dimensionless capillary number that can readily be applied to the mobilization of trapped bubbles. Bubbles will remain trapped if the hydraulic force is insufficient to overcome the capillary force. This is expressed by the inequality

Table 3.1. Classification of Bubbles and Their Ability to Transport

\begin{tabular}{|l|l|l|l||}
\hline Bubble Category & $\begin{array}{l}\text { Diameter } \\
\text { Range }\end{array}$ & Where Discussed & Comments on Bubble Transport \\
\hline \hline Typical bubbles & $\begin{array}{l}0.1 \mathrm{~mm} \text { to } \\
10 \mathrm{~mm}\end{array}$ & Section 3.2 & $\begin{array}{l}\text { All typical bubbles are effectively } \\
\text { trapped by capillary forces or by } \\
\text { the yield strength of the waste. }\end{array}$ \\
\hline $\begin{array}{l}\text { Very small bubbles } \\
\text { (without attached } \\
\text { particles) }\end{array}$ & $\begin{array}{l}\text { less than } \\
0.1 \mathrm{~mm}\end{array}$ & Section 3.3 & $\begin{array}{l}\text { Very small bubbles quickly disap- } \\
\text { pear due to their high internal } \\
\text { pressure, so none exist to trans- } \\
\text { port. }\end{array}$ \\
\hline $\begin{array}{l}\text { Hitchhiker bubbles } \\
\text { (armored bubbles) }\end{array}$ & $\begin{array}{l}\text { very small, } \\
\text { a few tens } \\
\text { of microns }\end{array}$ & $\begin{array}{l}\text { Section 3.4 } \\
\text { (max. size for fil- } \\
\text { tration and ability } \\
\text { to flow with liquid) }\end{array}$ & $\begin{array}{l}\text { This is the only bubble that can } \\
\text { possibly be carried to the DCRT. } \\
\text { However, only a small fraction of } \\
\text { retained bubbles are hitchhiker } \\
\text { bubbles that are small enough to } \\
\text { pass through the pore space within } \\
\text { the waste. }\end{array}$ \\
\hline $\begin{array}{l}\text { Section 3.5 } \\
\text { (volume fraction of } \\
\text { bubbles this small) }\end{array}$
\end{tabular}




$$
\frac{(\mathrm{Q} / 2 \pi \mathrm{RH}) \mu}{\sigma}<10^{-3}
$$

where

$Q=$ volumetric pumping rate $\left(\mathrm{m}^{3} / \mathrm{s}\right.$ - converted from gpm)

$\mathrm{R}=$ radius from the center of the salt-well screen $(\mathrm{m})$

$\mathrm{H}=$ interstitial liquid level (m), i.e., the height of the liquid in the salt well

$\mu=$ liquid viscosity (Pa-s)

$\sigma=$ surface tension $(\mathrm{N} / \mathrm{m})$.

Using typical values of $0.08 \mathrm{~N} / \mathrm{m}$ for surface tension (Norton and Pederson 1994), $20 \mathrm{cP}$ for viscosity (Stewart et al. 1996), an interstitial liquid level of $3 \mathrm{~m}$, and a $5 \mathrm{gpm}$ liquid flow, the capillary number in Eq. (3.1) is about $3 \times 10^{-5}$ for bubbles at the salt-well screen $(15 \mathrm{~cm}$ radius). This shows that all bubbles, even those immediately adjacent to the salt-well screen, will remain trapped at a pumping rate of $5 \mathrm{gpm}$.

If the bubbles interconnect to form a continuous gas phase (dendritic bubbles), then the gas is no longer trapped as a discrete bubble. However, in this case, Peurrung et al. (1996) have shown that the dominant force is upward so gas comprising dendritic bubbles does not enter the salt well.

Even if "typical" bubbles were to enter the salt-well screen, their terminal rise velocity would be greater than the downward velocity of the liquid in the salt well. Using Eq. (3.8) in Section 3.5 with a $5 \mathrm{gpm}$ flow rate, all bubbles with diameter greater than about 300 microns would rise faster than the pump-induced flow. We conclude that typical bubbles are not transported into the DCRT.

\subsection{Conditions for the Existence of Very Small Bubbles}

The pressure inside a bubble of any size is always higher than the external pressure because of surface tension. The pressure difference due to surface tension in a spherical bubble is

$$
\Delta \mathrm{P}_{\sigma}=\frac{4 \sigma}{\mathrm{d}}
$$

where $\sigma$ is the surface tension, and $d$ is the bubble diameter. The surface tension pressure increases rapidly as the diameter decreases. The pressure in a 1-micron bubble is over $3 \mathrm{~atm}$ higher than the external hydrostatic pressure.

Whether a free bubble can exist is dictated by basic thermodynamics. If the pressure in the bubble exceeds the equilibrium pressure of the dissolved gas in the surrounding liquid, the gas inside the bubble diffuses into the liquid to maintain thermodynamic equilibrium. But this shrinks the bubble and increases the pressure still further, accelerating diffusion and quickly annihilating the bubble (Leighton 1994). Only relatively large free bubbles, whose internal pressure is slightly less than the equilibrium pressure of the dissolved gas, can exist in a steady state. 
The annihilation process is very rapid. The time required for a small bubble to collapse can be predicted from an estimate of the mass flux across the gas-liquid interface. For small bubbles, the peak diffusive molar flux can be calculated from the following correlation (McCabe and Smith 1976):

$$
\mathrm{N}_{\mathrm{Sh}}=2.0+0.31 \mathrm{~N}_{\mathrm{Sc}}^{1 / 3} \mathrm{~N}_{\mathrm{Gr}}^{1 / 3}
$$

where

$$
\begin{aligned}
& \mathrm{N}_{\mathrm{sh}}=\text { Sherwood number (ratio of total mass transfer rate to mass diffusion) } \\
& \mathrm{N}_{\mathrm{sc}}=\text { Schmidt number (ratio of momentum diffusion to mass diffusion) } \\
& \mathrm{N}_{\mathrm{gr}}=\text { Grashof number (ratio of buoyant force to viscous force). }
\end{aligned}
$$

For bubbles smaller than about 100 microns, the term involving the Schmidt and Grashof numbers is negligible, and the Sherwood number can be set to 2.0. Applying the definition of the Sherwood number and the mass transfer coefficient gives the following expression for the molar flux of gas out of the bubble:

$$
j=2 \frac{\rho_{\mathrm{l}} \mathrm{D}}{d \mathrm{M}_{\mathrm{g}}}\left(\mathrm{y}_{\mathrm{b}}-\mathrm{y}_{\mathrm{l}}\right)
$$

where

$\mathrm{j}=$ molar flux of gas out of the bubble (moles $\left./ \mathrm{m}^{2}-\mathrm{s}\right)$

$\rho_{1}=$ liquid density $\left(\mathrm{kg} / \mathrm{m}^{3}\right)$

$\mathrm{D}=$ diffusion coefficient of the gas through the liquid $\left(\mathrm{m}^{2} / \mathrm{s}\right)$

$\mathrm{d}=$ bubble diameter $(\mathrm{m})$

$M_{g}=$ molecular weight of the gas $(\mathrm{kg} / \mathrm{mole})$

$\mathrm{y}_{\mathrm{b}}=$ mole fraction of dissolved gas in the liquid at the bubble surface

$\mathrm{y}_{1}=$ mole fraction of dissolved gas far from the bubble.

Converting the molar flux to the rate of bubble diametral contraction via the ideal gas law yields

$$
\dot{d}=4 \frac{\rho_{1} D R T}{d P M_{g}}\left(y_{b}-y_{1}\right)
$$

where

$$
\begin{aligned}
\dot{\mathrm{d}}= & \text { rate of diametral contraction of the bubble }(\mathrm{m} / \mathrm{s}) \\
\mathrm{R}= & \text { universal gas constant }(8314 \mathrm{~N}-\mathrm{m} / \mathrm{kg} \text { mol-K) } \\
\mathrm{T}= & \text { gas temperature }(\mathrm{K}) \\
\mathrm{P}= & \text { bubble internal pressure }\left(\mathrm{N} / \mathrm{m}^{2}\right), \mathrm{P}=4 \sigma / \mathrm{d}+\mathrm{P}_{\mathrm{H}} \text { where } \mathrm{P}_{\mathrm{H}} \text { is the local hydrostatic } \\
& \text { pressure. }
\end{aligned}
$$

The mole fractions of gas in the liquid can be related to an equilibrium gas pressure via Henry's Law, which can be expressed (in a somewhat different form than Eq. 2.1) by 


$$
y=\frac{M_{1}}{\rho_{1}} K_{H} \frac{P}{P_{0}}
$$

where

$\mathbf{M}_{1}=$ molecular weight of the liquid ( $\left.\mathrm{kg} / \mathrm{mole}\right)$

$\mathrm{K}_{\mathrm{H}}=$ Henry's Law coefficient for the gas (mole $/ \mathrm{m}^{3}$ liquid-atm)

$P_{0}=$ pressure conversion factor $\left(101,320 \mathrm{~N} / \mathrm{m}^{2}\right.$-atm $)$.

The pressure corresponding to $y_{b}$ is the bubble internal pressure. The pressure corresponding to the background mole fraction, $y_{1}$, is the local hydrostatic pressure, $P_{\mathrm{H}}$, plus a small increment, $\delta$, the small supersaturation necessary for bubbles to exist in the steady state. Substituting Eq. (3.2) and (3.6) into Eq. (3.5) gives the final expression for the rate of bubble contraction as

$$
\dot{\mathrm{d}}=4 \frac{\mathrm{DRTK}_{\mathrm{H}}}{\mathrm{dP}_{0}} \frac{\mathrm{M}_{1}}{\mathrm{M}_{\mathrm{g}}}\left(\frac{1-\frac{\mathrm{d} \delta}{4 \sigma}}{1+\frac{\mathrm{dP}_{\mathrm{H}}}{4 \sigma}}\right)
$$

Eq. (3.7) actually gives only the peak initial rate of mass transfer. As gas diffuses into the liquid, concentration gradients decrease, reducing the mass transfer rate. However, the internal bubble pressure and the corresponding dissolved gas concentration at the interface increase rapidly as the bubble shrinks, which tends to maintain the driving force for mass transfer. This effect dominates the model below a few tens of microns.

Figure 3.1 shows the collapse time as a function of initial diameter obtained by numerically integrating Eq. (3.7) for a bubble containing mostly hydrogen and nitrogen. Two cases are shown. The first case adjusts the dissolved gas supersaturation pressure, $\delta$, to make the initial contraction rate, $\dot{\mathrm{d}}, 0$ (stable) for a 100 -micron bubble. The second case repeats the adjustment but for a minimum stable diameter of $1 \mathrm{~mm}$. The values of the parameters used to evaluate the equation are listed in Table 3.2. The figure shows that even bubbles approaching a stable diameter of 100 microns collapse within a few minutes. For either choice of minimum stable diameter, a 10 -micron bubble is annihilated in less than 0.05 seconds, while a 1 -micron bubble collapses in less than 0.2 milliseconds.

This analysis shows that free bubbles smaller than a few tens of microns (and possibly a few hundred microns within the uncertainty of the model) in diameter cannot exist in the steady state. Even if a large number of them were to nucleate at the same time, the collapse time is many orders of magnitude shorter than the time required for them to be transported to the saltwell screen and into the DCRT. Small free bubbles are simply not a physically plausible consideration.

To exist, these small bubbles must be attached to or shielded by solid particles so that their effective radius of curvature is much larger than that of a free bubble with the same volume. The internal pressure of these so-called armored bubbles must be approximately equal to that of larger, stable free bubbles to prevent their collapse and allow them to grow. These bubbles are 


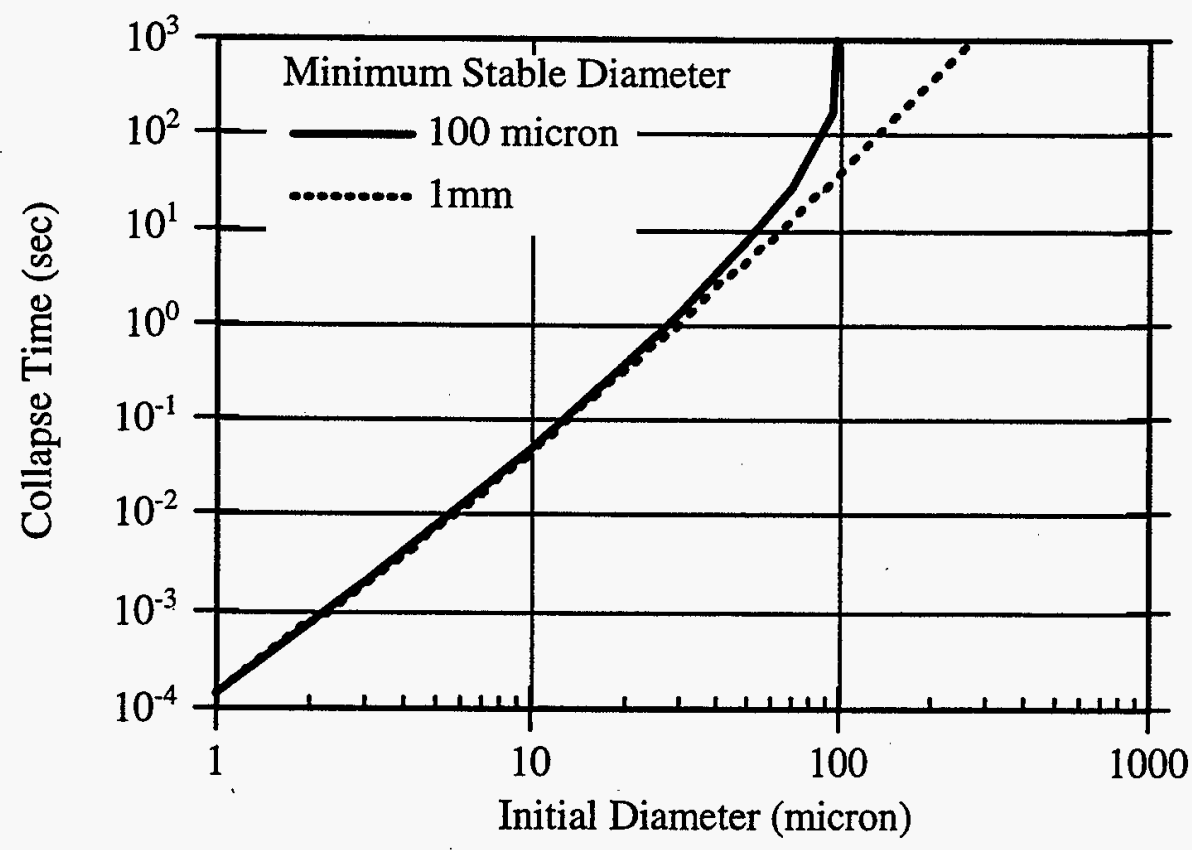

Figure 3.1. Free Bubble Collapse Time Versus Diameter

discussed in Section 3.4. However, the model also shows that even if a small armored bubble is somehow transported to the DCRT as a hitchhiker, it does not necessarily contribute to the headspace flammability. If the bubble retains its armoring particles, the gas may remain trapped and not dissolve into the waste. However, if it is somehow detached from the armoring particles (by agitation or dilution), it will collapse almost immediately into the liquid. It could then diffuse through the liquid and partition into the DCRT headspace.

Table 3.2. Parameter Values for Bubble Collapse Calculation

\begin{tabular}{||l|l|l||}
\hline Parameter & Value & Source \\
\hline $\mathrm{M}_{1}$ & $55 \mathrm{~kg} / \mathrm{mole}$ & $\begin{array}{l}\text { computed from typical liquid composition from } \\
\text { SST core samples }\end{array}$ \\
\hline $\mathrm{M}_{\mathrm{g}}$ & $18 \mathrm{~kg} / \mathrm{mole}$ & $\begin{array}{l}\text { for a gas mixture of } 50 \% \mathrm{H}_{2}, 30 \% \mathrm{~N}_{2} \text { and } 20 \% \\
\mathrm{~N}_{2} \mathrm{O}\end{array}$ \\
\hline $\mathrm{D}$ & $2.6\left(10^{-10}\right) \mathrm{m}^{2} / \mathrm{s}$ & $\begin{array}{l}\text { D for } \mathrm{H}_{2} \text { in water, } 5.13\left(10^{-9}\right) \mathrm{m}^{2} / \mathrm{s}, \text { reduced by ra- } \\
\text { tio of viscosities, } 1 \mathrm{cP} / 20 \mathrm{cP} \text { to account for effect } \\
\text { of dissolved salts }\end{array}$ \\
\hline $\mathrm{K}_{\mathrm{H}}$ & $\begin{array}{l}0.06 \mathrm{~mole} / \mathrm{m}^{3}- \\
\text { atm }\end{array}$ & $\begin{array}{l}\text { typical of range for } \mathrm{H}_{2} \text { and } \mathrm{N}_{2} \text { computed from } \\
\text { RGS results in Shekarriz et al. (1997) }\end{array}$ \\
\hline $\mathrm{T}$ & $320 \mathrm{~K}$ & from Norton and Pederson (1994) \\
\hline$\sigma$ & $0.08 \mathrm{~N} / \mathrm{m}$ & represents pressure under several meters of waste \\
\hline $\mathrm{P}_{\mathrm{H}}$ & $1.5 \mathrm{~atm}$ & \multicolumn{2}{|l}{}
\end{tabular}




\subsection{Transport of Hitchhiker Bubbles Through the Waste}

Because of strong capillary trapping, reflected in Eq. (3.1), only bubbles smaller than pore throats between particles within the waste can be transported by moving fluid. To determine the maximum size of a hitchhiker bubble that can transport through the waste, the waste can be approximated as a filter medium. If the hitchhiker bubbles are too large, they will be filtered by the waste. An established approximation from filtration literature is the "one-seventh" rule (Kahtib and Vittal 1989; Abrams 1977; Herzig et al. 1970): particles with a median diameter smaller than one-seventh the median pore throat diameter can pass through a filter without internal plugging (by bridging).

Unfortunately, no direct information is available for the pore throat diameter of SST wastes. However, the throat diameter can be readily estimated from the particle size of the waste. For beds of packed particles, Dullien (1992) shows that the median pore-throat diameter is roughly one-third the particle diameter. Accordingly, hitchhiker bubbles must be smaller than that, $(1 / 7) \cdot(1 / 3)$, or about one-twentieth, of the typical particle diameter in the waste. Based on visual observations of saltcake waste shown in Gauglitz et al. (1996), a conservative estimate (upper bound) for a median waste particle diameter is 200 microns. With this estimate, only hitchhiker bubbles smaller than 10 microns can be transported through the waste without being effectively filtered out.

Though particles smaller than about 10 microns in diameter can theoretically migrate through the pore throats between waste particles, buoyancy (or non-buoyancy) may still trap hitchhiker bubbles in the matrix. If the terminal velocity of the hitchhiker bubble is less than the flow velocity, the flow can move the particle against gravity and can therefore potentially transport it through the waste to the salt well. The path a particle must follow is not straight. There will be a statistically significant fraction of the path that is nearly vertical. A buoyant particle whose terminal velocity is higher than the flow speed in a downward segment will be trapped, as will a non-buoyant particle in an upward segment.

At the terminal velocity, the buoyant force is balanced by the drag force. The buoyant force on a hitchhiker bubble is equal to the volume of liquid displaced:

$$
\mathrm{F}_{\mathrm{BUOY}}=\frac{\pi \mathrm{d}^{3}}{6} \mathrm{~g} \rho_{1}\left[1-(1-\alpha) \frac{\rho_{\mathrm{s}}}{\rho_{1}}\right]
$$

where

$\mathrm{d}=$ effective diameter of the armored bubble $(\mathrm{m})$

$\rho_{1}=$ liquid density $\left(\mathrm{kg} / \mathrm{m}^{3}\right)$

$\rho_{s}=$ solid density $\left(\mathrm{kg} / \mathrm{m}^{3}\right)$

$\alpha=$ gas volume fraction of the armored bubble (gas volume/gas + solids volume).

Assuming the velocity is within the Stokes flow regime (the Reynolds number, $\operatorname{Re}<1$ ), the drag force is expressed as 


$$
F_{D R A G}=\frac{\pi d^{2}}{8} C_{D} \rho_{1} U^{2}
$$

where $C_{D}$ is the Stokes drag coefficient $\left(C_{D}=24 / R e\right)$, and $U$ is the terminal velocity. Equating forces, substituting the definition of Reynolds number, and solving for the velocity yields

$$
\mathrm{U}=\frac{\rho_{1} \mathrm{gd}^{2}}{18 \mu}\left[1-(1-\alpha) \frac{\rho_{\mathrm{s}}}{\rho_{1}}\right]
$$

where $\mu$ is the liquid viscosity $\left(\mathrm{N}-\mathrm{s} / \mathrm{m}^{2}\right)$.

The flow velocity in the pores during salt-well pumping depends on the radial distance from the salt-well screen $(-30 \mathrm{~cm}$ in diameter), the porosity, and the interstitial liquid level. It can be computed as

$$
\mathrm{U}_{\mathrm{SWP}}=\frac{\mathrm{Q}}{2 \pi \mathrm{RH} \phi}
$$

where

$$
\begin{aligned}
& \mathrm{Q}=\text { volumetric pumping rate }\left(\mathrm{m}^{3} / \mathrm{s}-\right.\text { converted from gpm) } \\
& \mathrm{R}=\text { radius from the center of the salt-well screen }(\mathrm{m}) \\
& \mathrm{H}=\text { interstitial liquid level }(\mathrm{m}) \\
& \phi=\text { porosity of the waste. }
\end{aligned}
$$

A particle can theoretically be transported if the terminal velocity in Eq. (3.10) is less than the flow velocity from Eq. (3.11). Solving the inequality for the radius from the salt-well centerline gives an expression for the region in which the flow is strong enough to transport a hitchhiker bubble of a given size and gas fraction. The expression is

$$
\mathrm{R}<\frac{9 \mu \mathrm{Q}}{\pi \mathrm{d}^{2} \mathrm{H} \phi \mathrm{p}_{1}\left[1-(1-\alpha) \frac{\rho_{\mathrm{s}}}{\rho_{1}}\right]}
$$

The maximum radius given by Eq. (3.12) is plotted against the fraction of neutral buoyancy in Figure 3.2. Eq. (3.12) is symmetric about the neutral buoyancy gas fraction, so the figure actually covers the range from $0<\alpha<2 \alpha_{\mathrm{NB}}$. The parameter values used in the plot are listed in Table 3.3. The figure shows that, for a pumping rate of $5 \mathrm{gpm}$, a 20 -micron armored bubble can theoretically be transported almost all the way from the tank wall no matter how buoyant or nonbuoyant. Larger bubbles can be transported only from smaller radii where the flow is stronger or if they are more nearly neutrally buoyant. 


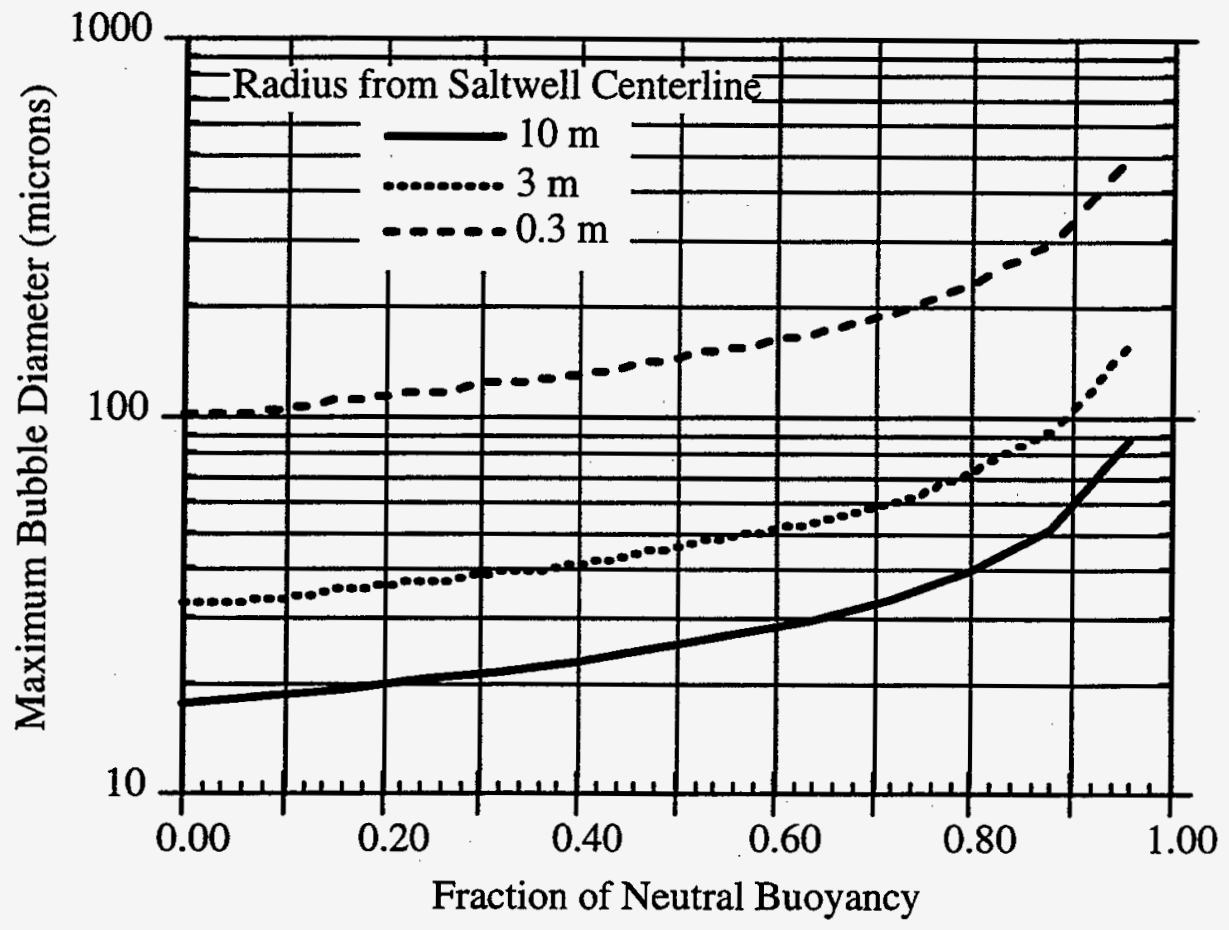

Figure 3.2. Maximum Size of Hitchhiker Bubbles

However, it has already been shown that armored bubbles must be less than about $10 \mathrm{mi}-$ crons in diameter to fit through the waste matrix. Figure 3.2 shows that these small clusters can, under a purely hydrodynamic criterion, be transported easily at $5 \mathrm{gpm}$. Even at $1 \mathrm{gpm}$ flows, 10micron clusters can be transported from all radii if their gas fraction is at least $40 \%$ of neutral buoyancy.

Table 3.3. Parameter Values Used in Bubble Transport Calculations

\begin{tabular}{|c|l|l||}
\hline Parameter & Value & Source \\
\hline$\rho_{1}$ & $1500 \mathrm{~kg} / \mathrm{m}^{3}$ & typical value determined from core samples \\
\hline$\rho_{\sigma}$ & $2000 \mathrm{~kg} / \mathrm{m}^{3}$ & $\begin{array}{l}\text { typical value calculated from core sample analysis (not } \\
\text { including interstitial liquid) }\end{array}$ \\
\hline$\alpha_{\mathrm{NB}}$ & 0.25 & calculated from $\alpha_{\mathrm{NB}}=1-\rho_{1} / \rho_{\sigma}$ \\
\hline$\mu$ & $20 \mathrm{cP}$ & from DST ball rheometer data (Stewart et al. 1996) \\
\hline$\phi$ & 0.4 & typical value assumed for SST waste \\
\hline $\mathrm{H}$ & $3 \mathrm{~m}$ & conservative liquid level for SSTs to be pumped \\
\hline
\end{tabular}




\subsection{The Fraction of Gas Contained in Small Bubbles}

The previous sections have shown that bubbles can exist that are sufficiently small to migrate through the waste and into the DCRT. However, they must be armored by solid particles so that their effective radius of curvature is approximately the same as the smallest stable free bubble (several hundred microns). The flammability hazard created in the DCRT by these small bubbles depends on the volume of gas they can contain compared with the larger free bubbles that do not enter the salt well.

The gas volume contained in bubbles below a given diameter is conveniently expressed by a cumulative bubble volume distribution. The bubble volume distribution is determined by the nucleation rate and bubble growth rate. For a significant gas volume to reside within the smaller bubbles, the number of larger bubbles must be minimized. A 1-mm-diameter bubble contains a million times the gas volume of a 10-micron bubble.

Conditions in waste tanks to be salt-well pumped tend to favor larger bubble sizes. Bubble nucleation requires some amount of supersaturation or overpressure of dissolved gas in the liquid. After a sufficient number of bubbles have been formed, however, nucleation ceases as dissolved gas begins diffusing preferentially into existing bubbles instead of creating new ones (Allemann et al. 1991). The required armoring particles on hitchhiker bubbles reduce the surface area available for diffusion so that larger free bubbles tend to grow more rapidly. As larger bubbles become available, supersaturation may be reduced to the point that gas begins diffusing out of smaller bubbles into the larger ones (Ostwald ripening). The combined effect of these processes makes the probability of bubbles sufficiently small to hitchhike relatively low.

Bubble size distributions have not yet been measured in tank waste, although some visual evidence is available. Bubbles as large as a few millimeters can be seen in core sample extrusions (Meyer et al. 1997; Gauglitz and Aiken 1997). An armored bubble of about 50 microns was observed in photomicrographs of SY-101 waste (Herting et al. 1992). Gas retention experiments with actual waste samples (Gauglitz et al. 1996) produce bubbles ranging from $100 \mathrm{mi}-$ crons (approximate limit of detectability with the naked eye) to a few millimeters, the latter size visually predominant.

An approximate bubble size distribution can be derived from a simple growth model. Conservatively, assume that existing bubbles do not hinder nucleation and that armoring particles allow small bubbles to have the same internal pressure as the larger free bubbles so that Ostwald ripening does not occur. Also assume that the mole flux of gas (moles of gas/unit bubble surface area/unit time) across the bubble interface is uniform and constant. With a constant internal pressure and temperature, this implies a constant and uniform gas volume flux into the bubble.

Under these assumptions, the rate of increase in volume of an individual bubble, $i$, is, therefore, simply

$$
\frac{d V_{i}}{d t}=J A_{i}
$$


where $J$ is the volume flux into the bubble $\left(\mathrm{m}^{3} / \mathrm{m}^{2}\right)$ and $A_{i}$ is the bubble surface area $\left(\mathrm{m}^{2}\right)$. Substituting diameter-based expressions for volume and area $\left(\mathrm{V}=\pi \mathrm{d}^{3} / 6, \mathrm{~A}=4 \pi \mathrm{d}^{2}\right)$ and solving yields the following simple linear model for diametral growth:

$$
d_{i}(t)=d_{0}+2 J\left(t-t_{i, 0}\right)
$$

where $d_{0}$ is the equivalent bubble diameter at nucleation $(m)$ and $t_{i, 0}$ is time $(\mathrm{sec})$ at which the given bubble was nucleated.

If the nucleation time is a uniform random variable, the diameter of an arbitrarily selected bubble is also a uniform random variable. That is, bubbles of all sizes from $d_{0}$ to the maximum size at a given time are equally likely.

There is also some support from cluster nucleation theory where the cluster size distribution develops a qualitatively uniform character at intermediate times (Gunton et al. 1983). As clusters continue to grow, however, the distribution develops a "fat" tail in which a very few of the clusters become very large while a large number of the smallest remain. This follows the same trend as the Pareto distribution, which has been shown to match the size distribution in free-rising bubble swarms in stirred tanks (Stewart et al. 1993). The Pareto probability density function is given by

$$
f(x ; \theta, \kappa)=\frac{\kappa}{\theta}\left(1+\frac{x}{\theta}\right)^{-(\kappa+1)}
$$

The Pareto mean is given by

$$
\mu=\frac{\theta}{\kappa-1}, \quad \kappa>1
$$

With the parameter $\kappa=2$, the parameter $\theta$ is equal to the mean.

The cumulative volume fraction is the fraction of the total gas volume contained in bubbles up to a given diameter. It is computed by integrating the product of the bubble diameter probability density and bubble volume from $\mathrm{d}_{0}$ to $\mathrm{d}_{\max }$ and normalizing by the total volume.

$$
V(d)=\frac{\int_{d_{0}}^{d} f(x) x^{3} d x}{\int_{d_{0}}^{d_{\max }} f(x) x^{3} d x}
$$

where $f(x)$ is the probability density. The cumulative volume fraction for a uniform distribution $(f(x)=$ constant $)$ increases as the fourth power of the bubble diameter. 
Figure 3.3 shows the cumulative volume fractions computed using Eq. (3.17) for a uniform size distribution with a maximum diameter of $1 \mathrm{~mm}$ and mean diameter of 500 microns and for a Pareto distribution with a mean diameter of 10 microns and a maximum of $1 \mathrm{~mm}$. (The mean and maximum bubble diameters cannot be specified here with great accuracy; these values reflect our judgement of reasonable bubble sizes. In particular, the Pareto mean diameter of 10 microns was selected because it reasonably represents a bubble armored with many 1-micron particles.) Figure 3.3 shows that although the Pareto distribution classifies $75 \%$ of the bubbles as smaller than 10 microns in diameter, the entire collection of these small bubbles that could potentially hitchhike makes up only $5 \times 10^{-4}$ of the volume. About $90 \%$ of the gas is contained in bubbles larger than 150 microns. The uniform distribution allows a factor of only $10^{-8}$ of the volume for bubbles below 10 microns in diameter, and $90 \%$ of the gas is contained in the bubbles greater than $\mathbf{5 5 0}$ microns in diameter. This is corroborated by the x-ray analysis of SST core samples in which $50-80 \%$ of the gas was found to be contained in bubbles larger than $500 \mathrm{mi}$ crons (Mahoney et al. 1997).

The two fractions of the free gas volume available to hitchhike predicted by the two distributions, $5 \times 10^{-4}$ and $10^{-8}$, differ by four and a half orders of magnitude, leading to similarly large differences in the predicted total hitchhiker bubble volume. A typical tank contains on the order of 100 SCM of free gas (Mahoney et al. 1997). Applying the Pareto distribution result, if up to $5 \times 10^{-4}$ of this volume could potentially hitchhike, the total volume would be 0.05 SCM (50 standard liters) over the entire course of salt-well pumping. Applying the uniform distribution would yield a volume of only $10^{-6} \mathrm{SCM}(1 \mathrm{~mL})$.

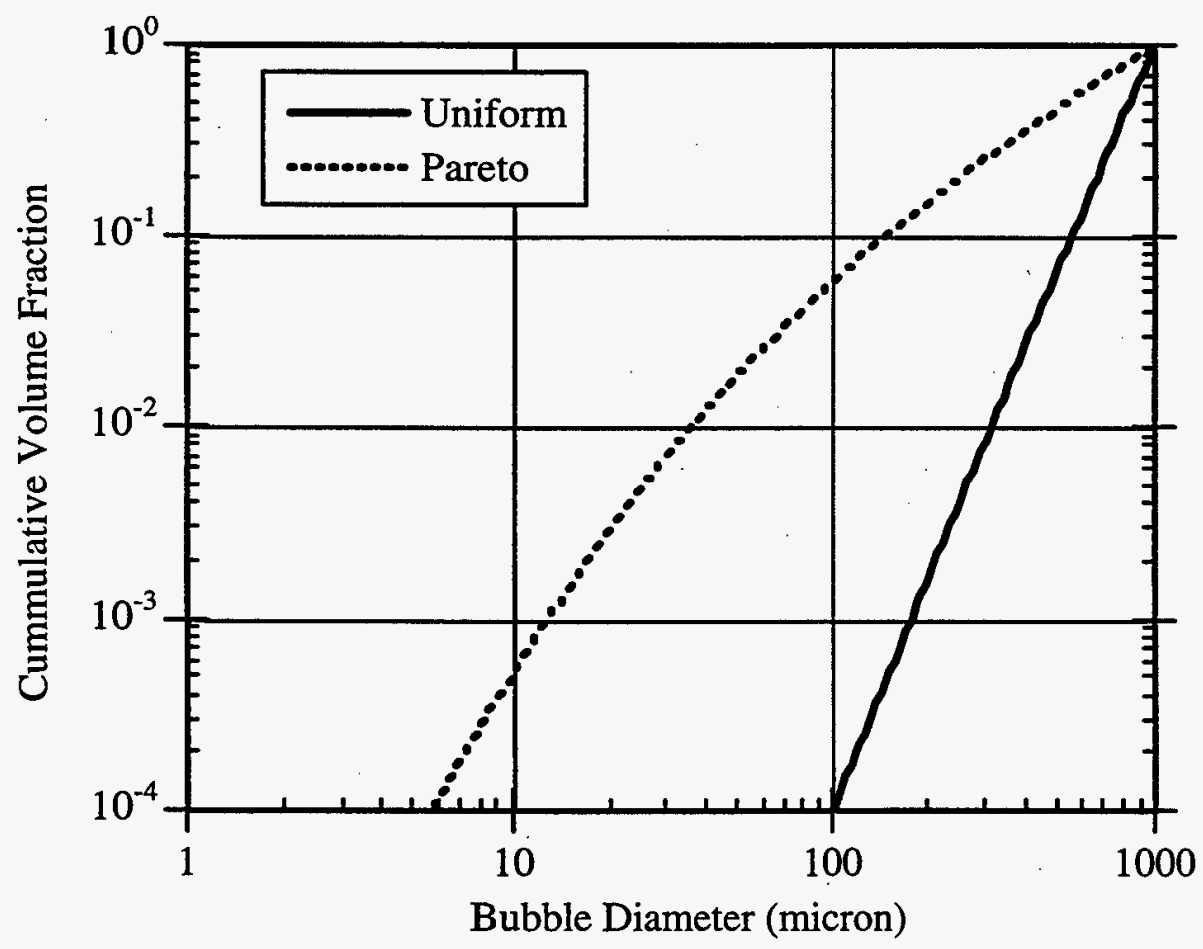

Figure 3.3. Cumulative Volume Fraction Versus Bubble Diameter 
Which prediction is correct? There is no guarantee that the Pareto distribution, while appropriate for free-rising bubble swarms in stirred liquid, is appropriate for gas bubbles trapped within solids. The uncertainty in the mean bubble diameter is also large, with a value larger than 10 microns leading to a smaller volume fraction held in small bubbles. The actual armored bubble volume in a source tank is probably somewhere between $1 \mathrm{~mL}$ and $50 \mathrm{~L}$, but it is difficult to narrow this range any further. Instead, let us note that even $50 \mathrm{~L}$ of free gas (mostly hydrogen) released into a DCRT over the course of pumping an entire source tank would raise the flammability of the DCRT by an insignificant degree. Because the larger DCRTs have an operating capacity of about 30,000 gallons, each would be filled 15 to 20 times to drain the liquid from a million-gallon source tank. Each fill would thus receive $1 / 15^{\text {th }}$ to $1 / 20^{\text {th }}$ of the hitchhiker gas, or about $3 \mathrm{~L}$.

When mixed into the DCRT headspace volume of $30,000 \mathrm{~L}$ (7,500 gallons), the hydrogen concentration would rise by three parts in 30,0000 , or $0.01 \%$. Since the LFL for hydrogen is $4 \%$, flammability would rise by only $0.25 \%$.

We conclude that, though there may be a large number of armored bubbles of a transportable size range, the basic physics of bubble nucleation and growth dictate that they make up a truly insignificant portion of the total gas volume. Therefore, hitchhiker bubbles do not contribute to the flammability hazard in DCRTs. 


\subsection{Gas Adsorption onto Solids}

Gas could also be carried over from a source tank to a DCRT by adsorption onto the surfaces of entrained solids. The discussion in this section estimates the relative importance of this potential mechanism. There are several unknowns needed for a complete analysis, including particle size, the amount of solids carried over, and the equilibrium and kinetic rate constants governing the partitioning of gases. However, even a conservative approach, assuming one complete monolayer of molecules (including dissolved gases, ions, and water) on particle surfaces, shows the mechanism to be an insignificant contributor of flammable gas compared with carryover in solution. Moreover, previous laboratory experiments failed to show significant sorbed gas on tank waste solids.

\subsection{Background}

Adsorption refers to the binding of liquid, gas, or dissolved species to the surface of a solid particle. The attachments may take the form of chemical bonds (chemisorption) or weaker intermolecular forces such as van der Waals forces (physisorption). Typically, up to a monolayer of gas may adsorb to a particle's surface, with the degree of coverage controlled by a set of partition coefficients between each species and the solid and the concentration of each species in the ambient medium.

Hedengren et al. (1997) did not consider adsorption as a gas carryover mechanism for DCRTs. However, the possibility that flammable gases may be adsorbed to solid particles in tank waste has been considered from time to time. For example, the safety assessment for the SY-101 mixer pump alludes to a potential change in the amount of "bound," "unreleasable" gas caused by changes in crystal size distribution (Sullivan 1997, p. P-4). The safety assessment found no indication that mixer pump operation had caused any changes in "unreleasable" gas.

Pederson and Bryan (1996) conducted laboratory tests with DST simulants to assess whether ammonia sorbed onto tank solids in significant quantities. (While the behavior of SST solids cannot be inferred directly from these studies, these are the only experimental data available.) Henry's Law constants were determined as a function of temperature for the decantate (no solids) and the complete simulant for mixtures SY1-SIM-91A (containing sodium nitrate, nitrite, aluminate, hydroxide, and carbonate) and SY1-SIM-92A (containing components of $-91 \mathrm{~A}$ plus transition metal salts and other minor components). Henry's Law constants are calculated on the basis of the quantity of water present in the sample, not on sample volume. Thus the addition of an inert solid that does not adsorb ammonia would have no effect on the magnitude of the Henry's Law constant. For SY1-SIM-91A, Henry's Law constants were indistinguishable for the decantate and slurry sample, as shown in Figure 4.1, indicating that any ammonia adsorption onto solid surfaces is very small compared with that dissolved in the liquid. For SY1-SIM-92A, the slurry simulant showed a somewhat reduced ammonia solubility, the reverse of what was expected if ammonia were adsorbed onto solids. Since the simulant was allowed to stand without agitation at room temperature for more than a year before separating the decantate, dissolved salt concentrations were probably lower than expected due to the formation 


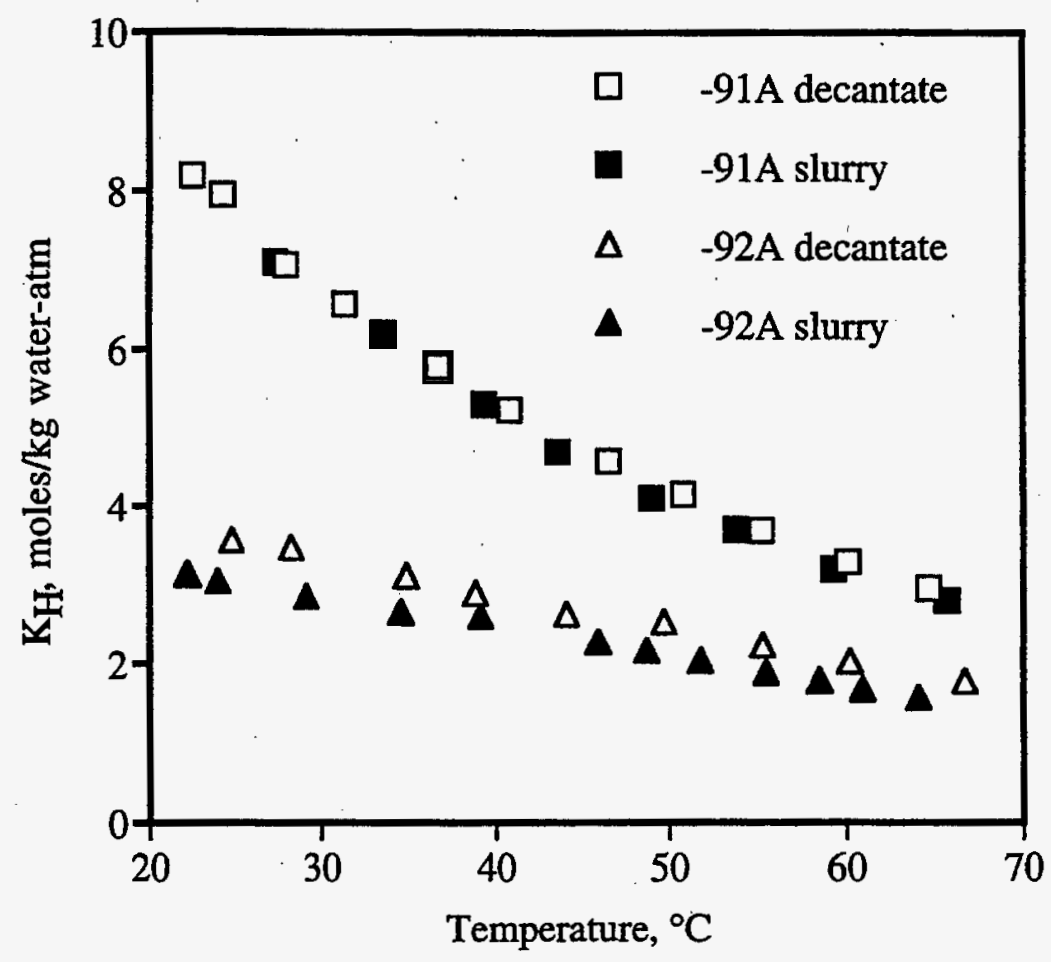

Figure 4.1. Comparison of Henry's Law Constants for the Decantate and Complete Slurry Simulant for SY1-SIM-91A and SY1-SIM-92A (no evidence was apparent for large-scale adsorption of ammonia onto solid surfaces) (Pederson and Bryan 1996)

of concentration gradients (Pederson and Bryan 1996). While ammonia sorption onto solid surfaces may well occur, the amount adsorbed appears to be too small to measurably alter the overall ammonia solubility.

\subsection{Retention and Release of Adsorbed Gas}

To estimate the amount of gas carried over via adsorption, an estimate of the amount of gas sorbed to particles in the source tank must be combined with an estimate of the fraction of those particles carried over to the DCRT. The analysis below combines some conservative with some best-estimate assumptions to yield an upper limit for this estimate, which will be shown to be far below the level of concern. However, there are significant unknowns in the analysis, including the number of potential monolayers, the relative affinity of the solids for the various species, the kinetics of adsorption and desorption, the solid particle size distribution, and the degree to which particles are able to pass through the salt-well screen. If the behavior of sorbed gas is different from that assumed, the analysis may be inaccurate.

The total amount of material that could be adsorbed to a solid surface is controlled by the number of monolayers (or the degree of complete monolayer coverage) and the site density. While, theoretically, more than one monolayer could be present, the fact that tank waste solids 
are hydrophilic argues for less than a complete monolayer. However, this argument is qualitative at best, driving us to assume (conservatively) one complete monolayer of coverage. A typical site density would be $10^{15}$ sites $/ \mathrm{cm}^{2}$, that is, $10 \AA^{2}$ per adsorbed molecule or ion.

The resulting quantity of material that could be adsorbed onto the waste solids in the source tank depends on the solid particle size and number of particles present. Figure 4.2 shows the result, in moles per kilogram of waste, as a function of average particle size. In this case, the average would be based on particle surface area, which would tend to favor smaller particles. For tank wastes, a surface-area average particle size would be on the order of 1 micron (Herting et al. 1992), leading to a predicted $0.02 \mathrm{~mol} / \mathrm{kg}$ waste of adsorbed material in the source tank. The calculation assumes that the particles are solid (i.e., nonporous) and cubic, the average solids density is $2.3 \mathrm{~g} / \mathrm{cm}^{3}$, and the waste in the source tank is made up of $50 \mathrm{wt} \%$ undissolved solids and $40 \mathrm{wt} \%$ water.

The calculation shows that a considerable quantity of adsorbed material may be present in the source tank. However, flammable gases must compete for those surface sites with water and dissolved salts in the waste liquid. The relative amounts of each component on the particle surfaces would depend on the degree to which each is attracted to the solid, with polar materials predominating. An exact calculation of the composition of the adsorbed layer would require a

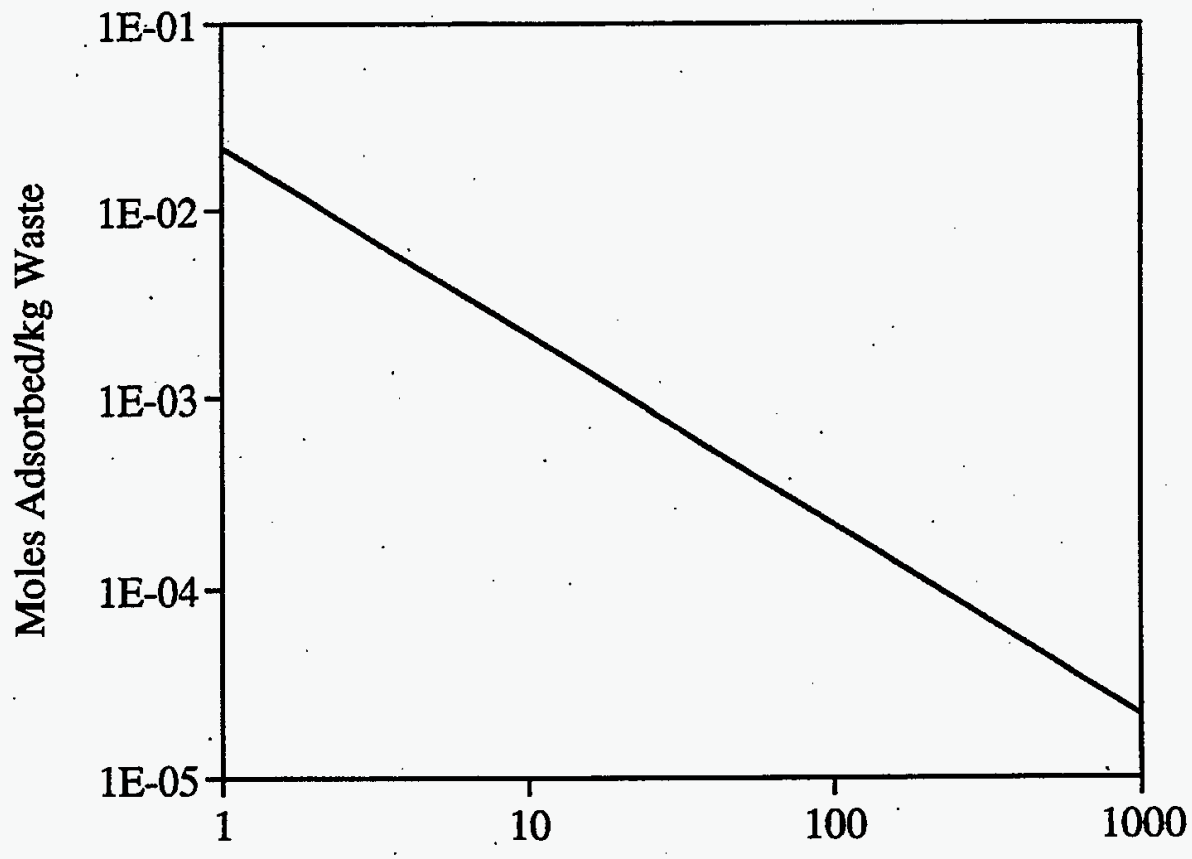

Particle Size, Microns

Figure 4.2. Quantity of Material Adsorbed Versus Average Solid Particle Size in $\mathrm{mol} / \mathrm{kg}$ Waste. We assume that molecules adsorb onto solids at monolayer coverage, the solid particles are cubic, the average solids density of $2.3 \mathrm{~g} / \mathrm{cm}^{3}$, and the waste is composed of $50 \%$ solids and $40 \%$ water by weight. 
set of partition coefficients governing the thermodynamic equilibrium between dissolved and adsorbed species. In the absence of such a set of partition coefficients, a rough approximation would be to assume that the composition of the adsorbed layer reflects the composition in the waste liquid. This approximation should be conservative for flammable gas calculations since hydrogen and methane, as nonpolar molecules, should be poorly adsorbed.

The waste liquids have a water concentration of approximately $55 \underline{\mathrm{M}}$ and a varying total salt concentration in the range of roughly 10-15 $\underline{\mathrm{M}}$. Liquid-phase ammonia concentrations vary from tank to tank but tend to run in the range of 0.004 to 0.18 molar (see Table 2.2; note conversion from $\mu \mathrm{g} / \mathrm{mL}$ to $\mathrm{mol} / \mathrm{L}$ ). Dissolved hydrogen, nitrous oxide, and methane concentrations also vary but are typically two to three orders of magnitude smaller. Thus the amount of adsorbed ammonia would be only 0.004 to $0.3 \%$ of the total adsorbed material (e.g., $0.18 \mathrm{M}$ / $(0.18 \underline{\mathrm{M}}+15 \underline{\mathrm{M}}+55 \underline{\mathrm{M}})=0.3 \%)$, with other adsorbed gases present in even smaller trace quantities. Of the estimated total amount of 0.02 moles adsorbed material per $\mathrm{kg}$ waste in the source tank, only about $6 \times 10^{-5} \mathrm{~mol} / \mathrm{kg}$ would be ammonia (choosing the higher value of $0.2 \mathrm{M}$ ammonia). Still, for a million-gallon waste tank and at $22.4 \mathrm{~L}$ gas per mole, this would create about 10,000 standard liters (10 SCL) of ammonia gas if freed.

However, this calculation only estimates how much adsorbed gas may be present on the solids in the source tank. The vast majority of solids are retained by the salt-well screen, not transferred to the DCRT. To calculate the amount of adsorbed gas transferred to the DCRT, one must multiply by the fraction of solids that might pass through the screen (neglecting that smaller particles with higher surface-area-to-volume ratios may be selectively transferred). No estimates are available of the amount of solids that pass the screen. There is evidence of a layer of solids on the bottom of only one DCRT, TX, ${ }^{(a)}$ and it is thought that only a few inches of material is present that was deliberately transferred as solids from the Plutonium Finishing Plant. ${ }^{(b)}$ In the absence of a more rigorous estimate, a $1 \%$ solids carryover would seem to be a reasonable orderof-magnitude approximation. This level would cause some turbidity of the liquid but would not significantly alter its specific gravity (which is monitored) or produce large amounts of settled material. The resulting amount of ammonia carried over would then be on the order of $6 \times 10^{-7} \mathrm{~mol} / \mathrm{kg}$ waste in the source tank, or about 100 standard liters of gas.

\subsection{Conclusions}

With this approximation, we see that only on the order of $100 \mathrm{~L}$ of ammonia gas might be transferred by this mechanism over the course of pumping an entire SST, an amount far surpassed by the liberation of dissolved gas. Moreover, this is an upper limit estimate, given that monolayer coverage is unlikely to be achieved and that a high ammonia concentration $(0.2 \underline{\mathrm{M}}$, or $4000 \mu \mathrm{g} / \mathrm{mL}$ ) was assumed. The calculation has not considered the kinetics of release of adsorbed gas. If release were slow, that is, if gases were tightly bound and difficult to strip from the solids, even less gas would be released before the liquid was transferred out of the DCRT. Finally, the calculations are consistent with the laboratory observation that the presence of solids did not measurably alter the quantity of ammonia retained in a slurry simulant.

(a) BX may also have a solids layer. LJ Kripps, personal communication, 11/21/97.

(b) Westinghouse Hanford Company. 1996. Safety Assessment of Flammable Gas Accidents in Double-

Contained Receiver Tanks. WHC-SD-WM-SAD-037 Rev. 0 (Draft 9/19/96), p. 4. 


\subsection{Gas Generation in DCRTs}

The preceding sections have discussed mechanisms that transfer flammable gases from the source tank to the DCRT with the waste. Waste within a DCRT, however, continues to generate flammable gas through radiolysis, thermolysis, and corrosion of the DCRT wall. The concentrations of flammable gas mixtures in DCRTs therefore also depend on the generation rate of gases of interest. This section discusses the applicability of current gas generation models for estimating gas generation rates in DCRTs.

While flammable gas generation rates in Tanks SY-101 and SY-103 have been reasonably well established through laboratory studies and tank behavior observations, there are many other tanks for which such rates are not known but are desired. Both Hopkins (1994, 1995) and Graves (1994) have developed equations to estimate the rate of hydrogen generation from tank wastes as a function of temperature and waste composition. Kinetic gas generation parameters determined in laboratory tests by Bryan et al. (1996) and Person (1996) using actual waste samples were not available when the reports by Hopkins $(1994,1995)$ and Graves (1994) were prepared. Incorporating recently determined kinetic parameters allows us to make incremental improvements in the estimates of Hopkins and Graves.

The thermal and radiolytic calculations summarized by $\mathrm{Hu}$ (1997) are based on the thermal and radiolytic models first outlined by Hopkins (1994) and Graves (1994), as modified by Pederson and Bryan (1996). The flammable gas mixtures in DCRTs reported by Hedengren et al. (1997) were calculated using the equations and models summarized by $\mathrm{Hu}$ (1997). These same equations and models were also used in modeling in this report, as described in Section 9.

As discussed in the following sections, it is appropriate to use the gas generation equations and models summarized by $\mathrm{Hu}$ (1997) for predicting the hydrogen gas generation rates from DCRTs. There are large uncertainties and differences in tank-to-tank waste components, however, and the models use only a few parameters related to waste composition as inputs to predict gas generation rates. In the absence of other means to predict gas generation rates in the DCRTs, the models used by Hedengren and Hu do represent the best prospect for estimating these rates.

To understand the applicability and limitations of the gas generation model used in DCRT modeling, the next three sections provide a chronology of the derivation of the model. Section 5.1 briefly summarizes historical hydrogen generation rate models. Sections 5.2 and 5.3 provide models that incorporate recently determined hydrogen generation rate parameters, which are the same models used in DCRT studies, and Section 5.4 compares field measured rates with the hydrogen generation rates calculated from the same models used in DCRT modeling.

\subsection{Hydrogen Generation Rate Estimates Proposed by Hopkins and Graves}

Hopkins (1994) used hydrogen generation rates determined for the waste in Tank SY-101 as the baseline to estimate hydrogen generation rates for other waste compositions based on their total organic carbon (TOC) content, aluminum content, and temperature. Thermal and radiolytic contributions to hydrogen generation rates were treated separately. 


\subsubsection{Thermolytic Rates (Hopkins and Graves)}

For the thermally activated component of hydrogen generation, differences in waste temperature were accounted for using Eq. (5.1) if a particular waste was cooler than that in Tank SY-101 and Eq. (5.2) if the waste was warmer:

$$
\begin{aligned}
& r_{t, X}=r_{t, S Y-101} \frac{[\mathrm{TOC}]_{X}}{[\mathrm{TOC}]_{\mathrm{SY}-101}} \frac{[\mathrm{Al}]_{\mathrm{X}}}{[\mathrm{Al}]_{\mathrm{SY}-101}} \exp \left(-26.0\left(\frac{1}{\mathrm{~T}_{\mathrm{X}}}-\frac{1}{\mathrm{~T}_{\mathrm{SY}-101}}\right)\right) \\
& \left(\mathrm{T}_{\mathrm{X}}<47 \mathrm{C}\right) \\
& \mathrm{r}_{\mathrm{t}, \mathrm{X}}=\mathrm{r}_{\mathrm{t}, \mathrm{SY}-101} \frac{[\mathrm{TOC}]_{\mathrm{X}}}{[\mathrm{TOC}]_{\mathrm{SY}-101}} \frac{[\mathrm{Al}]_{\mathrm{X}}}{[\mathrm{Al}]_{\mathrm{SY}-101}} \exp \left(-90.0\left(\frac{1}{\mathrm{~T}_{\mathrm{X}}}-\frac{1}{\mathrm{~T}_{\mathrm{SY}-101}}\right)\right) \\
& \left(\mathrm{T}_{\mathrm{X}}>47 \mathrm{C}\right)
\end{aligned}
$$

where

$\mathrm{r}_{\mathrm{t}} \quad=$ the thermolytic hydrogen generation rate per unit waste; $\mathrm{X}$ denotes the waste for which the rate is being calculated, SY-101 denotes the rate for Tank 241-SY-101

$[\mathrm{TOC}]=\%$ TOC in the waste

$[\mathrm{Al}]=\% \mathrm{Al}$ in the waste

$\mathrm{T}=$ the absolute temperature $(\mathrm{K})$ of the waste.

An activation energy of $26 \mathrm{~kJ} / \mathrm{mol}$ for estimating generation rates for temperatures less than that of Tank SY-101, while much smaller than that observed in any laboratory tests with either simulated or actual wastes, was selected to provide conservatism (Hopkins 1994). The base hydrogen generation rate in Tank SY-101 was given by Hopkins as $2.37 \times 10^{-4} \mathrm{ft}^{3} \mathrm{H}_{2}$ per $\mathrm{ft}^{3}$ of waste per day $\left(5.76 \times 10^{-9} \mathrm{~mole}_{2}\right.$ per liter waste per minute, or $5.27 \times 10^{-6}$ moles $\mathrm{H}_{2}$ per kilogram of waste per day), assuming a waste density of $1.59 \mathrm{~g} / \mathrm{cm}^{3}$.

Graves (1994) selected the baseline hydrogen generation rate reported by Meisel et al. (1993) for the simulant "POI" at $90^{\circ} \mathrm{C}$. This material has also been identified as simulant SY1SIM-91C in Bryan and Pederson (1994). Containing sodium nitrite, sodium nitrate, sodium aluminate, sodium hydroxide, water, and no carbonate, this simulant is virtually identical to the one used at the Georgia Institute of Technology, SY1-SIM-91B-NC. The designation "O" in "POI" indicates that the organic components of the simulants were $0.065 \underline{\mathrm{M}}$ EDTA, $0.65 \underline{\mathrm{M}}$ HEDTA, and $0.10 \mathrm{M}$ sodium citrate (Meisel et al. 1993). Corrections in estimated rates were made by Graves (1994) based on the TOC content and the liquid volume fraction of the wastes being compared. An Arrhenius expression with an activation energy of $40.9 \mathrm{~kJ} / \mathrm{mol}$ was used to calculate waste behavior at different temperatures, this being the value reported by Meisel et al. (1993) for hydrogen generation by glyoxylate. The expression used was

$$
r_{t, X}=r_{t, P O I} \frac{\left[T_{O}\right]_{X}}{[T O C]_{P O I}} \frac{\alpha_{L, X}}{\alpha_{L, P O I}} \exp \left(-40.9\left(\frac{1}{T_{X}}-\frac{1}{T_{P O I}}\right)\right)
$$

where 
$\mathrm{r}_{\mathrm{t}}=$ the thermolytic hydrogen generation rate per unit waste; $\mathrm{X}$ denotes the waste for which the rate is being calculated, POI denotes the rate for simulant POI

$[\mathrm{TOC}]=\%$ TOC in the waste

$\alpha_{\mathrm{L}} \quad=$ volume percent liquid in the waste (equal to $100 \%$ for the simulant).

The baseline hydrogen generation rate given by Meisel et al. (1993) for the simulant POI at $60^{\circ} \mathrm{C}$ is $8.3 \times 10^{-9} \mathrm{~mol} / \mathrm{min}-\mathrm{L}$, or $1.0 \times 10^{-5} \mathrm{moles} / \mathrm{kg}-\mathrm{d}$, assuming a density of $1.2 \mathrm{~g} / \mathrm{cm}^{3}$. No corrections were made for differences in sodium aluminate concentrations, as Hopkins did in Eq. (5.1) and (5.2).

\subsubsection{Radiolytic Rates (Hopkins and Graves)}

For the radiolytic portion of hydrogen generation, both Hopkins $(1994,1995)$ and Graves (1994) based their calculations on the form of a relation given in Eq. (5.4) developed by Meisel et al. (1991a, 1991b, 1991c, 1993). Meisel et al. (1993) found that the hydrogen yield increased approximately linearly with the concentration of $\mathrm{C}-\mathrm{H}$ and $\mathrm{N}-\mathrm{H}$ bonds present in the simulant, without regard to the identities of specific organic solutes. A relation was developed to estimate radiolytic hydrogen generation rates for each organic species:

$$
\mathrm{G}_{\mathrm{H} 2}=0.031+0.013 \eta_{\xi-\mathrm{H}}[\mathrm{R}]
$$

where

$$
\begin{aligned}
& \eta_{\xi-\mathrm{H}}=\text { the number of } \mathrm{C}-\mathrm{H} \text { and } \mathrm{N}-\mathrm{H} \text { bonds in a given organic molecule present in } \\
& \text { the wastes } \\
& {[R]=\text { the molar concentration of that organic component }} \\
& \mathrm{G}_{\mathrm{H} 2}=\text { the radiolytic yield, molecules of hydrogen produced per } 100 \mathrm{eV} \text { energy }
\end{aligned}
$$

Hopkins used a radiolytic yield, $\mathrm{G}\left(\mathrm{H}_{2}\right)=0.100$ molecules $/ 100 \mathrm{eV}$, that combines hydrogen produced from the radiolysis of water with that produced by radiolytic reactions involving organic solutes. Graves (1994) arrived at a similar yield, $\mathrm{G}\left(\mathrm{H}_{2}\right)=0.0977$ molecules $/ 100 \mathrm{eV}$. This yield is nearly double that obtained using Eq. (5.4), assuming all TOC in Tank SY-101 waste is EDTA.

\subsection{Modified Estimate of Hydrogen Generation}

Pederson and Bryan (1996) proposed an incremental improvement in expressions given by Hopkins $(1994,1995)$ and Graves (1994) for estimating the rate of hydrogen generation in Hanford wastes using kinetic parameters obtained recently in laboratory tests with actual waste samples. Bryan et al. (1996) obtained very good agreement between hydrogen generation rates estimated for Tank SY-103 from laboratory measurements and the actual tank observations reported by Wilkins (1995). They determined both the thermal and the radiolytic components of gas generation from Tank SY-103 wastes. Person (1996) likewise obtained very important kinetic parameters for gas generation from Tank SY-101 core composite samples. That study emphasized the effect of dilution with sodium hydroxide solution and the effect of oxygen as a cover gas on the rate and stoichiometry of gas generation. In consideration of the good 
statistical basis for kinetic parameters reported by Bryan et al. (1996) and agreement between laboratory and tank observations, Tank SY-103 is chosen as the baseline for estimating hydrogen generation in other waste tanks.

\subsubsection{Thermolytic Rates (modified)}

The thermal component of hydrogen generation was found by Bryan et al. (1996) to obey a simple Arrhenius behavior characterized by an activation energy of $91 \pm 9 \mathrm{~kJ} / \mathrm{mol}$ and a preexponential factor of $9 \mathrm{E} 08 \pm 1 \mathrm{E} 08 \mathrm{~mol} / \mathrm{kg}$ waste-day. The activation energy is similar to that chosen by Hopkins (1994) of $90 \pm 45 \mathrm{~kJ} / \mathrm{mol}$ for wastes maintained at temperatures greater than that in Tank SY-101 but with a substantial improvement in measurement uncertainty. In the results of Bryan et al. (1996), the indicated uncertainty in the activation energy for thermal hydrogen generation reflects a $95 \%$ confidence level.

Delegard (1980), Ashby et al. (1994), Bryan and Pederson (1994), and others have found first-order kinetic dependencies of hydrogen generation on hydroxide, aluminate, nitrite, and organic solute concentrations in studies with simulated wastes. Using correction factors in gas generation estimates for each of these waste components is not appropriate, however, because this behavior sometimes holds for only narrow concentration ranges. For example, first-order dependence on the nitrite ion concentration holds for concentrations up to approximately $0.5 \mathrm{M}$; for higher concentrations, gas generation rates are nearly independent of the nitrite ion concentration (Delegard 1980). A significant number of Hanford waste mixtures contain well over $0.5 \underline{\mathrm{M}}$ sodium nitrite, so minor differences in nitrite ion concentrations can be ignored. This rule holds for all the modeled tank wastes except those from T-104 and T-110, which are unusually dilute in all salts including nitrite.

Person (1996) studied the effect of diluting Tank SY-101 samples with sodium hydroxide solutions on the thermal rate of gas generation. The concentration of the diluent was chosen such that the sodium hydroxide concentration in the waste sample was insensitive to the extent of dilution. Person found that dilution of core composite samples to $65 \%$ of their original concentration of unsaturated components slowed the initial rate of gas generation to $52 \%$ of that determined for the undiluted sample. Dilution of the soluble organic fraction alone should lower the gas generation rate to $65 \%$ of that determined for the undiluted sample, as noted by Person. If the aluminate concentration and the soluble organic concentration were lowered by this same factor (and both show first-order kinetic dependencies), the rate should decrease to $(0.65)^{2}=42 \%$ of the original from the results of studies with simulated wastes. Similarly, first-order dependencies on aluminate, nitrite, and soluble organic concentrations should result in a decrease in the gas generation rate to $(0.65)^{3}=27 \%$ of the original value. Dissolution of any nitrite or aluminate present as solids in the original waste would decrease the effect of dilution on thermal gas generation rates. The results of Person (1996) are most consistent with the hypothesis that thermal gas generation reactions show first-order kinetic dependence on two components. Delegard (1980) found gas generation rates to be insensitive to the concentration of nitrite ions at the concentration of that component found in Tank SY-101. This leaves soluble organic solutes and aluminate ions as components on which thermal gas generation rates directly depend, consistent with the approach of Hopkins (1994, 1995).

A modified expression to estimate the thermal component of hydrogen generation from a given waste, based on Tank SY-103 behavior, is given in Eq. (5.5): 


$$
r_{t, X}=r_{t, S Y-103} \frac{[\mathrm{TOC}]_{X}}{[\mathrm{TOC}]_{S Y-103}} \frac{[\mathrm{Al}]_{\mathrm{X}}}{[\mathrm{Al}]_{\mathrm{SY}-103}} \exp \left(-91\left(\frac{1}{\mathrm{~T}_{\mathrm{X}}}-\frac{1}{\mathrm{~T}_{\mathrm{SY}-103}}\right)\right)
$$

where

$\mathrm{r}_{\mathrm{t}} \quad=$ the thermolytic hydrogen generation rate per unit waste; $\mathrm{X}$ denotes the waste for which the rate is being calculated, SY-103 denotes the rate for Tank 241-SY-103

$[\mathrm{TOC}]=\%$ TOC in the waste

$[\mathrm{Al}]=\% \mathrm{Al}$ in the waste

$\mathrm{T}=$ the absolute temperature $(\mathrm{K})$ of the waste.

The baseline rate for thermally activated hydrogen generation from Tank SY-103 is $3.5 \mathrm{x}$ $10^{-7} \mathrm{~mol} / \mathrm{kg} /$ day at $31.7^{\circ} \mathrm{C}$, as given by Bryan et al. (1996). Other parameters are (in wt\%) $\mathrm{TOC}=0.74 \%$ (convective layer) and $\mathrm{Al}=2.8 \%$ (Wilkins 1995). All of the $\mathrm{TOC}$ in the convective layer sample from SY-103 derived from soluble organic compounds; insoluble compounds such as oxalate should be excluded. Eq. (5.5) is identical in form to that originally proposed by Hopkins $(1994,1995)$ but with Tank SY-103 wastes rather than Tank SY-101 wastes used as the baseline.

Using TOC as a scaling parameter to predict gas generation capacity should be viewed with some caution. Baldwin et al. (1994) demonstrated that sensitivity factors vary widely for different organic compounds, from 0.1 to 1 depending on the method of analysis used (persulfate oxidation or total furnace oxidation). Unfortunately, there is no other measure of the organic solute content widely available for Hanford tank wastes. A method that applies vibrational spectroscopy to evaluate the concentration of specific organic functional groups is under development (Wahl et al. 1996). This approach shows considerable promise as a means to estimate the enthalpy of reaction of a complex mixture of organic solutes without requiring the precise identification of each organic component.

\subsubsection{Radiolytic Rates (modified)}

The radiolytic portion of hydrogen generation derives from two principal reactions (Meisel et al. 1993): the direct radiolysis of water and abstraction of a hydrogen atom from organic solutes by a hydrogen radical. Meisel et al. (1993) determined a $\mathrm{G}\left(\mathrm{H}_{2}\right)$ value for a simulated waste (simulant "P") in the absence of organics of 0.031 molecules $/ 100 \mathrm{eV}$. If the nitrate ion concentration is maintained at $0.5 \underline{\mathrm{M}}$ or higher and the nitrite ion concentration is $2 \underline{\mathrm{M}}$ or higher, hydrogen yields from direct water radiolysis are not expected to vary substantially from the given value for different waste mixtures. Meisel et al. (1993) developed a correlation between hydrogen generation rates by radiolysis and the total $\mathrm{C}-\mathrm{H}$ and $\mathrm{N}-\mathrm{H}$ bond density, given as Eq. (5.4). Unfortunately, it is difficult to apply that correlation to actual wastes because detailed organic compositional information is available for only a small number of tanks.

Bryan et al. (1996) determined a $\mathrm{G}\left(\mathrm{H}_{2}\right)$ value of $0.14 \pm 0.02$ molecules $/ 100 \mathrm{eV}$ for the convective layer of Tank SY-103. The organic fraction contains principally chelators and chelator fragments, with a TOC value in the convective layer of $0.74 \mathrm{wt} \%$ (Campbell et al. 1996). The hydrogen yield due to radiolytic reactions involving organic solutes can be estimated by subtracting the $\mathrm{G}\left(\mathrm{H}_{2}\right)$ value for radiolysis of a simulated waste containing no organic solutes $(0.031$ molecules $/ 100 \mathrm{eV})$ from the total $\mathrm{G}\left(\mathrm{H}_{2}\right)$ value for the waste $(0.14 \pm 0.02$ molecule) to 
give 0.11 molecules of hydrogen per $100 \mathrm{eV}$. Normalizing to the organic carbon content, the radiolytic yield of hydrogen from an organic source is $0.11 / 0.74=0.15 \pm 0.05$ molecules of hydrogen per $100 \mathrm{eV}$ per gram TOC, assuming a $20 \%$ relative uncertainty in the TOC concentration. The estimated radiolytic hydrogen yield for a waste, consistent with recent results of Bryan et al. (1996) and Eq. (5.5) (Meisel et al. 1993), is thus

$$
\mathrm{G}\left(\mathrm{H}_{2}\right)=0.031+0.15[\mathrm{TOC}]
$$

The term in Eq. 5.6 associated with radiolytically generating hydrogen in the absence of organics $(0.031$ molecules $/ 100 \mathrm{eV})$ is valid under waste conditions where the nitrate and nitrite concentrations are higher than approximately $0.5 \underline{\mathrm{M}}$. Several tanks contain sufficiently low nitrate and nitrite concentrations, which could significantly alter, and increase, the G-values for hydrogen generation from the baseline value of 0.031 molecules $/ 100 \mathrm{eV}$. An empirical formula (Eq. 5.7) given by Tabata (1991) relates the variability of the G-value for hydrogen production in nitrite and nitrate brines. For low nitrite and/or nitrate wastes, the predicted G-value for hydrogen production from water radiolysis (no organics) could exceed the baseline value of 0.031 . In these instances, the value 0.031 in Eq. 5.6 should be substituted for $\mathrm{G}\left(\mathrm{H}_{2}\right)_{\text {nitrate, nitrite }}$ from $\mathrm{Eq} 5.7$.

$$
\mathrm{G}\left(\mathrm{H}_{2}\right)_{\text {nitratenitrite }}=0.45-0.31 *\left[\mathrm{NO}_{2}^{-}\right]^{1 / 3}-0.41 *\left[\mathrm{NO}_{3}^{-}\right]^{1 / 3}
$$

where

$\left[\mathrm{NO}_{2}^{-}\right]=$molar concentration of nitrite in solution

$\left[\mathrm{NO}_{3}{ }^{-}\right]=$molar concentration of nitrate in solution .

Eq. (5.6) estimates about a factor of 2 more radiolytic production of hydrogen than Hopkins (1994) or Graves (1994) for Tank SY-101 for a specified radiation dose rate. Again, we caution that TOC is a less than ideal parameter. Baldwin et al. (1994) demonstrated at least a factor of 10 variation in sensitivity factors for different organic compounds. Some compounds that contribute to TOC have little or no gas generation capacity. But in the absence of a better global characterization of the organic content of a given waste, TOC is used.

\subsection{Rate of Generation by Corrosion}

As well as the thermolytic and radiolytic hydrogen generation rates discussed in Section 5.2, Hu's total hydrogen generation estimate also included a factor for tank wall corrosion that assumes a corrosion rate of $0.1 \mathrm{mil} / \mathrm{yr}$ and a stoichiometry of 1 mole of hydrogen generated per mole of iron corrosion (Hu 1997). Although the established corrosion allowance for these tanks is $1 \mathrm{mil} / \mathrm{yr}$, corrosion rates measured in simulated Hanford wastes under thermal and irradiated conditions show steel corrosion rates on the order of $0.01 \mathrm{mil} / \mathrm{yr}$ (Strachan 1994). The low corrosion rates were measured under conditions of high $\mathrm{pH}(>13)$ where the mild steel is expected to be passivated (Porbaix 1974). Even under the reduced $\mathrm{pH}$ conditions of some SSTs (as low as 9.5), the mild steel is expected to remain passive (Wodrich et al. 1992). Under conditions of neutral or acidic $\mathrm{pH}-\mathrm{a}$ condition not expected in Hanford wastes-the mild steel is expected to be strongly corroded, and expected corrosion rates would be much higher than the allowance of $1 \mathrm{mil} / \mathrm{yr}$ (Pourbaix 1974; Elmore 1997). For Hanford wastes with adequately high $\mathrm{pH}$ control, Hu's assumption for corrosion rates is appropriately conservative. 


\subsection{Comparison of Calculated Hydrogen Release Rates at Steady-State and Field-Measured Values for Hanford Wastes}

This section compares the calculated hydrogen release rates at steady state from models used by $\mathrm{Hu}$ and Hedengren with field-measured values from Wilkins et al. (1997a). As discussed in detail in this section, the gas generation model used by Hedengren and Hu predicts gas generation within a factor of 2 or better for DST wastes. When used to predict SST wastes, which are of concern for DCRT operations, the model consistently overpredicts hydrogen gas generation. The model used for predicting the hydrogen gas generation rates from DCRTs is used appropriately. It should be noted that there is great uncertainty and difference in tank-totank waste components, and the models use only few parameters related to waste composition as inputs to predict gas generation rates. However, in the absence of any other means to predict gas generation rates in the DCRTs, the models used by Hedengren and Hu do represent the best prospect for estimating these rates.

The thermal and radiolytic calculations summarized by $\mathrm{Hu}$ (1997) and used in DCRT modeling are based on the thermal and radiolytic models first outlined by Hopkins (1994) and Graves (1994), as modified by Pederson and Bryan (1996). The flammable gas mixtures in DCRTs reported by Hedengren et al. (1997), and re-estimated in Section 9 of this report, were calculated using the equations and models summarized by $\mathrm{Hu}$ (1997).

Using the thermal, radiolytic, and corrosion models outlined above, $\mathrm{Hu}$ calculated the steady-state hydrogen gas generation rates for seven Hanford DSTs and compared these values with field measurement data available for these tanks (Wilkins et al. 1997a). The comparisons between model and field data were made for Tanks AN-103, AN-104, AN-105, AW-101, AY102, SY-101, and SY-103. The results of this comparison are shown in Table 5.1.

The gas generation rates determined by the model overestimate the amount of hydrogen gas generated for all waste types in Table 5.1 except for AW-101. For AW-101, the ratio of the predicted versus the field data was 0.74 , which represents an underestimate of $26 \%$ by the model. When evaluating the ability of the model to predict measured hydrogen generation rates, the measured $\mathrm{H}_{2} / \mathrm{N}_{2} \mathrm{O}$ product ratio (shown in Table 5.1) in the headspaces of these tanks provides some insight into the conservatism of the model. For most tanks, the headspace $\mathrm{H}_{2} / \mathrm{N}_{2} \mathrm{O}$ ratio ranges from approximately 1 to 15 . For the tanks with a hydrogen-to-nitrous oxide ratio in this range, the model is accurate and slightly overpredicts hydrogen. For AW-101, the $\mathrm{H}_{2} / \mathrm{N}_{2} \mathrm{O}$ ratio is approximately 33, much higher than for the other tanks. We believe the inability of the model to predict the hydrogen generation rate for AW-101 is related to the unusually high $\mathrm{H}_{2} / \mathrm{N}_{2} \mathrm{O}$ ratio.

Figure 5.1 shows a comparison of predicted and measured hydrogen generation rates from Table 5.1 as a function of the headspace $\mathrm{H}_{2} / \mathrm{N}_{2} \mathrm{O}$ ratio. The data are grouped by waste type: the complexant concentrate (CC) wastes (SY-101 and SY-103) are in one group, the double-shell slurry feed (DSSF) and double-shell slurry wastes (AN-103, AN-104, AN-105, and AW-101) compose a second group. The trend in the data suggests that the higher the $\mathrm{H}_{2} / \mathrm{N}_{2} \mathrm{O}$ ratio, the less the model tends to overpredict the hydrogen generation from the waste. For AW-101 waste $\left(\mathrm{H}_{2} / \mathrm{N}_{2} \mathrm{O} \sim 33\right)$, the model underpredicts hydrogen generation. 
Table 5.1. Comparison of Model and Field Data Hydrogen Generation Rates for DSTs (Hu 1997)

\begin{tabular}{|c|c|c|c|c|}
\hline Tank ID & $\begin{array}{c}\text { Total } \mathrm{H}_{2} \\
\text { generation rate } \\
\text { using field data } \\
\text { (cfm) }\end{array}$ & $\begin{array}{c}\text { Total } \mathrm{H}_{2} \\
\text { generation rate } \\
\text { using model } \\
\text { (cfm) }\end{array}$ & $\begin{array}{c}\text { Ratio of } \mathrm{H}_{2} \\
\text { generation rate } \\
\text { between model } \\
\text { and field data }\end{array}$ & $\begin{array}{c}\mathrm{H}_{2} / \mathrm{N}_{2} \mathrm{O} \text { ratio } \\
\text { from field data }\end{array}$ \\
\hline $241-\mathrm{AN}-103$ & $4.28 \mathrm{E}-3$ & $5.05 \mathrm{E}-3$ & 1.18 & 15 \\
\hline $241-\mathrm{AN}-104$ & $4.35 \mathrm{E}-3$ & $5.9 \mathrm{E}-3$ & 1.36 & 7 \\
\hline $241-\mathrm{AN}-105$ & $5.06 \mathrm{E}-3$ & $7.4 \mathrm{E}-3$ & 1.46 & 6.9 \\
\hline $241-\mathrm{AW}-101$ & $5.8 \mathrm{E}-3$ & $4.3 \mathrm{E}-3$ & 0.74 & 33 \\
\hline $241-\mathrm{AY}-102$ & $1.05 \mathrm{E}-2$ & $1.78 \mathrm{E}-2$ & 1.70 & - \\
\hline $241-\mathrm{SY}-101$ & $2.9 \mathrm{E}-2$ & $3.65 \mathrm{E}-2$ & 1.25 & 1.48 \\
\hline $241-\mathrm{SY}-103$ & $5.11 \mathrm{E}-3$ & $5.9 \mathrm{E}-3$ & 1.15 & 2.5 \\
\hline \multicolumn{5}{|l|}{ (a) Ratios of $\mathrm{H}_{2} / \mathrm{N}_{2} \mathrm{O}$ from field data are summarized in Pederson and Bryan 1996. } \\
\hline
\end{tabular}

The reason for the relatively high $\mathrm{H}_{2} / \mathrm{N}_{2} \mathrm{O}$ ratio observed in AW-101 relative to other tanks is not known but is of interest. The presence of molecular oxygen has been found to have a marked effect on the distribution of gaseous products formed in thermally activated reactions involving HEDTA (Barefield et al. 1995, 1996). Yields of hydrogen were significantly enhanced in the presence of an oxygen-containing cover gas, while yields of nitrogen-containing gaseous products (nitrous oxide, nitrogen, and ammonia) were reduced. Camaioni et al. (1995, 1996) observed similar trends in aging studies dominated by radiolytic reactions. While the mechanism responsible for this behavior is not well understood, it is expected that oxygen reacts with active

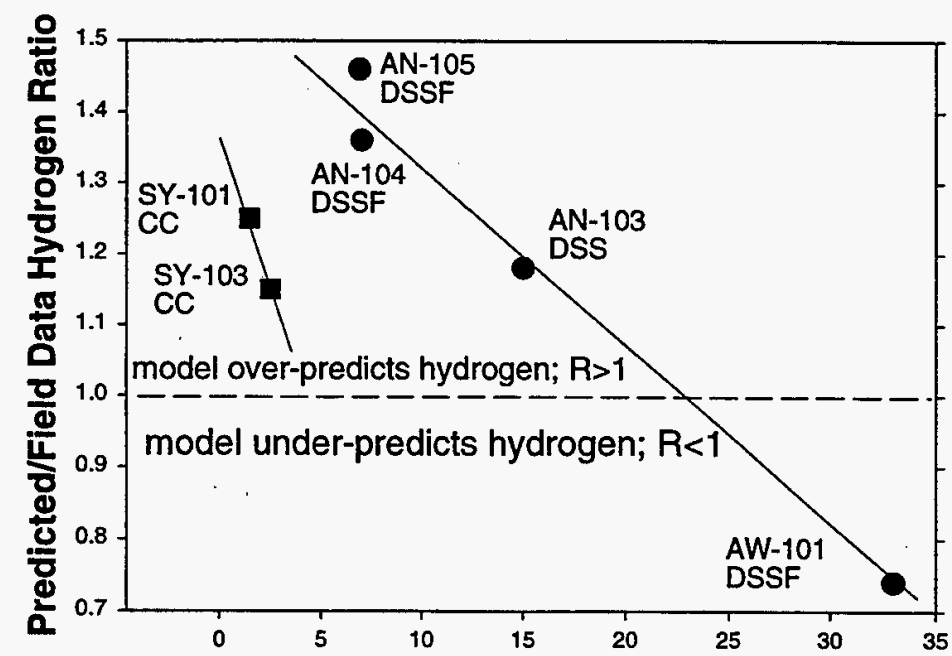

$\mathrm{H}_{2} / \mathrm{N}_{2} \mathrm{O}$ Product Ratio

Figure 5.1. Comparison of Hydrogen/Nitrous Oxide Product Ratios to Model (predicted)/Field Data Hydrogen Ratios for DSTs 
nitrogen oxide radicals that otherwise would eventually form nitrogen-containing gases (Meisel et al. 1993; Camaioni et al. 1995, 1996; Barefield et al. 1996). Thus, oxygen reactions could be related to the correlation between the $\mathrm{H}_{2} / \mathrm{N}_{2} \mathrm{O}$ ratio and the hydrogen generation rate shown in Figure 5.1.

Including oxygen in the cover gas of laboratory tests led to an increase in the overall rate of gas generation (Person 1996). Hydrogen production was significantly increased and oxygen was consumed, while nitrous oxide and nitrogen yields remained essentially unchanged. Studies with simulated wastes conducted by Barefield et al. (1996), Camaioni et al. (1995, 1996), and Meisel et al. (1993) found that oxygen enhanced hydrogen production but depressed the formation of nitrogen-containing gases. Long diffusion times preclude atmospheric oxygen from being an effective source in most waste tanks. However, oxygen will be produced radiolytically in low concentrations, as described by Meisel et al. (1993). Oxygen will probably be rapidly consumed by reaction with organic solutes in tanks such as 101-SY and SY-103, but it may build up in tanks containing low concentrations of reactive organic solutes or in relatively cool wastes.

Field data for SSTs have been compared with gas generation rates predicted from the model summarized in $\mathrm{Hu}$ (1997). These values are summarized in Table 5.2. As can be seen from this table, the model overpredicts the amount of hydrogen generation in all cases except $U$ 105. The overprediction is not unexpected, since the model is based on waste types (DST CC waste) containing relatively active organic complexants compared with the waste types in the SSTs. The relative oxalate concentration of CC waste in SY-103 is less than $10 \%$ TOC; the balance is reactive chelators and chelator fragments. In contrast, the relative fraction of TOC in many SSTs is much higher than 50\% oxalate (Carlson 1997), indicating that less than half the TOC in SSTs is available for hydrogen-producing reactions.

Table 5.1 includes the hydrogen/nitrous oxide gas product ratios measured in the headspaces of these tanks. As with the DSTs above, Figure 5.2 shows a comparison of predicted and measured hydrogen generation rates from SST data in Table 5.2 as a function of the $\mathrm{H}_{2} / \mathrm{N}_{2} \mathrm{O}$ ratio. Broadly speaking, the conservatism in the hydrogen generation model increases (with considerable scatter) as the $\mathrm{H}_{2} / \mathrm{N}_{2} \mathrm{O}$ ratio increases, the opposite of the trend seen in DSTs. In this figure, the data do not group according to waste type (noncomplexed [NCPLX] versus DSSF). However, there is an apparent grouping depending on the Hanford Tank Cluster Designation value (HTCE) as described by Remund et al. (1995). This grouping may provide some insight into the uncertainty that variations in waste composition introduce into hydrogen generation rate predictions.

The measured hydrogen generation rates from waste types described in Remund et al. (1995) from HTCE group \#13 correlate very well with calculated hydrogen generation rates. The ratio of predicted to measured hydrogen generation rates varied from 0.75 to 2 for all the wastes within HTCE group \#13, an agreement which is surprisingly good given the basic differences among the waste types in the SSTs for which the hydrogen rates were predicted and the DSTs from which the hydrogen generation models were derived. The HTCE \#13 group has, as their primary and secondary waste types, either saltcake from the S1 evaporator campaign or salt slurry from the S2 evaporator campaign. Tank U-105 contains the only waste for which the predicted hydrogen generation rate is less than the measured; it also has the second-lowest headspace $\mathrm{H}_{2} / \mathrm{N}_{2} \mathrm{O}$ ratio. 
Table 5.2. Comparison of Model and Field Data Hydrogen Generation Rates for SSTs

\begin{tabular}{|c|c|c|c|c|c|c|}
\hline Tank ID & $\begin{array}{c}\text { Model } \\
\text { prediction of } \\
\text { hydrogen } \\
\text { generation } \\
\left(\mathrm{m}^{3} / \mathrm{day}\right)\end{array}$ & \begin{tabular}{|c|} 
In-Tank \\
measurement \\
of hydrogen \\
generation \\
$(\mathrm{a})$ \\
$\left(\mathrm{m}^{3} / \mathrm{day}\right)$ \\
\end{tabular} & $\begin{array}{c}\text { Ratio of } \mathrm{H}_{2} \\
\text { generation rate } \\
\text { between model } \\
\text { and field data }\end{array}$ & $\begin{array}{c}\mathrm{H}_{2} / \mathrm{N}_{2} \mathrm{O} \\
\text { ratio } \\
\text { from } \\
\text { field data } \\
\text { (b) }\end{array}$ & $\begin{array}{l}\text { Waste } \\
\text { type }\end{array}$ & $\begin{array}{l}\text { HTCE cluster } \\
\text { designation }^{(\mathrm{c})}\end{array}$ \\
\hline S-102 & 0.077 & 0.066 & 1.2 & 2.78 & DSSF & $\# 13$ \\
\hline S-111 & 0.045 & 0.009 & 5 & 5 & NCPLX & $\# 20$ \\
\hline S-112 & 0.106 & 0.004 & 26.5 & 3.5 & NCPLX & $\# 20$ \\
\hline SX-103 & 0.317 & 0.052 & 6.1 & 4.2 & NCPLX & $\# 20$ \\
\hline SX-105 & 0.409 & 0.028 & 14.6 & 5.4 & DSSF & $\# 20$ \\
\hline SX-106 & 0.1 & 0.05 & 2 & 2.7 & NCPLX & $\# 13$ \\
\hline U-103 & 0.148 & 0.118 & 1.26 & 0.81 & NCPLX & $\# 13$ \\
\hline U-105 & 0.133 & 0.178 & 0.75 & 0.4 & NCPLX & $\# 13$ \\
\hline $\mathrm{U}-107$ & 0.058 & 0.052 & 1.11 & 0.74 & DSSF & $\# 13$ \\
\hline U-108 & 1 & 0.068 & 1.47 & 1.08 & NCPLX & $\# 13$ \\
\hline & & & & & & \\
\hline
\end{tabular}

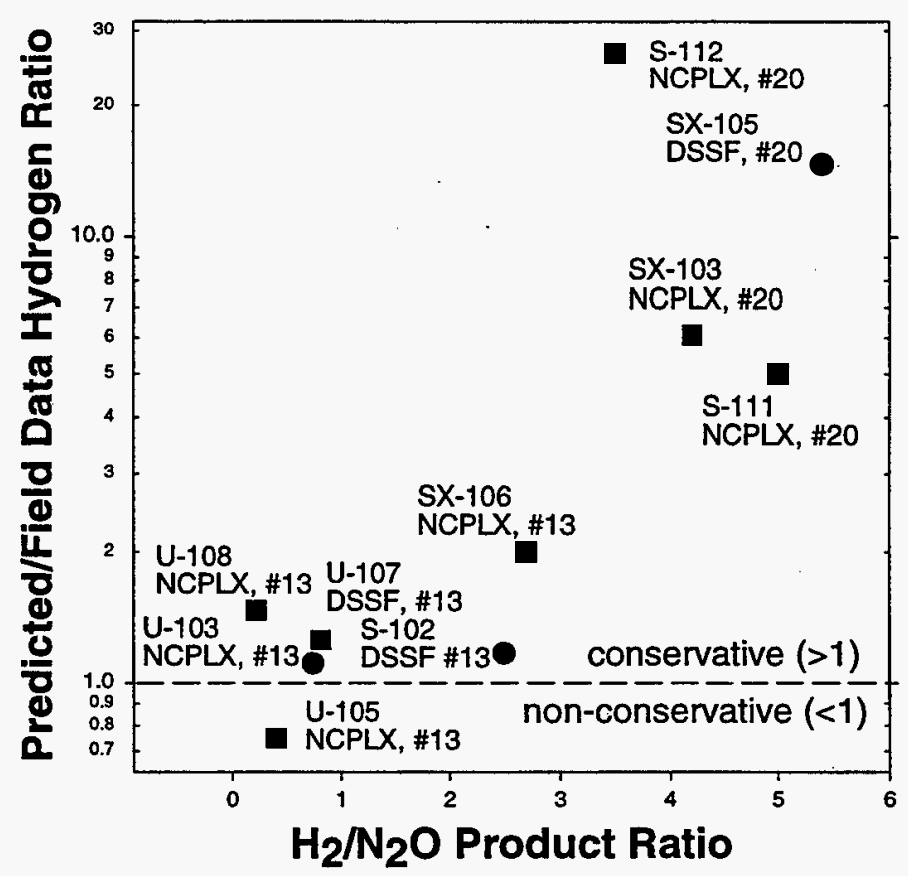

Figure 5.2. Comparison of Hydrogen/Nitrous Oxide Product Ratios to Model (predicted)/Field Data Ratios for SSTs 
The measured hydrogen generation rates from waste types described in Remund et al. (1995) from HTCE group \#20 show a very poor correlation to calculated hydrogen generation rates. The ratio of predicted-to-measured hydrogen generation rates varies from 5 to 26.7 for all the wastes within that group. The HTCE group $\# 20$ has as its primary waste source saltcake from the S1 evaporator campaign. Its secondary waste source varies but most commonly originates from REDOX (1952-1958) or aluminum cladding REDOX waste (1961-1967). Because the gas generation models were based on DST complex concentrate wastes, high in organic carbon and rich in chelator and chelator fragments, it is not surprising that the predictions for hydrogen generation rates tend to be biased high.

\subsection{Summary}

The model for thermal and radiolytic gas generation summarized by Hu (1997) and used by Hedengren et al. (1997) has predictive capabilities within a factor of 2 or better, and except for Tank AW-101 (discussed above), the model always overpredicts hydrogen generation rates in DSTs. When used to predict SST wastes, which are of concern for DCRT operations, the model also consistently overpredicts. We conclude that the model is used appropriately for predicting the hydrogen gas generation rates from DCRTs. There is great uncertainty and difference in tank-to-tank waste components, and the models use only few parameters related to waste composition as inputs to predict gas generation rates. However, in the absence of any other means to predict gas generation rates in the DCRTs, the models used by Hedengren and Hu do represent the best prospect for estimating these rates.

Hu's total hydrogen generation estimate also included a factor for tank wall corrosion that assumes a corrosion rate of $0.1 \mathrm{mil} / \mathrm{yr}$, compared to the established corrosion allowance for these tanks of $1 \mathrm{mil} / \mathrm{yr}$ and corrosion rates measured in high-pH simulants on the order of $0.01 \mathrm{mil} / \mathrm{yr}$. For Hanford wastes with adequately high $\mathrm{pH}$ control, Hu's assumption for corrosion rates overestimates hydrogen generation from this source. 


\subsection{Gas Retention in a Nonconvective Layer}

Flammable gas that is generated by radiolysis and chemical reactions can accumulate in a nonconvective solid-liquid matrix that forms as solid particles settle out of or precipitate from a waste slurry. If sufficient gas is retained to make the nonconvective layer buoyant, a buoyant displacement instability may occur that can release a large fraction of the retained gas into the tank's headspace. Even if the nonconvective layer does not become buoyant, its retained gas will be released if the waste matrix is disrupted. In any case, the potential for formation of a nonconvective layer and the consequences of gas retention and release therefrom must be considered in assessing the flammable gas hazard in DCRTs. The factors discussed in this section show that, although there is a potential for significant gas retention and release, the LFL is not likely to be exceeded and the time required to form the nonconvective layer and accumulate gas is so long that it is a concern only in very abnormal DCRT operations.

\subsection{Formation of a Nonconvective Layer in a DCRT}

The system is designed to avoid transferring solids sufficiently large to settle out in the DCRT during normal salt-well pumping operations. Solid particles sufficiently small to flow with the liquid would remain suspended. On the way to the DCRT, a solid particle must be sufficiently small to migrate through the pore structure in the waste, through the salt-well screen, and be entrained by the pump. Only particles with a diameter less than about 10 microns satisfy these criteria (see the discussion in Section 3). A 10-micron particle requires on the order of a month to settle through 3 meters of liquid. The settling time for a 1-micron particle, which are the most numerous in wastes in which size distributions have been measured (see Herting et al. 1992 , for example), is on the order of one year.

Given that essentially no solids that can settle are transferred in, a significant nonconvective solids layer can form in a DCRT only by precipitating from the liquid when solubility is reduced. The most likely cause of a reduction of solubility in a DCRT is cooling of the liquid transferred from a warmer tank. This process would primarily precipitate sodium salts.

Precipitation due to cooling is clearly evident in some core samples. Segments from the lower liquid layer of A-101 contained 8-17 cm of solids when extruded in the hot cell (Field et al. 1997). This large amount of solid material is attributed to precipitation since the uniform temperature profile, the absence of gas found in RGS samples, or the x-ray images taken immediately after the samples were removed from the tank indicate the material was a liquid in situ (Shekarriz et al. 1997). The temperature of A-101 liquid samples decreased from $60^{\circ} \mathrm{C}$ in the tank to about $38^{\circ} \mathrm{C}$ in the hot cell, a $22^{\circ} \mathrm{C}$ difference. This caused $50-130$ grams of solids to form in the sampler, with a bulk density of $1750 \mathrm{~kg} / \mathrm{m}^{3}$ measured in the hot cell. Assuming complete sample recovery of a $310 \mathrm{~mL}$ sampler volume (consistent with $\mathrm{x}$-rays), the solids volume fraction averages about 0.18 . This implies that, if either an S- or BX-type DCRT were filled to operating capacity with liquid from the lower layer in A-101 and allowed to cool as much as the sample did in the hot cell, a nonconvective solids layer 0.75 to $0.8 \mathrm{~m}$ deep would precipitate. 
Though this depth of nonconvective material is significant, a very long time is required for the waste to cool enough to precipitate it. If the specific heat of the waste is $3000 \mathrm{~J} / \mathrm{kg}-\mathrm{K},{ }^{(2)}$ if ventilation air flows around the exterior of the tank at $2.8 \mathrm{~m}^{3} / \mathrm{min}(100 \mathrm{cfm})$, and if the ventilation air temperature is assumed to rise $10^{\circ} \mathrm{C}$ from inlet to exhaust, it would take 118 days for the S DCRT and 172 days for a BX-type DCRT to cool to $38^{\circ} \mathrm{C}$. This is far longer than the liquid would be allowed to remain in the DCRT in normal practice. Such cooling, with its attendant solids precipitation, would be of concern only in an off-normal event where waste could not be transferred out of the tank for an extended period.

Solubility may also be reduced due to $\mathrm{pH}$ changes or chemical reactions when waste streams are mixed. This process could precipitate aluminum hydroxide as a colloidal gel upon mixing, without the long time delay associated with cooling described above. Gel formation is a complex, somewhat controversial issue, and a full discussion is beyond the scope of this document. Suffice it to say that, while not completely quantifiable and not very probable, the formation of a significant nonconvective layer in a DCRT cannot be ruled out.

Therefore, we shall investigate gas retention and release in DCRTs as a parametric study, varying the nonconvective layer depth over the full operating depth of the tanks rather than attempting to determine a specific depth of precipitated solids. By doing this, all possibilities are covered. However, the analyses to follow will show that there is a relatively narrow range of layer depths for which a large, sudden gas release is possible, and even the largest of these do not cause the tank headspace to exceed the LFL. Also, such a release would require on the order of a year for sufficient gas to accumulate and thus would be of concern only in an off-normal event where waste remained the tank for an extended period.

\subsection{Potential for Gas Release from a DCRT Nonconvective Layer}

There are three questions to be answered in assessing the potential for gas release in waste configured as a nonconvective layer under a relatively deep layer of supernatant liquid (Johnson et al. 1997): 1) Can the waste retain sufficient gas to become buoyant? 2) If so, is the energy released during the buoyant displacement (rollover) sufficient to allow a significant gas release? and 3) If so, is a sufficiently large volume of gas released to make the tank headspace flammable? The following sections will treat each of these aspects in sequence.

\subsubsection{Potential for Buoyant Displacement Event}

A region of nonconvective waste becomes buoyant if gas accumulation causes its average density to become less than that of the supernatant liquid above it. At this point, the average gas fraction in the waste is equal to the gas fraction for neutral buoyancy, which is determined by the ratio of densities of the convective and nonconvective layer. The steady state gas fraction profile can be predicted as a function of nonconvective layer depth, densities, gas generation rate, and

(a) Calculation by LA Mahoney, PNNL. Personal communication, November 1997. 
temperature..$^{\left(a_{1}\right.}$ If the integral of the predicted steady state gas fraction profile exceeds the neutral buoyancy gas fraction, a buoyant displacement will have occurred before steady state is achieved.

The steady state void profile is predicted based on a balance between

- Gas release, which occurs solely by slow bubble migration that qualitatively obeys Stokes Law (see Eq. [6.4] below).

- The waste viscosity (determining bubble rise velocity), which increases linearly with waste depth from zero at the top of the nonconvective layer and the rate of increase (slope) is the same for all tanks.

- The steady-state void profile, which is a reasonable approximation of the actual void profile at the time the layer becomes buoyant, if it does so.

The second assumption is based on ball rheometer measurements on the five DSTs that are known to experience buoyant displacements (Meyer et al. 1997).

The model is described by gas mass and bubble number continuity along with equations for the bubble rise velocity and the gas state. The gas mass continuity equation is

$$
\frac{\mathrm{d}(\mathrm{mu})}{\mathrm{dz}}=\mathrm{G}(\mathrm{z})
$$

where $\mathrm{m}$ is the number of moles of gas per unit volume $\left(\mathrm{mol} / \mathrm{m}^{3}\right), u$ is the bubble velocity $\left(\mathrm{m} /\right.$ day), and $G$ is the volumetric gas generation rate $\left(\mathrm{mol} / \mathrm{m}^{3}\right.$-day). The bubble number continuity equation is

$$
\frac{\mathrm{d}(\mathrm{nu})}{\mathrm{dz}}=\mathrm{N}(\mathrm{z})
$$

where $\mathrm{n}$ is the number of bubbles per unit volume $\left(\# / \mathrm{m}^{3}\right)$ and $\mathrm{N}$ is the volumetric bubble nucleation rate $\left(\# / \mathrm{m}^{3}\right.$-day). The ideal gas equation of state is expressed as:

$$
(\mathrm{m} / \mathrm{n})=\mathrm{p}(\mathrm{z}) \mathrm{V}_{\mathrm{B}}(\mathrm{z}) / \mathrm{RT}(\mathrm{z})
$$

where $\mathrm{p}$ is the pressure $(\mathrm{Pa}), \mathrm{V}_{\mathrm{B}}$ is the average bubble volume, $\mathrm{R}$ is the gas constant $(8314 \mathrm{~J} / \mathrm{kg}$ $\mathrm{K}$ ), and $\mathrm{T}$ is the temperature $(\mathrm{K})$. The bubble velocity, $\mathrm{u}$, is computed by a modified version of Stokes law as follows:

(a) This model was developed for the Gas Release Event Safety Analysis Stage II Expert Panel Elicitation Workshop \#2, February 9-13, 1998, in Richland, Washington. The model is used in the analysis framework to determine whether a DST will have buoyant displacements and provides the steady-state void fraction in tanks that do not. A full derivation of the model will be published in PNNL11536 Rev. 2 in August 1998. 


$$
\mathrm{u}(\mathrm{z})=\mathrm{C} \frac{\rho_{\mathrm{S}} \mathrm{V}_{\mathrm{B}}^{2 / 3}}{\mu(\mathrm{z})}
$$

where $\rho_{s}$ is the nonconvective layer density and $\mu$ is the viscosity.

Assuming the nucleation rate and gas generation rates are uniform, and neglecting spatial variation of pressure and temperature (which have been shown to have a negligible effect), the solutions of Eq. (6.1) through (6.4) yield the following equation for the void fraction profile:

$$
\alpha(\eta)=\frac{C}{\rho_{S}}\left(\frac{R T}{p}\right)^{1 / 3} H^{2}(1-\eta)\left[G \eta+\frac{\alpha_{0} \rho_{S}}{C H^{2}}\left(\frac{p}{R T}\right)\right]^{1 / 3}\left[V_{0} N \eta+\frac{\alpha_{0} \rho_{S}}{C H^{2}}\right]^{2 / 3}
$$

where $\eta=\mathrm{z} / \mathrm{H}, \mathrm{H}$ is the nonconvective layer height, and $\alpha_{0}$ and $\mathrm{V}_{0}$ are the initial gas fraction and bubble volume, respectively, at $\mathrm{z}=0$.

There are two important limiting cases of Eq. (6.5). The first assumes a uniform nucleation rate and a zero initial void fraction. This simplification results in the following expression for the void profile:

$$
\alpha(\eta)=\frac{C}{\rho_{s}}\left(\frac{G T}{p}\right)^{1 / 3} H^{2} \eta(1-\eta)
$$

Where the nucleation rate is contained in the leading constant. The other limiting case is formed by setting the nucleation rate to zero, assuming all bubbles to enter at the lower boundary and grow due to gas generation as they rise. This case is expressed by

$$
\alpha(\eta)=C\left(\frac{G T}{\rho_{s} p}\right)^{1 / 3} H^{2 / 3} \eta^{1 / 3}(1-\eta)
$$

where the initial void fraction is contained in the leading coefficient. This case is probably more physical than the former because nucleation is suppressed by the presence of existing bubbles. Since it also provides somewhat more conservative predictions, Eq. (6.7) is chosen for application to DCRTs.

The leading coefficient, C, in Eq. (6.7) is adjusted so that the most stable of the six DSTs in which sudden large gas releases have been observed is predicted to be only just buoyant in the steady state (i.e., a buoyant displacement is just possible) by Eq. (6.7). This done, the model predicts that, with the possible exception of AN-107, ${ }^{(a)}$ the remaining 20 DSTs do not have buoyant displacement gas releases.

(a) The marginal result for AN-107 may be the result of either an artificially high gas generation rate predicted as a result of its high TOC or because of a low neutral buoyancy void fraction resulting from uncertainty in the nonconvective layer density. 
A model developed and calibrated for the DSTs is conceptually a good representation for any nonconvective layer that might form in a DCRT. Both wastes form by settling of solids precipitated from salt solution pumped from SSTs and both have considerable supernatant liquid. Except for scale, the waste configuration is almost identical.

The average void fraction depends on the nonconvective layer depth and gas generation rate. If the gas generation rate is high, buoyancy can occur in a relatively thin nonconvective layer. This is illustrated in Figure 6.1 where the ratio of average void fraction to neutral buoyancy void fraction is plotted against nonconvective layer depth for three gas generation rates. The waste is essentially buoyant at a void ratio of 1.0. The lowest gas generation rate represents SSTs that would feed the BX DCRT, the middle rate is typical of tanks that would feed the S-DCRT, and the highest is approximately that of SY-101, which shows the highest gas generation rate in Hanford tanks.

The figure shows that buoyancy can be achieved in nonconvective layers deeper than $\sim 0.75 \mathrm{~m}$ with representative gas generation rates. The BX DCRT is reported to contain a heel layer less than $0.6 \mathrm{~m}$ deep based on the known height of the lowest dip tube. ${ }^{(2)}$ This analysis clearly indicates that large buoyant displacement gas releases from this shallow layer are not of concern unless the gas generation rate is shown to be extremely high.

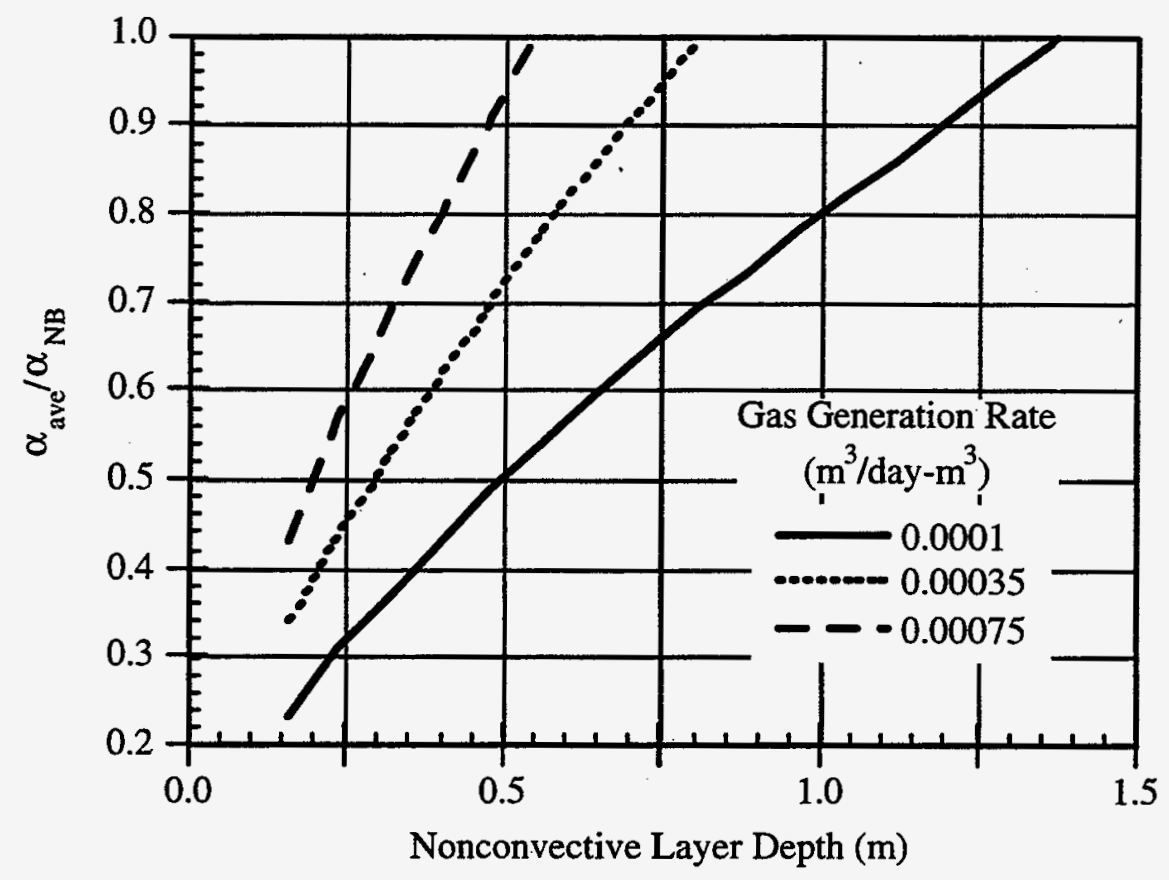

Figure 6.1. Void Ratio Versus Nonconvective Layer Depth

(a) Randy Powers, LMHC, personal communication December 1998. 


\subsubsection{Potential for Gas Release by Buoyant Displacement}

Even if the nonconvective layer becomes buoyant, the resulting instability must release sufficient energy to yield the material and release the retained gas. This requires a relatively deep layer of supernatant liquid. The ratio of buoyant energy released to energy required to yield the layer is given in Meyer et al. (1997). Assuming that the gas fraction at the initiation of the instability is equal to the neutral buoyancy value, the ratio is expressed as

$$
\frac{E_{b}}{E_{y}}=\frac{\alpha_{N B} \rho_{L} g H}{\left(1-\alpha_{N B}\right) \varepsilon_{y} \tau_{y}}((1+1 / \gamma) \ln (1+\gamma)-1)
$$

where

$$
\begin{aligned}
& \mathrm{E}_{\mathrm{b}}=\text { buoyant energy released }(\mathrm{J}) \\
& \mathrm{E}_{\mathrm{y}}=\text { energy required to yield the nonconvective waste }(\mathrm{J}) \\
& \alpha_{\mathrm{NB}}=\text { gas fraction at neutral buoyancy } \\
& \mathrm{P}_{\mathrm{L}}=\text { density of the supernatant liquid }\left(\mathrm{kg} / \mathrm{m}^{3}\right) \\
& \mathrm{g}=\text { acceleration of gravity }\left(\mathrm{m} / \mathrm{s}^{2}\right) \\
& \mathrm{H}=\text { depth of the supernatant liquid }(\mathrm{m}) \\
& \varepsilon_{\mathrm{y}}=\text { strain at complete yield }(\text { assumed equal to } 1.0) \\
& \tau_{\mathrm{y}}=\text { average yield stress }(\mathrm{Pa}) \\
& \mathrm{P}_{\mathrm{A}}=\text { atmospheric pressure }(101,320 \mathrm{~Pa})
\end{aligned}
$$

and the parameter $\gamma$ is given by

$$
\gamma=\rho_{\mathrm{L}} \mathrm{gH} / \mathrm{P}_{\mathrm{A}}
$$

The average yield stress can be estimated based on the observation from DST in situ rheology data (Meyer et al. 1997), that the yield stress increases linearly from zero at the top of the nonconvective layer with a slope of $1 \mathrm{~Pa} / \mathrm{cm}$. We also assume that the waste is completely yielded such that gas is released at $100 \%$ strain.

Based on the experimental evidence and the behavior of the DSTs that have large, sudden gas releases, the energy ratio must exceed 5 to allow a significant gas release. The energy ratio computed with Eq. (6.8) for a horizontal DCRT filled to operating capacity (2.74 m) exceeds 5 , indicating gas releases can occur, for nonconvective layer depths up to $1.1 \mathrm{~m}$ for $\alpha_{\mathrm{NB}}=0.1$ and $1.3 \mathrm{~m}$ for $\alpha_{\mathrm{XB}}=0.15 .^{\mathrm{a}}{ }^{2}$ Vertical S DCRTs at operating capacity $(3.74 \mathrm{~m})$ have sufficient energy to release gas with nonconvective layer depths up to $1.7 \mathrm{~m}$ and $2.0 \mathrm{~m}$, respectively. At greater depths, the energy ratio falls below 5.0 and there is insufficient buoyant potential energy to yield the material and release the gas.

The relationship of the nonconvective layer depth required for buoyancy at a given gas generation rate and the requirement for sufficient buoyant energy to release gas are combined to

(a) A neutral buoyancy gas fraction of 0.10 is typical of the currently burping DSTs. The higher 0.15 gas fraction would represent a somewhat more dilute supernatant liquid. 
provide criteria for potential gas release in Figure 6.2. Each type of DCRT is represented by envelopes of gas generation rate and nonconvective layer depth, for neutral buoyancy gas fractions of 0.1 and 0.15 , where a buoyant displacement gas release can occur. The range of gas generation rates anticipated for BX, S, TX and U DCRTs is shown along the left side (Hedengren et al. 1997). The maximum gas generation rate (for SY-101) is indicated at the top.

Below and to the left of a tank's buoyant displacement envelope, the gas fraction is insufficient for the waste to become buoyant. To the right of the envelope there is insufficient buoyant energy to cause a gas release. Therefore, only the range of nonconvective layer depths between approximately 0.5 and $1.5 \mathrm{~m}$ in the horizontal DCRTs and between about 0.5 and $2.0 \mathrm{~m}$ in the vertical DCRTs may have the potential for buoyant displacement gas releases, depending on the gas generation rate. Also note that the gas generation rates expected in the BX and TX DCRTs fall below the BX envelope, and buoyant displacement is not a concern in these tanks regardless of nonconvective layer depth. Buoyant displacements apparently are possible only in the $S$ and $U$ DCRTs.

\subsubsection{Gas Release Volume}

The volume of gas released is determined by the average gas fraction of the nonconvective layer at neutral buoyancy, the volume of the "gob" that rises, and the fraction of its retained gas that the gob releases. In a buoyant displacement, the size of the "gob" of nonconvective layer that actually participates is limited by the geometry of the tank. Models developed to predict the gob size in DSTs are not applicable to the smaller DCRTs, especially the horizontal cylinder design. Physically, no more than about half of the waste can rise in any one event, since

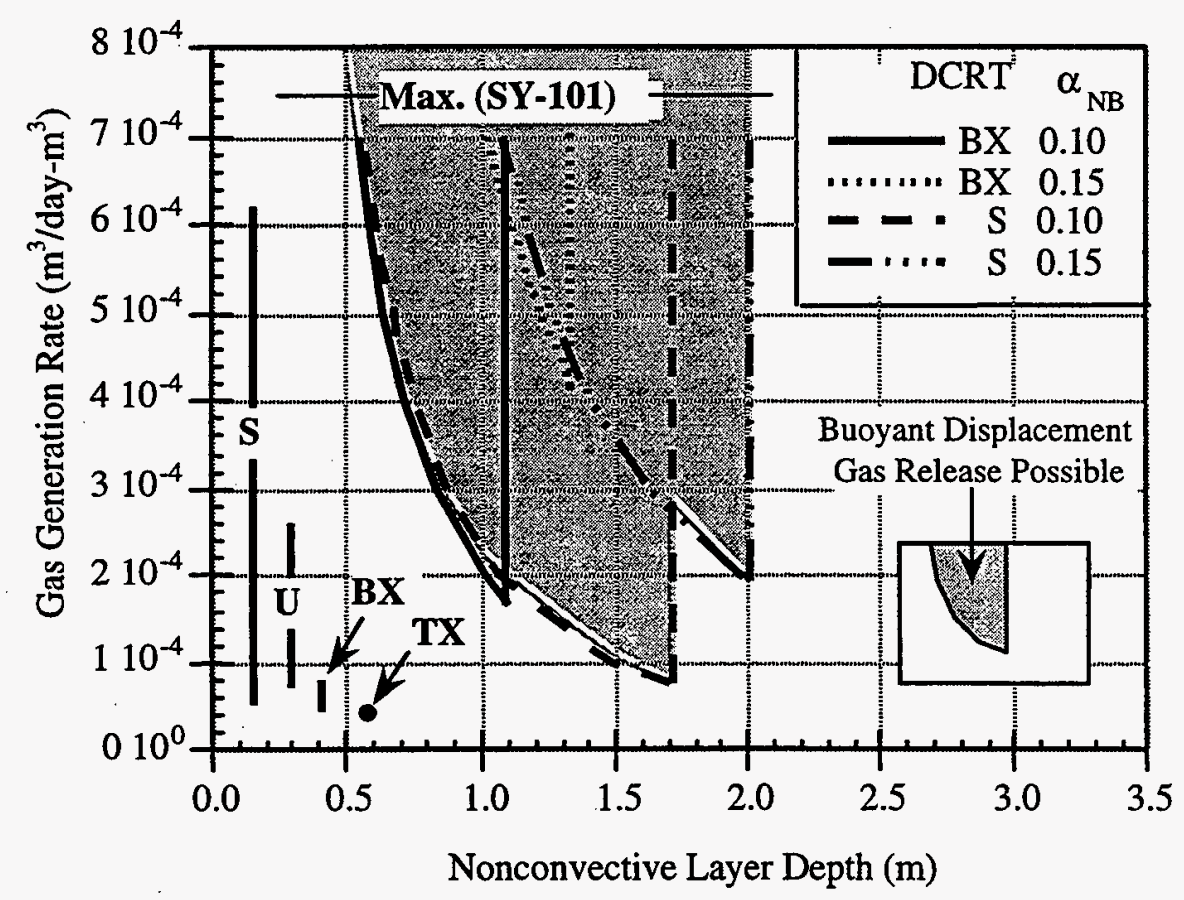

Figure 6.2. Envelope of Potential Buoyant Displacement Gas Release in DCRTs 
the rising portion must be replaced by liquid descending. Experimental evidence suggests that the maximum gob diameter should be no more than 2-3 times the nonconvective layer depth (Meyer et al. 1997). We shall somewhat conservatively assume that the nonconvective layer is made up of two gobs in vertical cylinder S DCRT and three gobs in the BX-type horizontal cylinder DCRTs.

Not all the gas stored in the gob is released. A useful theory (Sullivan 1994; Meyer et al. 1997) states that a gob releases only the amount of gas necessary to bring it back to neutral buoyancy at $1 \mathrm{~atm}$. With this assumption the release fraction is computed as

$$
\mathrm{f}_{\mathrm{REL}}=1-\frac{\mathrm{P}_{\mathrm{A}}}{\mathrm{p}_{\mathrm{NCL}}}
$$

where $\mathrm{p}_{\mathrm{NCL}}$ is the average pressure of the retained gas in the nonconvective layer. The higher the pressure is, the higher the release fraction is.

Given the volume fraction, pressure, release fraction and gob size, the maximum gas release resulting from a buoyant displacement can be computed from the following:

$$
V_{\text {REL }}=\frac{f_{\text {REL }}}{N_{\text {GOB }}} \alpha_{N B} V_{N C L} \frac{p_{N C L}}{P_{A}}
$$

where $\mathrm{N}_{\mathrm{GOB}}$ is the number of gobs in the nonconvective layer and $\mathrm{V}_{\mathrm{NCL}}$ is the total volume of the nonconvective layer.

The maximum gas release volume occurs at the maximum nonconvective layer depth for a given void fraction. This condition is represented by the lowest point on the buoyant displacement envelopes depicted in Figure 6.2. The maximum buoyant displacement gas releases predicted by Eq. (6.10) in either type of DCRT do not make the headspace flammable, but all cases exceed $25 \%$ of the LFL.

For the S-type DCRTs, Eq. (6.10) predicts a release of 0.6 and $1.0 \mathrm{~m}^{3}$ for neutral buoyancy gas fractions of 0.1 and 0.15 , respectively. Assuming $80 \%$ hydrogen in the release gas, this brings the headspace to $30 \%$ and $50 \%$ of the LFL, respectively. A BX-type DCRT has maximum gas releases of 0.3 and $0.6 \mathrm{~m}^{3}$, which brings the headspace to $-30 \%$ and $50 \%$ of the LFL, respectively. This calculation is summarized in Table 6.1.

As with the formation of the nonconvective layer in the first place, accumulation of sufficient gas to cause a buoyant displacement requires a long time. Assuming a gas generation rate equal to that of SY-101, it takes 143 days to reach the neutral buoyancy at a gas fraction of 0.10 and 214 days at a void fraction of 0.15 . This gas generation rate exceeds that expected in all of the SSTs that might affect a DCRT (Hedengren et al. 1997). At generation rates more typical of the waste expected to pass through DCRTs, one-fourth to one-third that of SY-101, the time approaches two years. We conclude that buoyant displacement gas release in a DCRT is not a 
Table 6.1. Gas Release from a DCRT Nonconvective Layer

\begin{tabular}{|c|c|c|c|c|}
\hline Parameter & \multicolumn{2}{|c|}{ S (vertical) DCRT } & \multicolumn{2}{|c|}{ BX (horizontal) DCRT } \\
\hline Diameter $(\mathrm{m})$ & \multicolumn{2}{|c|}{4.57} & \multicolumn{2}{|c|}{3.66} \\
\hline Height or length (m) & \multicolumn{2}{|c|}{4.72} & \multicolumn{2}{|c|}{10.67} \\
\hline No. of gobs & \multicolumn{2}{|c|}{2} & \multicolumn{2}{|c|}{3} \\
\hline Operating depth (m) & \multicolumn{2}{|c|}{3.74} & \multicolumn{2}{|c|}{2.74} \\
\hline Headspace volume $\left(\mathrm{m}^{3}\right)$ & \multicolumn{2}{|c|}{41.2} & \multicolumn{2}{|c|}{22.4} \\
\hline Neutral Buoyancy & 0.10 & 0.15 & 0.10 & 0.15 \\
\hline NCL depth (m) & 1.70 & 2.0 & 1.10 & 1.33 \\
\hline CL depth (m) & 2.04 & 1.75 & 1.64 & 1.41 \\
\hline Pressure (atm) & 1.42 & 1.41 & 1.32 & 1.31 \\
\hline Release fraction & 0.30 & 0.29 & 0.24 & 0.24 \\
\hline Gas release $\left(\mathrm{m}^{3}\right.$ at $\left.1 \mathrm{~atm}\right)$ & 0.58 & 1.0 & 0.30 & 0.57 \\
\hline \% LFL (@80\% hydrogen) & 28 & 49 & 27 & 50 \\
\hline
\end{tabular}

concern for normal operations but must be considered in off-normal situations where a tank is left full for an extended length of time. Even if they should occur, buoyant displacement gas releases would not be expected to exceed the LFL.

\subsection{Conclusions}

Based on core sample analysis of A-101 waste, a significant nonconvective solids layer $(\sim 0.75 \mathrm{~m}$ deep for A-101 liquid) could form in a DCRT by precipitating of sodium salts from the liquid if it is allowed to cool, though cooling would require many months. Precipitation of aluminum hydroxide may also occur on a much shorter time scale if the $\mathrm{pH}$ is reduced when different wastes are mixed.

The amount of gas that can be retained in nonconvective layer depends on the layer depth and gas generation rate. If a nonconvective solids layer depth exceeds about $0.5 \mathrm{~m}$, the relatively high gas generation rates expected in the $\mathrm{S}$ and $\mathrm{U}$ DCRTs could create a void fraction sufficiently high to make the layer buoyant, given enough time for the gas to accumulate. The gas generation rates expected in the BX and TX DCRTs are too low to achieve buoyancy. The time required for gas accumulation to the point of buoyancy is on the order of a year or more.

If the solids layer becomes buoyant, the buoyant potential energy must be sufficient to yield the waste and release the gas. This requires about 1.5 to $1.75 \mathrm{~m}$ of supernatant liquid. Therefore, significant gas releases can only occur below a maximum nonconvective layer depth of 1.7 to $2.0 \mathrm{~m}$ in the vertical S-DCRT and 1.0 to $1.3 \mathrm{~m}$ in a horizontal DCRT at operating capacity.

The maximum gas release will occur at the maximum nonconvective layer depth for a given void fraction. Gas releases of 0.3 to $0.6 \mathrm{~m}^{3}$ (at standard pressure and temperature) are 
predicted for horizontal DCRTs and 0.6 to $1.0 \mathrm{~m}^{3}$ in the vertical S DCRT. At operating capacity (minimum headspace) and assuming the released gas contains $80 \%$ hydrogen, the headspace in either class of DCRTs reaches 30 to $50 \%$ of the LFL.

The calculations given in this section show that relatively large, sudden gas releases are theoretically possible in the S and U DCRTs. However, even the largest gas releases would not cause the tank headspace to exceed the LFL but could exceed 25\% of the LFL. A much longer time is required for gas accumulation than waste would normally be allowed to stand in a DCRT. Therefore we conclude that gas retention and release from a nonconvective layer in a DCRT is not a concern for normal operations but must be considered in highly off-normal cases where a full tank must stand for about a year. 


\subsection{DCRT Ventilation}

Ventilation has probably the strongest influence of any parameter on flammable gas accumulation in the headspace of a DCRT. However, the DCRTs were not designed to provide a given ventilation flow through the catch tank. A 100-125 cfm exhauster fan pulls air from both the vault and the catch tank. While pressure measurements indicate a vacuum in both, ${ }^{(2)}$ no specific air inlet has been provided to ventilate the catch tank except in the U DCRT, where an inlet filter is tied directly to the catch tank. As a result, the only ventilation that can be credited with confidence in a safety analysis is the $5 \mathrm{cfh}$ air flow bubbling through three small-diameter DP tubes that measure fluid level and specific gravity. ${ }^{(b)}$ A simple sketch of the overall system is shown in Figure 7.1.

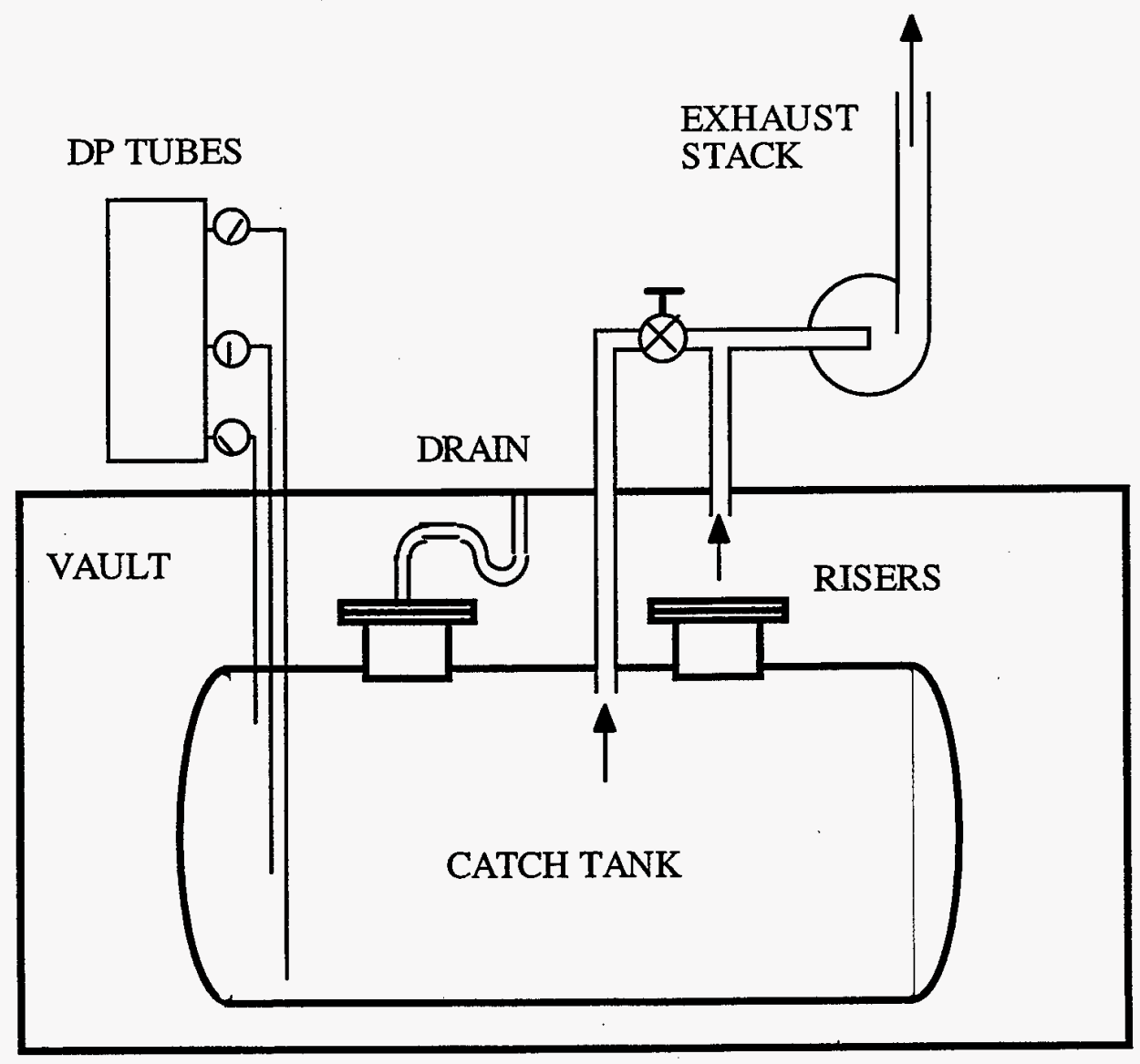

Figure 7.1. Schematic of DCRT Ventilation System

(a) Personal communication with Randy Powers (LMHC).

(b) These are the DP or "dip" tubes. The pressure to maintain a low rate of air flow is approximately equal to the local gauge pressure. Three pressure measurements at different elevations allow the fluid level and density to be calculated. 
As shown in Section 9, additional ventilation above the assumed 3-cfh bubbler flow would reduce flammability substantially after the DCRT has been filled and allowed to stand but less significantly during tank filling. The calculations of Hedengren et al. (1997) show that even this minuscule ventilation is sufficient in many cases to keep the headspace below the LFL, even with very conservative assumptions on gas release and generation rates. This section investigates whether additional ventilation might be occurring through leakage and provides some suggestions as to how the ventilation rate might be measured.

\subsection{Paths for Ventilation Inflow}

Potential paths for ventilation inflow include transfer lines, floor drains, leaks around riser penetrations, leaks around the manual tape level instrument, and leaks around riser covers. The $3 \mathrm{cfh}$ DP tube flow has already been evaluated and will not be further discussed here.

Transfer lines do not normally provide a ventilation flow path. Lines entering the DCRT would originate at a salt-well jet pump, whose inlet would be submerged at the bottom of the salt well. Lines leaving the DCRT likewise originate at the transfer pump, whose inlet is submerged in the DCRT. In both cases the line is liquid-sealed. We have not investigated whether there are valve and/or jumper configurations that could be used to provide airflow through inlet lines from the pump pit.

Floor drains have a trap designed to make a seal when filled with water. If the water seal were removed and the drains were not blocked with debris, the 1- to 3-in.-diameter drain lines would provide a very large ventilation flow.

Drawings indicate that essentially all riser penetrations are welded and thus do not provide any potential ventilation path. However, S-type DCRTs have spray rings inside the 12-in. transfer pump riser and the 24-in. inlet riser that are fed by 1 -in. raw water lines through hose connectors in the flush pit. It might be possible to open the inlet valves to provide ventilation through these water lines.

A manual tape is used for positive liquid level measurement in all but the S DCRTs, where the level is measured only by DP tubes. The manual tape control box is not tightly sealed, so the tape can move freely and a significant, if not large, vent flow may exist. The staff of the Tank Farm Operations Project are attempting to measure this flow. ${ }^{(a)}$ It would be possible to install a HEPA-filtered inlet by placing a "Y" in the 6-in. riser under the manual tape box. This large flow area would enable vent flow at the full fan capacity.

The transfer pump flange may also provide a significant ventilation flow. Other riser covers are gasketed and torqued using a specific procedure with the objective of getting a good seal. ${ }^{(\mathrm{b})}$ However, the transfer pump rests directly on the riser flange with no specific effort to seal the joint. Slight misalignment of the pump base and flange, irregularities of the mating surfaces, and dirt and dust caught between them are all likely to create a gap through which air could flow.

(a) Personal communication with Randy Powers (LMHC).

(b) Personal communication with.D. Nunamaker (LMHC), JW Bailey (NHC) and MR Koch (LMHC). 


\subsection{Potential Ventilation Flow Rates}

The potential flow rate through the pump flange can be calculated by assuming laminar flow between parallel plates as sketched in Figure 7.2. Including entrance and exit losses, the flow velocity can be computed with the quadratic equation (Blevins 1984):

$$
\frac{\left(\mathrm{K}_{\mathrm{ex}}+\mathrm{K}_{\mathrm{ent}}\right)}{2} \rho \mathrm{U}^{2}+\frac{12 \mu \mathrm{L}}{\mathrm{h}^{2}} \mathrm{U}-\Delta \mathrm{p}=0
$$

where

$$
\begin{array}{ll}
\mathrm{K}_{\mathrm{ex}} & =\text { exit loss coefficient }(1.0) \\
\mathrm{K}_{\mathrm{ent}} & =\text { entrance loss coefficient }(0.64) \\
\rho & =\text { vent flow density entering riser }\left(\mathrm{kg} / \mathrm{m}^{3}\right) \\
\mathrm{U} & =\text { maximum flow velocity between the plates }(\mathrm{m} / \mathrm{s}) \\
\mu & =\text { vent flow viscosity }\left(\mathrm{N}-\mathrm{s} / \mathrm{m}^{2}\right) \\
\mathrm{L} & =\text { length of the flow path }(\text { flange outside radius minus inside radius, } \mathrm{m}) \\
\mathrm{h} & =\text { estimated plate spacing }(\mathrm{m}) \\
\Delta \mathrm{p} & =\text { pressure difference driving the flow }(\mathrm{Pa}) .
\end{array}
$$

The volumetric flow rate is simply the product of the flow velocity and the minimum flow area, which is equal to the plate spacing times the inner perimeter of the 12-in.-diameter pump riser (assuming a uniform gap around the circumference).

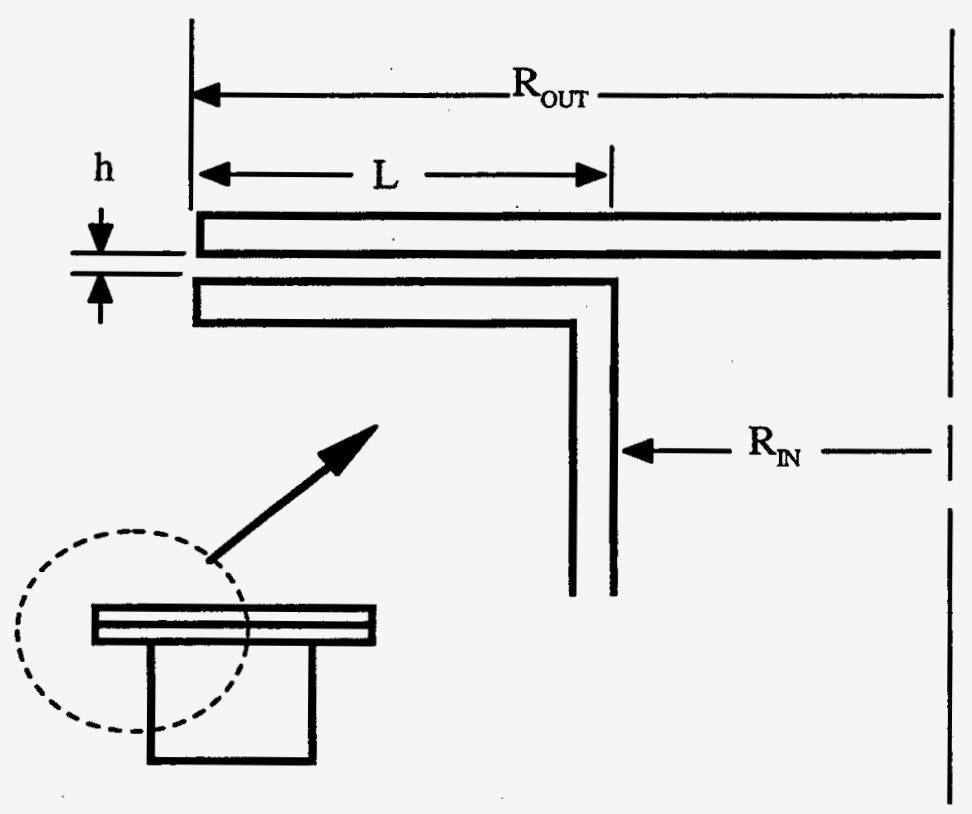

Figure 7.2. Riser Leak Path Model Schematic 
Figure 7.3 shows the results of a calculation solving Eq. (7.1) for velocity over a range of plate spacings assuming a minimal pressure difference of $1 / 2$ in. of water (gauge) with air flow at a "typical" $30^{\circ} \mathrm{C}$. The BX-type DCRTs have a 25 -in. square flange (approximated as a 25 -in.diameter round flange), and the S-type DCRT uses a 36-in.-diameter round flange. The latter creates a longer flow path and therefore a lower vent flow for a given pressure difference.

A significant ventilation flow can be achieved through a very narrow gap. The 3-cfh bubble flow can be exceeded with a leakage gap of only 0.01 in. in a BX-type DCRT and 0.013 in. in an S-type DCRT. Flow rates close to the 5-cfm typical of passively ventilated SSTs can be achieved with a gap of 0.06 to 0.07 in.

\subsection{Confirming Ventilation Flow Rates}

Although a small leak can yield a large ventilation flow rate, there is no way to determine exactly what the effective gap spacing is. Therefore, unless the vent flow can actually be measured, the 3-cfh DP tube flow is the maximum that can be used in safety calculations. Several methods that might provide a useful vent flow measurement are discussed in this section.

Ventilation flow could be determined by sampling for a gas known to be given off by the waste but not present in air. It is possible to reverse the flow on the upper DP tube and draw off a sample of the headspace gas for analysis. The ventilation exhaust can also be sampled. The

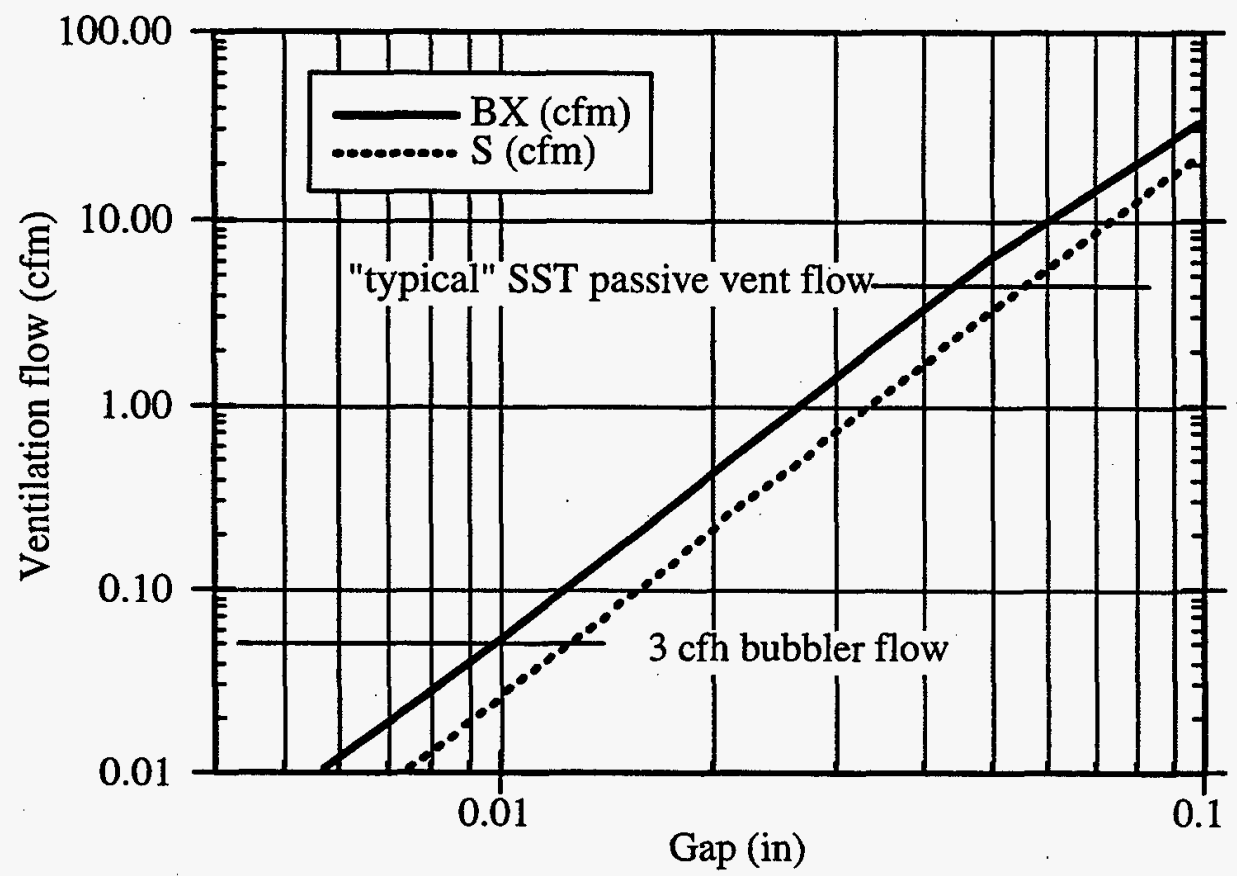

Figure 7.3. Potential Ventilation Flow Through Transfer Pump Flange 
fraction of the total ventilation flow coming out of the catch tank is equal to the ratio of the concentration of the selected gas measured in the exhaust stack to that measured through the DP tube. This has already been attempted using ammonia. ${ }^{(a)}$ However, most of the ammonia apparently condensed out in the DP tube, and the measurement was not successful.

To avoid the tendency of ammonia to collect on any available surface, a non-condensable gas like helium could be used as a tracer using the same method as is currently being used to assess passive ventilation flow rates in SSTs (Huckaby et al. 1997). A volume of helium could be injected into the catch tank through the high DP tube that would bring the average concentration to a few hundred ppm. Then, periodic samples could be drawn back through the same DP tube and the ventilation flow determined through the exponential decay of the helium concentration. The advantage of this method is that it does not require a separate measurement of the gas concentration in the exhaust stack. However, if the ventilation flow is truly low, the measurement might require several weeks to complete.

The flow could be determined in a shorter period by injecting helium at a steady, known rate into the high DP tube and measuring the helium concentration in the exhaust stack. Again, the ratio of the injection flow to the product of the exhaust flow and exhaust concentration would give the fraction of the exhaust flow coming from the catch tank headspace. However, the measurement would depend on how accurately the exhaust flow was known.

Whichever method is used, it is very likely that the measured DCRT ventilation rate will be significantly higher than is currently assumed. Even considering the uncertainty in gas release and/or generation in the waste itself, a relatively small increase in ventilation flow may provide sufficient dilution to prevent DCRT headspace flammability, particularly when a filled DCRT has been allowed to stand and hydrogen generation becomes important.

(a) Personal communication with KM Hodgson (LMHC). 


\subsection{Estimating Flammability}

A flame can be ignited and propagate in a gas mixture only when the combustion reactions release energy at a sufficiently rapid rate relative to heat losses to maintain the required flame temperature. Flame propagation in fuel-rich mixtures is limited by oxygen availability and in lean mixtures by the amount of fuel available. Thus the conditions of flammability are characterized by the upper (rich) and lower (lean) flammability limits of fuel gas concentration. In considering the flammability hazard in DCRTs, we are concerned mainly with the LFL, which is determined by the gas composition, the energy and location of the ignition source, the direction of flame propagation relative to gravity, and whether the gas is quiescent or being mixed.

In a quiescent atmosphere the transition to flammability is fairly abrupt, and the LFL is higher (i.e., more fuel is required) for downward flame propagation than for upward propagation because gravity assists the latter. In a turbulent, well-mixed atmosphere, the transition to flammability is more gradual, with combustion pressures increasing linearly from, roughly, the upward propagation limit. However, the flame propagation speed remains relatively low for concentrations below the downward propagation limit (Cashdollar et al. 1992). A very energetic ignition source has an effect similar to turbulence.

\subsection{Flammability of Hydrogen-Methane-Ammonia Mixtures}

Hydrogen is the most effective fuel of concern in Hanford tanks. Methane and ammonia also contribute to mixture flammability, though their concentrations are too low to have a dominant effect in typical waste tank scenarios. Other organic gases may also be present at very small concentrations but likewise have no practical effect on flammability (Hedengren et al. 1997). The lower flammability limits for both upward and downward propagation for the three major gases, hydrogen, methane, and ammonia, are given in Table 8.1. ${ }^{\text {(a) }}$

Experiments (Cashdollar et al. 1992) have shown that the LFL of a mixture of hydrogen, ammonia, and methane in an air-nitrous oxide atmosphere (with at least 13-17\% oxygen present) can be computed from the LFL of each fuel using LeChatelier's linear mixing law:

Table 8.1. Lower Flammability Limits in Air

\begin{tabular}{|l|c|c|}
\hline & \multicolumn{2}{|c|}{ Lower Flammability Limit (vol\%) } \\
Fuel & Upward Propagation & Downward Propagation \\
\hline Hydrogen & 4 & 8 \\
Methane & 5 & 5 \\
Ammonia & 15 & 18 \\
\hline
\end{tabular}

(a) Shepherd JE. April 30, 1997. "Combustion and Explosion Experiments at Caltech." Presentation to SCOPE Workshop, Richland, Washington. 


$$
\frac{1}{[\mathrm{MIX}]_{\mathrm{LFL}}}=\frac{\left[\mathrm{H}_{2}\right]_{\mathrm{MIX}}}{\left[\mathrm{H}_{2}\right]_{\mathrm{LFL}}}+\frac{\left[\mathrm{CH}_{4}\right]_{\mathrm{MIX}}}{\left[\mathrm{CH}_{4}\right]_{\mathrm{LFL}}}+\frac{\left[\mathrm{NH}_{3}\right]_{\mathrm{MIX}}}{\left[\mathrm{NH}_{3}\right]_{\mathrm{LFL}}}
$$

where

$$
\begin{aligned}
& {[\mathrm{MIX}]_{\mathrm{LF}}=\text { concentration of the gas mixture at the LFL in air }} \\
& {[\mathrm{gas}]_{\mathrm{MT}}=\text { concentration of the gas comprising the fuel mixture }} \\
& {[\mathrm{gas}]_{\mathrm{LR}}=\text { concen ation of the pure gas at the LFL in air. }}
\end{aligned}
$$

The concentration of hydrogen is usually monitored to detect flammable conditions. The hydrogen concentration at which a mixture of hydrogen with other gases is flammable in air is given by

$$
\left[\mathrm{H}_{2}\right]_{\mathrm{MIX}, \mathrm{LFL}}=\left[\mathrm{H}_{2}\right]_{\mathrm{MIX}}[\mathrm{MIX}]_{\mathrm{LFL}}
$$

For example, using the data in Table 8.1 for upward propagation, Eq. (8.1) predicts that the retained gas bubbles in A-101, a mixture of $75 \%$ hydrogen, $5.6 \%$ nitrous oxide, $0.7 \%$ methane, $2.4 \%$ ammonia, and $16 \%$ nitrogen (Shekarriz et al. 1997), would be flammable at a concentration of 5.3 in air. At that point, the hydrogen concentration would be 3.9 via Eq. (8.2).

As in a full-size waste tank, the headspace in a DCRT would generally be expected to be turbulent, and the upward flammability limit is appropriate for determining whether ignition is possible. However, the pressure calculations should include the effect of low flame speed in lean mixtures.

\subsection{Flammability of Ammonia-Rich Mixtures}

The gas in the DCRT headspace may contain much more ammonia relative to hydrogen and other gases than in a typical waste tank. As discussed in Section 3, we do not expect saltwell pumping to transport a significant amount of gas in the form of bubbles into a DCRT. In the initial stages of pumping, gas generation is not expected to play a significant role, and evaporation of dissolved gas is generally expected to be the dominant gas release mechanism with ammonia as the dominant flammable component.

There are several important implications of a potentially high ammonia concentration. Ammonia is difficult to ignite. In fact, ammonia was not even considered flammable as late as 1951 (Buckley and Husa 1962). Ammonia has a very low flame speed and a high ignition energy (8-680 mJ compared with $\sim 0.01 \mathrm{~mJ}$ for methane) and requires a relatively high concentration ( $15 \%$ LFL) to support combustion. ${ }^{(a)}$

The presence of nitrous oxide $\left(\mathrm{N}_{2} \mathrm{O}\right)$ decreases the downward propagation limit in ammonia-hydrogen-air mixtures, although it has essentially no effect on the LFL in hydrogen-air mixtures and actually decreases the flame propagation speed (Breshears et al. 1997). Nitrous

(a) Pfahl U and JE Shepherd. April 29, 1997. "Flammability and Flame Propagation in $\mathrm{H}_{2}-\mathrm{N}_{2} \mathrm{O}-\mathrm{CH}_{4}$ $\mathrm{NH}_{3}-\mathrm{O}_{2}-\mathrm{N}_{2}$ Mixtures." Report FM97-4, Explosion Dynamics Laboratory. 
oxide begins to participate in the combustion reactions when the temperature exceeds $1000 \mathrm{~K}$. In hydrogen-nitrous oxide-air mixtures, this does not occur until the hydrogen concentration approaches the downward propagation limit of $\sim 8 \%$. However, since ammonia-nitrous oxide-air mixtures must be richer and ignited more aggressively, the $1000 \mathrm{~K}$ threshold is apparently exceeded more readily such that $\mathrm{N}_{2} \mathrm{O}$ participation aids flame propagation. The net effect is to make the downward propagation limit closer to the upward propagation limit, the latter being essentially unaffected by $\mathrm{N}_{2} \mathrm{O}$. $^{(a)}$

Water vapor raises the LFL of ammonia-air mixtures. If the water vapor volume fraction exceeds $11 \%$, the mixture is not flammable. For comparison, 17-19\% nitrogen is required to inert an ammonia-air mixture. In fact, the amount of water vapor necessary to prevent combustion increases from $\sim 8 \%$ at $25^{\circ} \mathrm{C}$, to $\sim 9 \%$ at $44^{\circ} \mathrm{C}$, to $\sim 11 \%$ at $80^{\circ} \mathrm{C}$ (Fenton et al. 1995). It is possible for the equilibrium headspace humidity to exceed this value at moderate temperatures.

The equilibrium water vapor fraction as a function of temperature and the flammability range for ammonia-air-water vapor mixtures are shown in Figure 8.1. The equilibrium water vapor fraction above pure water (CRC 1990) exceeds the inerting value at $41-48^{\circ} \mathrm{C}\left(106-118^{\circ} \mathrm{F}\right)$. The vapor pressure over a salt solution containing $50 \%$ water (shown by the dashed line) is about

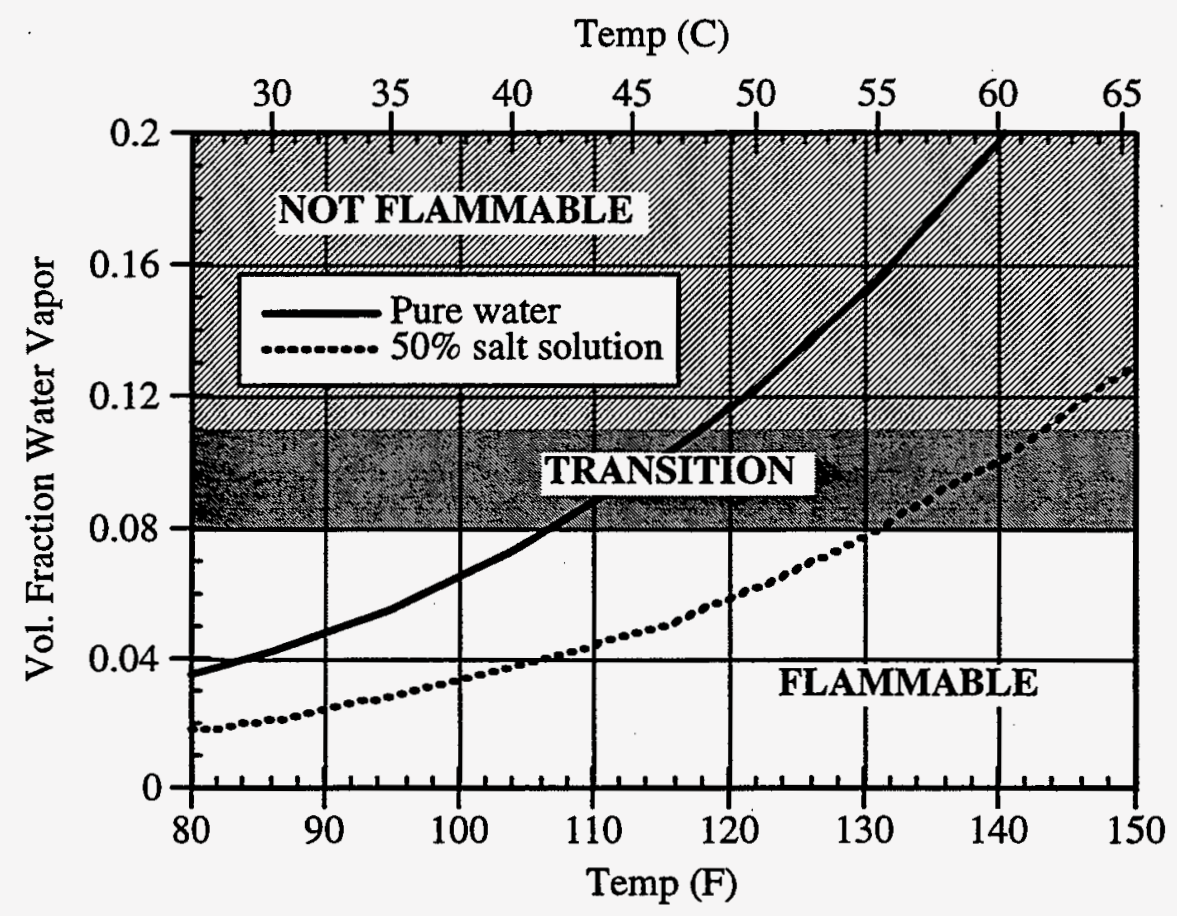

Figure 8.1. Equilibrium Water Vapor Fraction and Ammonia Flammability

(a) Shepherd JE. April 30, 1997. "Combustion and Explosion Experiments at Caltech." Presentation to SCOPE Workshop, Richland, Washington. 
half the vapor pressure of pure water based on a correlation developed by Mahoney and Trent (1995) from Tank 241-SY-101 chemical simulant data. This increases the temperature at which the mixture is inert to $55-61^{\circ} \mathrm{C}$, higher than a DCRT would normally be. However, even if the temperature were sufficiently high, water vapor could not confidently prevent combustion because the mixture will contain at least a small amount of hydrogen, which is not effectively inerted by water vapor. ${ }^{(a)}$

\subsection{Conclusions}

Whether or not the gas mixture is dominated by ammonia, flammability concerns in the DCRT headspace are not fundamentally different from those encountered in a full-size waste tank. The following conclusions are drawn from recent flammability research, which has been summarized above:

- The LFL for upward flame propagation is appropriate for determining flammability.

- The upward propagation LFL for a gas mixture can be determined using LeChatelier's linear mixing law (Eq. 8.1).

- Nitrous oxide can be considered an inert species unless fuel concentrations approach the (higher) LFL for downward flame propagation.

- Water vapor cannot be counted on to prevent combustion.

(a) Ibid. 


\subsection{DCRT Flammable Gas Model}

This section contains the derivation and results of two models for calculating the maximum hydrogen, ammonia, and methane concentrations in the headspace of a DCRT during and after it is filled. The first model assumes instantaneous equilibrium between the liquid and the gas/vapor in the DCRT; the second model takes mass-transfer limitations into account, using the mass-transfer coefficients discussed in Section 2.5.1. At the minimum ventilation rate $(3 \mathrm{cfh})$ and maximum feed rate ( $4 \mathrm{gpm}$ ), the equilibrium model proves to be only slightly conservative in its flammability estimates. As ventilation rates increase, however, the nonequilibrium model is more appropriate. To show the effect of these different approaches as well as different sets of input parameters, we present the results in the following manner:

- In Section 9.3, the equilibrium model is used to calculate DCRT headspace flammability for the full set of tanks that were modeled by Hedengren et al. (1997). Using the equilibrium model is appropriate because Hedengren et al. (1997) used an equilibrium approach (without depletion) to ammonia volatilization, and ammonia is the primary contributor to flammability for most of the wastes studied. The results of the two approaches using the same input parameters (e.g., ventilation rate, fill rate, dissolved gas concentrations) are compared and shown to be quite similar. In part, this comparison serves as a check on the results calculated by the present equilibrium model.

- Next, we change some of the input parameters (particularly initial dissolved gas concentrations) as recommended in Section 2 of this report. Still using the minimum ventilation rate and maximum fill rate, we use the equilibrium model to show the effect of the changed inputs on the calculated flammability of the modeled tank wastes. This effect is an indication (though not a direct calculation) of the extent to which the predicted flammability is affected by uncertainty in the dissolved concentrations in the feed.

- Using these same input parameters, we then show that the equilibrium and nonequilibrium models yield comparable results when the ventilation rate is low. Here, only selected tank wastes are presented. Using the nonequilibrium model, we also calculate the minimum ventilation rate necessary to keep headspace flammability for these wastes below $25 \%$ of the LFL.

Finally, the nonequilibrium model is used for an exploration of the sensitivity of the DCRT headspace flammability to various parameters.

Note that the current level of uncertainty regarding the ventilation rate in DCRTs prevents us from making a definitive estimate of DCRT headspace flammabilities. None of the results in this section should be construed an actual flammability prediction, because we believe that the assumed ventilation rate of $3 \mathrm{cfh}$ (which we use, as did Hedengren et al., in the absence of a better estimate) is far too low. 
The mechanisms considered in both the equilibrium and nonequilibrium models are the release of flammable gases dissolved in the liquid and hydrogen generation (by radiolysis, thermolysis, and DCRT corrosion). The assumptions made in the models are the following:

- In the equilibrium model, the gases dissolved in the liquid pumped into the DCRT instantaneously reach equilibrium with the headspace.

- In the nonequilibrium model, dissolved gases volatilize from the falling inlet stream and the standing liquid surface at finite rates given by the expressions for mass transfer derived in Section 2.

- In both models, the headspace is well mixed. Huckaby et al. (1997) found that mixing times in S-102 (an SST) were about one hour, apparently because of natural convection. The TEMPEST modeling of the same tank (Antoniak and Recknagle 1997) was in agreement with the observations. Similar convective velocities and mixing times are likely in the DCRT, and the resulting one-hour mixing time is much shorter than the time scales of filling or hydrogen generation.

- Vapor-liquid equilibrium is represented by Henry's Law, and the Schumpe model with tested parameters (Hermann et al. 1995; Norton and Pederson 1995) is used to estimate the Henry's Law constants.

- Other gas carryover mechanisms (hitchhiker bubbles, gas adsorbed on particles) are neglected, as justified by the results discussed in previous sections.

- The model suggested by Hu et al. (1997) is used to calculate the hydrogen generation in the DCRT. In the equilibrium model, the hydrogen generation rate (per unit volume of liquid in the DCRT) is treated as constant throughout filling, a simplifying assumption that introduces negligible error and allows the model to be solved analytically. In the nonequilibrium model (which is solved numerically), this assumption is not needed and the volumetric hydrogen generation rate varies with fill.

- Ammonia generation and methane generation in the DCRT are not modeled. The generation rate of ammonia is expected to be small compared with the reservoir in the dissolved liquid. The methane generation rate is expected to produce negligible flammability compared with the dissolved and generated hydrogen.

- The ventilation and fill flow rates are assumed to be constant throughout the operation. In the equilibrium model, this also permits the model to be solved analytically by treating the gas outflow from the DCRT as being constant throughout filling. This simplifying assumption introduces negligible error. A variable gas outflow rate is used in the nonequilibrium model (since it is solved numerically) to account for the additional flow of volatilized gases.

- Both models assume that the DCRT is initially empty. 
Headspace flammability results are reported immediately after the end of the fill (i.e., the "fill-end" flammability) as well as any "post-fill peak," if the flammability of the headspace increases once filling stops. The findings of the modeling work, given in detail in Sections 9.3, 9.4, 9.5, and 9.6, are the following:

- Using the revised inputs, the equilibrium model finds that 10 tanks (S-102, S-109, SX-102, SX-103, SX-105, SX-106, U-103, U-105, U-106, and U-108) have wastes that produce DCRT headspace flammabilities close to or exceeding $25 \%$ of the LFL at the minimum ventilation and maximum fill rates. These values should not be taken as actual flammability predictions, because a minimum ventilation rate was used to predict them, but they do serve as indicators of which wastes (or types of wastes) have the highest potential for flammability. The wastes with the highest potential flammability are those modeled as having high dissolved ammonia concentrations (S-102, SX-102, SX-103, SX-105, SX-106, U-103, U-105, and U-108), high temperatures (SX-102, SX-103, and SX-105), high dissolved hydrogen concentrations resulting from low salt in the liquid (S-109), or high hydrogen generation rates caused by high temperature or high TOC (SX-103, SX-105, U-103, U-105, and U-106). Hydrogen dominates the flammability for two tanks: S-109 (due to low salt concentrations) and U-106 (due to high post-fill hydrogen generation rates). The nonequilibrium model also predicts flammabilities that exceed $25 \%$ of the LFL for nine of these wastes; the exception is S-109.

- Of the eight wastes in which the dissolved ammonia leads to high flammability in the "base-case" scenario, only SX-103 and U-103 have had actual measurements of the dissolved ammonia in the waste. The uncertainty of the ammonia flammability for wastes from the other six tanks is therefore quite high, and the predicted flammabilities should be considered preliminary until data are acquired to confirm them.

- Five of the tanks with wastes modeled as producing high DCRT headspace flammability, SX-103, SX-105, U-103, U-105, and U-106, are modeled as having hydrogen generation rates high enough to make hydrogen a flammability concern in the post-fill period. There is evidence (based on hydrogen generation rates calculated from tank headspace measurements, as discussed in Section 5) that the hydrogen generation model overestimates the generation rate of wastes from three of these tanks, SX-103, SX-105, and U-106. The hydrogen contribution to the DCRT headspace flammability therefore is exaggerated for these three tanks. Further work may be needed to develop an improved hydrogen generation model, a more complete set of hydrogen generation estimates from headspace hydrogen measurements, or both.

- Compared with the nonequilibrium model, the equilibrium model overestimates the hydrogen flammability by more than a factor of 2 during fill and by $10 \%$ or less after filling is complete. Because hydrogen is not a major contributor to DCRT flammability for most of the tank wastes, the equilibrium model in most cases gives a fairly close estimate (within $20 \%$ of the nonequilibrium value) of the total DCRT headspace flammability when the ventilation rate is in the range of 3 to $30 \mathrm{acfh}$ (actual $\mathrm{ft}^{3} / \mathrm{hr}$ ). However, at a higher ventilation rate of $5 \mathrm{acfm}(300 \mathrm{acfh})$, which may be more realistic, the equilibrium model overestimates the flammability by $20-50 \%$ compared 
with the nonequilibrium model. The S-109 waste is an exception to the low overprediction trend: much of its headspace flammability comes from dissolved hydrogen, and the equilibrium model predicts twice the total fill-end flammability given by the nonequilibrium model.

- $\quad$ Though the total headspace flammability predicted by the equilibrium model is not much higher than that predicted by the nonequilibrium model, the small difference in predicted flammability translates into a large difference in the ventilation rate required to produce $25 \%$ of LFL in the headspace. This comes about because an increase in ventilation has a relatively small influence on reducing the headspace flammability. Therefore, the equilibrium model substantially overpredicts the ventilation rates required to maintain DCRT headspace flammability below $25 \%$ of the LFL.

- The minimum required ventilation rates calculated by the nonequilibrium model are highest for wastes from Tanks SX-103 and SX-105, at 2 and 2.5 acfm (130 and 150 acfh), respectively. While Hedengren et al. (1997) suggested possible operational changes, such as reducing the feed rate, that might allow such tanks to be pumped without exceeding $25 \%$ of the LFL even with minimal ventilation, this document does not formally address such changes.

- The nonequilibrium model shows that a ventilation rate of under 3 acfm maintains the headspace below $25 \%$ of the LFL (based on the present ammonia concentration data). By contrast, the extremely low 3-acfh flow that has been assumed in previous safety analyses predicts that at least nine wastes can exceed $25 \%$ of the LFL (for the present inputs of ammonia and hydrogen concentration and hydrogen generation rate). Because even a small ventilation flow can mitigate headspace flammability (especially under post-fill conditions), it is vital to measure the actual flow under typical operating conditions.

Parametric sensitivity tests were carried out with the nonequilibrium model and are discussed in Section 9.6. Some of the conclusions drawn from those tests are as follows:

- A high-temperature waste (SX-103 waste was used as an example) will, for the basecase minimum-ventilation fill scenario, produce a fill-end DCRT headspace flammability greater than $25 \%$ of the LFL if the dissolved hydrogen is more than $5 \times 10^{-4} \underline{\mathrm{M}}$ at zero ammonia or the dissolved ammonia is more than $0.06 \underline{\mathrm{M}}(1000 \mu \mathrm{g} / \mathrm{mL})$ at zero hydrogen. For comparison, the median dissolved hydrogen concentration is $3.1 \times 10^{-5} \mathrm{M} \mathrm{H}_{2}$. Several tanks have measured ammonia concentrations above $0.06 \underline{\mathrm{M}}$, but a tank would need to have a hydrogen partial pressure of about 17 atm to have $5 \times 10^{-4} \underline{\mathrm{M}}$ of dissolved hydrogen. Low-temperature waste (U-103 was modeled as an example) can contain ammonia at up to $0.29 \underline{\mathrm{M}}(4900 \mu \mathrm{g} / \mathrm{mL})$ without causing a fillend DCRT headspace flammability greater than $25 \%$ of the LFL at zero hydrogen. 
- When a (possibly) more realistic ventilation rate of $5 \mathrm{acfm}$ (300 acfh) is used, the ammonia concentration becomes the limiting flammability source. For SX-103 waste (at high temperature), the limiting ammonia concentration at zero hydrogen was found to be $0.13 \underline{\mathrm{M}}(2200 \mu \mathrm{g} / \mathrm{mL})$. For U-103 waste (at low temperature), the limiting ammonia concentration at zero hydrogen was found to be $0.36 \underline{\mathrm{M}}$ $(6100 \mu \mathrm{g} / \mathrm{mL})$.

- Decreasing the feed rate to the DCRT does not always cause a decrease in the fill-end flammability. It can cause an increase, depending on the hydrogen generation rate and the ratio of dissolved hydrogen to ammonia in the feed. Thus assuming a maximum flow rate does not necessarily produce a conservative estimate of DCRT headspace flammability. Case-by-case modeling is therefore required to account for the variability of waste properties.

Section 9.7 contains a brief discussion of the possible effects of mixing wastes from two different tanks in a DCRT. An example shows that mixing two different wastes can increase the fill-end headspace flammability in a DCRT over what would have been present for either of the unmixed wastes. The effects of cold water, hot water, and caustic addition (line flushes and $\mathrm{pH}$ adjustment) are also estimated and found to be small.

\subsection{Equilibrium Model Derivation}

The first step in deriving the DCRT flammable-gas equilibrium model is to define the flammable gas concentrations in the feed to the DCRT. (As was discussed in Section 3, hitchhiker bubbles and adsorbed gas do not contribute significantly to the flammable gas that is fed to the DCRT.) The dissolved ammonia/ammonium ion concentration in the feed, hereafter referred to as $\mathrm{c}_{\mathrm{B} 0}$, is found by direct measurement. When $\mathrm{c}_{\mathrm{B} 0}$ is known, the concentration of dissolved ammonia alone $\left(\mathrm{c}_{\mathrm{A} 0}\right)$ can be found by using the definition of the base dissociation constant for ammonia:

$$
\mathrm{K}_{\mathrm{b}}=\frac{\mathrm{c}_{\mathrm{i} 0} \mathrm{c}_{\mathrm{y} 0}}{\mathrm{c}_{\mathrm{A} 0}}
$$

where

$$
\begin{aligned}
\mathrm{K}_{\mathrm{b}}= & \text { the base dissociation constant for ammonia (equal to } 1.85 \times 10^{-5} \underline{\mathrm{M}} \\
& \text { in the temperature range of interest) }(\mathrm{CRC} 1975) \\
\mathrm{c}_{\mathrm{i} 0}= & \text { the dissolved ionic ammonium concentration (mol } \mathrm{NH}_{4}^{+} / \mathrm{L} \text { liquid) } \\
\mathrm{c}_{\mathrm{A} 0}= & \text { the dissolved ammonia concentration }(\mathrm{mol} \mathrm{NH} / \mathrm{L} \text { liquid) } \\
c_{\mathrm{y} 0}= & \text { the hydroxide concentration (mol } \mathrm{OH}^{-} / \mathrm{L} \text { liquid). }
\end{aligned}
$$

The hydroxide concentration is also a measured quantity, so the dissolved ammonia concentration can be found:

$$
c_{A 0}=\frac{c_{B 0}}{1+K_{b} / c_{y 0}}
$$


The dissolved concentrations of hydrogen, methane, and nonflammable gas (modeled as nitrogen) in the feed are not measured but are calculated by assuming equilibrium between the gas and liquid at a pressure equal to the partial pressure of the gas. The gas is assumed to consist of a mole fraction $f_{H}$ of hydrogen, $f_{M}$ of methane, and $f_{N}$ of nonflammable gas. (To obtain results that are readily comparable with those in Hedengren et al. [1997], $\mathrm{f}_{\mathrm{H}}$ is set at $0.97, \mathrm{f}_{\mathrm{M}}$ at 0.03 , and $f_{N}$ at 0 .) The gas/vapor in the source tank is assumed to have a total pressure equal to the average hydrostatic pressure, $\mathrm{P}_{0}$, at which gas is stored in the source waste tank. The dissolved concentrations of hydrogen, methane, and nonflammable gas are, according to the Henry's Law equilibrium relation,

$$
\begin{aligned}
& c_{H 0}=K_{H} f_{H}\left(P_{0}-\frac{c_{B 0} / K_{A}}{1+K_{b} / c_{y 0}}-p_{w}\right) \\
& c_{M 0}=K_{M} f_{M}\left(P_{0}-\frac{c_{B 0} / K_{A}}{1+K_{b} / c_{y 0}}-p_{w}\right) \\
& c_{N 0}=K_{N} f_{N}\left(P_{0}-\frac{c_{B 0} / K_{A}}{1+K_{b} / c_{y 0}}-p_{w}\right)
\end{aligned}
$$

where

$\mathrm{c}_{\mathrm{H} 0}=$ dissolved concentration of hydrogen in the feed (mol $\mathrm{H}_{2} / \mathrm{L}$ liquid)

$\mathrm{K}_{\mathrm{H}}=$ Henry's Law constant of hydrogen (mol/L liq/atm) at feed conditions

$\mathrm{f}_{\mathrm{H}}=$ mole fraction of hydrogen in the retained gas in the source tank

$\mathrm{p}_{\mathrm{w}}=$ water vapor pressure at feed conditions

$\mathrm{c}_{\mathrm{M} 0}=$ dissolved concentration of methane in the feed (mol $\mathrm{CH}_{4} / \mathrm{L}$ liquid)

$\mathrm{K}_{\mathrm{M}}=$ Henry's Law constant of methane (mol/L liq/atm) at feed conditions

$f_{M}=$ mole fraction of methane in the retained gas in the source tank

$\mathrm{c}_{\mathrm{N} 0}=$ dissolved concentration of nonflammable gas in the feed ( $\mathrm{mol} \mathrm{N}_{2} / \mathrm{L}$ liquid)

$\mathrm{K}_{\mathrm{N}}=$ Henry's Law constant of nonflammable gas, modeled as nitrogen (mol/L liq/atm), at feed conditions

$f_{N}=$ mole fraction of nonflammable gas in the retained gas in the source tank

$\mathrm{K}_{\mathrm{A}}=$ Henry's Law constant of ammonia (mol/L liq/atm) at feed conditions.

Water, like the flammable gases, is treated as being at equilibrium with the DCRT headspace. The water vapor pressure at feed conditions, $\mathrm{p}_{\mathrm{w}}$, is calculated using Eq. 6.2 and Table 6.2 of Mahoney and Trent (1995), which relates the water vapor pressure over a simulant solution to the salt concentration and temperature of the solution. Eq. (9.2) and (9.3) completely describe the dissolved gases in the feed to the DCRT.

Mass balances relate the accumulation of gas species in the DCRT to the feed and generation rates and to the gas outflow:

$$
\frac{\mathrm{dn}_{\mathrm{H}}}{\mathrm{dt}}=\mathrm{Fc}_{\mathrm{HO}}+\mathrm{rFt}-\frac{\mathrm{Qp}_{\mathrm{H}}}{\mathrm{RT}}
$$




$$
\begin{aligned}
& \frac{\mathrm{dn}_{\mathrm{M}}}{\mathrm{dt}}=\mathrm{Fc}_{\mathrm{M} 0}-\frac{\mathrm{Qp}_{\mathrm{M}}}{\mathrm{RT}} \\
& \frac{\mathrm{dn}_{\mathrm{B}}}{\mathrm{dt}}=\mathrm{Fc}_{\mathrm{B} 0}-\frac{\mathrm{Qp}_{\mathrm{A}}}{\mathrm{RT}} \\
& \frac{\mathrm{dn} \mathrm{N}_{\mathrm{N}}}{\mathrm{dt}}=\frac{\mathrm{EP}}{\mathrm{RT}}+\mathrm{Fc}_{\mathrm{N} 0}-\frac{\mathrm{Qp}_{\mathrm{N}}}{\mathrm{RT}}
\end{aligned}
$$

where

$$
\begin{aligned}
\mathrm{t}= & \text { time (days) } \\
\mathrm{F}= & \text { volumetric flow rate of feed (L/day); because the flow rate is } \\
& \text { assumed constant, the volume of liquid in the DCRT at time } \mathrm{t} \\
& \text { is equal to Ft, assuming that the DCRT is initially empty } \\
\mathrm{E}= & \text { volumetric flow rate of ventilation air (actual L/day) } \\
\mathrm{Q}= & \text { volumetric flow rate of gas leaving the DCRT (actual L/day) during the fill } \\
\mathrm{P}= & \text { total pressure in the DCRT (assumed to be } 1 \text { atm) } \\
\mathrm{T}= & \text { the temperature }(\mathrm{K}) \text { in the headspace (assumed the same as that } \\
& \text { in the waste) } \\
\mathrm{R}= & \text { ideal gas constant, } 0.08206 \text { atm L/mol K } \\
\mathrm{n}_{\mathrm{H}}= & \text { total moles of hydrogen in the DCRT } \\
\mathrm{p}_{\mathrm{H}}= & \text { partial pressure of hydrogen in the DCRT (atm } \left.\mathrm{H}_{2}\right) \\
\mathrm{r}= & \text { hydrogen generation rate per volume of liquid in the DCRT } \\
& \text { (mol } \mathrm{H}_{2} / \text { day/L liquid) } \\
\mathrm{n}_{\mathrm{M}}= & \text { total moles of methane in the DCRT } \\
\mathrm{p}_{\mathrm{M}}= & \text { partial pressure of methane in the DCRT (atm } \left.\mathrm{CH}_{4}\right) \\
\mathrm{n}_{\mathrm{B}}= & \text { total moles of ammonium ion and ammonia in the DCRT } \\
\mathrm{p}_{\mathrm{A}}= & \text { partial pressure of ammonia in the DCRT (atm } \left.\mathrm{NH}_{3}\right) \\
\mathrm{n}_{\mathrm{N}}= & \text { total moles of air in the DCRT } \\
\mathrm{p}_{\mathrm{N}}= & \text { partial pressure of air in the DCRT (atm air). }
\end{aligned}
$$

In Eq. (9.4a), the first term on the right is the hydrogen added by inflow; the second, hydrogen generation; and the third, hydrogen outflow. The equations for the other constituents are organized similarly.

Henry's Law and the ideal gas law provide a relationship between the partial pressure $p_{i}$ of any component $\mathrm{i}$ except ammonia, and $\mathrm{n}_{\mathrm{i}}$, the total moles of the component:

$$
\mathrm{p}_{\mathrm{i}}=\frac{\mathrm{n}_{\mathrm{i}}}{\mathrm{FtK}_{\mathrm{i}}+(\mathrm{V}-\mathrm{Ft}) / \mathrm{RT}}
$$

where

$$
\begin{aligned}
& \mathrm{V}=\text { the total DCRT volume }(\mathrm{L}) \text {, of which } \mathrm{Ft} \text { is occupied by liquid and }(\mathrm{V}-\mathrm{Ft}) \text { by } \\
& \text { gas/vapor. }
\end{aligned}
$$


The corresponding equation for ammonia, one that incorporates the equilibrium between ammonia and ammonium ion, is

$$
\mathrm{p}_{\mathrm{A}}=\frac{\mathrm{n}_{\mathrm{B}}}{\mathrm{FtK}_{\mathrm{A}}\left(1+\mathrm{K}_{\mathrm{b}} / \mathrm{c}_{\mathrm{y} 0}\right)+(\mathrm{V}-\mathrm{Ft}) / \mathrm{RT}}
$$

We assume that the temperature and salt concentration of the waste in the DCRT are the same as those in the source tank, meaning that the water vapor pressure and the Henry's Law constants of the gases are the same. We also assume that, for the purposes of this model, the Henry's Law constant of nitrogen $\left(\mathrm{K}_{\mathrm{N}}\right)$ can be used for air (which is treated as another nonflammable gas, the presence of sufficient oxygen to support combustion being taken for granted). The dissolved air concentration is small, and it is not a crucial variable. Then Eq. (9.4) can be expressed in terms of moles instead of partial pressure:

$$
\begin{aligned}
& \frac{\mathrm{dn}_{\mathrm{H}}}{\mathrm{dt}}=\mathrm{Fc}_{\mathrm{H} 0}+\mathrm{rFt}-\frac{\mathrm{Qn}_{\mathrm{H}}}{\mathrm{V}+\mathrm{Ft}\left(\mathrm{K}_{\mathrm{H}} \mathrm{RT}-1\right)} \\
& \frac{\mathrm{dn_{ \textrm {M } }}}{\mathrm{dt}}=\mathrm{Fc}_{\mathrm{M} 0}-\frac{\mathrm{Qn}_{\mathrm{M}}}{\mathrm{V}+\mathrm{Ft}\left(\mathrm{K}_{\mathrm{M}} \mathrm{RT}-1\right)} \\
& \frac{\mathrm{dn}_{\mathrm{B}}}{\mathrm{dt}}=\mathrm{Fc}_{\mathrm{B} 0}-\frac{\mathrm{Qn}_{\mathrm{B}}}{\mathrm{V}+\mathrm{Ft}\left(\mathrm{K}_{\mathrm{A}} \mathrm{RT}\left(1+\mathrm{K}_{\mathrm{b}} / \mathrm{c}_{\mathrm{y} 0}\right)-1\right)} \\
& \frac{\mathrm{dn} \mathrm{N}_{\mathrm{N}}}{\mathrm{dt}}=\frac{\mathrm{EP}}{\mathrm{RT}}+\mathrm{Fc} \mathrm{N}_{\mathrm{N} 0}-\frac{\mathrm{Qn}_{\mathrm{N}}}{\mathrm{V}+\mathrm{Ft}\left(\mathrm{K}_{\mathrm{N}} \mathrm{RT}-1\right)}
\end{aligned}
$$

The hydrogen generation rate, $r$, is the sum of the generation rates due to tank wall corrosion and radiolytic and thermolytic mechanisms (Hu et al. 1997). The corrosion-based generation of hydrogen depends only on the wetted wall area and therefore varies as the tank is filled. Radiolysis depends on nitrate, nitrite, and TOC concentrations and on the radioactive heat generation rate in solution. Thermolysis depends on the temperature and the aluminate and TOC concentrations. The hydrogen generation rates per unit volume liquid from radiolysis and thermolysis (as modeled) do not depend on the tank fill.

There is one more constraint to consider. The pressure in the headspace must remain constant at $\mathrm{P}(1 \mathrm{~atm})$ in spite of ventilation, the release of gas from solution, hydrogen generation, and the piston effect of rising liquid. For the pressure to be constant, $\mathrm{Q}$ must be approximated as

$$
\mathrm{Q}=\mathrm{F}+\left(\mathrm{E}+\frac{\mathrm{RT}}{\mathrm{P}}\left(\mathrm{rXV} / 2+\mathrm{F}\left\{\mathrm{c}_{\mathrm{H} 0}+\mathrm{c}_{\mathrm{MO}}+\mathrm{c}_{\mathrm{N} 0}\right\}\right)\right)\left(1+\frac{\mathrm{p}_{\mathrm{w}}}{\mathrm{P}}+\frac{\mathrm{c}_{\mathrm{B} 0}}{\mathrm{PK}_{\mathrm{A}}\left(1+\mathrm{K}_{\mathrm{b}} / \mathrm{c}_{\mathrm{y} 0}\right)}\right)
$$

where $\mathrm{X}=$ the fraction of the DCRT volume that contains liquid when filling is complete. 
Thus $Q$ is the sum of the liquid feed rate, the inflow ventilation rate, the average hydrogen generation rate in the tank, and the feed of low-solubility gases (which, for this purpose, are treated as entirely released). The outflowing gas volume is augmented by water and ammonia evaporation, as shown by the last multiplying factor in Eq. (9.7).

To make Eq. (9.6) analytically solvable, the hydrogen generation rate per unit volume of liquid, $r$, and the gas outflow rate, $\mathrm{Q}$, must be constant. But the volumetric rate $\mathrm{r}$ is not constant because DCRT corrosion increases during filling as more of the tank surface is wetted. However, an average value for $r$, one calculated when the tank is one-fourth of the way to its final fill volume, can be used with little error (as is demonstrated in Section 9.3 by comparing it with the Hedengren et al. model, which uses a variable volumetric hydrogen generation rate).

As suggested by Eq. (9.7), the gas outflow rate, Q, is close to constant (as are most of its elements). The initial conditions must be consistent with the definition of $\mathrm{Q}$, as will be seen.

At $\mathrm{t}=0$ :

$$
\begin{aligned}
& \mathrm{n}_{\mathrm{H}}=0 \\
& \mathrm{n}_{\mathrm{M}}=0 \\
& \mathrm{n}_{\mathrm{B}}=\frac{\mathrm{c}_{\mathrm{B} 0} \mathrm{~V}}{\mathrm{~K}_{\mathrm{A}} \mathrm{RT}\left(1+\mathrm{K}_{\mathrm{b}} / \mathrm{c}_{\mathrm{y} 0}\right)} \\
& \mathrm{n}_{\mathrm{N}}=\frac{\mathrm{V}}{\mathrm{RT}}\left(\mathrm{P}-\mathrm{p}_{\mathrm{w}}-\frac{\mathrm{c}_{\mathrm{B} 0}}{\mathrm{~K}_{\mathrm{A}}\left(1+\mathrm{K}_{\mathrm{b}} / \mathrm{c}_{\mathrm{y} 0}\right)}\right)
\end{aligned}
$$

These initial conditions state that the DCRT is empty except for water and ammonia at the source vapor pressure. If the ammonia and water vapor were not included in the initial condition, the gas outflow, $\mathrm{Q}$, would need to incorporate a term for the gas pushed out of the DCRT by the initial evaporation.

All of the governing equations (Eq. 9.6) are of the same general form:

$$
\frac{\mathrm{dn}}{\mathrm{dt}}=\mathrm{A}+\mathrm{Dt}-\frac{\mathrm{Qn}}{\mathrm{V}+\mathrm{Bt}}
$$

where A, D, and B are constants that depend on the gas being considered. Eq. (9.9) can be integrated more easily by multiplying it by the integration factor $(\mathrm{V}+\mathrm{Bt})^{\mathrm{Q} / \mathrm{B}}$. This operation gives

$$
\frac{\mathrm{d}}{\mathrm{dt}}\left(\mathrm{n}(\mathrm{V}+\mathrm{Bt})^{\mathrm{Q} / \mathrm{B}}\right)=\mathrm{A}(\mathrm{V}+\mathrm{Bt})^{\mathrm{Q} / \mathrm{B}}+\mathrm{Dt}(\mathrm{V}+\mathrm{Bt})^{\mathrm{Q} / \mathrm{B}}
$$

The solution of Eq. (9.10) is 


$$
\begin{aligned}
\mathrm{n}= & \left(\mathrm{n}_{0}-\frac{\mathrm{AV}}{\mathrm{Q}+\mathrm{B}}+\frac{\mathrm{DV}^{2}}{\mathrm{~B}}\left(\frac{1}{\mathrm{Q}+\mathrm{B}}-\frac{1}{\mathrm{Q}+2 \mathrm{~B}}\right)\right)(1+\mathrm{BX} / \mathrm{F})^{-\mathrm{Q} / \mathrm{B}}+ \\
& \left(\frac{\mathrm{AV}}{\mathrm{Q}+\mathrm{B}}-\frac{\mathrm{DV}^{2}}{\mathrm{~B}(\mathrm{Q}+\mathrm{B})}\right)(1+\mathrm{BX} / \mathrm{F})+\frac{\mathrm{DV}^{2}}{\mathrm{~B}(\mathrm{Q}+2 \mathrm{~B})}(1+\mathrm{BX} / \mathrm{F})^{2}
\end{aligned}
$$

Here (XV/F) has been substituted for the time, $t$, which is consistent with the assumption of constant feed rate, $F$; and $n_{0}$ stands for the initial moles in the DCRT (Eq. 9.8). The definitions of the gas-dependent constants, $\mathrm{A}, \mathrm{D}$, and $\mathrm{B}$, are

for hydrogen:

$$
\mathrm{A}=\mathrm{Fc}_{\mathrm{H} 0} \quad \mathrm{~B}=\mathrm{F}\left(\mathrm{K}_{\mathrm{H}} \mathrm{RT}-1\right) \quad \mathrm{D}=\mathrm{Fr}
$$

for methane:

$$
\mathrm{A}=\mathrm{Fc}_{\mathrm{M} 0} \quad \mathrm{~B}=\mathrm{F}\left(\mathrm{K}_{\mathrm{M}} \mathrm{RT}-1\right) \quad \mathrm{D}=0
$$

for ammonia/ammonium ion:

$$
\mathrm{A}=\mathrm{Fc}_{\mathrm{B} 0} \quad \mathrm{~B}=\mathrm{F}\left(\mathrm{K}_{\mathrm{A}} \mathrm{RT}\left(1+\mathrm{K}_{\mathrm{b}} / \mathrm{c}_{\mathrm{y} 0}\right)-1\right) \quad \mathrm{D}=0
$$

for air:

$$
\mathrm{A}=\mathrm{EP} / \mathrm{RT}+\mathrm{Fc}_{\mathrm{N} 0} \quad \mathrm{~B}=\mathrm{F}\left(\mathrm{K}_{\mathrm{N}} \mathrm{RT}-1\right) \quad \mathrm{D}=0
$$

Eq. (9.11), (9.12), and (9.5) allow the partial pressures of hydrogen, methane, ammonia, and air $\left(\mathrm{p}_{\mathrm{H}}, \mathrm{p}_{\mathrm{M}}, \mathrm{p}_{\mathrm{A}}, \mathrm{p}_{\mathrm{N}}\right)$ to be calculated for any fractional fill, $\mathrm{X}$. The constant pressure constraint is used to test whether the approximation of constant $Q$ was accurate.

$$
\mathrm{p}_{\mathrm{H}}+\mathrm{p}_{\mathrm{M}}+\mathrm{p}_{\mathrm{A}}+\mathrm{p}_{\mathrm{N}}+\mathrm{p}_{\mathrm{w}} \approx \mathrm{P}
$$

In use, Eq. (9.13) is true to within $3 \%$ of the total pressure, P, so the constant outflow approximation holds to within the uncertainty of the inputs.

The equations that describe flammable gases in the DCRT under post-fill conditions are derived in the following way. Using the variable $t$ ' to represent the elapsed time after the fill was completed, the governing mass balance differential equations are

$$
\begin{aligned}
\frac{\mathrm{dn}_{\mathrm{H}}}{\mathrm{dt}^{\prime}} & =\mathrm{r}_{2} \mathrm{XV}-\frac{\mathrm{Q}_{2} \mathrm{n}_{\mathrm{H}}}{\mathrm{V}\left(1+\mathrm{X}\left[\mathrm{K}_{\mathrm{H}} \mathrm{RT}-1\right]\right)} \\
\frac{\mathrm{dn}_{\mathrm{M}}}{\mathrm{dt}^{\prime}} & =\frac{-\mathrm{Q}_{2} \mathrm{n}_{\mathrm{M}}}{\mathrm{V}\left(1+\mathrm{X}\left[\mathrm{K}_{\mathrm{M}} \mathrm{RT}-1\right]\right)}
\end{aligned}
$$




$$
\begin{aligned}
\frac{\mathrm{dn}_{\mathrm{B}}}{\mathrm{dt}^{\prime}} & =\frac{-\mathrm{Q}_{2} \mathrm{n}_{\mathrm{B}}}{\mathrm{V}\left(1+\mathrm{X}\left[\mathrm{K}_{\mathrm{M}} \mathrm{RT}\left(1+\mathrm{K}_{\mathrm{b}} / \mathrm{c}_{\mathrm{y} 0}\right)-1\right]\right)} \\
\frac{\mathrm{dn}_{\mathrm{N}}}{\mathrm{dt}^{\prime}} & =\frac{\mathrm{EP}}{\mathrm{RT}}-\frac{\mathrm{Q}_{2} \mathrm{n}_{\mathrm{N}}}{\mathrm{V}\left(1+\mathrm{X}\left[\mathrm{K}_{\mathrm{N}} \mathrm{RT}-1\right]\right)}
\end{aligned}
$$

where

$X=$ the final fill fraction in the DCRT

$r_{2}=$ the hydrogen generation rate (per unit liquid volume) in the DCRT at and after the completion of filling; units are $\mathrm{mol}_{2} /$ day/L liquid

$\mathrm{Q}_{2}=$ the gas outflow rate (L/day) after filling is complete.

$$
\mathrm{Q}_{2}=\left(\mathrm{E}+\frac{\mathrm{r}_{2} \mathrm{XVRT}}{\mathrm{P}}\right)\left(1+\frac{\mathrm{p}_{\mathrm{w}}}{\mathrm{P}}+\frac{\mathrm{c}_{\mathrm{B} 0}}{\mathrm{PK}_{\mathrm{A}}\left(1+\mathrm{K}_{\mathrm{b}} / \mathrm{c}_{\mathrm{y} 0}\right)}\right)
$$

Eq. (9.14a-d) are all linear differential equations of the form

$$
\frac{\mathrm{dn}}{\mathrm{dt}^{\prime}}+\mathrm{Wn}=\mathrm{U}
$$

The generic solution of Eq. (9.16) is

$$
\mathrm{n}=\mathrm{Ne}^{-\mathrm{wt}}+\frac{\mathrm{U}}{\mathrm{W}}\left(1-\mathrm{e}^{-\mathrm{wt}}\right)
$$

where $\mathrm{N}=$ the moles of the constituent that were in the DCRT when the filling was complete, at $t^{\prime}=0$; found using Eq. (9.11) and (9.12).

Depending on the fill-end concentrations of hydrogen, the ventilation rate, and the postfill hydrogen generation rate, Eq. (9.17) may lead to a steady-state hydrogen concentration that is greater or less than that at the end of the DCRT fill. Ammonia and methane, naturally, consistently decrease (because they have no modeled source terms). If the hydrogen steady-state concentration is greater than the fill-end value, the post-fill flammability rises to a peak with time, then declines as ammonia is removed by ventilation. If the steady-state concentration is less than the fill-end, the LFL decreases with time.

The definitions of the gas-dependent constants $U$ and $W$ in Eq. (9.17) are

for hydrogen:

$$
\mathrm{U}=\mathrm{r}_{2} \mathrm{XV} \quad \mathrm{W}=\frac{\mathrm{Q}_{2}}{\mathrm{~V}\left(1+\mathrm{X}\left[\mathrm{K}_{\mathrm{H}} \mathrm{RT}-1\right]\right)}
$$

for methane: 


$$
\mathrm{U}=0 \quad \mathrm{~W}=\frac{\mathrm{Q}_{2}}{\mathrm{~V}\left(1+\mathrm{X}\left[\mathrm{K}_{\mathrm{M}} \mathrm{RT}-1\right]\right)}
$$

for ammonia/ammonium ion:

$$
\mathrm{U}=0 \quad \mathrm{~W}=\frac{\mathrm{Q}_{2}}{\mathrm{~V}\left(1+\mathrm{X}\left[\mathrm{K}_{\mathrm{A}} \mathrm{RT}\left\{1+\mathrm{K}_{\mathrm{b}} / \mathrm{c}_{\mathrm{y} 0}\right\}-1\right]\right)}
$$

for air:

$$
\mathrm{U}=\frac{\mathrm{EP}}{\mathrm{RT}} \quad \mathrm{W}=\frac{\mathrm{Q}_{2}}{\mathrm{~V}\left(1+\mathrm{X}\left[\mathrm{K}_{\mathrm{N}} \mathrm{RT}-1\right]\right)}
$$

Eq. (9.17), (9.18), and (9.5) allow partial pressures of hydrogen, methane, ammonia, and air $\left(\mathrm{p}_{\mathrm{H}}, \mathrm{p}_{\mathrm{M}}, \mathrm{p}_{\mathrm{A}}, \mathrm{p}_{\mathrm{N}}\right)$ to be calculated, and the constant-pressure constraint is used to test the approximation of constant $\mathrm{Q}_{2}$. This approximation, like that of constant $\mathrm{Q}$, holds to within a few percent.

The flammability of the gases in the DCRT headspace is calculated using the following formula, which gives the fraction of the LFL:

$$
\text { fraction of } \mathrm{LFL}=\frac{\mathrm{p}_{\mathrm{H}}}{0.04 \mathrm{P}}+\frac{\mathrm{p}_{\mathrm{M}}}{0.05 \mathrm{P}}+\frac{\mathrm{p}_{\mathrm{A}}}{0.15 \mathrm{P}}
$$

Here the LFLs for the individual gases are taken to be the upward propagation flammability limits, $4 \mathrm{~mol} \%$ for hydrogen, $5 \mathrm{~mol} \%$ for methane, and $15 \mathrm{~mol} \%$ for ammonia, as discussed in Section 8.

In some cases, the post-fill hydrogen generation rate is high enough (compared with hydrogen outflow by ventilation) to cause the post-fill LFL fraction to reach a peak at some time. (After that time, the flammable gas levels gradually decline because hydrogen reaches a steadystate concentration, but ammonia and methane are constantly leaving the DCRT.) If there is a peak, it occurs when the time derivative of the LFL-fraction is 0. By neglecting methane, which has the least effect on the flammability, we find the peak time, $\tau$, to be approximately

$$
\tau \approx \frac{1}{\mathrm{~W}_{\mathrm{B}}-\mathrm{W}_{\mathrm{H}}} \ln \left(\frac{0.04 \mathrm{M}_{\mathrm{H}}}{0.15 \mathrm{M}_{\mathrm{B}}} \frac{\mathrm{W}_{\mathrm{B}}\left(\mathrm{N}_{\mathrm{B}}-\mathrm{U}_{\mathrm{B}} / \mathrm{W}_{\mathrm{B}}\right)}{\mathrm{W}_{\mathrm{H}}\left(\mathrm{U}_{\mathrm{H}} / \mathrm{W}_{\mathrm{H}}-\mathrm{N}_{\mathrm{H}}\right)}\right)
$$

where

$\mathrm{W}_{\mathrm{B}}=$ the $\mathrm{W}$ for ammonia/ammonium ion, Eq. (9.18c)

$\mathrm{N}_{\mathrm{B}}=$ moles of ammonia/ammonium ion in the DCRT when the fill is complete

$\mathrm{U}_{\mathrm{B}}=$ the $\mathrm{U}$ for ammonia/ammonium ion, Eq. (9.18c)

$\mathrm{W}_{\mathrm{H}} \quad=$ the $\mathrm{W}$ for hydrogen, Eq. (9.18a)

$\mathrm{N}_{\mathrm{H}}=$ moles of hydrogen in the DCRT when the fill is complete

$\mathrm{U}_{\mathrm{H}}=$ the $\mathrm{U}$ for hydrogen, Eq. (9.18a). 
In Eq. (9.20), $M_{B}$ and $M_{H}$ are variables of convenience, with no physical meaning. They are defined as

$$
\begin{aligned}
& M_{B}=P V\left(X_{A}\left(1+K_{b} / c_{y 0}\right)+(1-X) / R T\right) \\
& M_{H}=P V\left(X K_{H}+(1-X) / R T\right)
\end{aligned}
$$

The time at which the LFL fraction reaches some value, such as $25 \%$, is also of interest. This time can be approximated by making two assumptions: first, that the contribution of methane is insignificant, and second, that the ammonia partial pressure is constant over the period of interest. The second assumption is a fairly good one because the rate of ammonia outflow is so small compared with the reservoir dissolved in the liquid. With these simplifications, the time, $t_{L}$, when the $\mathrm{LFL}$ fraction reaches some value, $\mathrm{L}$, is

$$
\mathrm{t}_{\mathrm{L}}=-\frac{1}{\mathrm{~W}_{\mathrm{H}}} \ln \left[\left(\frac{0.04 \mathrm{M}_{\mathrm{H}}}{\mathrm{N}_{\mathrm{H}}-\mathrm{U}_{\mathrm{H}} / \mathrm{W}_{\mathrm{H}}}\right)\left(\mathrm{L}-\frac{\mathrm{U}_{\mathrm{H}} / \mathrm{W}_{\mathrm{H}}}{0.04 \mathrm{M}_{\mathrm{H}}}-\frac{\mathrm{N}_{\mathrm{B}}}{0.15 \mathrm{M}_{\mathrm{B}}}\right)\right]
$$

\subsection{Nonequilibrium Model Derivation}

The assumptions made in the nonequilibrium model differ from those in the equilibrium model as follows:

- The gases dissolved in the liquid pumped into the DCRT are released into the DCRT headspace at a rate limited by mass transfer. In this case, Henry's Law describes the equilibrium that is approached by mass transfer.

- The model suggested by Hu et al. (1997) is used to calculate the hydrogen generation in the DCRT, as in the equilibrium model. The volumetric hydrogen generation rate varies throughout filling in the nonequilibrium model, where it was treated as constant in the equilibrium model. (We show in Section 9.3 that the assumption of a constant rate makes little difference in the results. This assumption was made in the equilibrium model to allow analytical solution; because the nonequilibrium model required numerical solution, the assumption was relaxed.)

- The fill and ventilation inflows are assumed to be constant throughout the operation, as in the equilibrium model. However, the ventilation outflow is allowed to vary throughout filling. It was treated as constant in the equilibrium model, but this assumption was also relaxed in light of the use of a numerical solution.

Much of the notation and derivation that was used for the equilibrium model (see Section 9.1) can be carried over to the nonequilibrium model. We begin with the mass balances on the moles of each constituent in the liquid and vapor phases during DCRT filling:

$$
\frac{d v_{H}}{d t}=k_{H}^{\prime} A^{\prime}\left(\frac{c_{H 0}}{K_{H} R T}-\frac{v_{H}}{V-F t}\right)+k_{H} A\left(\frac{L_{H} / F t}{K_{H} R T}-\frac{v_{H}}{V-F t}\right)-\frac{Q v_{H}}{V-F t}
$$




$$
\begin{aligned}
& \frac{d L_{H}}{d t}=F c_{H 0}-k_{H}^{\prime} A^{\prime}\left(\frac{c_{H 0}}{K_{H} R T}-\frac{v_{H}}{V-F t}\right)-k_{H} A\left(\frac{L_{H} / F t}{K_{H} R T}-\frac{v_{H}}{V-F t}\right)+r F t \\
& \frac{d v_{M}}{d t}=k_{M}^{\prime} A^{\prime}\left(\frac{c_{M 0}}{K_{M} R T}-\frac{v_{M}}{V-F t}\right)+k_{M} A\left(\frac{L_{M} / F t}{K_{M} R T}-\frac{v_{M}}{V-F t}\right)-\frac{Q v_{M}}{V-F t} \\
& \frac{\mathrm{dL}_{\mathrm{M}}}{\mathrm{dt}}=\mathrm{Fc}_{\mathrm{M} 0}-\mathrm{k}_{\mathrm{M}}^{\prime} \mathrm{A}^{\prime}\left(\frac{\mathrm{c}_{\mathrm{M} 0}}{\mathrm{~K}_{\mathrm{M}} \mathrm{RT}}-\frac{\mathrm{v}_{\mathrm{M}}}{\mathrm{V}-\mathrm{Ft}}\right)-\mathrm{k}_{\mathrm{M}} \mathrm{A}\left(\frac{\mathrm{L}_{\mathrm{M}} / \mathrm{Ft}}{\mathrm{K}_{\mathrm{M}} \mathrm{RT}}-\frac{\mathrm{v}_{\mathrm{M}}}{\mathrm{V}-\mathrm{Ft}}\right) \\
& \frac{d v_{A}}{d t}=k_{A}^{\prime} A^{\prime}\left(\frac{c_{B 0}}{K_{A}\left(1+K_{b} / c_{y 0}\right) R T}-\frac{v_{A}}{V-F t}\right)+k_{A} A\left(\frac{L_{B} / F t}{K_{A}\left(1+K_{b} / c_{y 0}\right) R T}-\frac{v_{A}}{V-F t}\right)-\frac{Q v_{A}}{V-F t} \\
& \frac{\mathrm{dL}_{\mathrm{B}}}{\mathrm{dt}}=\mathrm{Fc}_{\mathrm{B} 0}-\mathrm{k}_{\mathrm{A}}^{\prime} \mathrm{A}^{\prime}\left(\frac{\mathrm{c}_{\mathrm{B} 0}}{\mathrm{~K}_{\mathrm{A}}\left(1+\mathrm{K}_{\mathrm{b}} / \mathrm{c}_{\mathrm{y} 0}\right) \mathrm{RT}}-\frac{\mathrm{v}_{\mathrm{A}}}{\mathrm{V}-\mathrm{Ft}}\right)-\mathrm{k}_{\mathrm{A}} \mathrm{A}\left(\frac{\mathrm{L}_{\mathrm{B}} / \mathrm{Ft}}{\mathrm{K}_{\mathrm{A}}\left(1+\mathrm{K}_{\mathrm{b}} / \mathrm{c}_{\mathrm{y} 0}\right) \mathrm{RT}}-\frac{\mathrm{v}_{\mathrm{A}}}{\mathrm{V}-\mathrm{Ft}}\right) \\
& \frac{d v_{N}}{d t}=k_{N}^{\prime} A^{\prime}\left(\frac{c_{N 0}}{K_{N} R T}-\frac{v_{M}}{V-F t}\right)+k_{N} A\left(\frac{L_{N} / F t}{K_{N} R T}-\frac{v_{N}}{V-F t}\right)-\frac{Q v_{N}}{V-F t}+\frac{E P}{R T} \\
& \frac{\mathrm{dL}_{\mathrm{N}}}{\mathrm{dt}}=\mathrm{Fc}_{\mathrm{N} 0}-\mathrm{k}_{\mathrm{N}}^{\prime} \mathrm{A}^{\prime}\left(\frac{\mathrm{c}_{\mathrm{N} 0}}{\mathrm{~K}_{\mathrm{N}} \mathrm{RT}}-\frac{\mathrm{v}_{\mathrm{N}}}{\mathrm{V}-\mathrm{Ft}}\right)-\mathrm{k}_{\mathrm{N}} \mathrm{A}\left(\frac{\mathrm{L}_{\mathrm{N}} / \mathrm{Ft}}{\mathrm{K}_{\mathrm{N}} \mathrm{RT}}-\frac{\mathrm{v}_{\mathrm{N}}}{\mathrm{V}-\mathrm{Ft}}\right) \\
& \frac{d v_{w}}{d t}=k_{w}^{\prime} A^{\prime}\left(\frac{p_{w}}{R T}-\frac{v_{w}}{V-F t}\right)+k_{w} A\left(\frac{p_{w}}{R T}-\frac{v_{w}}{V-F t}\right)-\frac{Q v_{w}}{V-F t}
\end{aligned}
$$

where

$$
\begin{aligned}
& \mathrm{t}=\text { time (days) } \\
& F=\text { volumetric flow rate of feed (L/day); because the flow rate is assumed constant, } \\
& E=\text { volumetric inflow rate of ventilation air (actual } L / \text { day) } \\
& \mathrm{Q}=\text { volumetric flow rate of gas/vapor leaving the DCRT (actual L/day) during the fill } \\
& \mathrm{P}=\text { total pressure in the DCRT (assumed to be } 1 \mathrm{~atm} \text { ) } \\
& \mathrm{T}=\text { the temperature }(\mathrm{K}) \text { in the headspace (assumed the same as that of the waste) } \\
& A=\text { surface area of the liquid in the tank }\left(\mathrm{m}^{2}\right) \\
& A^{\prime}=\text { surface area of the droplet stream }\left(\mathrm{m}^{2}\right) \\
& \mathrm{R}=\text { ideal gas constant, } 0.08206 \mathrm{~atm} \mathrm{L/mol} \mathrm{K} \\
& \mathrm{v}_{\mathrm{H}}=\text { moles of hydrogen gas in the DCRT } \\
& \mathrm{L}_{\mathrm{H}}=\text { moles of dissolved hydrogen in the DCRT }
\end{aligned}
$$


$\mathrm{K}_{\mathrm{H}}=$ Henry's Law constant of hydrogen ( $\left.\mathrm{mol} / \mathrm{L} \mathrm{liq} / \mathrm{atm}\right)$ at feed conditions $\mathrm{k}_{\mathrm{H}}^{\prime}=$ hydrogen mass-transfer coefficient from the droplets $\left(\mathrm{mol} / \mathrm{m}^{2} /\right.$ day $) /(\mathrm{mol} / \mathrm{L})$

$\mathrm{k}_{\mathrm{H}}=$ hydrogen mass-transfer coefficient from the surface $\left(\mathrm{mol} / \mathrm{m}^{2} /\right.$ day $) /(\mathrm{mol} / \mathrm{L})$

$\mathrm{r}=$ hydrogen generation rate per volume of liquid in the DCRT ( $\mathrm{mol} \mathrm{H}_{2} /$ day/L liquid)

$\mathrm{v}_{\mathrm{M}}=$ moles of methane gas in the DCRT

$\mathrm{L}_{\mathrm{M}}=$ moles of dissolved methane in the DCRT

$\mathrm{K}_{\mathrm{M}}=$ Henry's Law constant of methane (mol/L liq/atm) at feed conditions

$\mathrm{k}^{\prime}{ }_{M}=$ methane mass-transfer coefficient from the droplets $\left(\mathrm{mol} / \mathrm{m}^{2} /\right.$ day $) /(\mathrm{mol} / \mathrm{L})$

$\mathrm{k}_{\mathrm{M}}=$ methane mass-transfer coefficient from the surface $\left(\mathrm{mol} / \mathrm{m}^{2} / \mathrm{day}\right) /(\mathrm{mol} / \mathrm{L})$

$\mathrm{v}_{\mathrm{A}}=$ moles of ammonia vapor in the DCRT

$\mathrm{L}_{\mathrm{B}}=$ moles of dissolved ammonia and ammonium ion in the DCRT

$\mathrm{K}_{\mathrm{A}}=$ Henry's Law constant of ammonia (mol/L liq/atm) at feed conditions

$\mathrm{k}_{\mathrm{A}}^{\prime}=$ ammonia mass-transfer coefficient from the droplets $\left(\mathrm{mol} / \mathrm{m}^{2} /\right.$ day $) /(\mathrm{mol} / \mathrm{L})$

$\mathrm{k}_{\mathrm{A}}=$ ammonia mass-transfer coefficient from the surface $\left(\mathrm{mol} / \mathrm{m}^{2} /\right.$ day $) /(\mathrm{mol} / \mathrm{L})$

$\mathrm{v}_{\mathrm{N}}=$ moles of air as gas in the DCRT

$\mathrm{L}_{\mathrm{N}}=$ moles of dissolved air in the DCRT

$\mathrm{K}_{\mathrm{N}}=$ Henry's Law constant of nitrogen ( $\left.\mathrm{mol} / \mathrm{L} \mathrm{liq} / \mathrm{atm}\right)$ at feed conditions

$\mathrm{k}_{\mathrm{N}}^{\prime}=$ air mass-transfer coefficient from the droplets $\left(\mathrm{mol} / \mathrm{m}^{2} / \mathrm{day}\right) /(\mathrm{mol} / \mathrm{L})$

$\mathbf{k}_{\mathrm{N}}=$ air mass-transfer coefficient from the surface $\left(\mathrm{mol} / \mathrm{m}^{2} / \mathrm{day}\right) /(\mathrm{mol} / \mathrm{L})$

$\mathrm{v}_{\mathrm{w}}=$ total moles of water vapor in the DCRT

$\mathrm{p}_{\mathrm{w}}=$ vapor pressure of water in the DCRT (atm)

$\mathbf{k}^{\prime}{ }_{\mathrm{w}}=$ water mass-transfer coefficient from the droplets $\left(\mathrm{mol} / \mathrm{m}^{2} /\right.$ day $) /(\mathrm{mol} / \mathrm{L})$

$\mathrm{k}_{\mathrm{w}}=$ water mass-transfer coefficient from the surface $\left(\mathrm{mol} / \mathrm{m}^{2} /\right.$ day $) /(\mathrm{mol} / \mathrm{L})$.

The first term in each headspace constituent balance is the mass transfer from the falling droplets of feed to the headspace. The second term is the mass transfer from the bulk liquid. The third, containing $Q$, is the ventilation outflow. The air balance, on $v_{N}$, also includes a ventilation inflow term; the net mass transfer for air will generally be into the liquid, not out of it.

The first term in each dissolved constituent balance is the feed into the tank. The second and third terms are the mass transfer from the falling droplets of feed and from the bulk liquid. The hydrogen balance, or $\mathrm{v}_{\mathrm{H}}$, also includes hydrogen generation.

The mass-transfer coefficients in Eq. (9.23) through (9.27) are the overall mass-transfer coefficients defined by Eq. (2.16); they include the effects of both gas- and liquid-side masstransfer limitations (except in the case of water, for which only the gas-side limitations are pertinent). Note that when the liquid and vapor balances are summed for each constituent, we obtain total-moles balances, analogous to Eq. (9.6) for the equilibrium model.

The ventilation outflow rate, $Q$, is defined in such a way (analogous to Eq. 9.7) as to maintain a constant headspace pressure by including all the released vapor in the outflow: 


$$
\begin{aligned}
& Q=E+F+ \\
& \frac{R T}{P}\left[\left(k_{w}^{\prime} A^{\prime}+k_{w} A\right)\left(\frac{p_{w}}{R T}-\frac{v_{w}}{V-F t}\right)+\sum_{i=H, M, A, N}\left[k_{i}^{\prime} A^{\prime}\left(\frac{c_{F i}}{K_{i} R T}-\frac{v_{i}}{V-F t}\right)+k_{i} A\left(\frac{L_{i} / F t}{K_{i} R T}-\frac{v_{i}}{V-F t}\right)\right]\right]
\end{aligned}
$$

Eq. (9.23) through (9.26) cannot be solved analytically. These equations were integrated numerically to find the moles of each constituent in the headspace $\left(v_{i}\right)$; the parameters $Q, r, k_{i}^{\prime}$, $\mathrm{k}_{\mathrm{i}}, \mathrm{A}^{\prime}$, and $\mathrm{A}$ all varied as direct or indirect functions of the fill depth. The variation of the masstransfer coefficients was calculated by determining the coefficients at the beginning and end of the fill and linearly interpolating between those points. The initial conditions on $v_{i}, L_{i}$, and $v_{w}$ were zero in all cases.

Eq. (9.27) was solved analytically by treating $\mathrm{Q}, \mathrm{k}_{\mathrm{i}}^{\prime}, \mathrm{k}_{\mathrm{i}}, \mathrm{A}^{\prime}$, and $\mathrm{A}$ as constants; this equation is of the general form shown in Eq. (9.9), and its solution is

$$
\begin{aligned}
v_{w}= & \left(-\frac{\left(k_{w}^{\prime} A^{\prime}+k_{w} A\right) p_{w} V}{R T\left(k_{w}^{\prime} A^{\prime}+k_{w} A+Q-F\right)}\right)(1-X)^{\left(k_{w}^{\prime} A^{\prime}+k_{w} A+Q\right) / F}+ \\
& \left(\frac{\left(k_{w}^{\prime} A^{\prime}+k_{w} A\right) p_{w} V}{R T\left(k_{w}^{\prime} A^{\prime}+k_{w} A+Q-F\right)}\right)(1-X)
\end{aligned}
$$

The assumption that the various parameters are constant is sufficiently accurate for modeling the water vapor. In fact, $Q$ is constant within $5 \%$ during the latter $90 \%$ of the fill, though initial evaporation makes $Q$ higher at the beginning. The final value of $Q$ was used to find $v_{w}$. The mass-transfer terms vary by about a factor of three during fill; the average values of these terms were used in modeling water vapor. As was done for the equilibrium model, the assumption of constant headspace pressure was checked and found to hold within 3\%, indicating that $\mathrm{Q}$ was defined in a consistent manner.

The following are the mass-balance equations for the post-fill conditions (where the variable $t^{\prime}$ is used to represent elapsed time after the fill was completed):

$$
\begin{aligned}
& \frac{d v_{H}}{d t^{\prime}}=k_{H} A\left(\frac{L_{H} / X V}{K_{H} R T}-\frac{v_{H}^{\prime}}{V(1-X)}\right)-\frac{Q_{2} v_{H}}{V(1-X)} \\
& \frac{d L_{H}}{d t^{\prime}}=-k_{H} A\left(\frac{L_{H} / X V}{K_{H} R T}-\frac{v_{H}}{V(1-X)}\right)+r_{2} X V \\
& \frac{d v_{M}}{d t^{\prime}}=k_{M} A\left(\frac{L_{M} / X V}{K_{M} R T}-\frac{v_{M}}{V(1-X)}\right)-\frac{Q_{2} v_{M}}{V(1-X)} \\
& \frac{d L_{M}}{d t^{\prime}}=-k_{M} A\left(\frac{L_{M} / X V}{K_{M} R T}-\frac{v_{M}}{V(1-X)}\right)
\end{aligned}
$$




$$
\begin{aligned}
& \frac{\mathrm{dv}_{\mathrm{A}}}{d t^{\prime}}=\mathrm{k}_{\mathrm{A}} \mathrm{A}\left(\frac{\mathrm{L}_{\mathrm{B}} / \mathrm{XV}}{\mathrm{K}_{\mathrm{A}}\left(1+\mathrm{K}_{\mathrm{b}} / \mathrm{c}_{\mathrm{y} 0}\right) \mathrm{RT}}-\frac{\mathrm{v}_{\mathrm{A}}}{\mathrm{V}(1-\mathrm{X})}\right)-\frac{\mathrm{Q}_{2} \mathrm{v}_{\mathrm{A}}}{\mathrm{V}(1-\mathrm{X})} \\
& \frac{\mathrm{dL}_{\mathrm{B}}}{\mathrm{dt^{ \prime }}}=-\mathrm{k}_{\mathrm{A}} \mathrm{A}\left(\frac{\mathrm{L}_{\mathrm{B}} / \mathrm{XV}}{\mathrm{K}_{\mathrm{A}}\left(1+\mathrm{K}_{\mathrm{b}} / \mathrm{c}_{\mathrm{y} 0}\right) \mathrm{RT}}-\frac{\mathrm{v}_{\mathrm{A}}}{\mathrm{V}(1-\mathrm{X})}\right) \\
& \frac{\mathrm{dv}_{\mathrm{N}}}{\mathrm{dt^{ \prime }}}=\mathrm{k}_{\mathrm{N}} \mathrm{A}\left(\frac{\mathrm{L}_{\mathrm{N}} / \mathrm{XV}}{\mathrm{K}_{\mathrm{N}} \mathrm{RT}}-\frac{\mathrm{v}_{\mathrm{N}}}{\mathrm{V}(1-\mathrm{X})}\right)-\frac{\mathrm{Q}_{2} \mathrm{v}_{\mathrm{N}}}{\mathrm{V}(1-\mathrm{X})}+\frac{\mathrm{EP}}{\mathrm{RT}} \\
& \frac{\mathrm{dL}_{\mathrm{N}}}{d t^{\prime}}=-\mathrm{k}_{\mathrm{N}} \mathrm{A}\left(\frac{\mathrm{L}_{\mathrm{N}} / \mathrm{XV}}{\mathrm{K}_{\mathrm{N}} \mathrm{RT}}-\frac{\mathrm{v}_{\mathrm{N}}}{\mathrm{V}(1-\mathrm{X})}\right) \\
& \frac{\mathrm{dv}_{\mathrm{w}}}{\mathrm{dt^{ \prime }}}=\mathrm{k}_{\mathrm{w}} \mathrm{A}\left(\frac{\mathrm{p}_{\mathrm{w}}}{\mathrm{RT}}-\frac{\mathrm{v}_{\mathrm{w}}}{\mathrm{V}(1-\mathrm{X})}\right)-\frac{\mathrm{Q}_{2} \mathrm{v}_{\mathrm{w}}}{\mathrm{V}(1-\mathrm{X})}
\end{aligned}
$$

where

$\mathrm{X}=$ the final fill fraction in the DCRT

$\mathrm{r}_{2}=$ the hydrogen generation rate (per unit liquid volume) in the DCRT at and after the completion of filling; units are $\mathrm{mol}_{2} /$ day/L liquid

$\mathrm{Q}_{2}=$ the gas outflow rate ( $\mathrm{L} /$ day) after filling is complete; the definition of $\mathrm{Q}_{2}$ is the same as for the equilibrium model, Eq. (9.15).

If $\mathrm{Q}_{2}$ is considered constant, an assumption that is accurate to within a few percent, and if the mass-transfer coefficient for the surface is constant, which it should be, then Eq. (9.30) through (9.34) can be solved analytically. The general form of the solution for the post-fill moles of a non-water constituent, $v^{\prime}$, in the headspace is

$$
v_{i}^{\prime}=\frac{e^{-(b+c+u) t^{\prime} / 2}}{2(c-d) u}\left\{\begin{array}{l}
\left(1-e^{u t^{\prime}}\right)\left((c-d)\left(v_{f}(c-b)-a-2 b L_{f}\right)+b(f+a)+a d+f c\right]+ \\
\ldots u\left(1+e^{u u^{\prime}}\right)\left(v_{f}(c-d)-(a+f)\right)+2 u(a+f) e^{(b+c+u) t^{\prime} / 2}
\end{array}\right\}
$$

where $v_{f}$ and $L_{f}$ are, respectively, the moles of the constituent in the gas and liquid phases at the end of the fill (that is, the initial condition of the post-fill) and a, b, c, d, f, and u are coefficients that have the following meanings:

$$
\begin{aligned}
& a=\frac{E P}{R T} \text { for nitrogen, and is zero for other constituents } \\
& b=\frac{k_{i} A}{K_{i} R T X V} \text { for all non-water constituents }
\end{aligned}
$$


$c=\frac{k_{i} A+Q_{2}}{V(1-X)}$ for all non-water constituents

$d=\frac{k_{i} A}{V(1-X)}$ for all non-water constituents

$\mathrm{f}=\mathrm{VXr}_{2}$ for hydrogen, and is zero for other constituents

$u=\sqrt{(b-c)^{2}+4 b d}$ for all non-water constituents

The solution of Eq. (9.34) for the post-fill moles of water, $v^{\prime}$, in the DCRT headspace is simpler:

$$
v_{w}^{\prime}=\frac{k_{w} A p_{w} V(1-X)}{R T\left(Q_{2}+k_{w} A\right)}\left(1-e^{-\left(Q_{2}+k_{w} A\right) t / V(1-X)}\right)+v_{w f} e^{-\left(Q_{2}+k_{w} A\right) t / V(1-X)}
$$

where $\mathrm{v}_{\mathrm{wf}}=$ moles of water vapor in the DCRT at the end of the fill.

Eq. (9.35) through (9.42) were used to calculate the post-fill moles of vapor and gas. The assumption of constant headspace pressure was checked and found to hold within $3 \%$, indicating that $\mathrm{Q}_{2}$ was defined in a consistent manner. The fill-end and post-fill DCRT headspace flammabilities were calculated from the headspace moles using the same relation, Eq. (9.19), that was used for the equilibrium model.

\subsection{Testing the Equilibrium Model Against the Prior Model}

The equilibrium model derived in Section 9.1 was tested using the same tank-by-tank inputs that were employed by Hedengren et al. (1997) with their numerical model. The results of the comparison are given in part in Table 9.1. The purposes of the table are to allow a crosscheck with the Hedengren model and to illustrate the extent of the reduction in conservatism that results from including water vapor pressure, methane equilibrium, and ammonia loss from the liquid in the model (as noted in Section 2.5). Note that Hedengren et al. did not take credit for the gradual loss of ammonia; thus their post-fill flammabilities level off at a higher or lower steady-state value as a function of hydrogen generation rate in the DCRT. The present model predicts either a peak, followed by a decline, or a steady decline from the fill-end value.

The majority of the DCRT headspace flammability values calculated using the equilibrium model were within $\pm 1 \%$ of the LFL of those from the model used by Hedengren et al. (1997). For brevity, the flammability predictions that matched are not shown in Table 9.1. The exceptions were the post-fill results for Tanks S-106, SX-102, SX-103, SX-104, and SX-105, and the fill-end results for Tank T-104. In all these cases the model used by Hedengren et al. (1997) predicted more conservative (larger) flammabilities, as can be seen in the table. 
Table 9.1. Partial Comparison of Predictions Made by the Hedengren et al. (1997) and Present Models, Using the Same Inputs

\begin{tabular}{|c|c|c|c|c|c|c|c|c|c|}
\hline & \multicolumn{8}{|c|}{ Base Case: DCRT $80 \%$ full, feed rate $4 \mathrm{gpm}$, ventilation $3 \mathrm{acfh}$} \\
\hline & & \multicolumn{4}{|c|}{ Hedengren et al. Model } & \multicolumn{4}{|c|}{ Present Equilibrium Model } \\
\hline & & \multicolumn{2}{|c|}{ End of Fill } & \multicolumn{2}{|c|}{ Post-fill } & \multicolumn{2}{|c|}{ End of Fill } & \multicolumn{2}{|c|}{ Post-fill } \\
\hline Tank & DCRT & $\begin{array}{l}\mathrm{H}_{2} \\
\text { (\% of } \\
\text { LFL) }\end{array}$ & $\begin{array}{l}\text { Total } \\
\text { (\% of } \\
\text { LFL) }\end{array}$ & \begin{tabular}{|c} 
Steady- \\
state $\mathrm{H}_{2}$ \\
$(\%$ of \\
LFL)
\end{tabular} & \begin{tabular}{|c} 
Steady- \\
state \\
Total \\
(\% of \\
LFL) \\
\end{tabular} & $\begin{array}{l}\mathrm{H}_{2} \\
\text { (\% of } \\
\mathrm{LFL})\end{array}$ & $\begin{array}{l}\text { Total } \\
\text { (\% of } \\
\text { LFL) }\end{array}$ & $\begin{array}{c}\text { Steady- } \\
\text { state } \mathrm{H}_{2} \\
(\% \text { of } \\
\text { LFL) }\end{array}$ & $\begin{array}{l}\text { Peak } \\
\text { Total } \\
\text { (\% of } \\
\text { LFL) }\end{array}$ \\
\hline$S-106^{(b)}$ & $S$ & 3.1 & 4.7 & 3.2 & 4.8 & 3.2 & 4.8 & 3.2 & $\mathbf{D}^{(a)}$ \\
\hline SX-102 & $\underline{S}$ & 5.2 & 7.8 & 11.8 & 14.2 & 5.2 & 7.8 & 10.9 & 13.2 \\
\hline $\mathrm{SX}-103$ & $\underline{\mathbf{S}}$ & 8.7 & 13.1 & 30.5 & 34.7 & 8.2 & 12.6 & 26.1 & 29.3 \\
\hline SX-104 & $\underline{S}$ & 7.1 & 10.7 & 20.9 & 24.4 & 6.8 & 10.4 & 18.4 & 21.4 \\
\hline SX-105 & $\underline{\mathbf{S}}$ & 9.6 & 14.4 & 36.7 & 41.3 & 9.0 & 13.8 & 30.9 & 34.1 \\
\hline $\mathrm{T}-104^{(\mathrm{c})}$ & $\mathrm{TX}$ & 14.6 & 18.8 & 3.4 & 4.2 & 15.2 & 16.9 & 2.9 & D \\
\hline \multicolumn{10}{|c|}{$\begin{array}{l}\text { (a) D in the peak post-fill column indicates that the flammability does not reach a peak after filling, } \\
\text { but consistently declines. } \\
\text { (b) The boldface font indicates the \% of LFL values for which the present model disagrees with the } \\
\text { Hedengren et al. model by } 1 \% \text { of LFL or more. } \\
\text { (c) Because T- } 104 \text { was recently salt-well pumped, the base-case is assumed to be } 4 \text { gpm flow for } 25 \\
\text { minutes and } 0.5 \text { gpm thereafter; during the } 0.5 \text { gpm period, the dissolved hydrogen concentration is } \\
\text { reduced by } 50 \% \text { to account for lower pressure on the solution. }\end{array}$} \\
\hline
\end{tabular}

The Hedengren et al. (1997) model predicted only a very slight rise in the percent of the LFL in the DCRT headspace in the post-fill period, indicating that hydrogen generation and hydrogen outflow were nearly equal at the end of the fill. The present model, unlike that of Hedengren et al., includes water and ammonia evaporation as part of the volumetric outflow rate. That is, the gases that enter and leave the DCRT are treated as saturated with ammonia and water vapor. This increases the outflow by a few percent over the conservative Hedengren et al. value, making hydrogen outflow higher than generation in S-106 and causing a slow post-fill decline in flammability.

The differences in post-fill flammability predictions for the wastes from the four SX tanks also come from the equilibrium model's inclusion of water and ammonia evaporation. Tanks SX-102, SX-103, SX-104, and SX-105 (uniquely among the tanks considered) have waste temperatures that are higher than $55^{\circ} \mathrm{C}$. As a result, the combined water and ammonia vapor pressures are $9,18,14$, and $20 \%$, respectively, of the DCRT headspace pressure and increase the volumetric outflow rate correspondingly. The differences in the two models' predictions match the fractional increases from evaporation, as the table shows. (Note that the evaporative increase in flow affects all the tanks, but at the more usual low temperatures the effect is less than 5\%.)

The difference in the calculated total flammability for Tank T-104 arises from the methane contribution. Hedengren et al. (1997) predict a methane flammability of $3.4 \%$ of the LFL; with the same inputs, the equilibrium model shows $0.9 \%$ of the LFL. The Hedengren 
model's higher methane contribution comes from its assumption that all of the methane entering the DCRT is released to the final headspace. This assumption, which is not made by the present model, produces unusually high methane estimates for Tank T-104 because of its uniquely low feed rate ( $4 \mathrm{gpm}$ for the first 100 gallons and $0.5 \mathrm{gpm}$ for the rest of the fill). The longer fill time allows more ventilation to sweep out gases, a methane-removal mechanism reflected in the present model but not in the Hedengren et al. model.

Thus all of the significant differences between the Hedengren et al. (1997) DCRT flammable gas model and the equilibrium model in the present report have been examined and resolved. The approximations of constant gas outflow rate and hydrogen generation rate, therefore, do not seem to cause any significant systematic error. The present model tends to lead to less overprediction of the headspace flammability, especially at high waste temperatures, because it includes water and ammonia vapor in the gas outflow.

\subsection{Flammability Calculations Based on Section 2 Inputs}

The conclusions of Section 2 lead us to use gas solubilities and dissolved gas concentrations in the DCRT feed that are somewhat different than those used in Hedengren et al. (1997). To show the extent to which these changes, in and of themselves, affect the calculated headspace flammability, the equilibrium model was run with the dissolved gas concentrations and gas solubilities specified in Section 2. Other inputs:

- Tank pressures, salt and TOC concentrations, temperatures, etc., were taken from Hedengren et al. (1997) with the hydroxide concentration adjusted to reflect conversion to aluminate at high $\mathrm{pH}$ (see Section 2.2.6).

- A "base-case" fill scenario was used, with the maximum 4-gpm feed rate, the minimum 3 acfh ventilation, and $80 \%$ filling of the DCRT.

The results of the equilibrium model with changed inputs are given in Table 9.2, along with the results obtained by Hedengren et al. (1997) for the same base-case fill scenario but for their own set of dissolved concentration inputs. The differences in the predicted flammabilities are primarily the result of the changes in inputs (though there are minor differences resulting from model changes, as was shown in Table 9.1).

Using the changed inputs, ten tanks (S-102, S-109, SX-102, SX-103, SX-105, SX-106, U-103, U-105, U-106, and U-108) contain wastes that are predicted to produce DCRT headspace flammabilities that are close to or more than $25 \%$ of the LFL. None of these results should be construed as actual flammability predictions, since we believe that the assumed ventilation rate of 3 acfh (which we use, as did Hedengren et al. (1997), in the absence of a better estimate) is far too low. The results given in Table 9.2 do, however, provide a kind of sensitivity test to show which tank wastes are most likely to cause high DCRT headspace flammabilities. We therefore concentrate on these 10 tank wastes in subsequent modeling. 
Table 9.2. Comparison of Hedengren et al. (1997) Model Results with Previous Inputs and Equilibrium Model with Revised Inputs

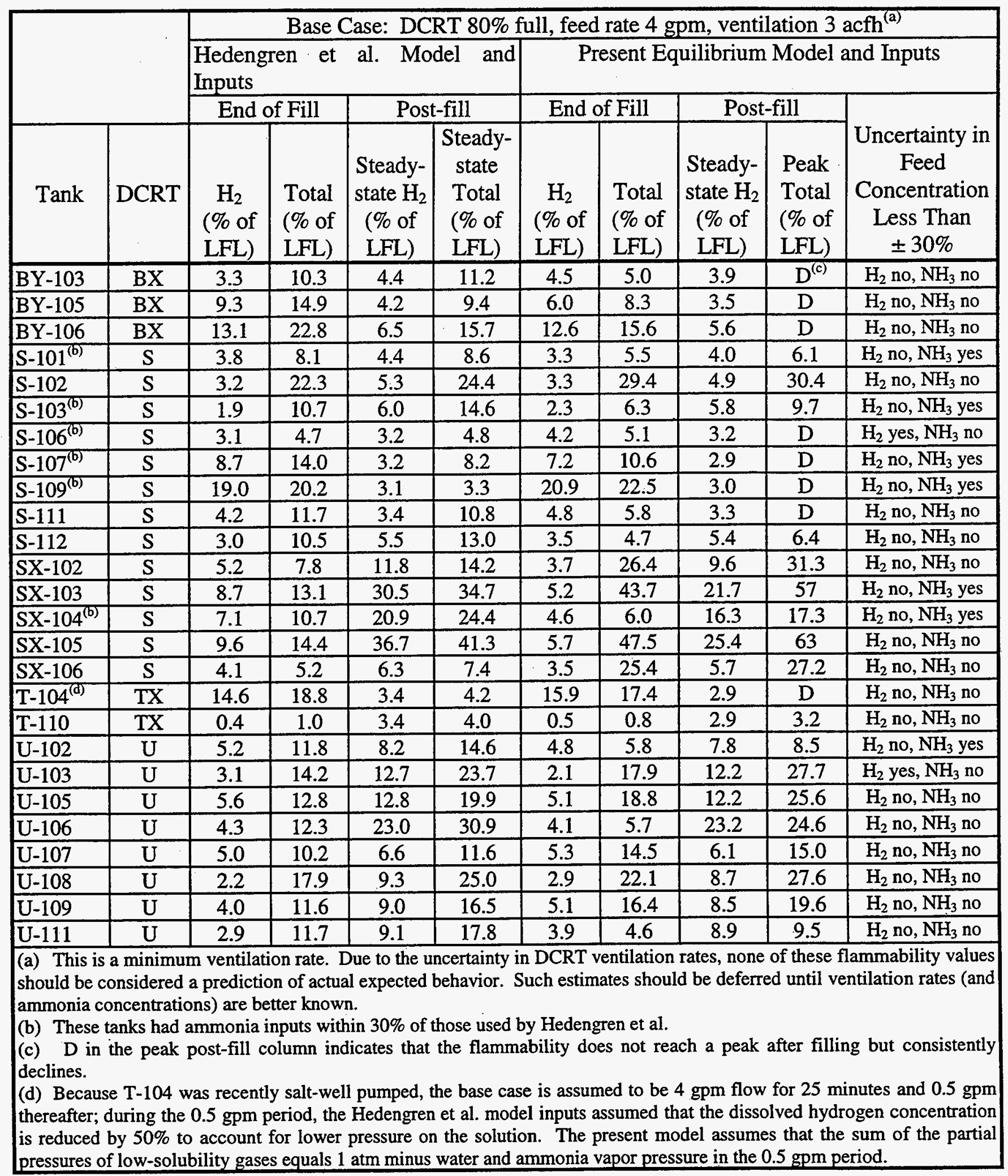


- In all of these ten wastes except those of S-109, SX-103, SX-105, and U-106, ammonia causes the predicted high DCRT headspace flammability. Among the exceptions, low salt concentrations lead to high carryover of dissolved hydrogen from S-109; hydrogen generation causes high post-fill flammability in the DCRT headspace for waste from U-106. The DCRT flammability produced by SX-103 and SX-105 waste is dominated by ammonia, but hydrogen generation alone could cause high flammability in the post-fill period.

- Table 9.2 shows which tanks have had hydrogen or ammonia measurements whose uncertainties are within $\pm 30 \%$ (based on the discussions in Section 2). Otherwise, uncertainties of $\pm 50 \%$ or more should be assumed. The uncertainties can be applied directly to the hydrogen and ammonia flammabilities. (Because the contribution of methane is small, the ammonia flammability is about equal to the difference between the total and hydrogen flammabilities.) Hydrogen and ammonia fill-end flammabilities are generally linearly proportional to the dissolved concentrations in the feed. The same is true for the ammonia post-fill flammability. However, the hydrogen post-fill flammability depends almost entirely on the hydrogen generation rate and so is not affected by feed concentration uncertainty.

As discussed in Section 9.3, water vapor is calculated to make up 9\% or more of the DCRT headspace gas over wastes from Tanks SX-103 and SX-105. The high concentrations of ammonia and water vapor in the DCRT headspace over wastes from these tanks may reduce the oxygen partial pressure enough to reduce the chances of combustion. But, as was pointed out in Section 8.2, there is no assurance that combustion would be prevented.

In the base-case (minimum-ventilation) fill scenario, the post-fill flammability peak occurs days to weeks after DCRT filling ends. In many cases, the higher the fill-end flammability, the sooner the peak occurs. The equilibrium model predicts that waste from S-102 produces a peak in 23 days for the base-case scenario; wastes from SX-102, SX-103, SX-105, and SX-106 require 25 to 28 days; and the time to peak ranges from 37 to 130 days for those of the remaining tanks in which peaks occur at all.

\subsection{Comparison of Equilibrium and Nonequilibrium Models}

The conservatism of the equilibrium model is of most concern when ventilation rates are high and when the wastes that cause higher DCRT headspace flammabilities are being modeled. Table 9.3 compares the flammabilities calculated by the equilibrium and nonequilibrium models, both using revised inputs, for the 10 tank wastes for which the equilibrium model yielded high DCRT headspace flammability. We still use the base-case minimum ventilation rate ( 3 acfh), fill rate (4 gpm), and final fill ( $80 \%$ of the DCRT volume). The equilibrium model predictions are therefore the same as those given in Table 9.2.

As can be seen in Table 9.3, the equilibrium model predicts higher fill-end flammabilities than the nonequilibrium model does, but at only 3 -acfh ventilation the overprediction is generally $20 \%$ or less of the nonequilibrium total flammability. The S-109 waste stands out as an exception: for this waste, much of whose flammability comes from dissolved hydrogen, the equilibrium model predicts twice the total fill-end flammability given by the nonequilibrium 
Table 9.3. Comparison of Predictions Made by the Equilibrium Model and the Nonequilibrium Model for 3-acfh Ventilation

\begin{tabular}{|l|c|c|c|c|c|c|c|c|}
\hline \multirow{8}{*}{} & \multicolumn{7}{|c|}{ Base Case: DCRT 80\% full, feed rate 4 gpm, ventilation 3 acfh, } \\
Section 2 inputs
\end{tabular}

model. This reflects the nonequilibrium model's consistent prediction of lower fill-end hydrogen contributions (often less than half the equilibrium model's values). The lower hydrogen contributions result from the low overall mass-transfer coefficients for hydrogen (see the discussion in Section 2.5.1). Ammonia has a much higher overall mass-transfer coefficient, and its flammability contributions are not much reduced by mass-transfer limitations.

For the post-fill flammabilities, the differences between the equilibrium and nonequilibrium model predictions are smaller. The total flammabilities predicted by the equilibrium model are higher, by $10 \%$ or less of the nonequilibrium values. However, the post-fill hydrogen contributions are slightly higher in the nonequilibrium model for both DCRTs. This difference appears to be numerical in nature: the equilibrium and nonequilibrium post-fill models are affected slightly differently by the assumptions that were made to obtain an analytical solution.

Table 9.4 makes the same comparison between the equilibrium and nonequilibrium models, but at the higher ventilation rate of 30 acfh $(0.5 \mathrm{acfm})$ rather than $3 \mathrm{acfh}$. Once again, fill-end hydrogen flammabilities are reduced more by mass-transfer limitations than are the total flammabilities, and the total flammabilities predicted by the equilibrium model are high by $20 \%$ or less of the nonequilibrium total flammability.

Table 9.5 extends the comparison of equilibrium and nonequilibrium models to the ventilation rate of $300 \mathrm{acfh}$ ( $5 \mathrm{acfm}$ ), which is typical of passively ventilated SSTs (as was mentioned in Section 7.2). At this ventilation rate, the total flammabilities predicted by the equilibrium model are high by $20-50 \%$ of the nonequilibrium total flammability. 
Table 9.4. Comparison of Predictions Made by the Equilibrium Model and the Nonequilibrium Model for 30-acfh Ventilation

\begin{tabular}{|c|c|c|c|c|c|c|c|c|}
\hline \multirow[b]{4}{*}{ Tank } & \multicolumn{8}{|c|}{ DCRT $80 \%$ full, feed rate $4 \mathrm{gpm}$, ventilation 30 acfh, Section 2 inputs } \\
\hline & \multicolumn{4}{|c|}{ Equilibrium Model } & \multicolumn{4}{|c|}{ Nonequilibrium Model } \\
\hline & \multicolumn{2}{|c|}{ End of Fill } & \multicolumn{2}{|c|}{ Post-Fill } & \multicolumn{2}{|c|}{ End of Fill } & \multicolumn{2}{|c|}{ Post-Fill } \\
\hline & $\begin{array}{l}\mathrm{H}_{2} \\
(\% \text { of } \\
\mathrm{LFL})\end{array}$ & $\begin{array}{l}\text { Total } \\
\text { (\% of } \\
\text { LFL) }\end{array}$ & $\begin{array}{c}\text { Steady- } \\
\text { state } \mathrm{H}_{2} \\
(\% \text { of } \\
\text { LFL) }\end{array}$ & $\begin{array}{l}\text { Peak } \\
\text { Total } \\
\text { (\% of } \\
\text { LFL) }\end{array}$ & $\begin{array}{c}\mathrm{H}_{2} \\
(\% \text { of } \\
\mathrm{LFL})\end{array}$ & $\begin{array}{l}\text { Total } \\
\text { (\% of } \\
\text { LFL) }\end{array}$ & $\begin{array}{c}\text { Steady- } \\
\text { state } \mathrm{H}_{2} \\
(\% \text { of } \\
\text { LFL) }\end{array}$ & $\begin{array}{l}\text { Peak } \\
\text { Total } \\
\text { (\% of } \\
\text { LFL) }\end{array}$ \\
\hline S-102 & 1.8 & 27.5 & 0.5 & $D^{(a)}$ & 0.7 & 25.1 & 0.5 & $\bar{D}$ \\
\hline S-109 & 11.6 & 12.6 & 0.3 & $\mathrm{D}$ & 5.6 & 6.0 & 0.3 & $\mathrm{D}$ \\
\hline $\mathrm{SX}-102$ & 2.0 & 24.1 & 1.0 & $\mathrm{D}$ & 0.8 & 21.2 & 1.0 & D \\
\hline SX-103 & 2.8 & 39.2 & 2.2 & $\mathrm{D}$ & 0.8 & 33.6 & 2.3 & D \\
\hline SX-105 & 3.0 & 42.3 & 2.6 & $\mathrm{D}$ & 0.9 & 36.0 & 2.7 & D \\
\hline SX-106 & 2.0 & 23.6 & 0.6 & $\bar{D}$ & 0.8 & 21.4 & 0.6 & $\bar{D}$ \\
\hline $\mathrm{U}-103$ & 1.3 & 17.0 & 1.2 & $\mathrm{D}$ & 0.4 & 15.6 & 1.3 & 15.8 \\
\hline$\overline{\mathrm{U}}-105$ & 2.9 & 16.5 & 1.2 & $\mathrm{D}$ & 1.2 & 14.5 & 1.2 & $\bar{D}$ \\
\hline U-106 & 2.5 & 4.0 & 2.3 & D & 0.8 & 2.2 & 2.3 & 3.7 \\
\hline U-108 & 1.7 & 20.7 & 0.9 & $\mathrm{D}$ & 0.6 & 19.2 & 0.9 & D \\
\hline
\end{tabular}

Table 9.5. Comparison of Predictions Made by the Equilibrium Model and the Nonequilibrium Model for 300-acfh Ventilation

\begin{tabular}{|c|c|c|c|c|c|c|c|c|}
\hline \multirow[b]{4}{*}{ Tank } & \multicolumn{8}{|c|}{ DCRT $80 \%$ full, feed rate $4 \mathrm{gpm}$, ventilation $300 \mathrm{acfh}$, Section 2 inputs } \\
\hline & \multicolumn{4}{|c|}{ Equilibrium Model } & \multicolumn{4}{|c|}{ Nonequilibrium Model } \\
\hline & \multicolumn{2}{|c|}{ End of Fill } & \multicolumn{2}{|c|}{ Post-Fill } & \multicolumn{2}{|c|}{ End of Fill } & \multicolumn{2}{|c|}{ Post-Fill } \\
\hline & $\begin{array}{l}\mathrm{H}_{2} \\
(\% \text { of } \\
\text { LFL) }\end{array}$ & $\begin{array}{l}\text { Total } \\
\text { (\% of } \\
\text { LFL) }\end{array}$ & $\begin{array}{c}\text { Steady- } \\
\text { state } \mathrm{H}_{2} \\
\text { (\% of } \\
\text { LFL) }\end{array}$ & $\begin{array}{l}\text { Peak } \\
\text { Total } \\
\text { (\% of } \\
\text { LFL) }\end{array}$ & $\begin{array}{l}\mathrm{H}_{2} \\
(\% \text { of } \\
\text { LFL) }\end{array}$ & $\begin{array}{l}\text { Total } \\
\text { (\% of } \\
\text { LFL) }\end{array}$ & $\begin{array}{c}\text { Steady- } \\
\text { state } \mathrm{H}_{2} \\
(\% \text { of } \\
\text { LFL) }\end{array}$ & $\begin{array}{l}\text { Peak } \\
\text { Total } \\
\text { (\% of } \\
\text { LFL) }\end{array}$ \\
\hline S-102 & 0.2 & 24.1 & 0.0 & $\mathrm{D}^{(\mathrm{a})}$ & 0.1 & 17.3 & 0.1 & $\mathrm{D}$ \\
\hline S-109 & 1.5 & 1.7 & 0.0 & $\mathrm{D}$ & 0.6 & 0.7 & 0.0 & $\mathrm{D}$ \\
\hline SX-102 & 0.3 & 19.6 & 0.1 & $\mathrm{D}$ & 0.1 & 12.9 & 0.1 & D \\
\hline SX-103 & 0.4 & 29.2 & 0.2 & $\mathrm{D}$ & 0.1 & 17.2 & 0.2 & $\mathrm{D}$ \\
\hline SX-105 & 0.4 & 30.9 & 0.3 & $\mathrm{D}$ & 0.1 & 17.9 & 0.3 & $\mathrm{D}$ \\
\hline SX-106 & 0.3 & 24.5 & 0.1 & $\mathrm{D}$ & 0.1 & 15.3 & 0.1 & $\mathrm{D}$ \\
\hline U-103 & 0.2 & 15.2 & 0.1 & D & 0.0 & 12.7 & 0.1 & D \\
\hline U-105 & 0.4 & 13.4 & 0.1 & $\bar{D}$ & 0.1 & 11.3 & 0.1 & D \\
\hline U-106 & 0.4 & 1.8 & 0.2 & $\mathrm{D}$ & 0.1 & 1.3 & 0.2 & $\mathrm{D}$ \\
\hline U-108 & 0.2 & 18.3 & 0.1 & $\mathrm{D}$ & 0.1 & 15.0 & 0.1 & $\mathrm{D}$ \\
\hline
\end{tabular}


Note that for all these tanks a 5-acfm ventilation rate is sufficient to reduce the DCRT headspace flammability to below $25 \%$ of the LFL. However, because of the uncertainty in the ammonia concentration of the unmeasured tanks, these flammability estimates should not be taken as complete assurance of flammability reduction.

In general, it appears that the equilibrium model overestimates the hydrogen flammability by more than a factor of 2 during fill and by $10 \%$ or less after filling is complete. Because dissolved hydrogen does not contribute much to headspace flammability for most wastes, the equilibrium model usually gives a fairly close estimate of total DCRT headspace flammability in the 3 to 30 acfh ventilation range. (Actual ventilation rates may be substantially higher, however, and at ventilation rates on the order of $5 \mathrm{acfm}$ the equilibrium model may overpredict by as much as $50 \%$.)

Though the total headspace flammabilities predicted by the equilibrium and nonequilibrium models are about the same, the equilibrium model does not accurately predict the ventilation rates required to maintain DCRT headspace flammability below $25 \%$ of the LFL. Table 9.6 shows the minimum ventilation rates calculated by the two models. Whenever the equilibrium model predicts minimum required ventilation rates that are more than about 10 acfh, it overpredicts the needed ventilation by a factor of 3 or more. The exception, once again, is the waste from Tank S-109. In this case, the equilibrium model underpredicts the needed ventilation. The flammability of S-109 waste comes primarily from dissolved hydrogen while the other wastes under consideration have high ammonia, of which there is a large reservoir in the liquid.

Because the headspace flammability does not vary strongly with ventilation rate, the small differences in flammability predicted by the two models require large differences in predicted ventilation to reach the same final flammability. Thus a nonequilibrium model is clearly preferable to an equilibrium model for calculating mitigating ventilation rates.

Table 9.6. Comparison of Mitigating Ventilation Rates Calculated by the Equilibrium and Nonequilibrium Models

\begin{tabular}{|l|c|c|}
\hline \multirow{2}{*}{ Tank } & \multicolumn{2}{|c|}{$\begin{array}{c}\text { Minimum ventilation needed to achieve 25\% of LFL } \\
\text { (acfh) DCRT 80\% full, feed rate 4 gpm, Section 2 inputs }\end{array}$} \\
\cline { 2 - 3 } & Equilibrium Model & Nonequilibrium Model \\
\hline S-102 & 180 & 32 \\
\hline S-109 & 0.37 & 0.58 \\
\hline SX-102 & 17 & 5.5 \\
\hline SX-103 & 520 & 125 \\
\hline SX-105 & 580 & 150 \\
\hline SX-106 & 6.4 & 3.9 \\
\hline U-103 & 3.9 & 3.8 \\
\hline U-105 & 3.2 & 3.1 \\
\hline U-106 & 3.0 & 3.0 \\
\hline U-108 & 4.3 & 4.0 \\
\hline
\end{tabular}


As shown in Table 9.6, the minimum required ventilation rates calculated by the nonequilibrium model are highest for wastes from Tanks SX-103 and SX-105, at 2 to 2.5 acfm (130 to 150 acfh), respectively. Hedengren et al. (1997), who assumed substantially lower dissolved ammonia concentrations for these two tanks but also assumed instantaneous equilibrium, predicted much lower ventilation rates necessary to maintain flammability below $25 \%$ of the LFL. Most of the difference between the Hedengren et al. predictions and those from the present study can be accounted for by the difference in the assumed ammonia concentration. Hedengren et al. also suggested possible operational changes, such as reducing the feed rate, that might allow such tanks to be pumped without exceeding $25 \%$ of the LFL even with minimal ventilation, but this document does not attempt formally to address such operational changes.

\subsection{Effects of Uncertainty in the Parameters}

Our discussion has established that there is substantial uncertainty in some of the variables used in the present model. Among the most uncertain inputs are the ventilation rate (Section 7), the dissolved ammonia concentration in the feed (Section 2), the solubility of hydrogen and methane (Section 2), and the hydrogen generation rate (Section 5). The differences between the flammability predictions made by Hedengren et al. (1997) and those of the present equilibrium model using the revised inputs (Table 9.2) are indications of the effects of the uncertainty in the DCRT feed concentrations. This section further explores the effects of input uncertainty and control measures such as changes in feed and ventilation rate, through parametric analyses. The nonequilibrium model and revised inputs are used throughout.

Figures 9.1 and 9.2 show the effects of varying the source concentrations, feed rate, percent fill, and ventilation in two different cases. The first case is waste from Tank U-103, a typical high-ammonia, low-temperature tank; the second case is that of waste from Tank SX-103, a typical high-ammonia, high-temperature tank. Note that wastes that are considerably different from the modeled waste (for example, S-109 waste, which contains less salt and more dissolved hydrogen) may not behave in the same way as the modeled wastes and so should be modeled specifically. Table 9.7 shows the input parameters used in modeling the wastes from $\mathrm{U}-103$ and SX-103.

Figure 9.1 is an overview of the effects of varying the feed concentrations and hydrogen generation rate on the DCRT headspace flammability, both at the end of the fill and afterward. The plot shows the feed concentrations of the tanks that were modeled in Section 9.3 and categorizes them into those for which the ammonia concentration in the feed has been measured and those for which it has not.

The plot at the left of Figure 9.1 shows the criterion that the dissolved hydrogen must meet, given a certain dissolved ammonia concentration, if the fill-end flammability is to be below $25 \%$ of the LFL. (It is appropriate to speak only of ammonia, rather than ammonia plus ammonium ion, because these two wastes are modeled at a $\mathrm{pH}$ high enough to ensure that no significant amount of ammonium ion is present.) In this plot, most of the controlling parameters in Table 9.3 are held at the specific U-103 or SX-103 values in the table, including the salt concentration, temperature, pressure, and solubility constants. The fill parameters, ventilation rate, and hydrogen generation rate were also held at the tabulated values. Only the dissolved hydrogen and ammonia concentrations were varied for the plot on the left of Figure 9.1. 
rate, and hydrogen generation rate were also held at the tabulated values. Only the dissolved hydrogen and ammonia concentrations were varied for the plot on the left of Figure 9.1.

This plot shows that the limiting concentrations (for $25 \%$ of LFL) are substantially different for U-103 and SX-103 wastes. The high temperature of the latter causes the same feed concentration of ammonia to have a higher impact on headspace flammability. For SX-103 waste parameters, when the dissolved hydrogen in the DCRT feed is greater than $5 \times 10^{-4} \underline{\mathrm{M}}$ at zero ammonia, or the dissolved ammonia is greater than $0.06 \mathrm{M}(1000 \mu \mathrm{g} / \mathrm{mL})$ at zero hydrogen, the fill-end flammability in the DCRT is likely to be above $25 \%$ of the LFL (for the base-case minimum ventilation rate of $3 \mathrm{acfh}$ ). For comparison, the median dissolved hydrogen concentration is $3.1 \times 10^{-5} \underline{\mathrm{M} \mathrm{H}} \mathrm{H}_{2}$. Several tanks have measured ammonia concentrations above $0.06 \underline{\mathrm{M}}$, but a tank would need a hydrogen partial pressure of about 17 atm to have $5 \times 10^{-4} \underline{\mathrm{M}}$ of dissolved hydrogen.

For U-103 waste parameters, the limits on the feed concentrations are much looser. The maximum ammonia concentration is about $0.3 \underline{\mathrm{M}}$, or $4900 \mu \mathrm{g} / \mathrm{mL}$ (for the base-case minimum ventilation rate of $3 \mathrm{acfh}$ ). None of the measured ammonia concentrations have been this high thus far.

The plot on the right of Figure 9.1 shows the criterion that the post-fill hydrogen generation rate must meet, given a certain dissolved ammonia concentration, if the post-fill peak flammability is to be below $25 \%$ of the LFL. In this plot, the waste salt concentration, temperature, pressure, and solubility constants, fill parameters, ventilation, and dissolved hydrogen concentration are held at the values in Table 9.7. Only the post-fill hydrogen generation rate and the feed ammonia concentration were varied from their tabulated values. (The post-fill peak flammability depends on the steady-state hydrogen concentration, so it is not sensitive to the dissolved hydrogen in the feed.)

The post-fill plot in Figure 9.2 shows that, once again, the hot SX-103 waste places tighter limits on the feed than the low-temperature U-103 waste does. The limiting ammonia concentrations for the U-103 and SX-103 wastes are about the same for the post-fill flammability as for the fill-end flammability. That is, in both the fill-end and post-fill cases the limiting ammonia concentrations are those at which ammonia alone could produce $25 \%$ of the LFL in the DCRT headspace.

At a feed ammonia concentration of zero, the maximum allowable volumetric hydrogen generation rate is between $4 \times 10^{-7}$ and $6 \times 10^{-7} \mathrm{~mol} \mathrm{H}_{2} / \mathrm{L} / \mathrm{hr}$ (for the minimum ventilation rate). SX-103 and SX-105 are the only tanks with hydrogen generation above the zero-ammonia limit, although SX-104 and U-106 come close. The average hydrogen generation rate for the modeled wastes is $1.3 \times 10^{-7} \mathrm{~mol} \mathrm{H}_{2} / \mathrm{L} / \mathrm{hr}$, which means a total hydrogen generation of $0.17 \mathrm{acf}_{2} /$ day in the $80 \%$ full S DCRT or 0.24 acf $\mathrm{H}_{2} /$ day in the other DCRTs. (For comparison, 3 acfh of ventilation would remove 0.72 acf $\mathrm{H}_{2} /$ day if the DCRT headspace contained $25 \%$ of the LFL of hydrogen alone.)

We have also considered the effect of feed concentrations and hydrogen generation at a higher (and probably more realistic) ventilation rate of $5 \mathrm{acfm}$ ( $300 \mathrm{acfh})$. The limiting 


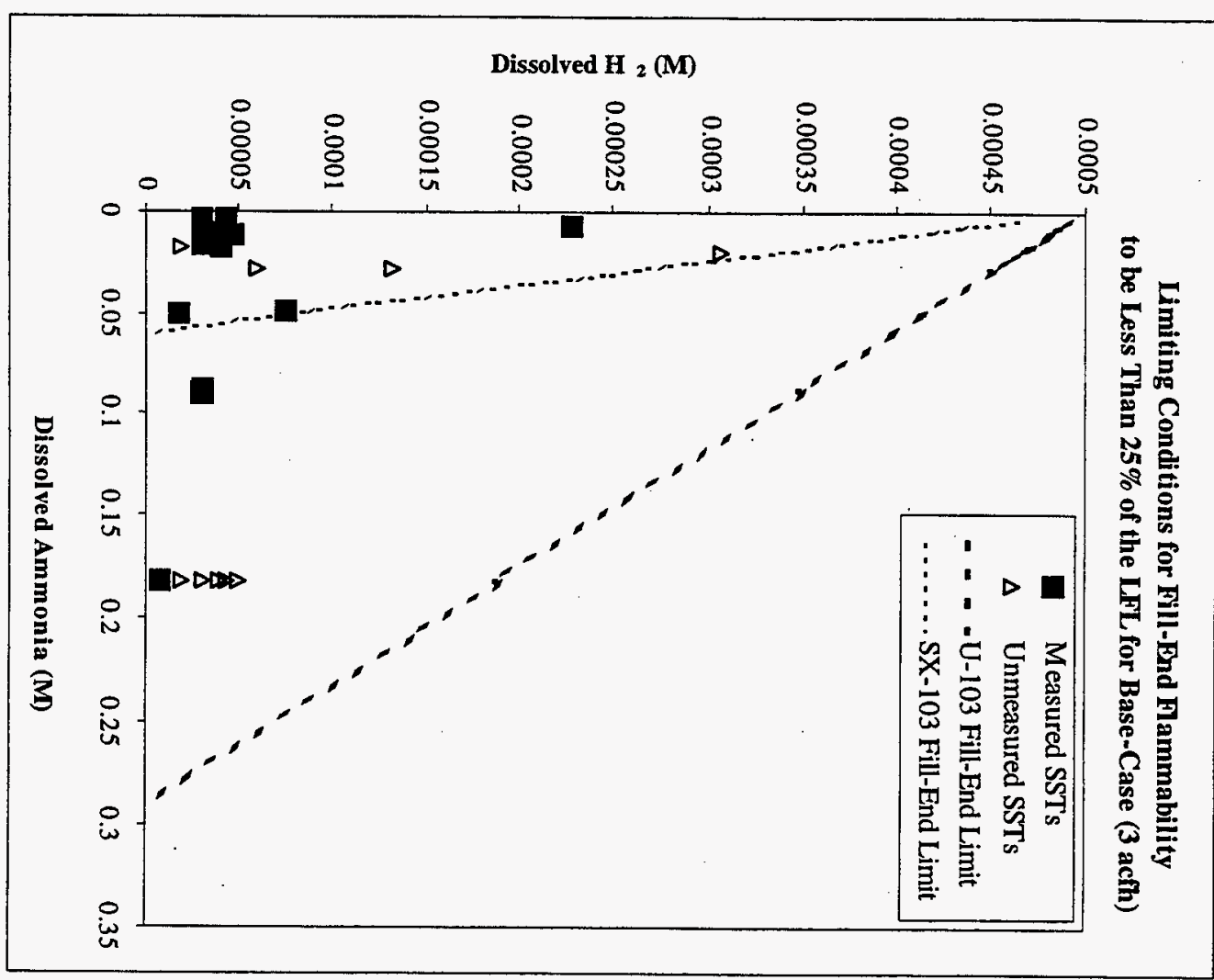

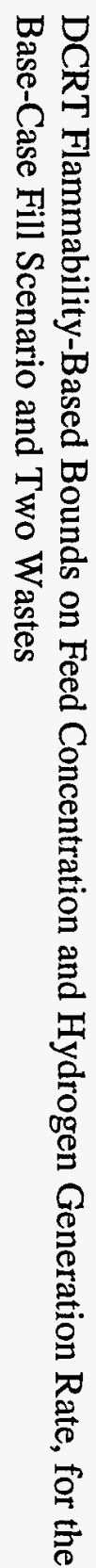

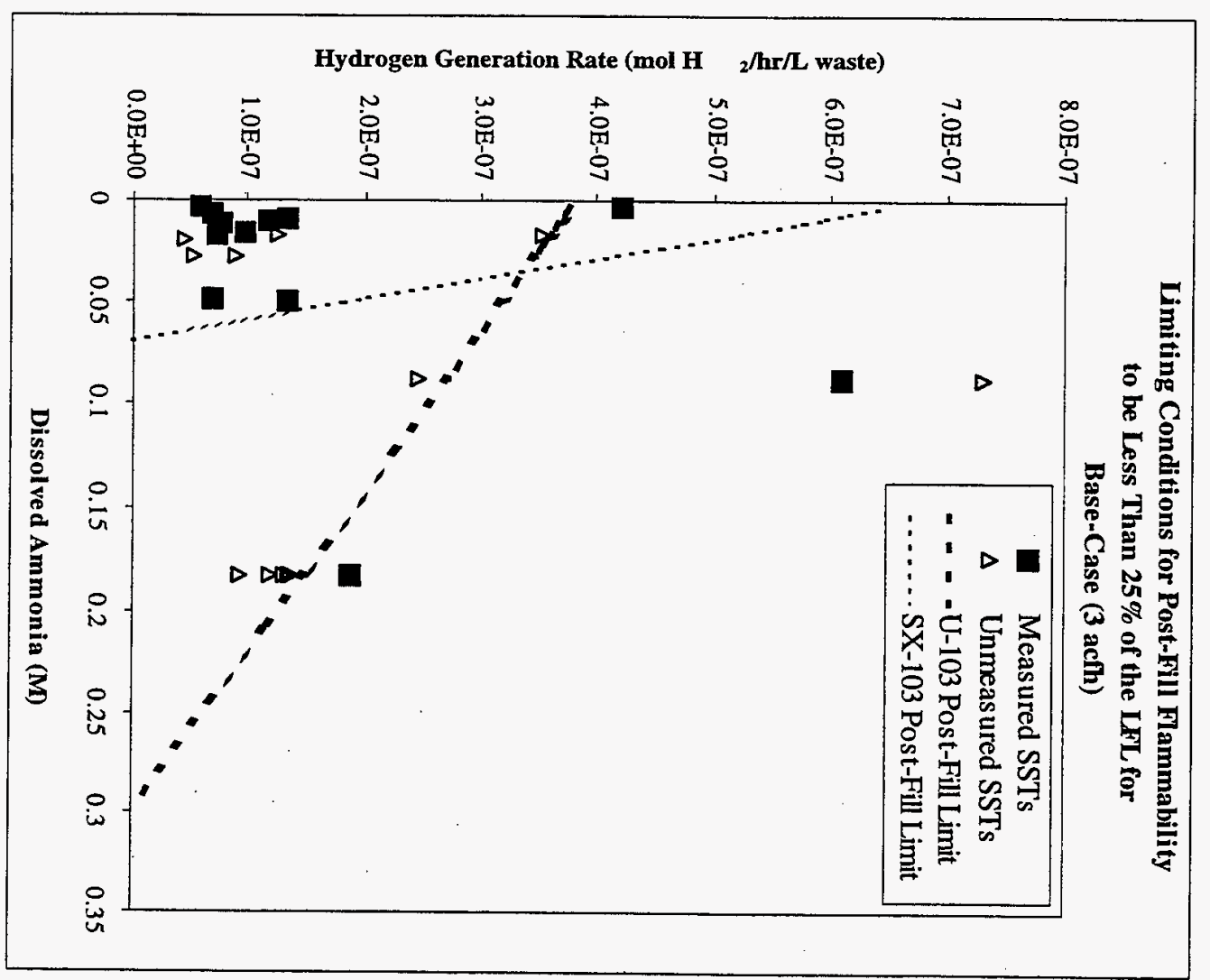


Table 9.7. DCRT Model Inputs for the Base Case for Two Wastes

\begin{tabular}{|c|c|c|}
\hline Input parameter & $\mathrm{U}-103$ & SX-103 \\
\hline Ventilation rate (acfh) & 3 & 3 \\
\hline Fill rate $(\mathrm{gpm})$ & 4 & 4 \\
\hline Final fraction of DCRT filled & 0.8 & 0.8 \\
\hline DCRT type & $\mathrm{U}$ & $\mathrm{S}$ \\
\hline \multicolumn{3}{|l|}{ Concentrations in the waste liquid (M) } \\
\hline $\mathrm{Na}^{+}$ & 12.0 & 10.7 \\
\hline $\mathrm{AlO}_{2}^{-}$ & 1.0 & 1.2 \\
\hline $\mathrm{Cr}^{+}$ & 0 & 0.02 \\
\hline $\mathbf{K}^{+}$ & 0 & 0.08 \\
\hline $\mathrm{OH}^{-}$ & 0.01 & 0.01 \\
\hline $\mathrm{NO}_{3}{ }^{-}$ & 3.9 & 3.6 \\
\hline $\mathrm{NO}_{2}^{-}$ & 2.4 & 2.5 \\
\hline $\mathrm{CO}_{3}^{2-}$ & 0.41 & 0.41 \\
\hline $\mathrm{PO}_{4}^{2-}$ & 0.03 & 0.04 \\
\hline $\mathrm{SO}_{4}{ }^{2-}$ & 0.05 & 0.05 \\
\hline $\mathbf{F}$ & 0.08 & 0 \\
\hline $\mathrm{Cl}^{-}$ & 0.27 & 0.20 \\
\hline Waste temperature $\left({ }^{\circ} \mathrm{C}\right)$ & 27.6 & 71.1 \\
\hline Pressure in source tank (atm) & 1.62 & 1.82 \\
\hline Waste density $\left(\mathrm{kg} / \mathrm{m}^{3}\right)$ & 1385 & 1460 \\
\hline Waste $\mathrm{pH}$ & 12 & 12 \\
\hline Mass fraction of water (wt\%) & 51.5 & 50.9 \\
\hline${ }^{137} \mathrm{Cs}$ concentration $(\mathrm{Ci} / \mathrm{mL})$ & $3.8 \times 10^{-4}$ & $4.5 \times 10^{-4}$ \\
\hline TOC concentration $(\mathrm{g} / \mathrm{L})$ & 15.4 & 5.0 \\
\hline Dissolved $\mathrm{H}_{2}$ concentration in feed (M) & $8.25 \times 10^{-6}$ & $3.06 \times 10^{-5}$ \\
\hline Dissolved $\mathrm{CH}_{4}$ concentration in feed $(\underline{\mathrm{M}})$ & $3.07 \times 10^{-7}$ & $1.19 \times 10^{-6}$ \\
\hline Dissolved $\mathrm{NH}_{3}$ plus $\mathrm{NH}_{4}{ }^{+}$concentration in feed $(\underline{\mathrm{M}})$ & 0.182 & 0.088 \\
\hline Henry's Law constant for $\mathrm{H}_{2}$ (mol/L liq/atm) & $2.4 \times 10^{-5}$ & $2.9 \times 10^{-5}$ \\
\hline Henry's Law constant for $\mathrm{CH}_{4}(\mathrm{~mol} / \mathrm{L}$ liq/atm) & $1.6 \times 10^{-5}$ & $1.5 \times 10^{-5}$ \\
\hline Henry's Law constant for $\mathrm{NH}_{3}$ (mol/L lig/atm) & 7.7 & 1.5 \\
\hline $\mathrm{H}_{2}$ generation rate after fill ( $\mathrm{mol} \mathrm{H}_{2} / \mathrm{L}$ liquid $/ \mathrm{hr}$ ) & $1.9 \times 10^{-7}$ & $6.1 \times 10^{-7}$ \\
\hline
\end{tabular}

relationship between hydrogen and ammonia continues to be linear. In general, ammonia concentration exerts the most limiting influence on the DCRT headspace flammability. The specifics are given in Table 9.8.

Figure 9.2 shows the effects of the fill scenario parameters on the fill-end and post-fill DCRT headspace flammabilities for U-103 and SX-103 wastes (defined in Table 9.7). In each of the three plots in the exhibit, one parameter is varied and the others are fixed at the base-case average waste values in Table 9.7. The minimum ventilation rate was used in this base-case. 
Table 9.8. Limiting Hydrogen/Ammonia Relationships to Maintain 25\% of the LFL

\begin{tabular}{|l|c|c|c|c|}
\hline \multirow{2}{*}{} & \multicolumn{2}{|c|}{ U-103 } & \multicolumn{2}{c|}{ SX-103 } \\
\cline { 2 - 5 } & at 3 acfh & $\begin{array}{c}\text { at } 5 \mathrm{acfm} \\
(300 \mathrm{acfh})\end{array}$ & at 3 acfh & $\begin{array}{c}\text { at } 5 \mathrm{acfm} \\
(300 \mathrm{acfh})\end{array}$ \\
\hline $\begin{array}{l}\text { Maximum dissolved } \mathrm{H}_{2}(\mathrm{~mol} / \mathrm{L}) \text { at zero } \\
\text { ammonia (for fill-end flammability) }\end{array}$ & $5 \times 10^{-4}$ & $9 \times 10^{-3}$ & $5 \times 10^{-4}$ & $1 \times 10^{-2}$ \\
\hline $\begin{array}{l}\text { Maximum dissolved } \mathrm{NH}_{3} \text { (mol/L) at } \\
\text { zero hydrogen (for fill-end and post-fill } \\
\text { flammabilities) }\end{array}$ & 0.29 & 0.36 & 0.06 & 0.13 \\
\hline $\begin{array}{l}\text { Maximum } \mathrm{H}_{2} \text { generation rate } \\
\text { (mol } \mathrm{H}_{2} / \mathrm{hr} / \mathrm{L} \text { waste) at zero ammonia } \\
\text { (for post-fill flammability) }\end{array}$ & $3.8 \times 10^{-7}$ & $3.8 \times 10^{-5}$ & $6.6 \times 10^{-7}$ & $6.6 \times 10^{-5}$ \\
\hline
\end{tabular}

The effect of ventilation is plotted on semi-logarithmic axes in the left-most plot in Figure 9.2. Ventilation rate has little effect on the fill-end flammability for the two wastes in the range from 3 to 30 acfh, though it substantially affects the post-fill flammability. This low ventilation has a small effect during filling because ventilation is only part of the gas outflow rate; at 4-gpm feed, the feed rate causes 10 times as much gas outflow as the ventilation does. When the ventilation rate exceeds about 30 acfh, however, its effect increases, and at $5 \mathrm{acfm}$ ( $300 \mathrm{acfh}$ ) ventilation is effective at reducing the headspace flammability below $25 \%$ of the LFL.

Figure 9.2 (middle plot) shows the effect of the fill fraction, X, on the DCRT headspace flammability at the end of the fill. The effect is in accord with physical intuition; decreased fill leads to decreased flammability for both the fill-end and post-fill regimes. The sharp drop in the fill-end flammability for very low fill fractions results from the drop in the ammonia vapor pressure caused by evaporative ammonia depletion in the liquid.

The feed rate (right plot in Figure 9.2) does not necessarily have a monotonic effect on the fill-end flammability: the SX-103 and U-103 wastes differ slightly in this respect. The response of the fill-end flammability to the feed rate depends, to a large extent, on the hydrogen generation rate; the amount of time taken by slow fills allows significant amounts of hydrogen to be generated. This mechanism is monotonic; higher feed rate always means less hydrogen generated by the time the fill ends.

However, the effect of feed rate also depends on how much of the flammable gas in the feed is low-solubility hydrogen and how much is ammonia. Even when the hydrogen generation rate is set to zero, the direction of the flammability response to the feed rate can be changed by varying the $\mathrm{NH}_{3} / \mathrm{H}_{2}$ ratio alone. For high feed $\mathrm{NH}_{3} / \mathrm{H}_{2}$ ratios, a decreased feed rate causes increased fill-end flammability; for low ratios, decreased feed rate causes decreased fill-end flammability. (For example, the waste in Tank T-104, which responds to lower feed rates with lower flammability, contains only about 90 times as much $\mathrm{NH}_{3}$ as $\mathrm{H}_{2}$ and has an unusually low hydrogen generation rate.) The $\mathrm{NH}_{3} / \mathrm{H}_{2}$ ratio in $\mathrm{SX}-103$ waste is about one-eighth of that in U-103 waste. This may be why SX-103 waste decreases in flammability with decreasing feed rate (over part of the feed rate range), while U-103 increases monotonically in flammability as the feed rate decreases. 

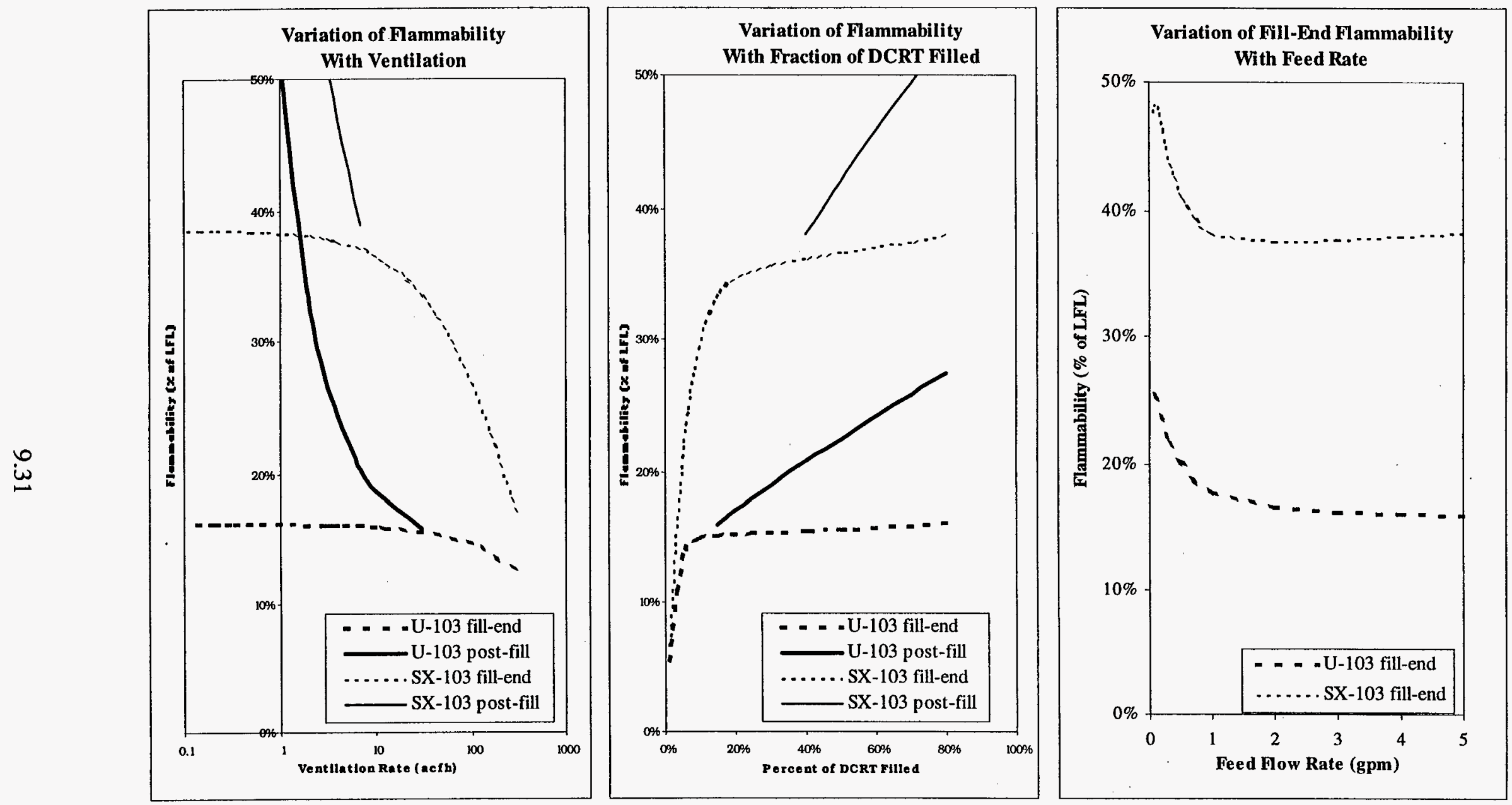

Figure 9.2. Variation of DCRT Dome Space Flammability for Two Wastes and the Base-Case Fill Scenario 
Figure 9.2 also demonstrates that feed rates somewhat.higher than the upper operational limit of $4 \mathrm{gpm}$ would have only a slight effect on headspace flammability. Therefore, the precision of flow rate control is not critical from a flammability perspective.

\subsection{Effect of Mixing Wastes}

Wastes that are in or entering a DCRT may mix with other wastes or with liquid (hot water, cold water, or caustic solution) that is used to flush the lines and prevent clogging. Caustic solution is also used to adjust the $\mathrm{pH}$ of waste already in the DCRT. The effect of mixing was studied by making the assumption that the two wastes are already mixed in unchanging proportion as they enter the DCRT. The headspace flammability resulting from filling the DCRT with the mixture to the final level was calculated. In practice, the DCRT is likelier to be partly filled with one waste, with another waste added to complete the fill. This practice differs from the model in that the proportions of the two wastes vary during filling, though the end point is the same. The modeling (as will be shown) captures the effect of having varying mixtures at the final $80 \%$ fill level, but not the effect of having varying mixtures while the DCRT is less than $80 \%$ full. Using the final fill level is expected to provide an overestimate of the effect of waste mixtures, because (as shown in the center plot of Figure 9.2) lower fill levels lead to lower headspace flammability.

We would expect mixing to have the greatest effect when one waste is high in temperature and salt concentration and low in dissolved flammable gases and the other is lower in temperature and/or salt and high in dissolved gases. The lower gas solubility in the first waste (for example, Tank SX-104) causes an extra release of the more concentrated dissolved gas than the second type (for example, Tank U-105). (Note that this example is purely cautionary; wastes from two different tank farms are very unlikely to be mixed.) Using the revised inputs for wastes from Tanks SX-104 and U-105, a base-case fill scenario (with the minimum 3-acfh ventilation), and the nonequilibrium model produces the mixing-versus-flammability plots in Figure 9.3. (Note that the pure U-105 and SX-103 flammabilities are not the same as in Table 9.2, which was based on the equilibrium model and used the U DCRT for U-105 waste.)

Both the fill-end and post-fill flammabilities in the S DCRT headspace reach maxima as the volume fraction of waste from Tank U-105 is increased from 0 to $100 \%$ of the waste in the S DCRT. The mixing fraction at which the post-fill maximum occurs is about $40 \% \mathrm{U}-105$ waste and $60 \%$ SX-104 waste. Situations in which such flammability maxima can occur are probably rare but illustrate that considering only single-tank flammabilities can lead to underestimates when mixing wastes. For this reason, waste mixing in the DCRTs should be modeled on a caseby-case basis.

Waste can also be mixed with line flushes of hot water, cold water, or caustic solution (depending on what is needed to prevent clogging in the transfer lines). Hot water is often used in quantities that may be as much as $25 \%$ of the transferred waste volume. The wastes that are most likely to respond to a hot water flush with added flammability are those with low temperatures and high dissolved ammonia concentrations. Figure 9.4 represents the flammability effect of mixing one such waste, that from Tank U-105, with both hot water $\left(65^{\circ} \mathrm{C}\right)$ and cold water $\left(17^{\circ} \mathrm{C}\right)$. The figure is based on the U-105 waste properties used for Table 9.2 and assumes 4-gpm feed, $80 \%$ fill, and the minimum 3-acfh ventilation. The nonequilibrium model was used. 


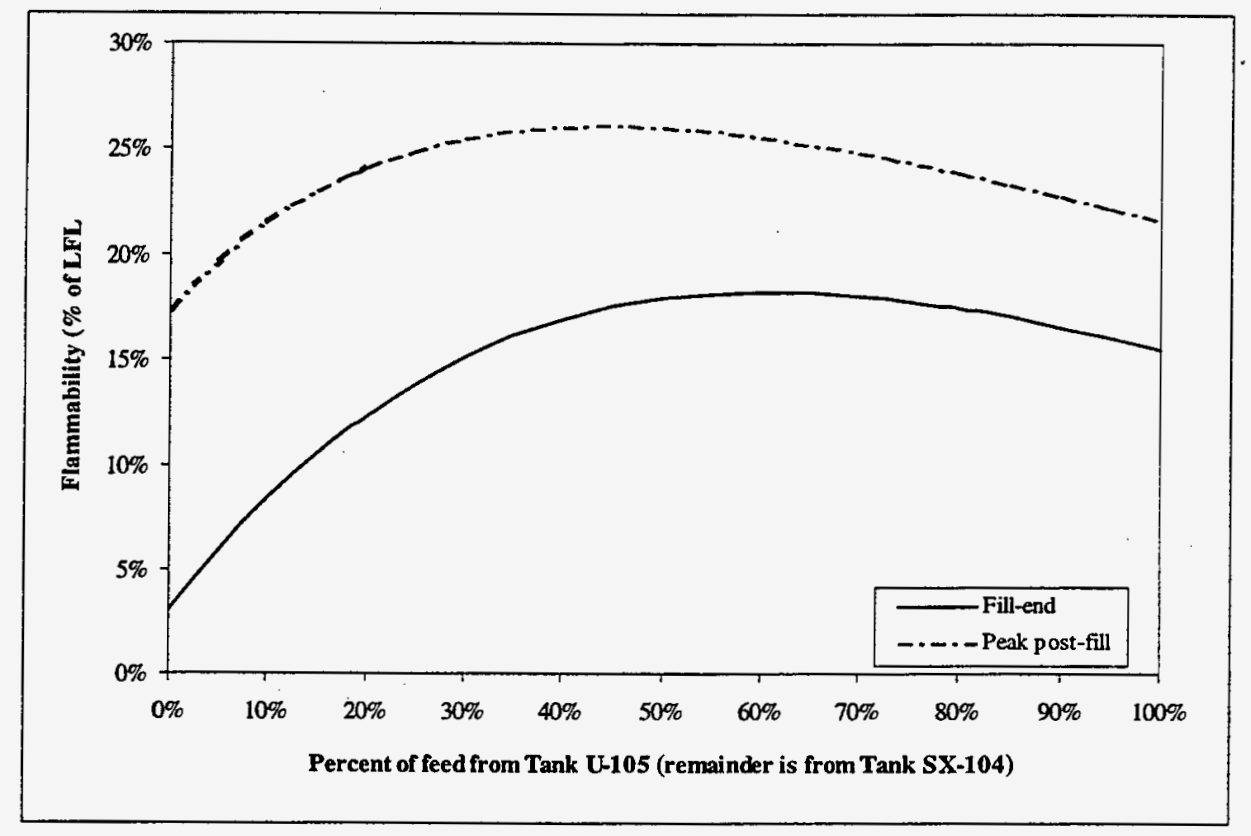

Figure 9.3. Effect on S DCRT Headspace Flammability of Mixing SX-104 and U-105 Wastes

Figure 9.4 shows that both the fill-end and post-fill flammabilities consistently decrease as more water is added, whether the water is cold or hot. Although the higher temperature of the hot water increases the ammonia vapor pressure, the added dilution overcomes that increase by allowing more ammonia to remain in solution. A cold water flush reduces the flammability of the headspace gas even more. The flammability difference between the hot and cold water flushes is 5\% LFL or less. Note that the flammability does not go to zero at pure water; this is the result of spurious hydrogen generation by the generation model's corrosion mechanism, which does not vary with concentration or temperature. The amount of extra hydrogen introduced by this means is small and only pertinent in modeling very dilute wastes.

Caustic flushes and $\mathrm{pH}$ adjustments are also a possibility; if $\mathrm{NaOH}$ was added to a dilute waste with low $\mathrm{pH}$ and high ammonium ion concentration, ammonia could be released. Figure 9.5 represents the flammability effect of mixing such a waste with $50 \%$ molar $\mathrm{NaOH}$ (at $25^{\circ} \mathrm{C}$ ) or with a cold water line flush. (The $50 \%$ molar $\mathrm{NaOH}$ is used for $\mathrm{pH}$ adjustments.)

The waste used for this prediction is based on T-104 waste except that it has been assigned an unrealistically high concentration of dissolved ammonia plus ammonium ion $(0.18 \underline{\mathrm{M}})$, an atypically low $\mathrm{pH}$ of 7 , and a higher temperature of $40^{\circ} \mathrm{C}$. The figure assumes the same equilibrium model and base-case fill scenario used to model Tank T-104 in Table 9.2. As the figure shows, the caustic produces a higher headspace fill-end flammability that peaks when very little caustic is added (typically, a relatively small amount of caustic would be added). The peak (the amount by which the post-caustic headspace flammability exceeds that of the unmixed waste) is $8 \%$ of the LFL or less. However, at higher temperatures (such as the $60-70^{\circ} \mathrm{C}$ of some of the SX tanks) the effect of the additional ammonia would be greater, so the effect of caustic flushes should be modeled for wastes from low-salt, high-temperature, high-ammonia tanks. 


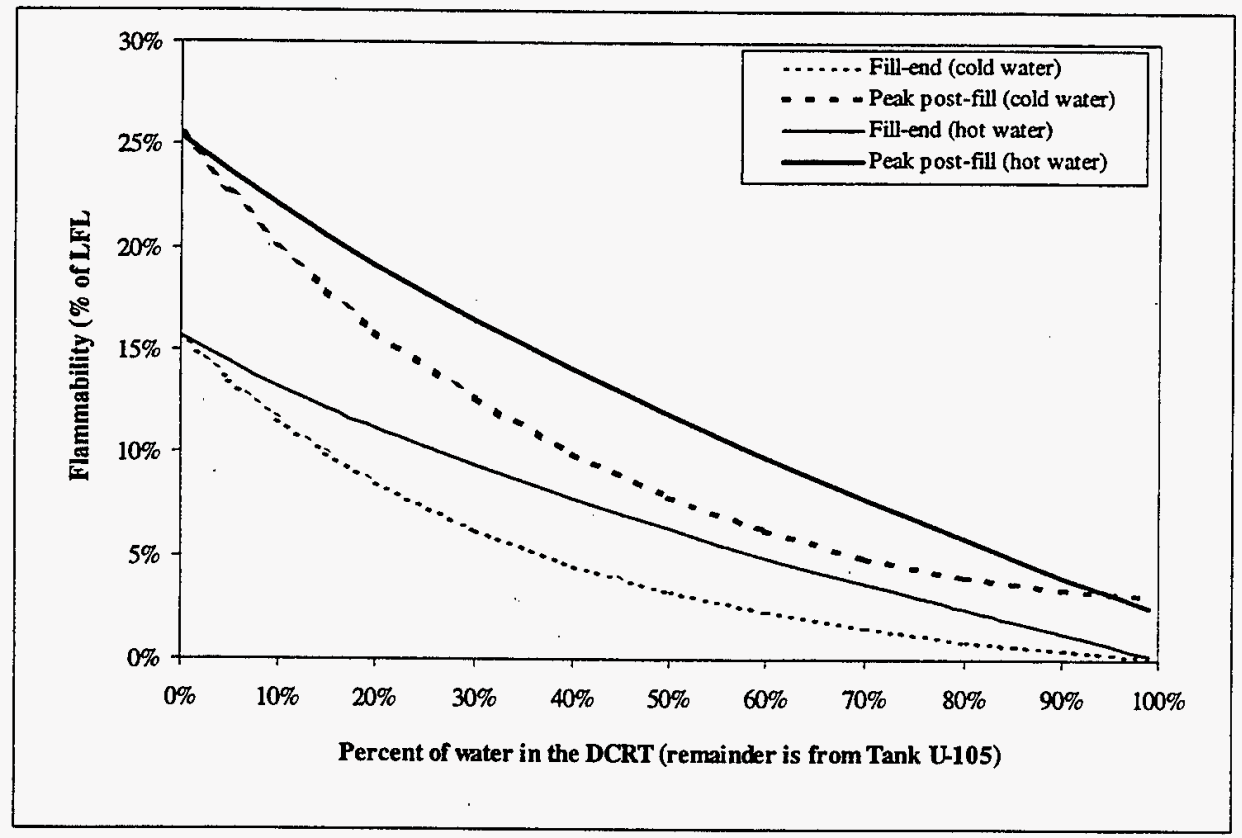

Figure 9.4. Effect on DCRT Headspace Flammability of Adding Hot and Cold Water Flushes to U-105 Waste

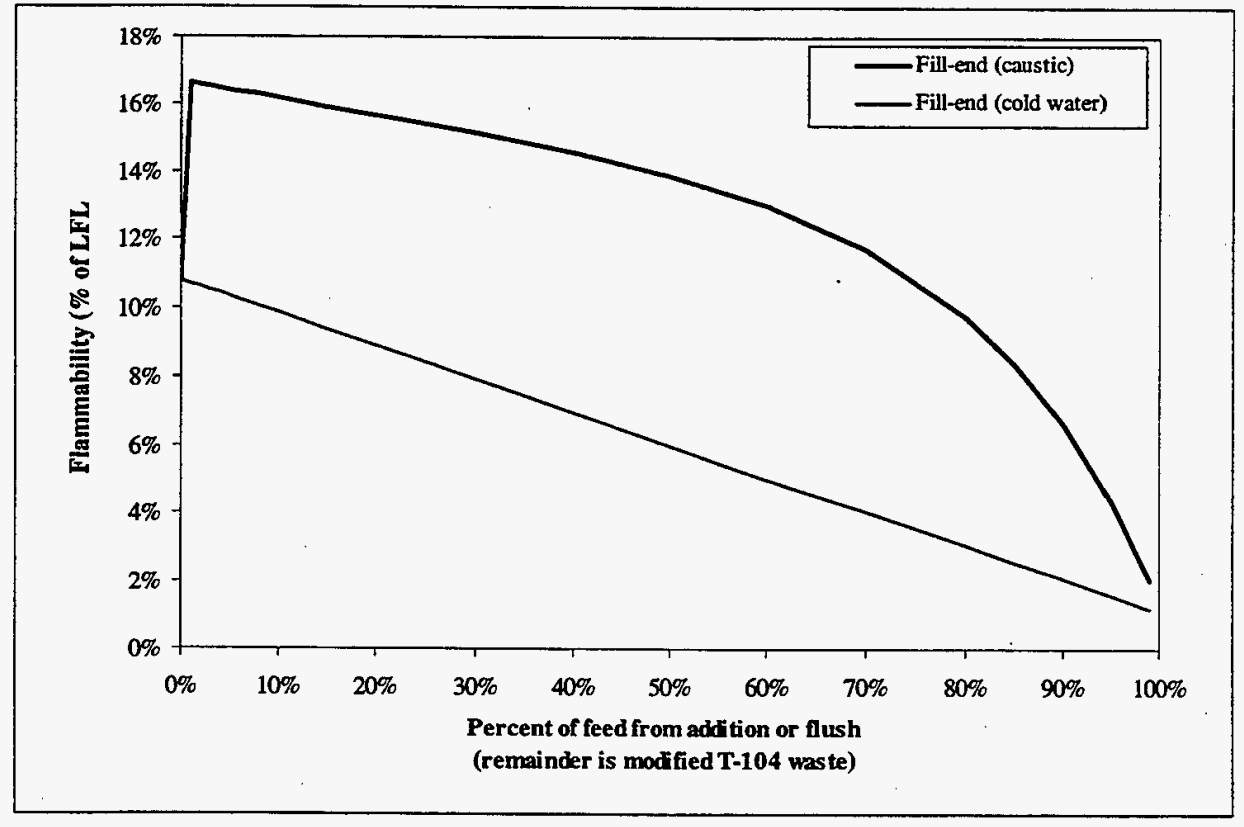

Figure 9.5. Effect on DCRT Headspace Flammability of Adding Caustic and Cold Water Flushes to Modified T-104 Waste 


\subsection{Overall Uncertainties and Conservatisms}

The conservatisms and uncertainties in the model(s) and inputs are set forth below, in order of decreasing importance. We begin with the conservatisms and uncertainties in the model algorithms themselves.

The Schumpe solubility model was used in both the equilibrium and nonequilibrium models. It employed the gas and ion parameters provided by Hermann et al. (1995), as discussed in Sections 2.2.5 and 2.2.6. Testing performed by Norton and Pederson (1995) showed that, for a simulant somewhat more dilute than most of the SST wastes modeled in this report, this solubility model and parameters tended to underestimate the solubilities of hydrogen and ammonia and overestimate the solubility of methane. The differences between the predicted and measured solubilities were $30 \%$ or less, and would result in underprediction of fill-end hydrogen (which depends on the solubility in the source tank) and overprediction of ammonia and methane in the DCRT headspace. There is no information to quantify the overpredictions or underpredictions made by the Schumpe model at the somewhat higher salt concentrations in most of the wastes.

The mass-transfer model used in the nonequilibrium model was described in Section 2.5. The ultimate upper bound on the headspace concentration achievable by high mass-transfer rates is equilibrium. The comparisons of equilibrium and nonequilibrium results in Table 9.3 show that mass-transfer limitations tend to reduce the hydrogen concentration in the headspace by a factor of 2 to 3 , but have little effect on the ammonia concentration. Implausibly high masstransfer rates would be required to asymptotically approach equilibrium for hydrogen, so the actual upper uncertainty for hydrogen is more likely to be $+50 \%$ or less than the $+100 \%$ or $+200 \%$ implied by the factor of 2 or 3 difference from equilibrium. The upper uncertainty for ammonia is probably $10 \%$ or less, since ammonia closely approaches equilibrium. The lower uncertainty on the mass-transfer model is harder to quantify. Lowering the mass-transfer coefficients by an arbitrary factor of 10 reduces the ammonia concentration in the headspace hardly at all, but decreases the hydrogen and methane concentrations by a factor of about 7 . Clearly there is more uncertainty in the downward direction, for hydrogen and methane, than in the upward direction, though the amount of uncertainty is unknown. However, the mass-transfer model does not contain any conceptual conservatisms; it is considered a best estimate.

By the same arguments, the equilibrium model is a factor of 2 or 3 conservative in its hydrogen (and methane) predictions, simply by virtue of assuming equilibrium, but is much less conservative in its ammonia predictions. To the extent that the total DCRT headspace flammability from a waste is dominated by ammonia, the conservatism introduced by equilibrium assumptions is not significant.

The water vapor model (included in both the equilibrium and nonequilibrium models) is not a large source of either conservatism or uncertainty. The water vapor pressure is less than $20 \%$ of atmospheric pressure even in the hottest tank wastes. Based on a comparison to experimental data taken using simulants, the maximum error in the water vapor pressure correlation was $15 \%$. This amounts to a maximum uncertainty of $3 \%$ of the flammability. 
Overall, the nonequilibrium model does not appear to contain any known conservatisms of more than about $30 \%$. It may underpredict the fill-end hydrogen in the DCRT headspace by $30 \%$ or less because of the underprediction of the hydrogen solubility by the Schumpe model. The uncertainty of the nonequilibrium model comes mostly from the mass-transfer model. The uncertainty may be $\pm 50 \%$ for hydrogen and methane but is much less for ammonia. The equilibrium model has higher conservatism, a factor of 2 or 3 for hydrogen and methane, which more than offsets the possible underprediction of fill-end hydrogen by the Schumpe model.

For most tank wastes, the uncertainty (or conservatism) in the inputs dominates over that in the model. The various sources of uncertainty and conservatism have substantially different impacts on different wastes, but some general statements can nevertheless be made. The major input uncertainties and conservatisms will be listed in order of decreasing significance.

- Of the eight tanks with wastes that cause high ammonia flammabilities in the basecase minimum-ventilation scenario, only two (SX-103 and U-103) have had actual measurements of the dissolved ammonia in the waste. The uncertainty of the ammonia flammability for wastes from the other six high-flammability tanks cannot be quantified meaningfully, although the use of relatively high ammonia concentrations for these wastes makes overprediction more likely than underprediction. Many of the wastes that were not modeled (in Table 9.2) as causing high DCRT headspace flammabilities also lacked waste ammonia measurements. In these cases, there is a greater likelihood of underprediction of the ammonia. The uncertainty of the ammonia flammabilities for the unmeasured tanks cannot be quantified.

- The ammonia flammability may be overpredicted for some tanks because of using the maximum ammonia measured in a tank (for those tanks for which measurements at several depths were available, as listed in Table 2.2). The extent of this overprediction depends on whether the liquid is pumped from zones of the source tank where the maximum concentration was observed. The conservatism in using the maximum cannot be assessed generically, but only on a case-by-case basis when actual pumping plans are known. A factor of 2 or more overprediction is possible.

- Three of the tanks with wastes for which high DCRT headspace flammability was predicted, SX-103, SX-105, and U-106, had hydrogen generation rates large enough to make hydrogen a separate flammability concern in the post-fill period (at the minimum ventilation rate). As discussed in Section 5 , in situ hydrogen generation rates have been estimated for two of these tanks (SX-103 and SX-105) using the model described in $\mathrm{Hu}$ et al. (1997), which was used to supply the hydrogen generation rate input to the present model, and also by back-calculating the hydrogen generation rate from the hydrogen concentration in the tank headspace (Wilkins et al. 1997a). The modeled in situ hydrogen generation rate was six times as high as the "observed" rate in SX-103 and 15 times as high in SX-105. Furthermore, Tank U-106 is part of the same HTCE cluster (cluster 20) as SX-103 and SX-105. The four Cluster 20 tanks for which comparisons could be made all showed substantial overprediction of the in situ hydrogen generation rate by the model used in $\mathrm{Hu}$ et al. (1997), as shown in Section 5. Thus, the high hydrogen contributions to post-fill 
flammability calculated for waste from these three tanks are probably overpredicted by a factor of five or more. The uncertainty in the hydrogen generation rates used in the present models is substantial for SST wastes such as these.

- The uncertainty in the ventilation rate has considerably less effect on the ammonia flammability than on the flammability contributed by dissolved and generated hydrogen. This point is made by a comparison of Tables 9.3,9.4, and 9.5. Increasing the ventilation from the base-case value of 3 acfh to $30 \mathrm{acfh}$ decreases the fill-end hydrogen by roughly a factor of 2 , the post-fill hydrogen by a proportional factor of 10 , and the ammonia by $10 \%$ or less. The next factor of 10 increase in ventilation (to $300 \mathrm{acfh}$ ) decreases the ammonia by 10 to $50 \%$, depending on the waste. Thus the degree of conservatism in the assumption of a 3 acfh ventilation rate depends on the extent to which ammonia dominates the flammability.

- The temperature of the waste in the DCRT may differ from that in the source tank because of more effective cooling in the transfer lines and DCRT, heating in the jet pump, or self-heating. Barring a detailed thermal analysis, only three things can be said about the uncertainty or conservatism caused by temperature change. First, it is likelier to affect the wastes with temperatures well above ambient (SX-102, SX-103, SX-104, and SX-105) by cooling them. Second, temperature has little effect on hydrogen solubility, but the ammonia vapor pressure decreases by 10 to $20 \%$ for each $5^{\circ} \mathrm{C}$ drop in temperature, giving a potentially noticeable conservatism. Third, the hydrogen generation rate (as calculated by the model used by $\mathrm{Hu}$ ) also decreases by roughly $20 \%$ for each $5^{\circ} \mathrm{C}$ drop in temperature.

- The fill-end hydrogen flammability is probably overpredicted by a small amount (less than $30 \%$ ) because the dissolved hydrogen concentration is based on the hydrostatic pressure at a depth that is greater than the actual average gas depth (see Section 2.3.) 


\subsection{Conclusions}

In our analyses we have evaluated several flammable gas carryover and generation mechanisms in DCRTs and discussed a number of associated technical issues. We have identified no major flaws in the approach used in the calc-note by Hedengren et al. (1997). Although we developed a somewhat different mathematical model for predicting flammable gas concentrations within the DCRT, we found little difference between our predictions and those of Hedengren et al. when the same initial dissolved gas concentrations were assumed and when instantaneous equilibrium between dissolved gases and headspace was assumed. We also developed a nonequilibrium model that accounts for mass-transfer limitations on the release rates of dissolved gases and found that for most purposes the assumption of equilibrium does not produce large overestimates of DCRT headspace flammability until ventilation rates are much higher than the 3 acfh assumed in the other analyses. However, since ventilation rates are likely to be higher than $3 \mathrm{acfh}$, the nonequilibrium model is preferred as more accurately predicting gas behavior. The nonequilibrium model is strongly preferred for predicting minimum ventilation rates required to maintain headspace flammability below $25 \%$ of the LFL. Of course, in a formal safety analysis, the analyst must determine what model to use.

We suggest that the initial concentrations of ammonia used in models be scaled to account for sample depletion relative to the in-waste values. There are two factors to consider: in-laboratory losses and sample representativeness. In-lab losses affect core samples and could be offset by multiplying measured ammonia concentrations by a factor of 1.5 . Representativeness of either grab or core samples must be judged on a case-by-case basis depending on the elevation of the sample with respect to the liquid to be pumped. We also suggest that the actual ventilation rate in the DCRTs may be considerably larger than the assumed value of $3 \mathrm{acfh}$. In-tank measurements are needed (Sections 2 and 7).

The analyses in this document suggest that carryover of free gas from the source tank to the DCRT in the form of "hitchhiker" bubbles is possible, but only as armored bubbles less than 10 microns in diameter. Even if released once they reach the DCRT, these bubbles would contribute an insignificant amount of flammable gas to the headspace. Carryover of adsorbed gas on entrained particles is also possible but would also contribute insignificantly to the flammability of the DCRT headspace. The dominant mechanism of gas carryover is therefore dissolved gas transferred with the pumped liquid (Sections 2, 3, and 4).

Because the residence time of the liquid in the salt well is short and the surface area small, no significant volatilization of flammable gas occurs within the salt well. Since losses in the salt well are small, there is little depletion of flammable gas from the waste as a result of pumping, and the concentrations in the liquid reaching the DCRT approximately reflect their concentrations in the source tank. However, if the source tank includes an upper layer of supernatant liquid, volatilization of dissolved gases over many years of storage reduces the dissolved gas concentrations relative to those in the interstitial liquid pumped from the nonconvective layer. Liquid pumped early in a campaign may therefore contain less gas than liquid pumped later in the campaign (Section 2).

Once the liquid reaches the DCRT, flammable gases dissolved in the liquid partition into the gas phase it contacts, in accordance with vapor-liquid equilibria described by Henry's Law. 
One can assume either that all of the liquid instantaneously equilibrates with the entire headspace (the equilibrium model) or that mass transfer limitations within the liquid will slow the volatilization rate (the nonequilibrium model). Both of these treatments differ from those used by Hedengren et al. (1997), who assumed either total release (for low-solubility gases such as hydrogen and methane) or an equilibrium-controlled release without depletion of the liquid (for ammonia, a highly soluble gas). Comparisons of calculated percent of LFL in the Hedengren approach and the equilibrium model, keeping other assumptions the same, show only small differences in the flammability at the end of fill. At low ventilation rates, the equilibrium and non-equilibrium models also yield comparable results. However, the equilibrium assumption loses validity because the ventilation rate increases and volatilization is no longer rapid enough to replenish the headspace. Thus, the flammability predicted by the nonequilibrium model falls relative to the equilibrium model predictions as ventilation increases (Sections 2, 9).

Calculating DCRT headspace flammabilities requires the dissolved gas concentrations and Henry's Law constants. The concentrations of low-solubility gases can be estimated from their gas-phase concentrations in the source tank, the pressure, and Henry's Law. RGS data should be used to provide gas-phase concentrations when available. For tanks with no available data, the median results from RGS sampling indicate that the composition of the low-solubility gas mixture in the waste matrix can be modeled as $65 \%$ hydrogen, $5 \%$ methane, and $30 \%$ nonflammable gases, including nitrogen, nitrous oxide, and other nitrogenous gases. The median composition found in RGS samples taken from separate liquid layers is $19 \%$ hydrogen, $7 \%$ methane, and $74 \%$ nonflammable gases. The choice of which of these compositions to use will depend on whether liquid is pumped primarily from the matrix or from separate liquid layers, which must be determined on a case-by-case basis. These values differ from those used by Hedengren et al. (1997): 97\% hydrogen and 3\% methane (Section 2).

The concentration of ammonia can be estimated from grab samples, core samples, or RGS data. Grab samples from the middle or bottom of the tank are more likely to represent the ammonia concentration in the liquid within the waste matrix. Grab samples from the middle or bottom of the salt-well screen are therefore preferred as sources of ammonia concentrations for modeling pumping scenarios where liquid comes primarily from within the matrix. However, top samples are more representative for cases in which liquid is pumped from a supernatant layer, which is likely to be depleted in ammonia (compared with the average in the pumpable waste matrix). The ammonia concentrations in near-surface samples may be substantially lower than the concentration in the pumpable waste matrix because of ammonia evaporation from the upper portion of the waste into the headspace. In addition, ammonia concentrations measured in conventional core samples may be a factor of 1.5 low because of in-lab ammonia loss from the drainable liquid during extrusion (Section 2).

The limited available data suggest that the Schumpe model, when used with experimentally tested parameters (Norton and Pederson 1995; Hermann et al. 1995), provides the current best estimates of Henry's Law constants and their dependence on temperature, $\mathrm{pH}$, and salt concentrations (Section 2).

Mixing wastes from different tanks or adding caustic or water may also cause flammable gas release by changing the solubility of the gases. In some scenarios, the amount of gas released by the mixture of wastes from two tanks is larger than the amount either of waste alone 
would release. Temperature increases in the tank, which would tend to release gas, are considered unlikely. Releases due to caustic or water addition are small and may, in fact, reduce flammability (Section 9).

Flammable gases are also generated within the DCRT itself by the continuing processes of radiolysis, thermolysis, and corrosion. The model described by $\mathrm{Hu}$ (1997) conservatively predicts the rates of hydrogen generation for calculating DCRT headspace flammability (Section 5).

If a significant nonconvective layer formed in a DCRT by precipitation of solids from liquid waste, some of this generated gas could begin to accumulate. Solids can precipitate in a DCRT if, for example, the waste temperature decreases or the $\mathrm{pH}$ is reduced when wastes are mixed. If enough gas were retained to make the nonconvective layer buoyant, a buoyant displacement instability could occur and release a large fraction of the retained gas into the tank's headspace. Even if the nonconvective layer does not become buoyant, its retained gas will be released if the waste matrix is disrupted. However, in either event the headspace is not expected to exceed the LFL. While there is a potential for significant gas retention and release, the time required to form the nonconvective layer and accumulate gas is so long (a year or longer) that it is only a concern in highly abnormal DCRT operations (Section 6).

Ventilation can strongly influence flammable gas concentrations in the headspace of a DCRT. While the only ventilation that can be credited with confidence in a safety analysis is the 3-acfh air flow bubbling through two DP tubes, significant additional inleakage of air almost certainly occurs around riser covers and the manual tape level instrument. This additional flow would reduce flammability substantially at steady state but less significantly during tank filling. The actual ventilation rate could be measured by sampling the DCRT or its ventilation exhaust for components of the waste gases that are not found in air or by using tracer gas techniques (Section 7).

The LFL for upward flame propagation is appropriate for determining flammability in a DCRT. The upward propagation LFL for a gas mixture can be determined using LeChatelier's linear mixing law. Nitrous oxide can be considered an inert species unless fuel concentrations approach the (higher) LFL for downward flame propagation and water vapor cannot be counted on to prevent combustion (Section 8).

The findings of the modeling work (Section 9) are

- Compared with the nonequilibrium mass-transfer-limited model, the equilibrium model overestimates the hydrogen contribution to flammability by more than a factor of 2 during fill and by $10 \%$ or less after filling is complete. Because hydrogen is not a major contributor to DCRT flammability for most of the tank wastes, the equilibrium model in most cases gives a fairly close estimate (within $20 \%$ of the nonequilibrium value) of the total DCRT headspace flammability when the ventilation rate is in the range of 3 to $30 \mathrm{acfh}$. At $5 \mathrm{acfm}$ (300 acfh) the equilibrium model predicts 20 to $50 \%$ higher flammability than the nonequilibrium model does. These results show the extent of the conservatism in the equilibrium assumptions used in other modeling (Hedengren et al. 1997). 
- Based on the presented methodology, high-temperature, low-salt, and/or highammonia wastes have the highest flammability potential. At a ventilation rate of 3 acfh, 10 wastes (S-102, S-109, SX-102, SX-103, SX-105, SX-106, U-103, U-105, U-106, and U-108) are predicted by the equilibrium model to produce flammabilities exceeding $25 \%$ of the LFL in the DCRT for the base-case fill scenario ( $80 \%$ fill, $4 \mathrm{gpm}$ ). These values should not be taken as actual flammability predictions because a minimum ventilation rate was used to predict them, but they do indicate which wastes (or types of wastes) have the highest potential for flammability. The wastes with the highest potential flammability are those modeled as having high dissolved ammonia concentrations (S-102, SX-102, SX-103, SX-105, SX-106, U-103, U-105, and U-108), high temperatures (SX-102, SX-103, and SX-105), high dissolved hydrogen concentrations resulting from low salt in the liquid (S-109), or high hydrogen generation rates caused by high temperature or high TOC (SX-103, SX-105, U-103, U-105, and U-106). Hydrogen dominates the flammability for S-109 (due to low salt concentrations) and U-106 (due to high post-fill hydrogen generation rates). The nonequilibrium model also predicts flammabilities that exceed $25 \%$ of the LFL for wastes from nine of these tanks; the exception is S-109.

- Of the eight tanks for whose wastes the ammonia flammability contribution exceeded $25 \%$ of the LFL in the base-case minimum-ventilation equilibrium scenario, only the predictions for the wastes in SX-103 and U-103 were based on measured dissolved ammonia concentrations. Modeling of the other six should be considered preliminary and highly uncertain pending ammonia concentration measurements.

- Five of the tanks whose wastes were predicted at minimum ventilation to produce high flammability in the DCRT headspace, SX-103, SX-105, U-103, U-105, and U106 , were predicted to have high enough hydrogen generation rates to make hydrogen a flammability concern in the post-fill, steady-state period. There is evidence (based on hydrogen generation rates calculated from tank headspace measurements) that the hydrogen generation model overestimates the generation rate in three of these tanks, SX-103, SX-105, and U-106. The hydrogen contribution to the DCRT headspace flammability therefore is exaggerated for these three tanks. Further research may be needed to develop an improved hydrogen generation model, a more complete set of hydrogen generation estimates from headspace hydrogen measurements, or both.

- The nonequilibrium and equilibrium models predict headspace flammabilities that are typically within $20 \%$ of each other at low ventilation rates. However, this small difference in predicted flammability translates into a large difference in the ventilation rate required to produce $25 \%$ of the LFL in the headspace, because increasing the ventilation tends to have a relatively small influence on reducing the headspace flammability. Therefore, the equilibrium model substantially overpredicts the ventilation rates required to maintain DCRT headspace flammability below $25 \%$ of the LFL. 
- The minimum required ventilation rates calculated by the non-equilibrium model are highest for wastes from Tanks SX-103 and SX-105, at 130 and 150 acfh, respectively. While Hedengren et al. (1997) suggested possible operational changes, such as reducing the feed rate, that might allow such tanks to be pumped without exceeding $25 \%$ of the LFL even with minimal ventilation, this document does not address such changes.

- The nonequilibrium model shows that a ventilation rate of less than $3 \mathrm{acfm}(180 \mathrm{acfh})$ maintains the headspace below $25 \%$ of the LFL (based on the present ammonia concentration data). By contrast, the extremely low 3-acfh flow that has been assumed in other analyses predicts that at least nine wastes can exceed $25 \%$ of the LFL (based on a conservative but probably overpredictive hydrogen generation model and on current assumptions for dissolved hydrogen and ammonia concentrations). Because even a small ventilation flow can mitigate headspace flammability (especially under post-fill conditions), it is vital to measure the actual flow under typical operating conditions.

- Decreasing the feed rate to the DCRT does not always cause a decrease in the fill-end flammability. It can cause an increase, depending on the ratio of dissolved hydrogen to ammonia in the feed and on the hydrogen generation rate. Thus, assuming a maximum flow rate does not necessarily produce a conservative estimate of DCRT headspace flammability. Case-by-case modeling is needed to establish the actual safety envelope for DCRT use. The tank wastes are too variable to allow the generic statement that headspace flammability is always highest at high feed rates.

\subsection{Summary of Key Conclusions}

- Dissolved gas (both ammonia and, to a lesser degree, hydrogen) is the dominant mechanism of flammable gas carryover from a source tank to a DCRT. This gas, along with hydrogen generated within the waste, volatilizes into the DCRT headspace. However, headspace flammable gas concentrations are likely to remain below their equilibrium values due to mass transfer limitations, even when DCRT ventilation rates are only in the cfh range.

- For some SSTs, particularly high-temperature, low-salt, and/or high-ammonia wastes, salt-well pumping at the maximum rate of $4 \mathrm{gpm}$ could result in a DCRT headspace exceeding $25 \%$ of the LFL if only the minimal ventilation rate of $3 \mathrm{cfh}$ were present. However, actual passive ventilation rates are probably significantly higher, and the calculations are based on unmeasured or uncertain gas concentrations in the waste. A formal uncertainty analysis is deferred, however, pending measurements of DCRT ventilation rates.

\subsection{Recommendations for Future Work}

Work in the following areas, either from lab measurements or measurements in tanks themselves, would significantly reduce the uncertainty of assessing flammability risks in DCRTs: 
- The actual ventilation rates in the DCRTs should be measured, preferably under operating conditions. Measurements are, in fact, under way. Once these data are available, this report can be revised and updated to reflect our better understanding of ventilation. Predictions of DCRT headspace flammability will then be more meaningful. A formal uncertainty analysis is also recommended upon revision of this document to provide uncertainty estimates along with the flammability predictions. Such an analysis was not included in this version of the report due to the large uncertainty in headspace ventilation rates.

- DCRT headspace gas compositions should be measured during pumping operations under a variety of fill conditions to assess the validity of flammability predictions.

- The actual steady-state and transient temperature conditions in DCRTs (as opposed to source-tank conditions) could be investigated and included in future analyses.

- Large uncertainties exist in the dissolved ammonia concentrations in some of the waste tanks, particularly those that have never been sampled. It is unclear, though, whether further costly sampling is justified given the difficulty in obtaining a representative sample and accurate ammonia analysis. However, the uncertainty analysis (one that includes an analysis of the uncertainty in the model itself, as distinct from its inputs) could be used to establish an envelope of flammable gas inputs (source dissolved ammonia, source hydrogen partial pressure, and hydrogen generation rates) within which the DCRT headspace flammability would remain below $25 \%$ of the LFL for a given fill scenario and ventilation rate. An envelope of this kind would make it easier to see whether, for a given tank waste (salt concentration, temperature, etc.), ammonia concentrations high enough to cause difficulties are even plausible. This could reduce the need for ammonia samples or point out the tank wastes for which samples are most needed.

- The model for gas generation rates could be refined to better estimate behavior in SSTs. 


\subsection{References}

Abrams AJ. May 1977. "Mud Design to Minimize Rock Impairment Due to Invasion." $J$. Petroleum Technology, pp. 586-592.

Allemann RT, ZI Antoniak, JR Friley, CE Haines, LM Liljegren, and S Somasundaram. 1991. Mechanistic Analysis of Double-Shell Tank Gas Release: Progress Report - November 1990. PNL-7657, Pacific Northwest National Laboratory, Richland, Washington.

Antoniak ZI and KP Recknagle. 1997. Initial Parametric Study of the Flammability of Plume Releases in Hanford Waste Tanks. PNL-11639, Pacific Northwest National Laboratory, Richland, Washington.

Ashby EC, DA Annis, EK Barefield, D Boatwright, F Doctorovich, CL Liotta, HM Neumann, A Konda, CF Yao, K Zhang, and NG McDuffie. 1994. Synthetic Waste Chemical Mechanism Studies. WHC-EP-0823, Westinghouse Hanford Company, Richland, Washington.

Baldwin DL, RW Stromatt, and WI Winters. 1994. Comparative Study of Total Organic Carbon (TOC) Methods for High-Level Mixed Waste. PNL-SA-2374, Pacific Northwest Laboratory, Richland, Washington.

Barefield EK, D Boatwright, A Deshpande, F Doctorovich, CL Liotta, HM Neumann, and S Seymore. 1995. Mechanisms of Gas Generation from Simulated SY Tank Farm Wastes: FY 1994 Progress Report. PNL-10822, Pacific Northwest Laboratory, Richland, Washington.

Barefield EK, D Boatwright, A Deshpande, F Doctorovich, CL Liotta, HM Neumann, and S Seymore. 1996. Mechanisms of Gas Generation from Simulated SY Tank Farm Wastes: FY 1994 Progress Report. PNL-11247, Pacific Northwest National Laboratory, Richland, Washington.

Blevins RD, ed. 1984. Applied Fluid Dynamics Handbook. Van Nostrand Reinhold Co., New York.

Bobroff S, RJ Phillips, and A Shekarriz. 1997. Nuclear Magnetic Resonance Measurements of Ammonia Diffusion in Dense Solid-Liquid Slurries. PNNL-11678 Rev. 1, Pacific Northwest National Laboratory, Richland, Washington.

Bredt PR and SM Tingey. 1996. The Effect of Dilution on the Gas Retention Behavior of Tank 241-SY-103 Waste. PNL-10893, Pacific Northwest National Laboratory, Richland, Washington.

Bredt PR, SM Tingey, and EH Shade. 1995. The Effect of Dilution on the Gas-Retention Behavior of Tank 241-SY-101 Waste. PNL-10781, Pacific Northwest Laboratory, Richland, Washington. 
Breshears WD, HA Fry, JL Lyman, RC Oldenbort, and DK Zerkle. 1997. Final Report: Gas Flammability Modeling. LA-UR-97-2206, Los Alamos National Laboratory, Los Alamos, New Mexico.

Brewster ME, NB Gallagher, JD Hudson, and CW Stewart. 1995. The Behavior, Quantity, and Location of Undissolved Gas in Tank 241-SY-101. PNL-10681, Pacific Northwest Laboratory, Richland, Washington.

Bryan SA, CM King, LR Pederson, SV Forbes, and RL Sell. 1996. Gas Generation from Tank 241-SY-103 Waste. PNNL-10978, Pacific Northwest National Laboratory, Richland, Washington.

Bryan SA and LR Pederson. 1994. Composition, Preparation, and Gas Generation Results from Simulated Wastes of Tank 241-SY-101. PNL-10075, Pacific Northwest Laboratory, Richland, Washington.

Buckley WL and HW Husa. 1962. "Combustion Properties of Ammonia." Chemical Engineering Progress, Vol. 58, pp. 81-84.

Caley SM, LA Mahoney, and PA Gauglitz. 1996. Summary of Tank Information Relating SaltWell Pumping to Flammable Gas Safety Issues. PNNL-11335, Pacific Northwest National Laboratory, Richland, Washington.

Camaioni DM, WD Samuels, SA Clauss, BD Lenihan, KL Wahl, JA Campbell, and WJ Shaw. 1995. FY95 Waste Aging Studies. PNL-10794, Pacific Northwest Laboratory, Richland, Washington.

Camaioni DM, WD Samuels, JC Linehan, SA Clauss, AK Sharma, KL Wahl, and JA Campbell. 1996. FY95 Waste Aging Studies. PNL-11312, Pacific Northwest Laboratory, Richland, Washington.

Campbell JA, S Clauss, KA Grant, FV Hoopes, GM Mong, JK Rau, RT Steele, and KL Wahl. 1996. Flammable Gas Safety Program: Actual Waste Organic Analysis, FY 1996 Progress Report. PNNL-11307, Pacific Northwest National Laboratory, Richland, Washington.

Carlson CD. 1997. Speciation of Organic Carbon in Hanford Waste Storage Tanks: Part 1. PNNL-11480, Pacific Northwest National Laboratory, Richland, Washington.

Cashdollar KL, M Hertzberg, IA Zlochower, CE Lucci, GM Green, and RA Thomas. 1992. Laboratory Flammability Studies of Mixtures of Hydrogen, Nitrous Oxide, and Air. WHC-SDWM-ES-219, Westinghouse Hanford Company, Richland, Washington.

Clegg SL and P Brimblecombe. 1989. "Solubility of Ammonia in Pure Aqueous and Multicomponent Solutions." Journal of Physical Chemistry, 93:7237-7248.

Clegg SL and P Brimblecombe. 1990. Geochim. Cosmochim. Acta, 54:3315. 
Clift R, JR Grace, and ME Weber. 1978. Bubbles, Drops, and Particles. Academic Press, Inc., New York.

CRC. 1975. CRC Handbook of Chemistry and Physics, 56th Edition, RC Weast, ed. CRC Press, Cleveland, Ohio.

CRC. 1990. CRC Handbook of Chemistry and Physics, 71st Edition, DR Lide, ed. CRC Press, Boston, Massachusetts.

Delegard C. 1980. Laboratory Studies of Complexed Waste Slurry Volume Growth in Tank 241SY-101. RHO-LD-124, Rockwell Hanford Operations, Richland, Washington.

Dullien FAL. 1992. Porous Media: Fluid Transport and Pore Structure. Academic Press, San Diego.

Ecology, EPA, and DOE. 1996. Hanford Federal Facility Agreement and Consent Order. Washington State Department of Ecology, U.S. Environmental Protection Agency, and U.S. Department of Energy, Olympia, Washington, as amended.

Edwards TJ, G Maurer, J Newman, and JM Prausnitz. 1978. AIChE Journal, 24:966.

Elmore MR. 1997. Corrosion of Mild Steel in Simulated Cesium Elution Process Solutions. PNNL-11284, Pacific Northwest National Laboratory, Richland, Washington.

Fenton DL, RD Kelley, AS Khan, and KS Chapman. 1995. "Combustion Characteristics: Review of Ammonia-Air Mixtures." ASHRAE Transactions, 101:476-485.

Field JG, DE Place, and RD Cromar. 1997. Tank Characterization Report for Single-Shell Tank 241-A-101. HNF-SD-WM-ER-673 Rev. 0, Lockheed Martin Hanford Corp., Richland, Washington.

Gauglitz PA, LA Mahoney, DP Mendoza, and MC Miller. 1994a. Mechanisms of Gas Bubble Retention. PNL-10120, Pacific Northwest Laboratory, Richland, Washington.

Gauglitz PA, RR Shah, and RL Davis. 1994b. Gas Distribution Effects on Waste Properties: Viscosity of Bubbly Slurries. PNL-10112, Pacific Northwest Laboratory, Richland, Washington.

Gauglitz PA, SD Rassat, MR Powell, RR Shah, and LA Mahoney. 1995. Gas Bubble Retention and Its Effect on Waste Properties: Retention Mechanisms, Viscosity, and Tensile and Shear Strengths. PNL-10740, Pacific Northwest Laboratory, Richland, Washington.

Gauglitz PA, SD Rassat, PR Bredt, JH Konynenbelt, SM Tingey, and DP Mendoza. 1996. Mechanisms of Gas Bubble Retention and Release: Results for Hanford Waste Tanks 241-S-102 and 241-SY-103 and Single-Shell Tank Simulants. PNNL-11298, Pacific Northwest National Laboratory, Richland, Washington. 
Gauglitz PA and JT Aikin. 1997. Waste Behavior During Horizontal Extrusion: Effect of Waste Strength for Bentonite and Kaolin/Ludox Simulants and Strength Estimates for Wastes from Hanford Waste Tanks 241-SY-103, AW-101, AN-103 and S-102. PNNL-11706, Pacific Northwest National Laboratory, Richland, Washington.

Graves RD. 1994. Topical Report on Flammable Gases in Non-Burping Waste Tanks. WHCSD-WM-SARR-015, Westinghouse Hanford Company, Richland, Washington.

Grimes GW. 1978. Jet Pump Development for Salt-Well Application. RHO-CD-316, Rockwell Hanford Operations, Richland, Washington.

Gunton JD, M San Miguel, and PS Sahni. 1983. "The Dynamics of First-order Phase Transitions." Phase Transitions, Vol. 8, Ch. 3. Academic Press.

Hanlon BM. 1996. Waste Tank Summary Report for Month Ending September 26, 1996. WHCEP-0182-102, Westinghouse Hanford Company, Richland, Washington.

Hedengren DC, JD Bingham, SA Barker, JM Conner, and SD Estey. 1997. Calculation of Flammable Gas Mixtures in Double-Contained Receiver Tanks. HNF-SD-WM-CN-118 Rev. 0, Lockheed Martin Hanford Company, Richland, Washington.

Hermann C, I Dewes, and A Schumpe. 1995. Chem. Eng. Sci., 50:1673.

Herzig JP, DM LeClerc, and P LeGoff. 1970. "Flow of Suspensions Through Porous Media: Application to Deep Bed Filtration." Ind. Eng. Chem., 62(5):8-35.

Herting DL, DB Bechtold, BE Hey, BD Keele, J Jensen, and TL Welsh. 1992. Laboratory Characterization of Samples Taken in December 1991 (Window E) from Hanford Waste Tank 241-SY-101. WHC-SD-WM-DTR-026, Westinghouse Hanford Company, Richland, Washington.

Hodgson KM, RP Anantatmula, SA Barker, KD Fowler, JD Hopkins, JA Lechelt, DA Reynolds, DC Hedengren, RE Stout, and RT Winward. 1996. Evaluation of Hanford Tanks for Trapped Gas. WHC-SD-WM-ER-526 Rev. 1, Westinghouse Hanford Company, Richland, Washington.

Hopkins JD. 1994. Criteria for Flammable Gas Watch List Tanks. WHC-EP-0702 Rev. 0, Westinghouse Hanford Company, Richland, Washington.

Hopkins JD. 1995. Methodology for Flammable Gas Evaluations. WHC-SD-WM-TI-724, Westinghouse Hanford Company, Richland, Washington.

Hu TA. 1997. Calculations of Hydrogen Release Rate at Steady State for Double-Shell Tanks. HNF-SD-WM-CN-117 Rev. 0, Lockheed Martin Hanford Corporation, Richland, Washington.

Hu TA, LW Shelton Jr, and TL Welsh. 1997. Tank Characterization Report for Double-Shell Tank 241-AN-104. HNF-SD-WM-ER-690 Rev. 0, Lockheed Martin Hanford Corporation, Richland, Washington. 
Huckaby JL, KB Olsen, DS Sklarew, JC Evans, and KM Remund. 1997. Measurements of Waste Tank Passive Ventilation Rates Using Tracer Gases. PNNL-11683, Pacific Northwest National Laboratory, Richland, Washington.

Johnson GD, WB Barton, JW Brothers, SA Bryan, PA Gauglitz, RC Hill, LR Pederson, CW Stewart, and LM Stock. 1997. Flammable Gas Project Topical Report. HNF-SP-1193 Rev. 2 (PNNL-11500), Lockheed Martin Hanford Corp., Richland, Washington.

Jo J, LW Shelton Jr, TL Welsh, and J Stroup. 1997. Tank Characterization Report for DoubleShell Tank 241-AN-105. HNF-SD-WM-ER-678 Rev. 0, Lockheed Martin Hanford Corporation, Richland, Washington.

Khatib ZI and S Vitthal. October 1989. "The Use of the Effective Medium Theory and a 3-D Network Model to Predict Matrix Damage in Sandstone Formations." Proceedings of $64^{\text {th }}$ Annual Technical Conference and Exhibition. Society of Petroleum Engineers, San Antonio, Texas.

Kreith F. 1973. Principles of Heat Transfer, $3^{\text {rd }}$ Ed. Intext Educational Publishers, New York.

Kubic WL Jr. 1997. Data Reconciliation Study of Tank 241-AW-101 at the Hanford Site. LAUR-97-2214, Los Alamos National Laboratory, Los Alamos, New Mexico.

Leighton TG. 1994. The Acoustic Bubble. Academic Press, London.

Mahoney LM, ZI Antoniak, and JM Bates. 1997. Composition and Quantities of Retained Gas Measured in Hanford Waste Tanks 241-U-103, S-106, BY-101 and BY-109. PNNL-11777, Pacific Northwest National Laboratory, Richland, Washington.

Mahoney LA and DS Trent. 1995. Correlation Models for Waste Tank Sludges and Slurries. PNL-10695, Pacific Northwest Laboratory, Richland, Washington.

McCabe WL and JC Smith. 1976. Unit Operations of Chemical Engineering, 3rd Edition. McGraw Hill, New York.

Meisel D, H Diamond, EP Horowitz, CD Jonah, MS Matheson, MC Sauer, Jr., and JC Sullivan. 1991a. Radiation Chemistry of Synthetic Waste. ANL-91/40, Argonne National Laboratory, Argonne, Illinois.

Meisel D, H Diamond, EP Horowitz, CD Jonah, MS Matheson, MC Sauer, Jr., and JC Sullivan. 1991b. Radiation Chemistry of Synthetic Waste. ANL-91/40, Argonne National Laboratory, Argonne, Illinois.

Meisel D, H Diamond, EP Horowitz, CD Jonah, MS Matheson, MC Sauer, Jr., JC Sullivan, F Barnabas, E Cerny, and YD Cheng. 1991c. Radiolytic Generation of Gases from Synthetic Waste: Annual Report 1991. ANL-91/41, Argonne National Laboratory, Argonne, Illinois. 
Meisel D, CD Jonah, S Kapoor, MS Matheson, and MC Sauer. 1993. Radiolytic and Radiolytically Induced Generation of Gases from Synthetic Wastes. ANL-93/43, Argonne National Laboratory, Argonne, Illinois.

Meyer PA, ME Brewster, SA Bryan, G Chen, LR Pederson, CW Stewart, and G Terrones. 1997. Gas Retention and Release Behavior in Hanford Double-Shell Waste Tanks. PNNL-11536 Rev. 1, Pacific Northwest National Laboratory, Richland, Washington.

Noorani YG. 1997. Tank Waste Remediation System Basis for Interim Operation. HNF-SDWM-BIO-001, Duke Engineering Services Hanford, Richland, Washington.

Norton JD and LR Pederson. 1994. Ammonia in Simulated Hanford Double-Shell Tank Wastes: Solubility and Effects on Surface Tension. PNL-10173, Pacific Northwest National Laboratory, Richland, Washington.

Norton JD and LR Pederson. 1995. Solubilities of Gases in Simulated Tank 241-SY-101 Wastes. PNL-10785, Pacific Northwest Laboratory, Richland, Washington.

Pasamehmetoglu K, WL Kubic Jr, J Spore, R Lin, J Dearing, and P Sadasivan. 1994b. 101-SY Modeling Issues. Los Alamos National Laboratory, Los Alamos, New Mexico.

Pederson LR and SA Bryan. 1996. Status and Integration of Studies of Gas Generation in Hanford Wastes. PNNL-11297, Pacific Northwest National Laboratory, Richland, Washington.

Perry RH and DW Green. 1984. Perry's Chemical Engineers' Handbook, $6^{\text {th }}$ Ed. McGrawHill, New York.

Person JC. 1996. Effects of Oxygen Cover Gas and NaOH Dilution on Gas Generation in Tank 241-SY-101 Waste. WHC-SD-WM-DTR-043, Westinghouse Hanford Company, Richland, Washington.

Peurrung LM, SM Caley, EY Bian, and PA Gauglitz. 1996. Gas Release During Salt-Well Pumping: Model Predictions and Comparisons to Laboratory Experiments. PNNL-11310, Pacific Northwest National Laboratory, Richland, Washington.

Peurrung LM, SM Caley, and PA Gauglitz. 1997. Gas Release During Salt-Well Pumping: Model Predictions and Laboratory Validation Studies for Soluble and Insoluble Gases. PNNL11621, Pacific Northwest National Laboratory, Richland, Washington.

Pitzer KS. 1987. Reviews in Mineralogy, 17:97.

Pitzer KS, ed. 1990. Activity Coefficients in Electrolyte. Solutions, 2nd ed. CRC Press, Boca Raton, Florida, p. 88.

Pourbaix M. 1974. Atlas of Electrochemical Equilibria. National Association of Corrosion Engineers, Houston, Texas. 
Rassat SD, PA Gauglitz, PR Bredt, LA Mahoney, SV Forbes, and SM Tingey. 1997. Mechanisms of Gas Bubble Retention and Release: Experimental Results for Hanford Waste Tanks 241-AW-101 and 241-AN-103. PNNL-11642, Pacific Northwest National Laboratory, Richland, Washington.

Rassat SD and PA Gauglitz. 1995. Bubble Retention in Synthetic Sludge: Testing of Alternative Gas Retention Apparatus. PNL-10661, Pacific Northwest Laboratory, Richland, Washington.

Remund KM, CM Anderson, and BC Simpson. 1995. Hanford Single-Shell Tank Grouping Study. PNL-10749, Pacific Northwest National Laboratory, Richland, Washington.

Rossen WR and SK Das. 1995. Mechanisms of Stability of Armored Bubbles: FY 1995 Final Report. PNNL-11133, Pacific Northwest National Laboratory, Richland, Washington.

Rossen WR and SI Kam. 1996. Mechanisms of Stability of Armored Bubbles: FY 1996 Progress Report. PNNL-11416, Pacific Northwest National Laboratory, Richland, Washington.

Schumpe A. 1993. Chem. Eng. Sci. 48:153.

Setschenow J. 1889. Z. Phys. Chem. 4:117.

Shekarriz A, DR Rector, LA Mahoney, MA Chieda, JM Bates, RE Bauer, NS Cannon, BE Hey, CG Linschooten, FJ Reitz, and ER Siciliano. 1997. Composition and Quantities of Retained Gas Measured in Hanford Waste Tanks 241-AW-101, A-101, AN-105, AN-104, and AN-103. PNNL-1 1450 Rev. 1, Pacific Northwest National Laboratory, Richland, Washington.

Stewart CW, CT Crowe, and SC Saunders. 1993. "A Model for Simultaneous Coalescence of Bubble Clusters." Chemical Engineering Science, 48:3347-3354.

Stewart CW, JM Alzheimer, ME Brewster, G Chen, RE Mendoza, HC Reid, CL Shepard, and G Terrones. 1996. In Situ Rheology and Gas Volume in Hanford Double-Shell Waste Tanks. PNNL-11296, Pacific Northwest National Laboratory, Richland, Washington.

Strachan DM. 1994. Status and Integration of the Gas Generation Studies Performed for the Hydrogen Safety Program-FY 1993. Annual Report. PNL-9459, Pacific Northwest Laboratory, Richland, Washington.

Sullivan LH. 1994. A Safety Assessment for Proposed Pump Mixing Operations to Mitigate Episodic Gas Releases in Tank 241-SY-101: Hanford Site, Richland, Washington. LA-UR-923196 Rev. 9, Los Alamos National Laboratory, Los Alamos, New Mexico.

Sullivan LH. 1997. A Safety Assessment for Proposed Pump Mixing Operations to Mitigate Episodic Gas Releases in Tank 241-SY-101: Hanford Site, Richland, Washington. HNF-SDWM-SAD-033 Rev. 3, Lockheed Martin Hanford Corp., Richland, Washington.

Tabata Y. 1991. CRC Handbook of Radiation Chemistry. CRC Press, Boca Raton, Florida. 
Terrones G, BJ Palmer, and JM Cuta. 1997. Ammonia Concentration Modeling Based on Retained Gas Sampler Data. PNNL-11674, Pacific Northwest National Laboratory, Richland, Washington.

Treybal RE. 1980. Mass-Transfer Operations. McGraw-Hill, Inc., New York.

Van Keuren JC and EC Ocoma. 1998. Calculation Note on Flammable Gas in Waste Transfer Lines. HNF-2251, Lockheed Martin Hanford Corp., Richland, Washington.

Wahl KL, JA Campbell, IE Burgeson, SA Bryan, DM Camaioni, RT Hallen, BD Lerner, and RD Scheele. 1996. Use of Organic Functional Group Concentrations as a Means of Screening for Energetics. PNNL-10883, Pacific Northwest National Laboratory, Richland, Washington.

Walker DD, CL Crawford, and NE Bibler. 1994. "Radiolytic Bubble Formation and Level Changes in Simulated High-Level Waste Salts and Sludges-Application to HLW Storage Tanks." Proceedings of Waste Management 1994, Tucson, Arizona, pp. 393-396.

Weisenberger S and A Schumpe. 1996. "Estimation of Gas Solubilities in Salt Solutions at Temperatures from 273 to 363K." AIChE Journal, 42:298-300.

Westinghouse Hanford Company. 1996. A Safety Assessment for Salt Well Jet Pumping Operations in Tank 241-A-101. WHC-SD-WM-SAD-036 Rev. 0, Westinghouse Hanford Company, Richland, Washington.

White FM. 1986. Fluid Mechanics, $2^{\text {nd }} E d$. McGraw Hill, New York.

Wilkins NE. 1995. Tank 241-SY-103 Core Sample: Interpretation of Results. WHC-SD-WMTI-712, Westinghouse Hanford Company, Richland, Washington.

Wilkins NE, RE Bauer, and DM Ogden. 1997a. Results of Vapor Space Monitoring of Flammable Gas Watch List Tanks. SD-WM-TI-797 Rev. 2, Lockheed Martin Hanford Corporation, Richland, Washington.

Wilkins NE, JG Field, LW Shelton, and TL Welsch. 1997b. Tank Characterization Report for Double-Shell Tank 241-AN-103. HNF-SD-WM-ER-702 Rev. 0, Lockheed Martin Hanford Corporation, Richland, Washington.

Wodrich DD, GS Barney, GL Borsheim, DL Becker, WC Carlos, MJ Klem, RE Van der Cook, and JL Ryan. 1992. Summary of SST Stability. WHC-EP-0347 (supplement), Westinghouse Hanford Company, Richland, Washington. 


\section{Appendix A}

Sampled Ammonia Results for Single-Shell Tanks 
Table A.1. Sampled Ammonia Results for Single-Shell Tanks (tanks in bold-face type are those modeled by Hedengren et al. 1997)

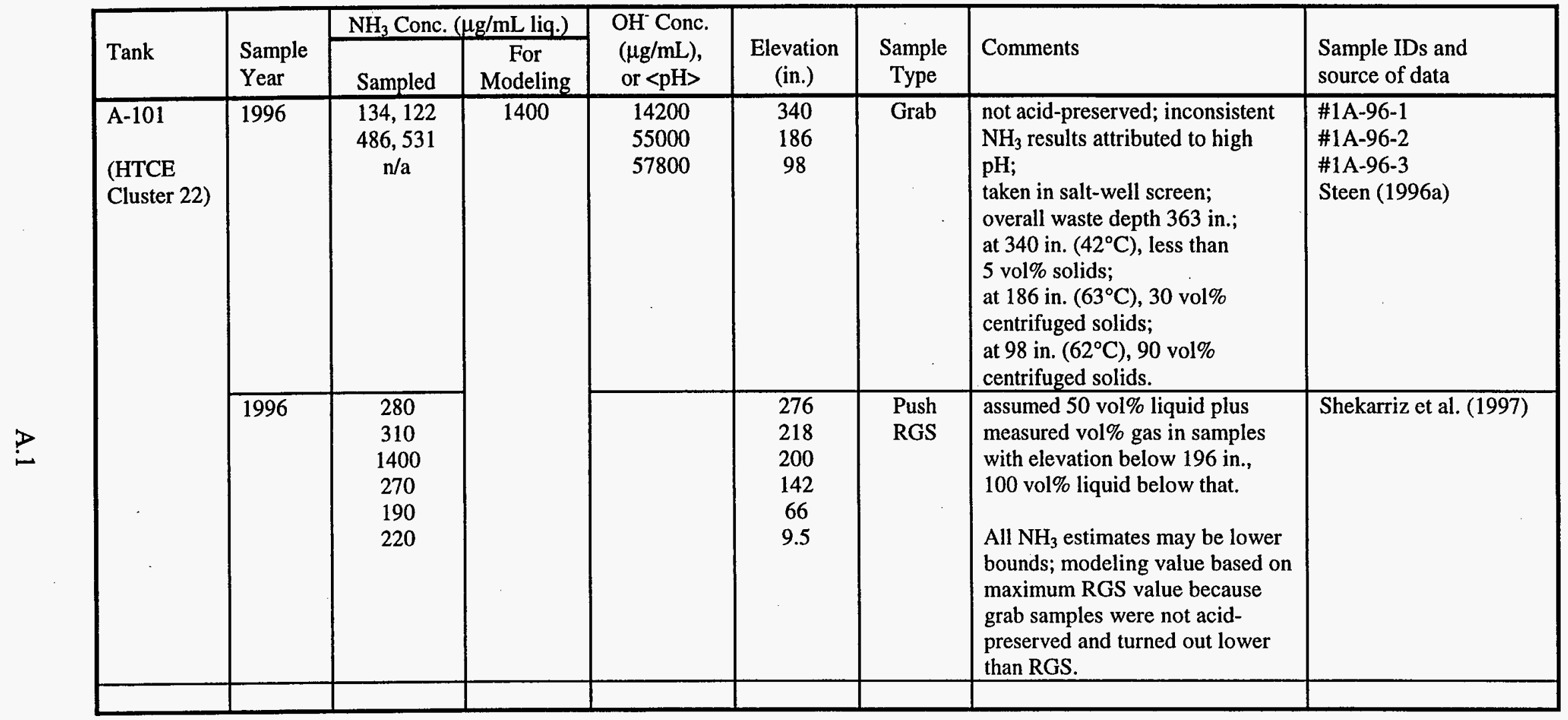


Table A.1 (contd)

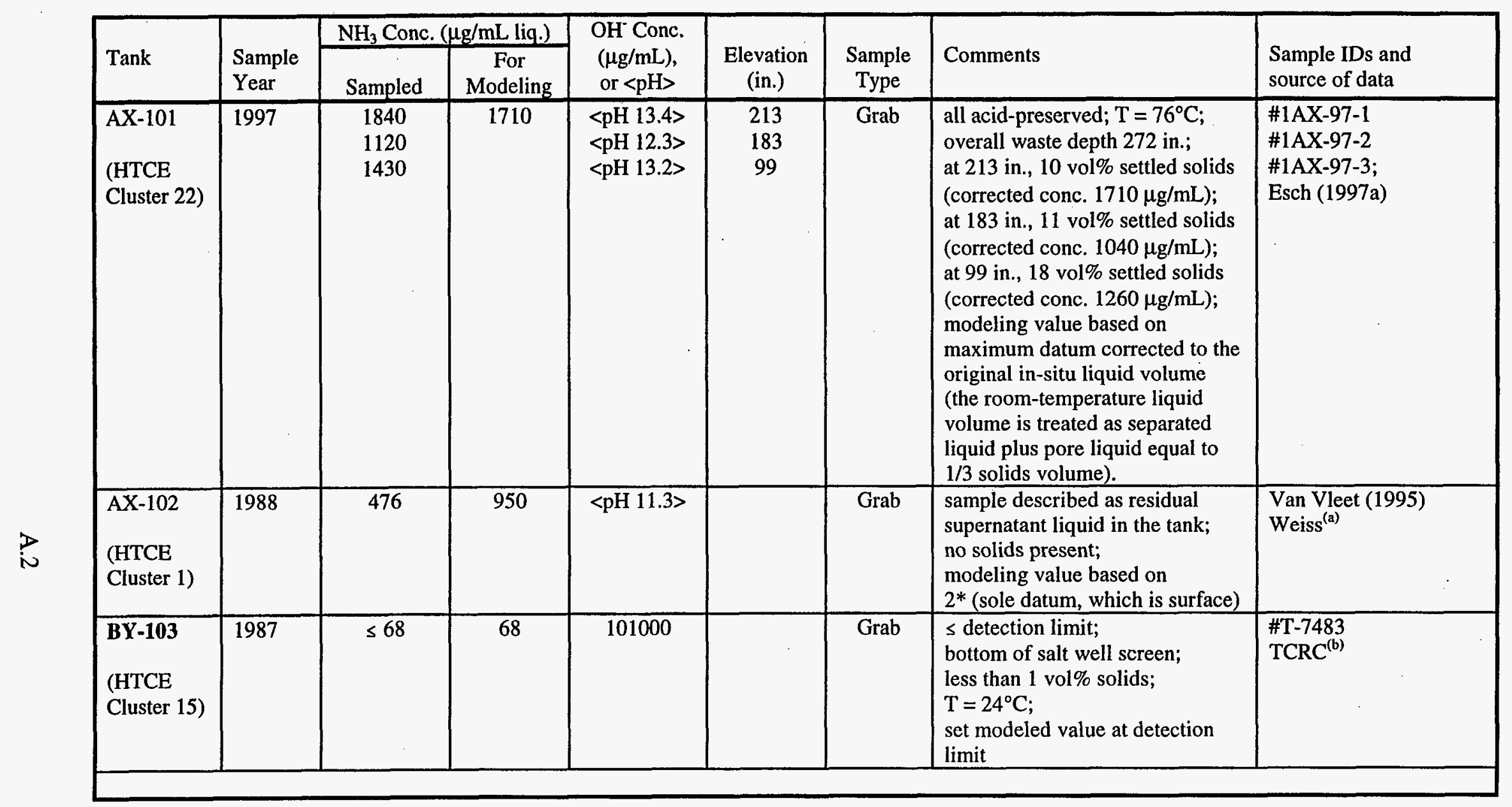

(a) Weiss RL. November 14, 1988. "Analysis of Tank 241-AX-102 Sample." Memo 12712-PCL88-018 to JA Eacker. Westinghouse Hanford Company, Richland, Washington.

(b) TCRC. 1987. "Sample Status Report for T-7483." Tank Characterization Resource Center (TCRC-5). Lockheed Martin Hanford Corporation, Richland, Washington. 
Table A.1 (contd)

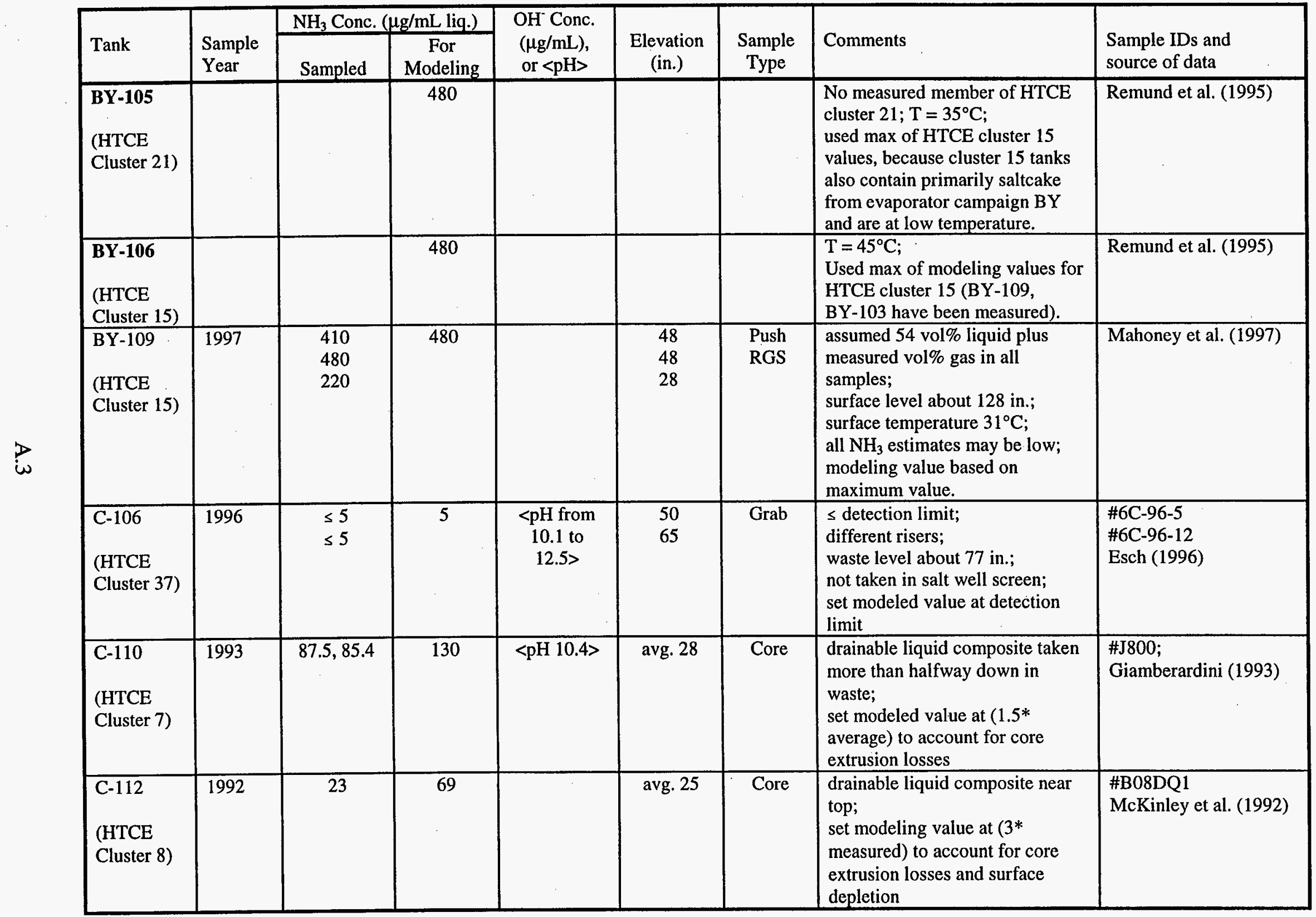


Table A.1 (contd)

\begin{tabular}{|c|c|c|c|c|c|c|c|c|}
\hline \multirow[b]{2}{*}{ Tank } & \multirow[b]{2}{*}{$\begin{array}{l}\text { Sample } \\
\text { Year }\end{array}$} & \multicolumn{2}{|c|}{$\mathrm{NH}_{3}$ Conc. $(\mu \mathrm{g} / \mathrm{mL}$ liq. $)$} & \multirow{2}{*}{$\begin{array}{l}\mathrm{OH}^{-} \text {Conc. } \\
(\mu \mathrm{g} / \mathrm{mL}) \\
\text { or }<\mathrm{pH}\rangle\end{array}$} & \multirow[b]{2}{*}{$\begin{array}{l}\text { Elevation } \\
\text { (in.) }\end{array}$} & \multirow[b]{2}{*}{$\begin{array}{l}\text { Sample } \\
\text { Type }\end{array}$} & \multirow[b]{2}{*}{ Comments } & \multirow[b]{2}{*}{$\begin{array}{l}\text { Sample IDs and } \\
\text { source of data }\end{array}$} \\
\hline & & Sampled & $\begin{array}{c}\text { For } \\
\text { Modeling }\end{array}$ & & & & & \\
\hline $\begin{array}{l}\text { S-101 } \\
\text { (HTCE } \\
\text { Cluster 11) }\end{array}$ & 1992 & 279 & 279 & $<\mathrm{pH} \mathrm{13.4>}$ & & Grab & $\begin{array}{l}\text { bottom of salt well screen; } \\
\text { less than } 10 \text { vol } \% \text { solids; } \\
\mathrm{T}=44^{\circ} \mathrm{C} ; \\
\text { set modeled value equal to } \\
\text { sampled because grab samples } \\
\text { experience little loss in analysis, } \\
\text { and it's a bottom sample, hence } \\
\text { undepleted }\end{array}$ & $\begin{array}{l}\text { \#R-1130 } \\
\text { Sutey }{ }^{(\mathrm{c})} \text { Pitkoff } \\
\text { (d) }\end{array}$ \\
\hline $\begin{array}{l}\text { S-102 } \\
\text { (HTCE } \\
\text { Cluster 13) } \\
\end{array}$ & & & 3100 & & & & $\begin{array}{l}\mathrm{T}=40^{\circ} \mathrm{C} ; \\
\text { Used max of modeling values for } \\
\text { HTCE cluster } 13 \text { (U-103, S-103, } \\
\text { U-111 have been measured). }\end{array}$ & Remund et al. (1995) \\
\hline $\begin{array}{l}\mathbf{S - 1 0 3} \\
\text { (HTCE } \\
\text { Cluster 13) }\end{array}$ & 1992 & 864 & 864 & $\langle\mathrm{pH} 13.3\rangle$ & & Grab & $\begin{array}{l}\text { bottom of salt-well screen; } \\
\text { less than } 10 \text { vol } \% \text { solids; } \\
\mathrm{T}=27^{\circ} \mathrm{C} ; \\
\text { set modeled value equal to } \\
\text { sampled because grab samples } \\
\text { experience little loss in analysis, } \\
\text { and it's a bottom sample, hence } \\
\text { undepleted }\end{array}$ & $\begin{array}{l}\# R-1137 \\
\text { Sutey, }{ }^{(d)} \text { Pitkoff } \\
\end{array}$ \\
\hline $\begin{array}{l}\text { S-104 } \\
\text { (HTCE } \\
\text { Cluster 14) }\end{array}$ & 1992 & $\begin{array}{l}\leq 40 \\
\leq 40 \\
\leq 40\end{array}$ & 40 & $\begin{array}{l}<\mathrm{pH} \mathrm{13.6>} \\
<\mathrm{pH} 13.6> \\
<\mathrm{pH} 13.1>\end{array}$ & $\begin{array}{l}104 \\
104 \\
104\end{array}$ & $\begin{array}{l}\text { Push } \\
\text { core }\end{array}$ & $\begin{array}{l}\text { s detection limit; } \\
\text { waste surface } 113 \text { in.; } \\
\text { all different risers; } \\
\text { taken in salt well screen; } \\
\text { set modeled value at detection } \\
\text { limit }\end{array}$ & $\begin{array}{l}\text { F\#2247 (BOB7B7) } \\
\text { F\#2249 (BOB7G2) } \\
\text { F\#2248 (BOB7G6) } \\
\text { Kocher (1993) }\end{array}$ \\
\hline
\end{tabular}

(c) Sutey MJ. December 4, 1995. "Waste Compatibility Assessment of Tanks 241-S-101, 241-S-103, 241-S-106, 241-S-107, 241-S108, 241-S-109, and 241-S-110 Waste with Tank 241-SY-102 Waste via DCRT 244-S.”. Memo 77240-95-030 to SJ Rifaey.

Westinghouse Hanford Company, Richland, Washington.

(d) Pitkoff C. October 4, 1991. Memo PM \#91-138, Westinghouse Hanford Company, Richland, Washington.

(e) Pitkoff C. September 30, 1991. Memo PM \#91-133, Westinghouse Hanford Company, Richland, Washington. 
Table A.1 (contd)

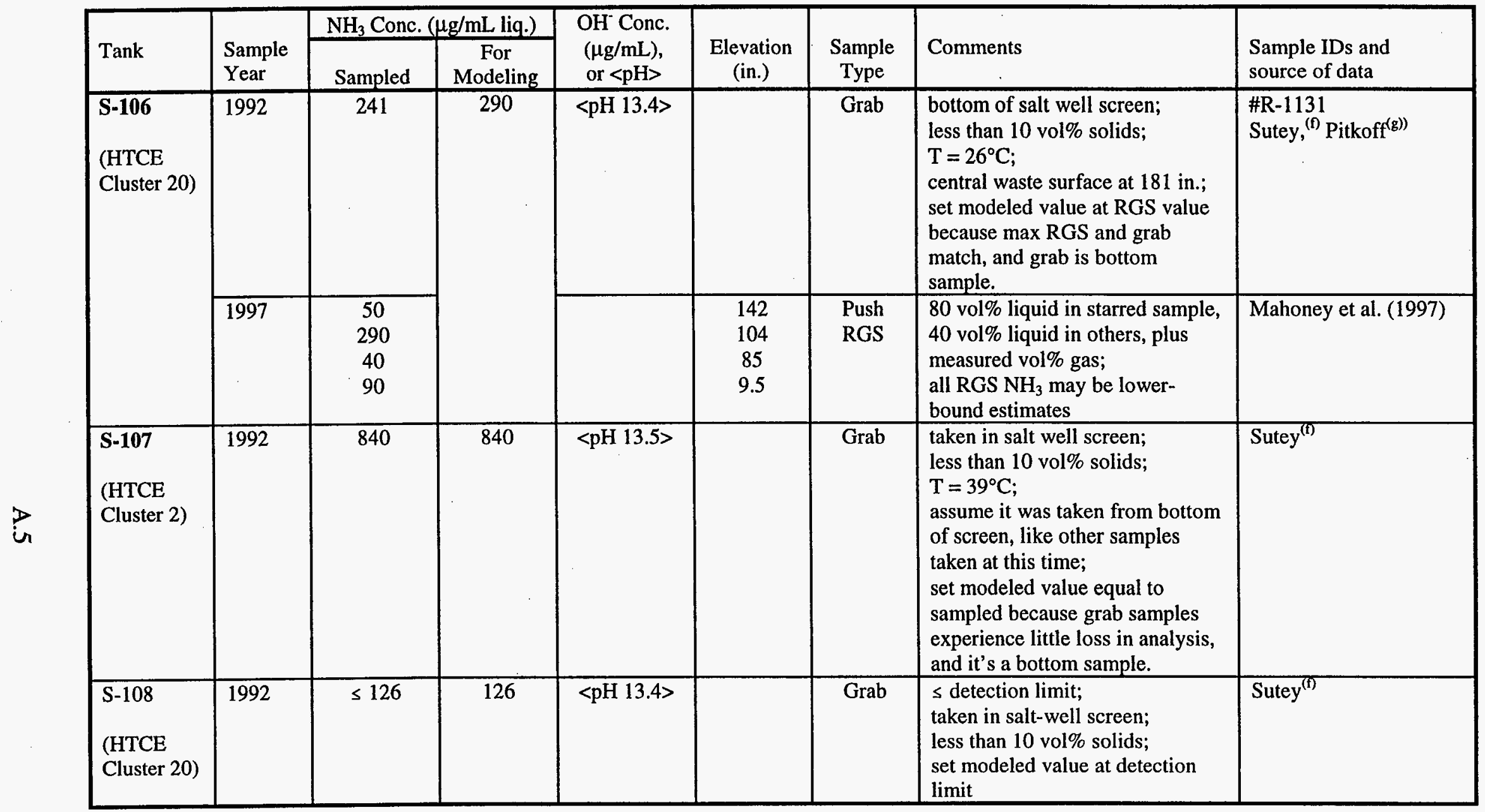

(f) Sutey MJ. December 4, 1995. "Waste Compatibility Assessment of Tanks 241-S-101, 241-S-103, 241-S-106, 241-S-107, 241-S108, 241-S-109, and 241-S-110 Waste with Tank 241-SY-102 Waste via DCRT 244-S." Memo 77240-95-030 to SJ Rifaey.

Westinghouse Hanford Company, Richland, Washington.

(g) Pitkoff C. October 4, 1991. Memo PM \#91-139, Westinghouse Hanford Company, Richland, Washington. 
Table A.1 (contd)

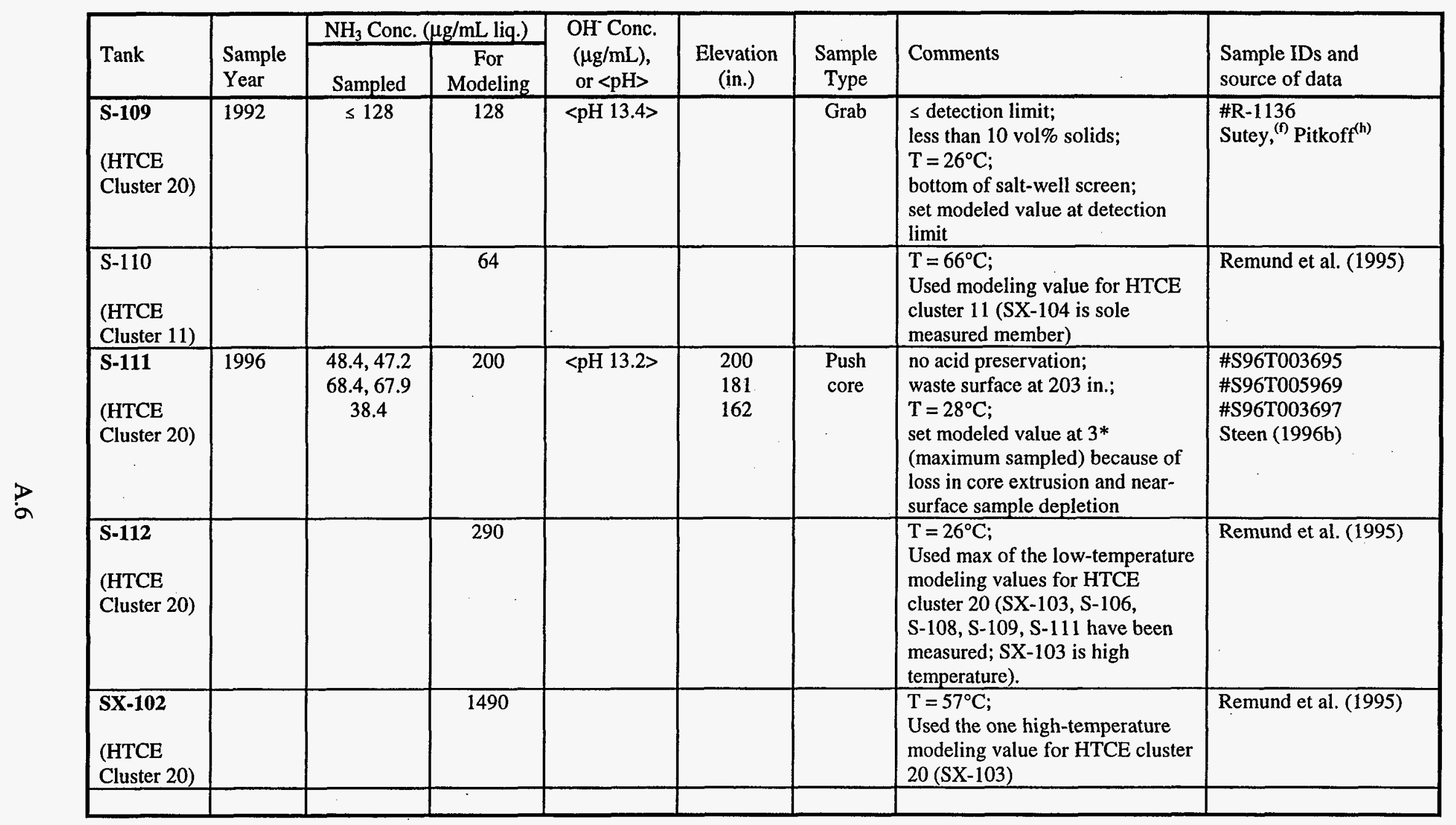

(h) Pitkoff C. October 11, 1991. Memo PM \#91-143, Westinghouse Hanford Company, Richland, Washington. 
Table A.1 (contd)

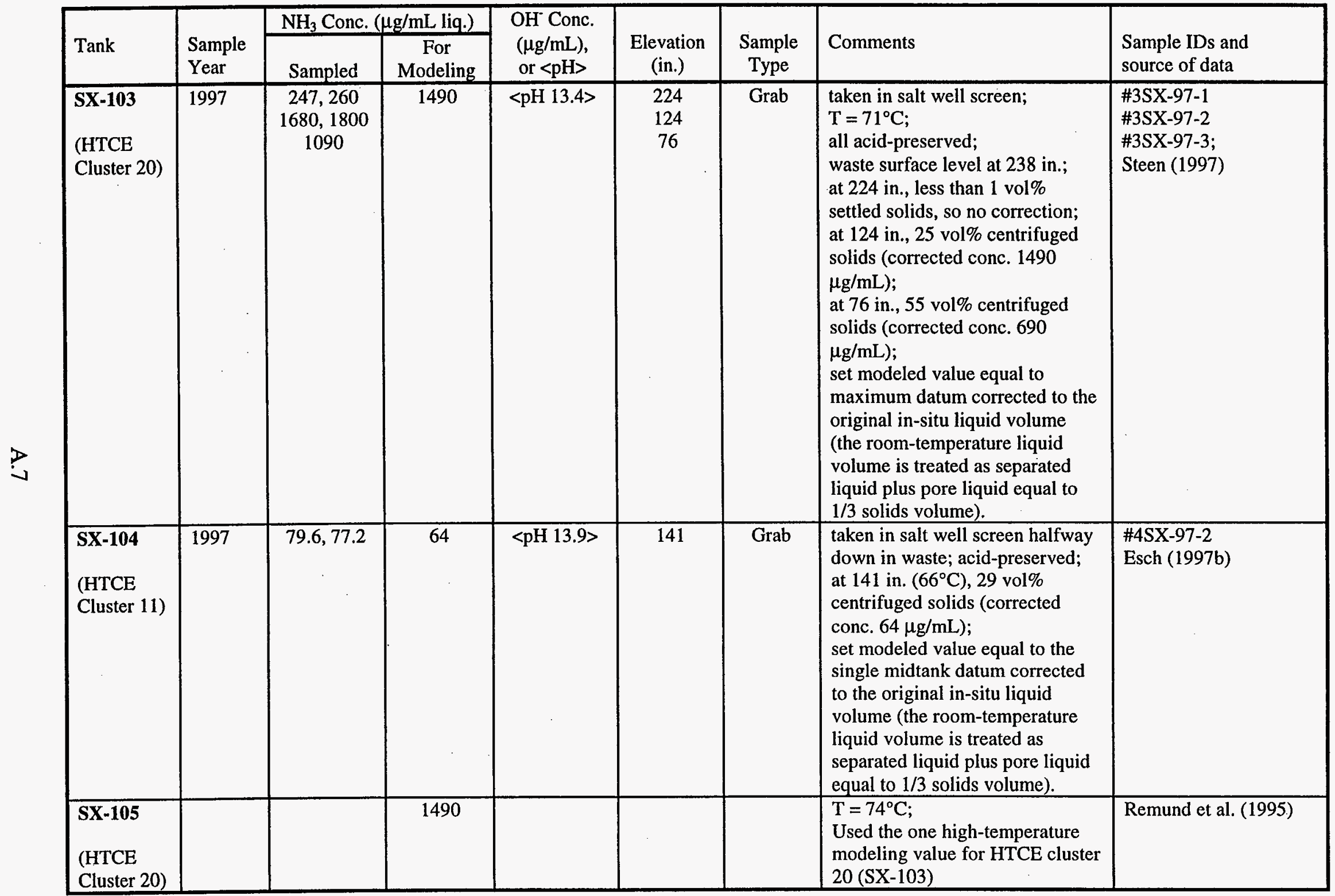


Table A.1 (contd)

\begin{tabular}{|c|c|c|c|c|c|c|c|c|}
\hline \multirow[b]{2}{*}{ Tank } & \multirow[b]{2}{*}{$\begin{array}{l}\text { Sample } \\
\text { Year }\end{array}$} & \multicolumn{2}{|c|}{$\mathrm{NH}_{3}$ Conc. $(\mu \mathrm{g} / \mathrm{mL}$ liq.) } & \multirow{2}{*}{$\begin{array}{l}\mathrm{OH}^{-} \text {Conc. } \\
(\mu \mathrm{g} / \mathrm{mL}) \text {, } \\
\text { or }<\mathrm{pH}>\end{array}$} & \multirow[b]{2}{*}{$\begin{array}{l}\text { Elevation } \\
\text { (in.) }\end{array}$} & \multirow[b]{2}{*}{$\begin{array}{c}\text { Sample } \\
\text { Type }\end{array}$} & \multirow[b]{2}{*}{ Comments } & \multirow[b]{2}{*}{$\begin{array}{l}\text { Sample IDs and } \\
\text { source of data }\end{array}$} \\
\hline & & Sampled & $\begin{array}{c}\text { For } \\
\text { Modeling }\end{array}$ & & & & & \\
\hline $\begin{array}{l}\mathbf{S X - 1 0 6} \\
\text { (HTCE } \\
\text { Cluster 13) } \\
\end{array}$ & & & 3100 & & & & $\begin{array}{l}\mathrm{T}=38^{\circ} \mathrm{C} ; \\
\text { Used max of modeling values for } \\
\text { HTCE cluster } 13 \text { (U-103, S-103, } \\
\text { U-111 have been measured). }\end{array}$ & Remund et al. (1995) \\
\hline $\begin{array}{l}\text { T-101 } \\
\text { (HTCE } \\
\text { Cluster 6) }\end{array}$ & 1993 & $\begin{array}{c}0 \\
42 \\
34\end{array}$ & 84 & $<\mathrm{pH} 11.6\rangle$ & $\begin{array}{l}\text { top } \\
\text { middle } \\
\text { bottom } \\
\text { of layer }\end{array}$ & Grab & $\begin{array}{l}\mathrm{T}=31^{\circ} \mathrm{C} ; \\
\text { all in } 12 \text {-in. deep supernatant } \\
\text { layer; } \\
\text { less than } 1 \text { vol\% solids; } \\
\text { modeling value based on } \\
2 * \text { (maximum of the surface } \\
\text { data) }\end{array}$ & $\begin{array}{l}\text { \#R-2846 } \\
\text { \#R-2847 } \\
\text { \#R-2926 } \\
\text { Sutey }^{(i)}\end{array}$ \\
\hline $\begin{array}{l}\text { T-104 } \\
\text { (HTCE } \\
\text { Cluster 7) } \\
\end{array}$ & & & 330 & & & & $\begin{array}{l}\mathrm{T}=19^{\circ} \mathrm{C} ; \\
\text { Used max of modeling values for } \\
\text { HTCE cluster } 7 \text { (T-107, C-110 } \\
\text { have been measured) }\end{array}$ & Remund et al. (1995) \\
\hline $\begin{array}{l}\text { T-107 } \\
\text { (HTCE } \\
\text { Cluster 7) }\end{array}$ & 1993 & $\begin{array}{c}83.0,80.3 \\
41.6,43.0 \\
217,225\end{array}$ & 330 & $\begin{array}{l}<\mathrm{pH} \mathrm{10.7>} \\
<\mathrm{pH} 9.6> \\
<\mathrm{pH} 10.3>\end{array}$ & $\begin{array}{l}\cdot 48 \\
19 \\
9.5\end{array}$ & $\begin{array}{l}\text { Push } \\
\text { core }\end{array}$ & $\begin{array}{l}\text { Waste level about } 61 \text { in.; } \\
\text { all drainable liquid composites; } \\
\text { modeling value based on } \\
1.5^{*} \text { (maximum measured) to } \\
\text { account for extrusion losses }\end{array}$ & $\begin{array}{l}\text { \#H442-5728, }-5828 \\
\text { \#H393-5728, }-5828 \\
\text { \#H494-5728, }-5828 \\
\text { Svancara }(1993)\end{array}$ \\
\hline $\begin{array}{l}\text { T-110 } \\
\text { (HTCE } \\
\text { Cluster 19) } \\
\end{array}$ & & & 400 & & & & $\begin{array}{l}\mathrm{T}=17^{\circ} \mathrm{C} ; \\
\text { Used modeling value for } \mathrm{HTCE} \\
\text { cluster } 19(\mathrm{~T}-105 \text { is sole } \\
\text { measured member) }\end{array}$ & Remund et al. (1995) \\
\hline $\begin{array}{l}\text { T-111 } \\
\text { (HTCE } \\
\text { Cluster 16) }\end{array}$ & 1994 & $\begin{array}{l}361 \\
370 \\
522\end{array}$ & 1040 & $\begin{array}{l}<\mathrm{pH} \mathrm{11.6>} \\
<\mathrm{pH} \mathrm{11.6>} \\
<\mathrm{pH} 11.8>\end{array}$ & & Grab & $\begin{array}{l}\text { All taken from liquid near } \\
\text { surface; } \\
\text { all less than } 1 \text { vol\% solids; } \\
\text { modeling value based on } \\
2^{*} \text { (maximum of surface data) }\end{array}$ & $\begin{array}{l}\text { \#T-546 } \\
\text { \#T-548 } \\
\text { \#T-550 } \\
\text { Brown }^{(j)}\end{array}$ \\
\hline
\end{tabular}

(i) Sutey MJ. March 10, 1993. "Tank 241-T-101 Waste Compatibility Assessment." Memo to SD Godfrey. Westinghouse Hanford Company, Richland, Washington. 
Table A.1 (contd)

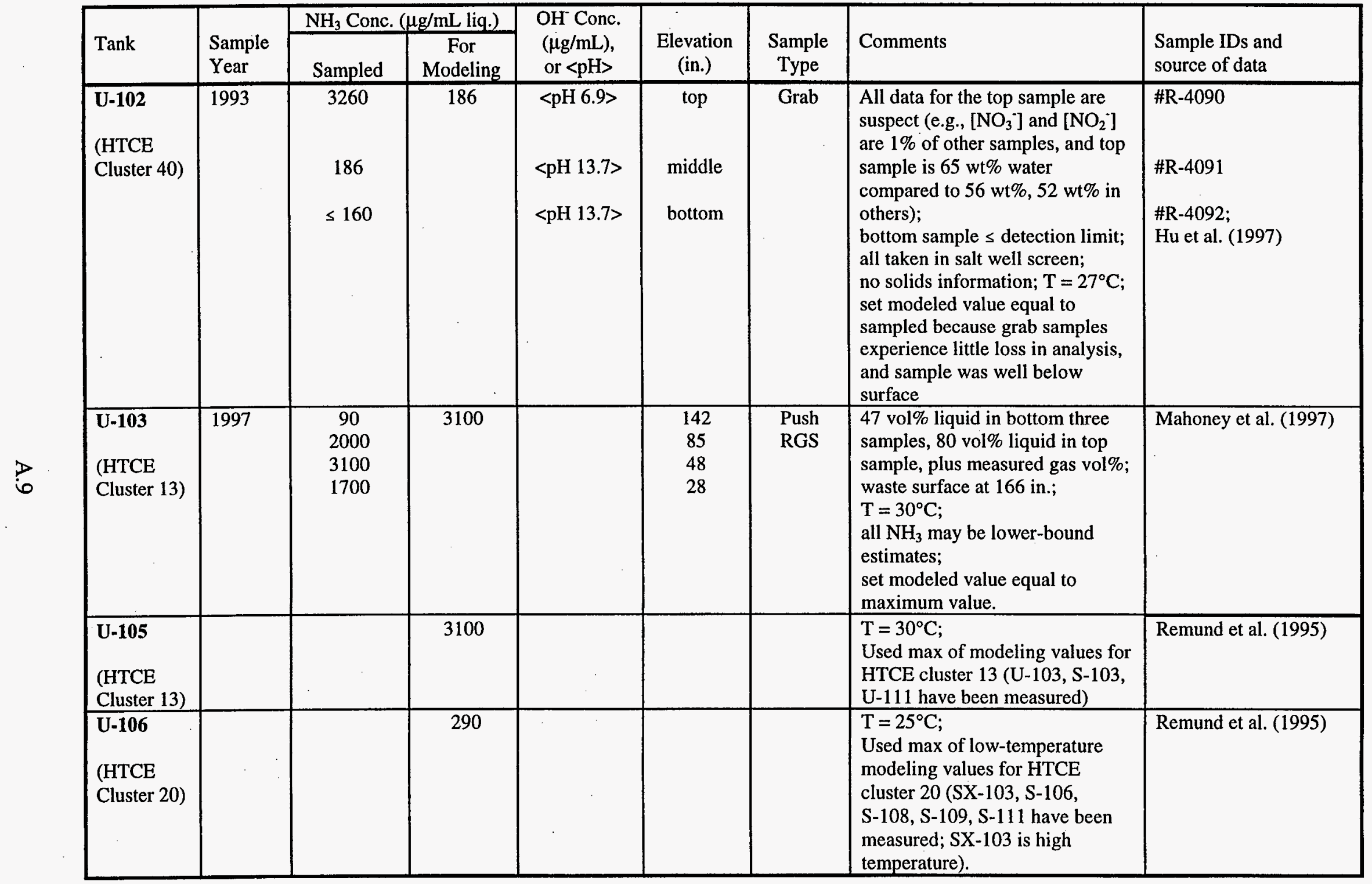

(j) Brown RG. January 8, 1998. "Re: Depths of Grab Samples". Email message (regarding Waste Compatibility Assessment \#7CF30-94-011) to LA Mahoney, Pacific Northwest National Laboratory, Richland, Washington. 
Table A.1 (contd)

\begin{tabular}{|c|c|c|c|c|c|c|c|c|}
\hline \multirow[b]{2}{*}{ Tank } & \multirow[b]{2}{*}{$\begin{array}{l}\text { Sample } \\
\text { Year }\end{array}$} & \multicolumn{2}{|c|}{$\mathrm{NH}_{3}$ Conc. $(\mu \mathrm{g} / \mathrm{mL}$ liq.) } & \multirow{2}{*}{$\begin{array}{l}\text { OH: Conc. } \\
(\mu \mathrm{g} / \mathrm{mL}) \\
\text { or }<\mathrm{pH}>\end{array}$} & \multirow[b]{2}{*}{$\begin{array}{l}\text { Elevation } \\
\quad \text { (in.) }\end{array}$} & \multirow[b]{2}{*}{$\begin{array}{c}\text { Sample } \\
\text { Type }\end{array}$} & \multirow[b]{2}{*}{ Comments } & \multirow[b]{2}{*}{$\begin{array}{l}\text { Sample IDs and } \\
\text { source of data }\end{array}$} \\
\hline & & Sampled & $\begin{array}{c}\text { For } \\
\text { Modeling }\end{array}$ & & & & & \\
\hline $\begin{array}{l}\text { U-107 } \\
\text { (HTCE } \\
\text { Cluster 13) }\end{array}$ & & & 3100 & & & & $\begin{array}{l}T=24^{\circ} \mathrm{C} ; \\
\text { Used max of modeling values for } \\
\text { HTCE cluster } 13 \text { (U-103, S-103, } \\
\text { U-111 have been measured) }\end{array}$ & Remund et al. (1995) \\
\hline $\begin{array}{l}\mathbf{U - 1 0 8} \\
\text { (HTCE } \\
\text { Cluster 13) }\end{array}$ & & & 3100 & & & & $\begin{array}{l}\mathrm{T}=27^{\circ} \mathrm{C} ; \\
\text { Used max of modeling values for } \\
\text { HTCE cluster } 13 \text { (U-103, S-103, } \\
\text { U-111 have been measured) }\end{array}$ & Remund et al. (1995) \\
\hline $\begin{array}{l}\text { U-109 } \\
\text { (HTCE } \\
\text { Cluster 13) } \\
\end{array}$ & & & 3100 & & & & $\begin{array}{l}\mathrm{T}=25^{\circ} \mathrm{C} ; \\
\text { Used max of modeling values for } \\
\text { HTCE cluster } 13 \text { (U-103, S-103, } \\
\text { U-111 have been measured) }\end{array}$ & Remund et al. (1995) \\
\hline $\begin{array}{l}\text { U-111 } \\
\text { (HTCE } \\
\text { Cluster 13) }\end{array}$ & 1993 & $\begin{array}{l}\leq 160 \\
\leq 160\end{array}$ & 160 & $\begin{array}{l}\mathrm{pH} \text { 13.9> } \\
<\mathrm{pH} \text { 13.9> }\end{array}$ & & Grab & $\begin{array}{l}\text { all surface samples; } \\
\text { all } \leq \text { detection limit; } \\
\text { no solids data; } \mathrm{T}=24^{\circ} \mathrm{C} ; \\
\text { set modeled value equal to } \\
\text { detection limit }\end{array}$ & $\begin{array}{l}\text { \#R-4093 } \\
\text { \#R-4095; Sutey }{ }^{(k)}\end{array}$ \\
\hline
\end{tabular}

(k) Sutey MJ. November 30, 1994. "Waste Compatibility Assessment of Tank 241-SY-102 with Tank 241-U-111 Waste via 244-U DCRT." Memo 71720-94-039 to DP Reber. Westinghouse Hanford Company, Richland, Washington. 


\section{References}

Esch RA. 1996. 222-S Laboratory Analytical Report for Tank 241-C-106, Grab Samples 6C96-1 Through 6C-96-16 \& 6C-96-17-FB. WHC-SD-WM-DP-183 Rev. 0, Westinghouse Hanford Company, Richland, Washington.

Esch RA. 1997a. Tank 241-AX-101, Grab Samples, 1AX-97-1 Through 1AX-97-3 Analytical Results for the Final Report. HNF-SD-WM-DP-268 Rev. 0, Waste Management of Hanford, Inc., Richland, Washington.

Esch RA. 1997b. Tank 241-SX-104, Grab Samples, 4SX-97-1 Through 4SX-97-3 Analytical Results for the Final Report. HNF-SD-WM-DP-248 Rev. 0, Waste Management of Hanford, Inc., Richland, Washington.

Giamberardini KK. 1993. 222-S Single-Shell Tank Waste Characterization, Tank C110, Validation Summary. WHC-SD-WM-DP-027 Addendum 1 Rev. OC, Westinghouse Hanford Company, Richland, Washington.

Hedengren DC, JD Bingham, SA Barker, JM Conner, and SD Estey. 1997. Calculation of Flammable Gas Mixtures in Double-Contained Receiver Tanks. HNF-SD-WM-CN-118 Rev. 0, Lockheed Martin Hanford Company, Richland, Washington.

Hu TA, LW Shelton Jr, and TL Welsh. 1997. Tank Characterization Report for Double-Shell Tank 241-AN-104. HNF-SD-WM-ER-690 Rev. 0, Lockheed Martin Hanford Corporation, Richland, Washington.

Kocher KL. 1993. 222-S Laboratory Single-Shell Tank Waste Characterization, Tank 241-S104 Cores 42, 43, and 44 Drainable Liquids. WHC-SD-WM-DP-031 Addendum 7 Rev. 0, Westinghouse Hanford Company, Richland, Washington.

Mahoney LA, ZI Antoniak, and JM Bates. 1997. Composition and Quantities of Retained Gas Measured in Hanford Waste Tanks 241-U-103, S-106, BY-101, and BY-109. PNNL-11777 Rev. 0, Pacific Northwest National Laboratory, Richland, Washington.

McKinley SG, LR Greenwood, EW Hoppe, JM Tingey, and MW Urie. 1992. Single-Shell Tank Waste Characterization Project and Safety Analysis Project Core 34 Data Report, Tank 241-C112. Pacific Northwest National Laboratory, Richland, Washington.

Remund KM, CM Anderson, and BC Simpson. 1995. Hanford Single-Shell Grouping Study. Pacific Northwest National Laboratory, Richland, Washington.

Shekarriz A, DR Rector, LA Mahoney, NS Cannon, BE Hey, MA Chieda, CG Linschooten, JM Bates, FJ Reitz, RE Bauer, and ER Siciliano. 1997. Composition and Quantities of Retained Gas Measured in Hanford Waste Tanks 241-AW-101, A-101, AN-105, AN-104, and AN-103. PNNL-11450 Rev. 1, Pacific Northwest National Laboratory, Richland, Washington. 
Steen FH. 1996a. Waste Compatibility and Final Report for Tank 241-A-101, Grab Samples 1A-96-1, 1A-96-2, and 1A-96-3. WHC-SD-WM-DP-186 Rev. 0, Westinghouse Hanford Company, Richland, Washington.

Steen FH. 1996b. Tank 241-S-111, Cores 149 and 150 Analytical Results for the Final Report. HNF-SD-WM-DP-195 Rev. 1, Waste Management of Hanford, Inc., Richland, Washington.

Steen FH. 1997. Tank 241-SX-103, Grab Samples, 3SX-97-1, 3SX-97-2, and 3SX-97-3

Analytical Results for the Final Report. HNF-SD-WM-DP-260 Rev. 0, Waste Management of Hanford, Inc., Richland, Washington.

Svancara GB. 1993. WHC 222-S and PNL 325 Single-Shell Tank Waste Characterization, Tank T-107 Cores 50, 51, and 52-Data Package and Validation Summaries. WHC-SD-WM-DP-042 Addendum 1A Rev. 1, Westinghouse Hanford Company, Richland, Washington.

Van Vleet RJ. 1995. Tank Waste Source Term Inventory Validation. WHC-SD-WM-ER-400 Rev. 0, Westinghouse Hanford Company, Richland, Washington.

WHC. 1993. WHC 222-S and PNL 325 Single-Shell Tank Waste Characterization, Tank T-105 Cores 53 and 54-Data Package and Validation Summaries. WHC-SD-WM-DP-047 Rev. 0, Westinghouse Hanford Company, Richland, Washington. 


\section{Distribution}

No. of

Copies

\section{Offsite}

2 DOE Office of Scientific and Technical Information

H. Babad 2540 Cordoba Court Richland, WA 99352

D. O. Campbell

102 Windham Road

Oak Ridge, TN 37830

P. d'Entremont

Westinghouse Savannah River Co.

703-H

Aiken, SC 29802

C. W. Forsberg

Oak Ridge National Laboratory

P.O. Box 2008, MS-6495

Oak Ridge, TN 37831-6495

B. C. Hudson

P.O. Box 271

Lindsborg, KS 67456

J. L. Kovach

P.O. Box 29151

70000 Huntley Road

Columbus, $\mathrm{OH} 43229$

T. S. Kress

102-B Newridge Road

Oak Ridge, TN 37830
No. of

Copies

Offsite

K. Lang

1041 Cloverleaf Bldg.

1900 Germantown Road

Germantown, MD 20874

T. E. Larson

2711 Walnut St.

Los Alamos, NM 87545

4 Los Alamos National Laboratory

P.O. Box 1663

Los Alamos, NM 87545

Attn: $\quad$ M. E. Brewster

B256

W. L. Kubic

K575

C. Unal

K575

D. Meisel

Argonne National Laboratory

9700 S. Cass Avenue

Argonne, IL 60439

D. A. Powers

Sandia National Laboratories

Nuclear Facilities Safety Department MS-0744

Albuquerque, NM 87185-0744

S. E. Slezak 806 Hermosa NE

Albuquerque, NM 87110 
No. of

Copies

Onsite

6 DOE Richland Operations Office
C. A. Groendyke
S7-54
D. H. Irby
S7-54
G. M. Neath
$\mathrm{K} 8-50$
G. W. Rosenwald
M. J. Royack
S7-54
S7-54
C. L. Sohn
S7-51

\section{PHMC Team}
S. A. Barker
W. B. Barton
R. E. Bauer
R. J. Cash
A. F. Choho
K. A. Gasper
T. C. Geer
J. M. Grigsby
D. C. Hedengren
D. L. Herting
K. M. Hodgson
T. A. $\mathrm{Hu}$
J. R. Jewett
G. D. Johnson (5)
N. W. Kirch
J. G. Kristofzski
C. E. Leach
J. E. Meacham
M. A. Payne

R2-11

R2-11

S7-14

S7-14

H6-35

G3-21

R1-43

R1-49

R2-11

T6-07

$\mathrm{H} 0-34$

R2-11

T6-07

S7-15

R2-11

R2-12

R1-49

S7-14

R2-58
No. of

Copies

J. C. Person

T6-09

D. A. Reynolds R2-11

D. J. Saueressig S8-05

E. R. Siciliano HO-31

L. M. Stock S7-14

J. E. Van Beek S2-48

$\begin{array}{ll}\text { D. T. Vladimiroff } & \text { R2-38 }\end{array}$

A. B. Webb A3-37

N. E. Wilkins R2-11

R. T. Winward A6-54

A. E. Young R1-10

46 Pacific Northwest National Laboratory
Z. I. Antoniak

J. M. Bates

S. Q. Bennett

K7-15

J. W. Brothers (5)

$\mathrm{K} 7-15$

K7-90

S. A. Bryan

K9-20

P. A. Gauglitz (3)

P7-25

L. K. Holton Jr.

J. L. Huckaby

P7-41

A0-21

L. A. Mahoney (5)

K6-80

P. A. Meyer

K7-15

L. R. Pederson

K7-15

L. M. Peurrung (15)

K2-44

S. D. Rassat

C. L. Shepard

P7-41

P7-41

K5-25

C. S. Simmons

K9-33

C. W. Stewart

K7-15

W. C. Weimer

P7-27

Information Release (5)

K6-06 
Report Number (14) PNNL--11836-ReV.I

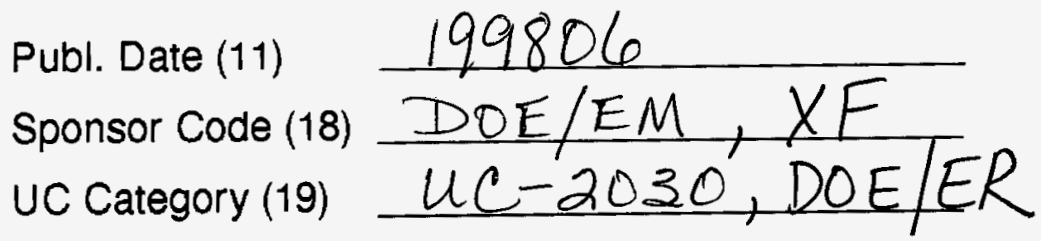

